\title{
Analyse des Kreuzungstyp-Locus des filamentösen Ascomyceten Sordaria macrospora
}

\author{
Dissertation \\ zur Erlangung des mathematisch-naturwissenschaftlichen Doktorgrades \\ "Doctor rerum naturalium" \\ der Georg-August-Universität \\ Göttingen
}

vorgelegt von

Volker Klix

aus Essen

Göttingen 2010 
Mitglieder des Betreuungsauschusses:

Prof. Dr. Stefanie Pöggeler

Prof. Dr. Gerhard Braus

Referentin: Prof. Dr. Stefanie Pöggeler

Korreferent: Prof. Dr. Gerhard Braus

Tag der mündlichen Prüfung: 27.10.2010 


\section{Danksagung}

Mein besonderer Dank gilt Frau Prof. Dr. Stefanie Pöggeler für ihre exzellente Betreuung dieser Doktorarbeit, für die aktuelle und interessante Themenstellung und ihr aufrichtiges Interesse am Fortgang dieser Arbeit. Nicht zuletzt möchte ich mich für ihre zahlreichen wissenschaftlichen Anregungen und der Bereitstellung von Laborplatz und Arbeitsmitteln bedanken.

Ein großer Dank gebührt Herrn Prof. Dr. Gerhard Braus für die Übernahme des Korreferats dieser Arbeit.

Am Lehrstuhl für Allgemeine und Molekulare Botanik in Bochum möchte ich mich bei Frau Swenja Elßel für ihre Hilfe und Anleitung bei der RNA-Präparation für die Microarray Experimente bedanken. Frau Dr. Minou Nowrousian war eine unschätzbare Hilfe bei der Auswertung eben jener Experimente. Herrn Jay C. Dunlap und Frau Jennifer J. Loros (Dartmouth Medical School, NH, USA) möchte ich für die Bereitstellung der Microarray Chips danken und Frau Carol Ringelberg für die Durchführung der Screens.

Ein Dankeschön gilt allen wissenschaftlichen, technischen und ehemaligen Mitarbeitern der Abteilung Genetik eukaryotischer Mikroorganismen für das gute Arbeitsklima. Ganz besonders möchte ich mich hiermit bei Herrn Oliver Voigt und Herrn Ronny Lehneck für die Durchsicht dieser Arbeit und ihre hilfreichen Kommentaren bedanken. Frau Sabine Riedel gebührt mein Dank für ihre Hilfe bei den Yeast-Two-Hybrid Analysen.

Mein ganzer Dank gilt meiner Familie für die außergewöhnliche Unterstützung auch in schwierigen Zeiten. Ganz besonderer Dank gebührt meinen Eltern, meiner Großmutter und Frau Madeleine Hübenthal ohne die diese Arbeit niemals möglich gewesen wäre.

Leider reicht der Platz hier nicht aus um allen Menschen zu danken, die mit Rat, Tat und Unterstützung zu dieser Arbeit beigetragen haben. Allen nicht Namentlich erwähnten sage ich hiermit: Danke. 


\section{Inhaltsverzeichnis}

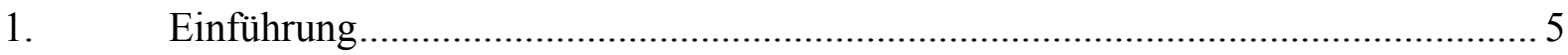

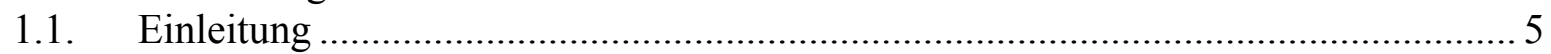

1.2. Zygomyceten: Phycomyces blakesleeanus ...................................................... 8

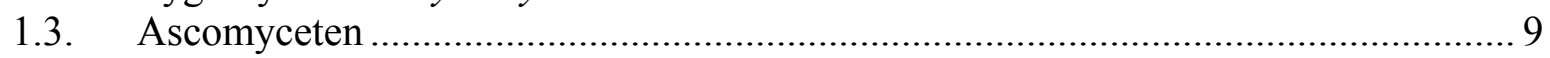

1.3.1. Unizelluläre Ascomyceten: Saccharomyces cerevisiae .................................... 10

1.3.2. Filamentöse heterothallische Ascomyceten: Neurospora crassa...................... 14

1.3.3. Filamentöse Ascomyceten: Sordaria macrospora …………………………..... 17

1.3.4. Filamentöse Ascomyceten: Penicillium chrysogenum ...................................... 18

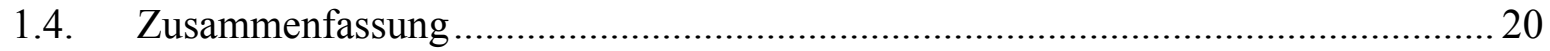

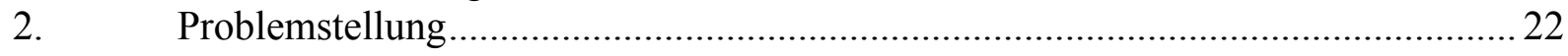

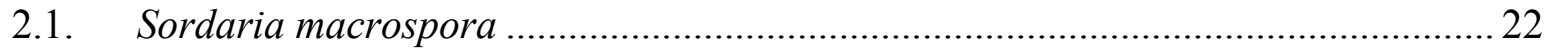

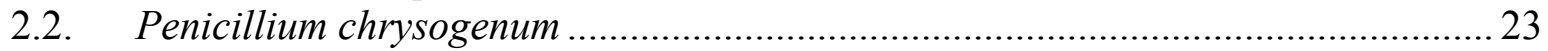

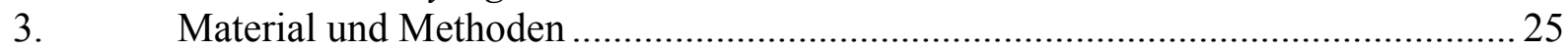

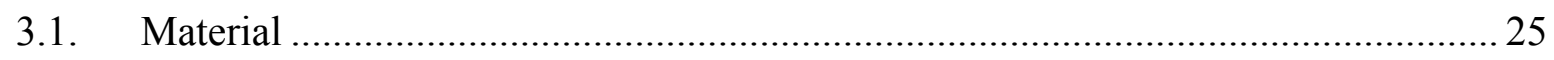

3.1.1. Verwendete Organismen ........................................................................ 25

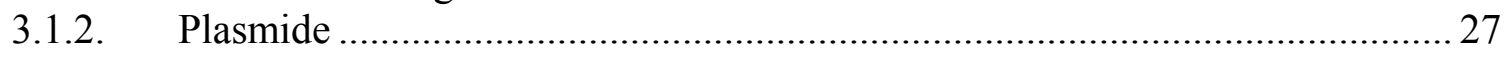

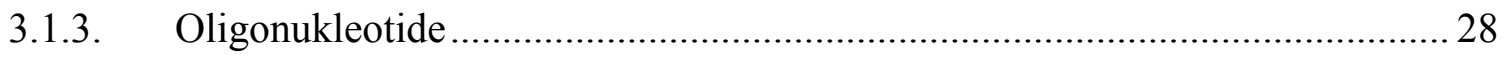

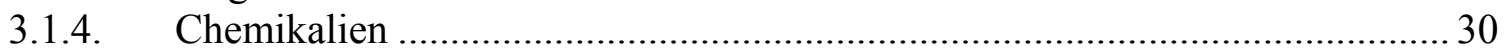

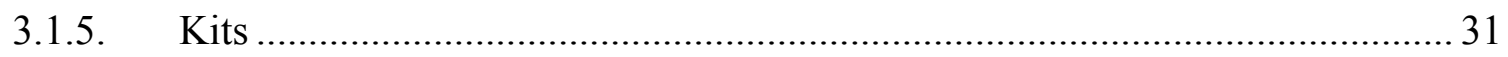

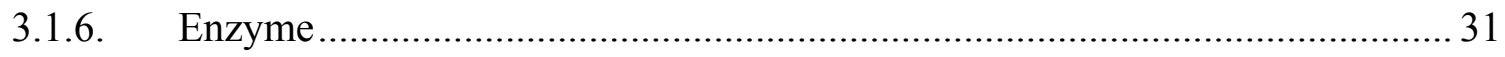

3.1.7. Nährmedien ……………………………………………………… 32

3.1.8. Häufig verwendete Puffer und Lösungen.......................................................... 33

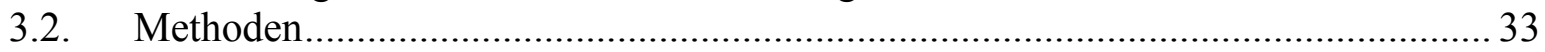

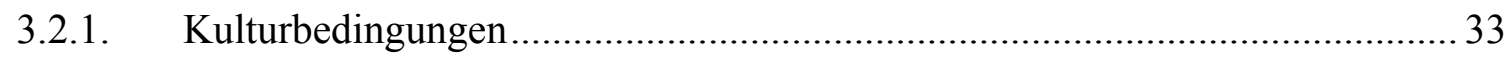

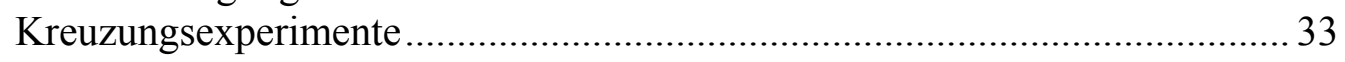

3.2.2. Herstellung kompetenter Zellen und Transformation ........................................ 34

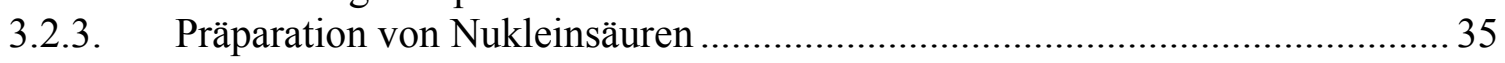

Isolierung von Plasmid-DNA aus E. coli ......................................................... 35

Isolierung von Plasmid-DNA aus S. cerevisiae ................................................... 35

Isolierung von Gesamt-Nukleinsäuren aus S. macrospora …………………......35

Isolierung von DNA aus Agarose-Gelen ...................................................... 35

Fällung von Nukleinsäuren ............................................................................35

Mikrodialyse wässriger DNA-Lösungen ……………………………………..... 36

Isolierung von Gesamt-RNA aus S. macrospora …………………………......36

3.2.4. Modifizierung von Nukleinsäuren ………………………………………...... 36

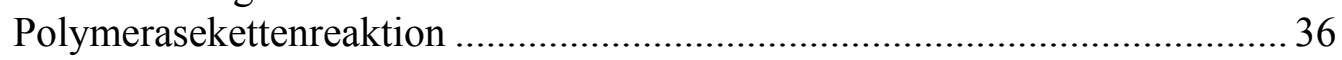

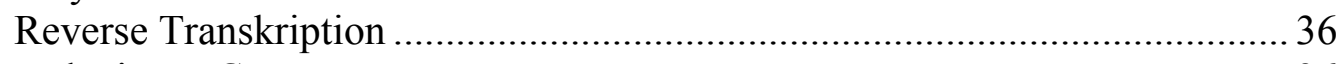

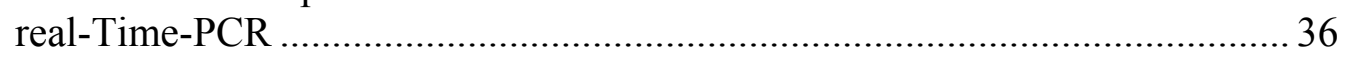

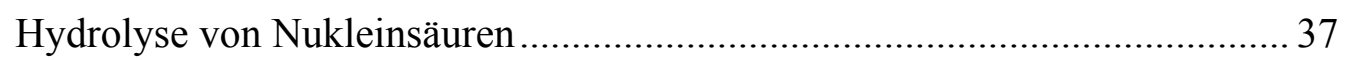

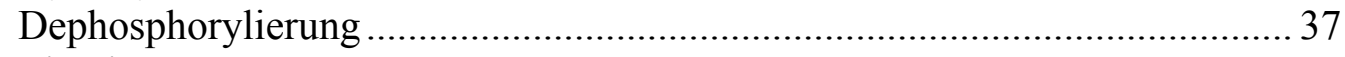

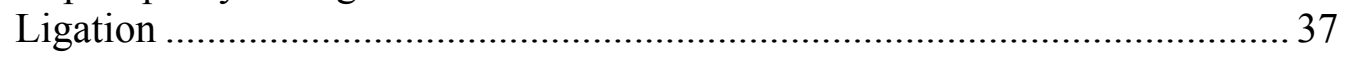

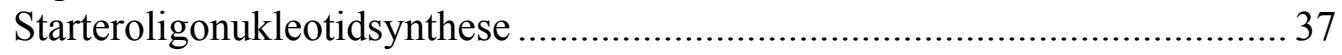

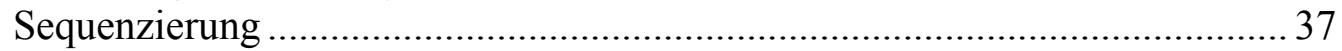

3.2.5. Erstellung rekombinanter Plasmide mittels homologer Rekombination........... 38

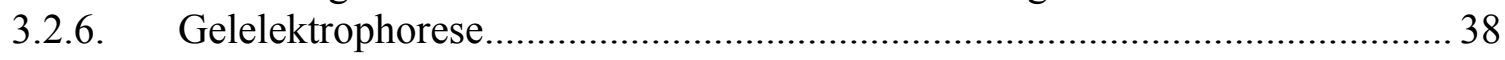




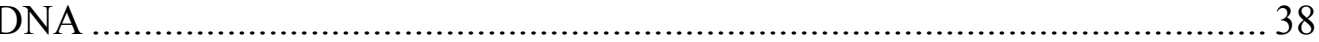

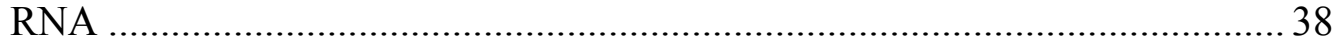

3.2.7. Blotverfahren und nicht-radioaktiver Nachweis von Nukleinsäuren ...................38

Herstellung nicht-radioaktiv markierter Nukleinsäuren.......................................38

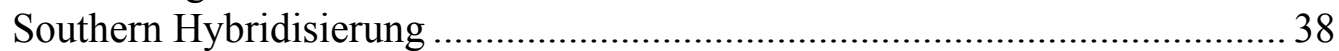

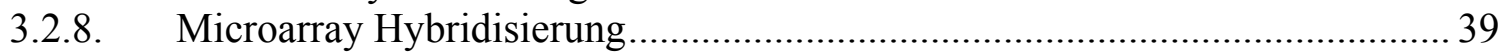

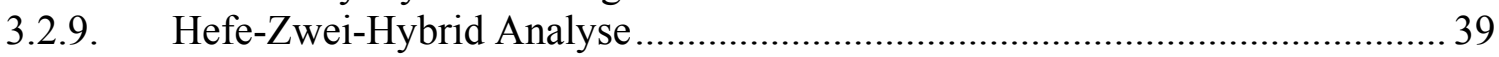

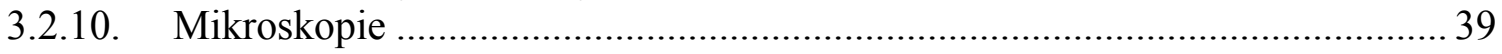

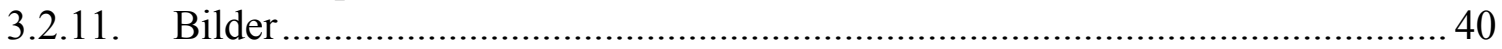

3.2.12. Analyse von Pheromon-Rezeptor-Interaktionen .......................................... 40

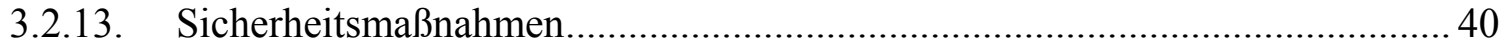

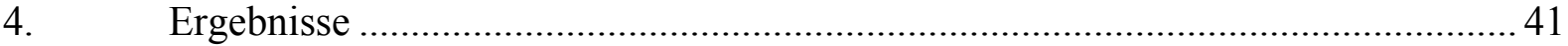

4.1. Untersuchung der MAT1-1-Kreuzungstyp-Gene in S. macrospora …..................... 41

4.1.1. Herstellung der MAT1-1 Deletionsmutanten................................................... 41

4.1.2. Phänotypische Untersuchung der Deletionsmutanten...................................... 44

4.1.3. Untersuchung der funktionellen Domäne des MAT1-1-2 Gens mittels

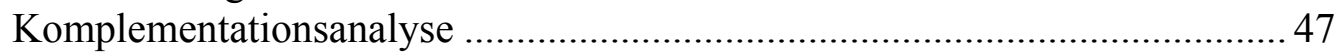

4.1.4. Transkriptionelle Expression der Pheromon- und Rezeptor-Gene ...................50

4.1.5. Microarray Analyse von $\Delta$ SmtA-1 und $\Delta$ SmtA-2 ……………………........52

4.1.6. Lokalisation der Keuzungstyp-Proteine mittels Fluoreszenzmikroskopie........57

4.1.7. Interaktionspartner des Kreuzungstyp-Proteins SMTA-2 …………………......59

4.2. Analyse der Pheromone und Rezeptoren aus P. chrysogenum .................................66

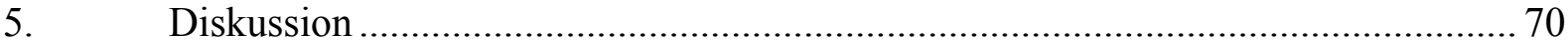

5.1. Ein HMG-Domänen Protein und ein PPF-Domänen Protein sind die Hauptregulatoren der sexuellen Entwicklung in S. macrospora ............................... 70

5.2. SMTA-2 besitzt mindestens eine funktionelle Domäne im C-Terminus, unabhängig

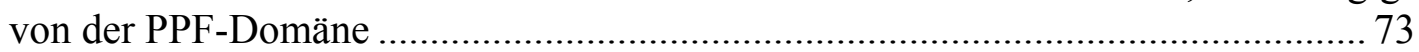

5.3. Die Proteine MAT1-1-2 und MAT1-1-3 lokalisieren im Cytosol ............................ 74

5.4. Die Proteine SMTA-1 und SMTA-2 sind an der Regulation der Expression von Pheromon-Genen beteiligt................................................................................... 75

5.5. Die Kreuzungstyp-Proteine SMTA-1 und SMTA-2 regulieren die Expression

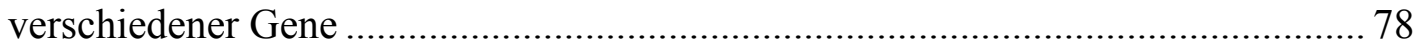

5.6. SMTA-2 interagiert mit verschiedenen regulatorischen Proteinen ............................ 82

5.7. Zusammenfassung der Untersuchung der MATI-1 spezifischen Gene aus

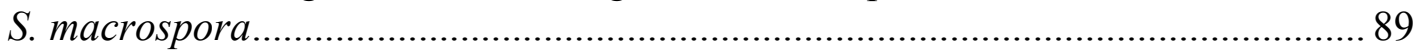

5.7.1. Das $\alpha$-Domänen Protein SMTA-1 ist nicht essentiell für die sexuelle Entwicklung in S. macrospora ………………………………………….... 89

5.7.2. Das Protein SMTA-3 zeigt keine Funktion in S. macrospora ……………....... 90

5.7.3. Das PPF-Domänen Protein SMTA-2 ist essentiell für die postmeiotische Entwicklung in S. macrospora ....................................................................... 90

5.8. Der asexuelle Ascomycet $P$. chrysogenum besitzt funktionelle Pheromone und Rezeptoren............................................................................................ 93

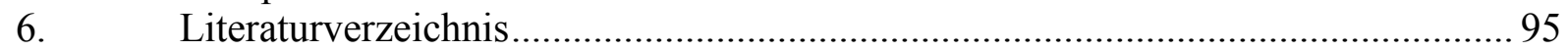

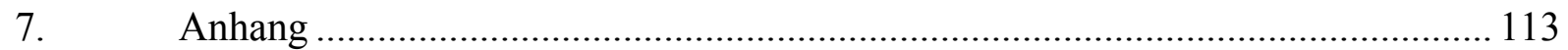

7.1. Überprüfung der Integration der Komplementationskonstrukte ........................... 113

7.2. Überprüfung der Integration der Fluoreszenzkonstrukte ...................................... 114

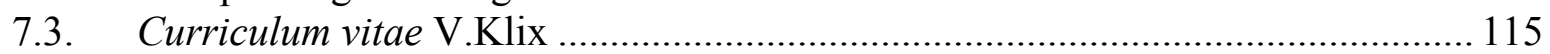




\section{Abkürzungen}

$\begin{array}{ll}\text { Abb. } & \text { Abbildung } \\ \text { Abschn. } & \text { Abschnitt } \\ \text { AS } & \text { Aminosäure } \\ \text { bp } & \text { Basenpaare } \\ \text { d } & \text { Tag } \\ \text { DNA } & \text { Desoxyribonukleinsäure } \\ \text { E.c. } & \text { Escherichia coli } \\ \text { ESI } & \text { Einzelsporisolat } \\ \text { h } & \text { Stunde } \\ \text { kb } & \text { Kilobasen } \\ \text { N.c. } & \text { Neurospora crassa } \\ \text { min } & \text { Minuten } \\ \text { ORF } & \text { offener Leserahmen } \\ \text { P.c. } & \text { Penicillium chrysogenum } \\ \text { PCR } & \text { Polymerase-Kettenreaktion } \\ \text { P.a. } & \text { Podospora anserina } \\ \text { RNA } & \text { Ribonukleinsäure } \\ \text { rpm } & \text { Umdrehungen pro Minute } \\ \text { RT } & \text { Reverse Transkription } \\ \text { S.c. } & \text { Saccharomyces cerevisiae } \\ \text { S.m. } & \text { Sordaria macrospora } \\ \text { Tab. } & \text { Tabelle } \\ \text { ü.N. } & \text { über Nacht } \\ \text { Wt } & \text { Wildtyp } \\ & \end{array}$

Allgemein gebräuchliche Abkürzungen sowie übliche Maßeinheiten sind nicht gesondert aufgeführt. 


\section{Einführung}

\subsection{Einleitung}

Die sexuelle Reproduktion stellt einen der zentralen Prozesse innerhalb des Lebenszyklus der meisten Eukaryoten dar. Dieser Prozess dient der Aufrechterhaltung der genetischen Varianz innerhalb einer Spezies und ist stark reguliert. Es existieren Mechanismen zur Erkennung kompatibler Partner, der richtigen Umweltbedingungen und auch der Prozess des eigentlichen Austausches von genetischem Material zwischen Individuen, Zellen, Zellkernen und Chromosomen unterliegt einer komplexen Regulationsmaschinerie. Zusätzlich haben sich in vielen Organismen im Laufe der Evolution Barrieren entwickelt, welche eine Selbstung und damit einen Austausch von genetischem Material zwischen Kernen eines Individuums ausschließen.

In niederen Eukaryoten, wie Pilzen, existieren meist simple Zell-Identitäts-Mechanismen, welche den sexuellen Austausch regulieren (Souza, et al., 2003). Grundsätzlich können Pilze dabei in homothallisch, selbst-fertil, und heterothallisch, selbst-steril, unterteilt werden (Lin und Heitman, 2007). Morphologische Unterscheidungen wie in höheren Eukaryoten sind dabei selten. Die physiologische Unterscheidung in verschiedene Kreuzungstypen beruht hier genetisch auf einer Kreuzungstyp-spezifischen Region innerhalb des Genoms, KreuzungstypLocus (,mating type locus“, „MAT-Locus“) genannt (Casselton L.A., 2008). Die genetische Sequenz innerhalb der beiden MAT-Loci ist dabei so polymorph, dass der Begriff „Idiomorph“ anstatt „Allel“ eingeführt wurde (Metzenberg und Glass, 1990). Eine einheitliche Nomenklatur der Kreuzungstyp-Loci und -Gene wurde eingeführt (Turgeon und Yoder, 2000) auf der Grundlage, dass ein Idiomorph aller bisher untersuchten heterothallischen Ascomyceten immer ein Gen enthält, welches für ein Protein mit einer $\alpha 1$ Domäne kodiert, bekannt aus dem $\alpha 1 \mathrm{p}$ Protein der Hefe Saccharomyces cerevisiae (Astell, et al., 1981). Dieser Idiomorph wird als Mat1-1 bezeichnet. Der andere Idiomorph, bezeichnet als Mat1-2, ist charakterisiert durch einen offenen Leserahmen („open reading frame“, ORF) welcher für ein Protein mit einer „high-mobility-group“-Domäne (HMG-Domäne) (Grosschedl, et al., 1994) kodiert.

Für einige Spezies, als Beispiele die Ascomyceten S. cerevisiae, Neurospora crassa oder Podospora anserina, werden immer noch die ursprünglichen Bezeichnungen der Kreuzungstypen und der entsprechenden Gene verwendet. In diesen Organismen wurden die MAT-Loci vor der Entwicklung 
Einführung

der Standardnomenklatur untersucht. So wird der MAT1-1 Locus jeweils als MATa, MAT A oder MAT(-), der MAT1-2 Locus als MATa, MAT a oder MAT(+) bezeichnet (Pöggeler, 2001).

Homothallische Pilze besitzen häufig ebenfalls Kreuzungstyp-Loci, wobei diese im Gegensatz zu heterothallischen Arten genetisch nicht unterscheidbar sind (Glass N.L., et al., 1990b). Meist existieren Homologe $\mathrm{zu}$ den MAT-Genen eines oder beider Kreuzungstypen verwandter, heterothallischer Arten (Abb. 1).

Eine Besonderheit der Gruppe der Sordariomyceten ist das Gen MAT1-1-2. Dieses kodiert für ein Protein ohne bekannte funktionelle Domäne. Es konnte jedoch ein in allen Sordariomyceten konserviertes Sequenzmotiv, bestehend aus den drei invariablen Aminosäuren Prolin, Prolin und Phenylalanin, gefunden werden. Dieses Sequenzmotiv wurde nach den drei Aminosäuren als PPF-Domäne benannt (Debuchy, et al., 2010).

Ursprünglich wurde die konservierte Domäne in MAT1-1-2 Proteinen als HPG-Domäne, nach den Aminosäuren Histidin, Prolin und Glycin bezeichnet (Debuchy und Turgeon, 2006). Bei einer Untersuchung von Vertretern der Gattung Diaporthe wurde dieses Sequenzmotiv dagegen nicht gefunden (Kanematsu, et al., 2007). Stattdessen konnten zwei Proline und ein Phenylalanin als invariabel identifiziert werden. Daraufhin wurde die Domäne in PPF-Domäne umbenannt (Debuchy, et al., 2010).

PPF-Domänen Proteine wurden in allen untersuchten MAT1-1 Kreuzungstyp-Loci der Sordariomyceten gefunden, in homothallischen wie heterothallischen. Außerhalb dieses Taxons sind PPF-Domänen Proteine unbekannt (Turgeon und Debuchy, 2007). 


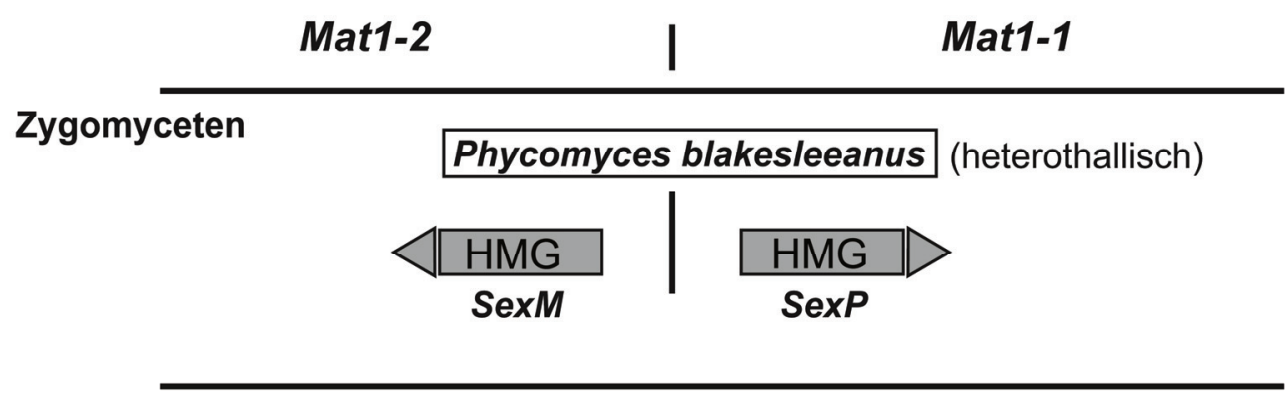

\section{Ascomyceten}

\begin{tabular}{|c|c|c|c|}
\hline Saccharomycotina & Sacc & evisiae (h & terothallisch \\
\hline$<?$ & Homeo & Homeo & $\alpha$ \\
\hline $\begin{array}{c}\text { Mat1-2-1 } \\
(\text { a2) }\end{array}$ & $\begin{array}{c}\text { Mat1-2-2 } \\
\text { (a1) }\end{array}$ & $\begin{array}{c}\text { Mat1-1-2 } \\
(\alpha 2)\end{array}$ & $\begin{array}{c}\text { Mat1-1-1 } \\
(\alpha 1)\end{array}$ \\
\hline
\end{tabular}

Pezizomycotina (Eurotiomycetes)

\section{Aspergillus fumigatus (heterothallisch)}

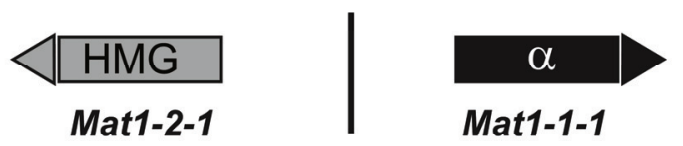

Penicillium chrysogenum (putativ heterothallisch)

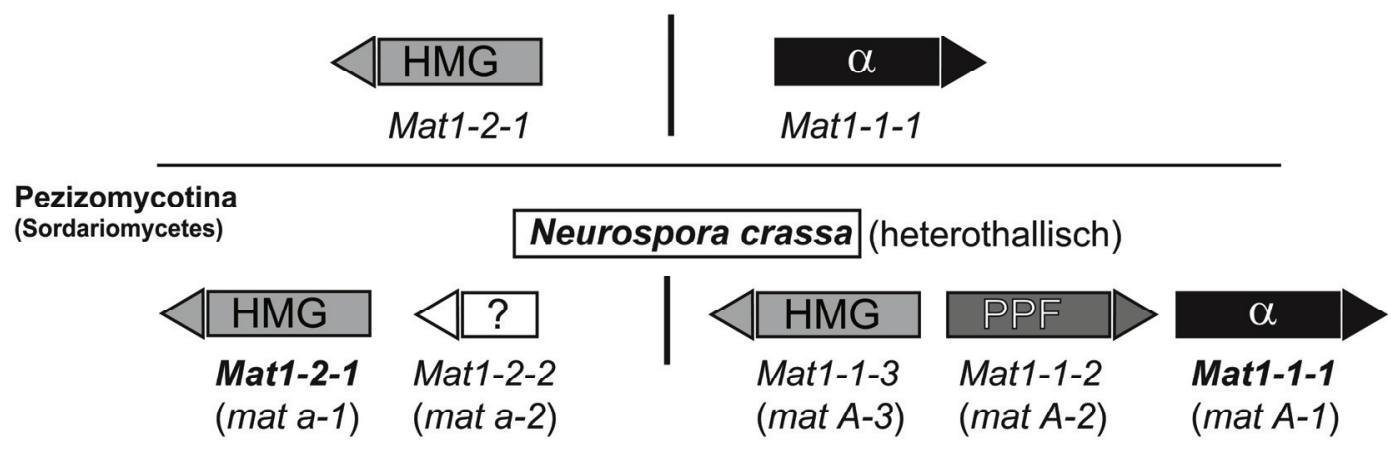

Sordaria macrospora (homothallisch)

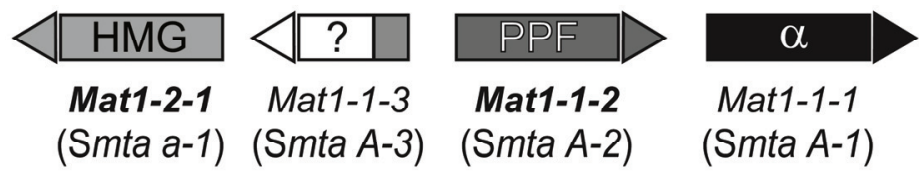

Abbildung 1: Schematischer Vergleich der Kreuzungstyp-Loci verschiedener homo- und heterothallischer Pilze. Die Boxen repräsentieren die Größe und Position der ORFs, die Pfeilspitzen zeigen die Leserichtung an. Die Standardnomenklatur der Gene, ebenso wie Spezies-spezifische Namen sind angegeben. Gene, welche für Proteine mit gleichen funktionellen Domänen kodieren, sind durch gleiche farbliche Kennzeichnung hervorgehoben. $\alpha$ : a-Domäne; HMG: HMG-Domäne; PPF: PPF-Domäne; ?: keine bekannten Domänen. Gene, welche für die sexuelle Entwicklung in den Spezies essentiell sind, sind hervorgehoben. ${ }^{1}$ Kreuzungstyp-Gene in P. chrysogenum wurden identifiziert, ein sexueller Zyklus konnte bisher jedoch nicht nachgewiesen werden. 
Im Gegensatz zu homothallischen Arten, die keinen Kreuzungspartner für die Vollendung des sexuellen Zyklus benötigen, sind heterothallische Arten darauf angewiesen einen Kreuzungspartner zu finden. In vielen Spezies aus dem Reich der Pilze wird die PartnerErkennung und die anschließende Zellfusion durch sogenannte Pheromone vermittelt.

In Zygomyceten dient ein einfaches Molekül, die Trisporsäure, als Pheromon und vermittelt die Fusion zweier Kreuzungspartner unterschiedlichen Kreuzungstyps (Schimek und Wostemeyer, 2009; van den Ende, 1967).

Die höher entwickelten Ascomyceten besitzen zwei verschiedene lösliche Peptid-Pheromone und korrespondierende G-Protein (GTP-bindendes Protein) gekoppelte Rezeptoren (Bistis, 1981; Bölker und Kahmann, 1993; Dohlman und Thorner, 2001). Die Expression der Pheromon-Gene ist dabei Kreuzungstyp-spezifisch und abhängig von den Transkriptionsfaktoren, die im Kreuzungstyp-Locus kodiert sind, wobei sie selber nicht Teil des MAT-Locus sind (Shen W. C., et al., 1999; Zhang, et al., 1998). Die Rezeptoren scheinen dagegen Kreuzungstyp-unabhängig kodiert zu sein. Im Gegensatz zu den Ascomyceten liegen bei den Basidiomyceten häufig die Pheromon-Gene innerhalb des Kreuzungstyp-Idiomorph (Raudaskoski und Kothe, 2010).

Innerhalb der heterothallischen Ascomyceten ist die Struktur und Sequenz der Pheromone und der korrespondierenden Rezeptoren hoch konserviert (Bobrowicz, et al., 2002; Coppin, et al., 2005; Kim H., et al., 2002; Kurjan, 1993; Shen W. C., et al., 1999). Auch in homothallischen Arten wurden Pheromone und Rezeptoren gefunden, auch wenn dort die Notwendigkeit der Partnererkennung nicht gegeben ist. So wurden in den homothallischen Arten Sordaria macrospora (Pöggeler, 2000) und Gibberella zeae Pheromon- und Rezeptor-Gene identifiziert und untersucht. In $S$. macrospora sind diese essentiell für die sexuelle Entwicklung (Mayrhofer und Pöggeler, 2005; Mayrhofer, et al., 2006), während sie in G. zeae an der sexuellen Entwicklung beteiligt, für diese aber nicht essentiell sind (Lee J., et al., 2008). Das am Besten untersuchte Pheromon-Rezeptor-System ist das der Hefe S. cerevisiae, welches als Modellsystem aller anderen heterothallischen Ascomyceten dienen kann.

\subsection{Zygomyceten: Phycomyces blakesleeanus}

Zygomyceten (Jochpilze) stellen eine frühe evolutionäre Linie innerhalb der Abteilung der Eumycota dar (Esser, 2000). In dieser Gruppe wurde auch zum ersten Mal das Phänomen des Homo- und Heterothallismus von Blakeslee beschrieben (Blakeslee, 1904). Der Pilz 
Einführung

Phycomyces blakesleeanus, als Beispiel, existiert in zwei verschiedenen Kreuzungstypen, genannt $M A T(-)$ und $M A T(+)$. Durch die Verfügbarkeit der Genomsequenz von P. blakesleeanus wurde eine Untersuchung der Kreuzungstypen auf genetischer Ebene möglich (Idnurm, et al., 2008). Sequenzanalysen zeigten Bereiche des Genoms, die zwischen Individuen unterschiedlichen Kreuzungstyps polymorph und gekoppelt zu einem speziellen Kreuzungstyp waren. Der $M A T(+)$-Locus ist 5,8 kb groß und enthält einen ORF, welcher für ein HMG-Domänen Protein kodiert. Der MAT(-)-Locus ist mit 3,4 kb kleiner, enthält aber ebenfalls ein Gen für ein HMG-Domänen Protein (Grosschedl, et al., 1994; Idnurm, et al., 2008) (Abb. 1). Die beiden Gene wurden als sexM (sexMinus) und sexP (sexPlus) bezeichnet. Die Kreuzungstyp-Proteine SexM und SexP zeigen nur eine geringe Aminosäure-Ähnlichkeit, trotzdem sind SexM und SexP die ähnlichsten Proteine zueinander im Genom von P. blakesleeanus (Idnurm, et al., 2008). Dies lässt darauf schließen, dass SexM und SexP divergente Homologe darstellen.

All diese Ergebnisse lassen den Schluss zu, dass ein HMG-Domänen kodierendes Gen den ursprüngliche Zustand des MAT-Locus in einem gemeinsamen Vorfahren der Pilze darstellt. Die niederen Zygomyceten repräsentieren damit den ursprünglichen genetischen Zustand, während die höher entwickelten Ascomyceten und Basidiomyceten im Laufe der Evolution weitere Kreuzungstyp-Gene, wie $\alpha$-Domänen oder Homeodomänen Gene erlangten (Casselton L.A., 2008; Dyer, 2008; Idnurm, et al., 2008).

\subsection{Ascomyceten}

Ascomyceten gehören zur Gruppe der Pilze (Mycophyta) und bilden die größte Klasse innerhalb dieser Gruppe. Es kommen sowohl einzellige Organismen, wie die Hefe Saccharomyces cerevisiae, als auch mehrzellige Organismen mit oftmals verzweigten und septierten Myzelien, wie der Hyphenpilz Neurospora crassa, in dieser Klasse vor. Die haploiden Hyphenpilze bilden nach der Paarung dikaryotische Hyphen, in denen Karyogamie und Meiose stattfinden. Aus diesen Hyphen entstehen dann typische Meiosporangien, die Asci, die dieser Klasse ihren Namen gegeben haben (Esser, 2000).

In allen bisher untersuchten, heterothallischen Ascomyceten, besteht der MAT-Locus eines Individuums aus einer oder zwei möglichen Sequenzen. Dieses Paarungssystem, mit zwei Kreuzungstypen determiniert durch zwei MAT-Idiomorphe, wird als „bipolar“ bezeichnet (Hsueh und Heitman, 2008). 
Einführung

Die meisten homothallischen Arten dagegen besitzen die Sequenzen beider KreuzungstypIdiomorphe in ihrem haploiden Genom, häufig genetisch gekoppelt (Abb. 1). Ein Beispiel für einen homothallischen Ascomyceten mit zwei ungekoppelten MAT-Loci in einem Genom ist Aspergillus nidulans. Hier liegen die beiden MAT-Loci ungekoppelt auf verschiedenen Chromosomen (Galagan, et al., 2005).

Die Kreuzungstyp-Loci der Ascomyceten folgen alle einem ähnlichen Organisationsmuster (Debuchy und Turgeon, 2006; Pöggeler, 2001). Der Standardnomenklatur folgend, besitzt das Protein MAT1-1-1 eine sogenannte $\alpha 1$-Domäne, welche Ähnlichkeiten mit dem $\alpha 1$ p DNABindeprotein aus S. cerevisiae aufweist (Astell, et al., 1981; Turgeon und Yoder, 2000).

Das MAT1-2-1 Protein dagegen weist eine HMG-Domäne auf, welche ebenfalls eine DNABindedomäne darstellt. In den meisten bisher untersuchten, heterothallischen Ascomyceten sind diese beiden Proteine die Hauptregulatoren der sexuellen Entwicklung in Individuen des entsprechenden Kreuzungstyps (Debuchy und Turgeon, 2006; Pöggeler, 2001; Souza, et al., 2003).

Eine Ausnahme dieser Regel stellen die unizellulären Hefen dar. Im Gegensatz zu den filamentösen Ascomyceten werden bei vielen Hefen wie S. cerevisiae oder Candida albicans keine HMGDomänen Proteine im MAT-Locus kodiert. Statt dessen finden sich hier sogenannte Homeodomänen Proteine (Astell, et al., 1981; Hull und Johnson, 1999).

Zusätzlich können noch weitere Gene in den MAT-Loci vorhanden sein. Ein Beispiel hierfür ist das Gen MAT1-1-2, welches bisher in allen untersuchten MAT1-1 Loci in der Gruppe der Sordariomyceten gefunden wurde (Debuchy und Turgeon, 2006).

\subsubsection{Unizelluläre Ascomyceten: Saccharomyces cerevisiae}

Die einzellige Hefe Saccharomyces cerevisiae gehört taxonomisch zu den Endomycetales aus der Gruppe der Hemiascomyceten (Esser, 2000). Unter natürlichen Bedingungen ist S. cerevisiae homothallisch und diploid, wobei unter Laborbedingungen auch haploide Stämme vermehrt werden können. Die Vermehrung findet unter günstigen Wachstumsbedingungen fortlaufend durch vegetative Knospung statt, ungünstige Wachstumsbedingungen dagegen führen zur Meiose und zur Sporulation, bei der vier haploide Ascosporen entstehen (Esser, 2000). Der Lebenszyklus von S. cerevisiae ist schematisch in Abbildung 2 dargestellt. 


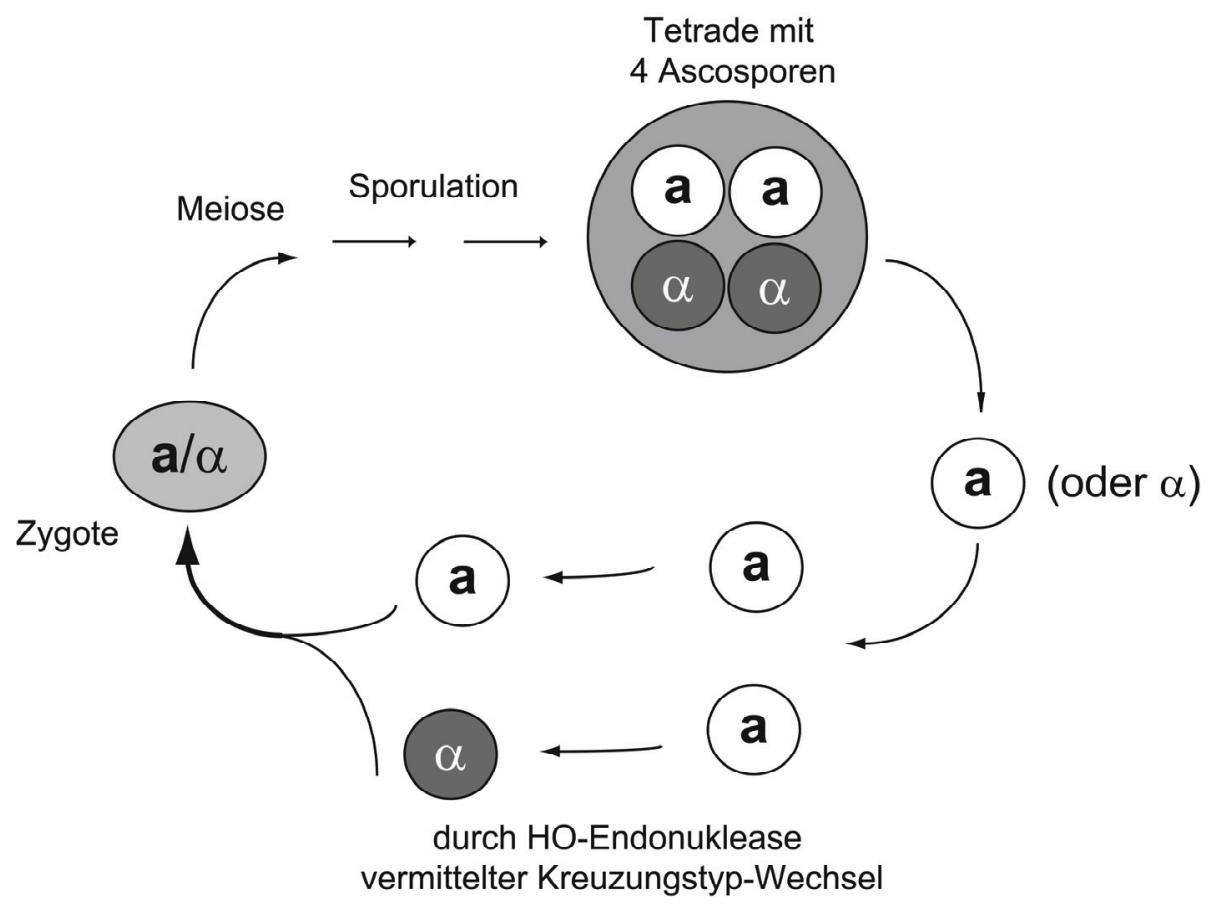

\begin{abstract}
Abbildung 2: Schematische Darstellung des Lebenszyklus von $S$. cerevisiae. Aus einer diploiden Zygote entstehen nach Meiose und Sporulation vier Ascosporen, je zwei vom Kreuzungstyp a bzw. $\alpha$. Zwei haploide Zellen unterschiedlichen Kreuzungstyps bilden nach Karyogamie erneut eine diploide Zygote. Innerhalb einer haploiden Zelle kann es zu einem Kreuzungstypwechsel kommen. Weitere Details werden im Text erläutert (verändert nach Esser 2000).
\end{abstract}

Der Kreuzungstyp-Locus und die sexuelle Vermehrung sind von allen Ascomyceten in der Hefe am Besten untersucht. Die MAT Idiomorphe MATa und MATa kodieren für regulatorische Proteine, welche, zusammen mit anderen Transkriptionsfaktoren, für ein spezifisches Expressionsmuster in allen drei Zelltypen verantwortlich sind: haploide MATa

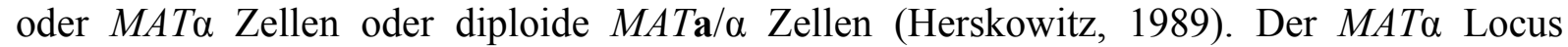
besteht dabei aus zwei Genen, $\alpha 1$ und $\alpha 2$ (Astell, et al., 1981) (Abb. 1). Das $\alpha 1$ Gen kodiert für ein Protein mit einer charakteristischen DNA-Bindedomäne, welche nach diesem Protein als $\alpha$-Domäne benannt wurde. Das Protein $\alpha 1 p$ ist ein positiver Regulator der Transkription $\alpha$ spezifischer Gene in haploiden, MATa Zellen. Zusammen mit den Transkriptionsfaktoren STE12 und MCM1 reguliert $\alpha 1 \mathrm{p}$ die Transkription von fünf $\alpha$-spezifischen Genen (Galgoczy, et al., 2004).

MCM1 ist ein essentielles, sequenz-spezifisches DNA-Bindeprotein und gehört zur Gruppe der MADS Box Transkriptionsfaktoren. MADS Box Transkriptionsfaktoren sind hochkonserviert und spielen eine Rolle bei der Regulation wichtiger biologischer Prozesse in vielen eukaryotischen Organismen von Hefen, Pflanzen über niedere Vertebraten bis zu Säugetieren (Shore und Sharrocks, 1995). 
Einführung

STE12 wird als divergentes Protein der Homeodomänen-Superfamilie angesehen und besitzt eine sequenzspezifische DNA-Bindedomäne. Die entsprechende Sequenz wird auch als „PheromonSignalantwort“ Sequenz bezeichnet (Dolan und Fields, 1991). Dies zeigt, dass der Homeodomänen Transkriptionsfaktor STE12 einen Regulator von Genen nach Pheromon-Induktion in S. cerevisiae darstellt (Johnson, 1995).

Das Genprodukt von $\alpha 2$ ist dagegen ein negativer Regulator der Transkription a-spezifischer Gene. Acht Gene werden spezifisch von einem $\alpha 2$ p-MCM1 Dimer reguliert, wovon sechs als a-spezifisch bekannt sind (Galgoczy, et al., 2004). Der MATa Locus besteht aus zwei Genen, $\boldsymbol{a} 1$ und $\boldsymbol{a} 2$, wovon nur $\boldsymbol{a} 1$ für ein funktionelles Protein kodiert (Abb. 1). Das Protein a1p besitzt eine Homeodomäne, spielt aber keine Rolle bei der Regulation a-spezifischer Gene. Diese Gene sind in MATa Zellen ohne den Einfluss des $\alpha 2 p$ Regulators konstitutiv exprimiert. In diploiden MATa/ $\alpha$ dagegen bildet a1p ein Heterodimer mit $\alpha 2 \mathrm{p}$. Dieses Heterodimer reprimiert die Expression von 23 haploid-spezifischen Genen (Galgoczy, et al., 2004). Das Gen $a 2$ kodiert für eine nicht-funktionelle Version von $\alpha 2$ (Dolan und Fields, 1991; Herskowitz, 1989).

Eine Besonderheit bei S. cerevisiae stellt die Fähigkeit dar, den Kreuzungstyp zu wechseln. Beide Kreuzungstyp-Allele sind als sogenannte Kassetten im Genom vorhanden, wobei der Kreuzungstyp durch die Information der Kassette im MAT-Locus bestimmt wird. Die Information beider Kreuzungstypen ist dabei in nicht transkribierten Loci im Genom vorhanden, in HML $\alpha$ für den $\alpha$ Kreuzungstyp und HMRa für den a Kreuzungstyp (Herskowitz, 1988; Nasmyth, 1982). Durch die Aktivität einer spezifischen Endonuklease, der HO-Endonuklease, wird durch Hydrolyse an einer degenerierten, 29 bp langen Sequenz am MAT-Locus ein Doppelstrangschnitt eingeführt (Nasmyth, 1982). Durch ein homologes Rekombinationsereignis mit den Kassetten HML bzw. HMR kommt es zur Genkonversion und damit zu einem Wechsel des Kreuzungstyps (Strathern, et al., 1982). Aus diesem Grund stellt S. cerevisiae, trotz Inkompatibilität von Zellen gleichen Kreuzungstyps, einen homothallischen Pilz dar.

Das Pheromon-System in Hefe ist das wohl am Besten untersuchte in allen Ascomyceten (Bölker und Kahmann, 1993). Zellen vom MATa Kreuzungstyp produzieren ein Peptid von zwölf Aminosäuren, welches durch Prozessierung aus einem längeren Vorläufermolekül entsteht. Dieses Vorläufermolekül enthält ein sogenanntes CAAX-Motiv im C-Terminus, ein 
Einführung

Signal für Carboxymethylierung und Farnesylierung (Anderegg, et al., 1988; Chen P., et al., 1997). Das prozessierte Peptid wird unabhängig vom klassischen Sekretionsweg in Hefe über einen ATP-bindenden Transporter (Ste6p) sekretiert, welcher Homologien zu Membran Glykoproteinen aus Säugetieren zeigt (Kuchler, et al., 1989).

Der $\alpha$-Faktor, welcher von MATa Zellen hergestellt wird, dagegen ist ein 13 Aminosäurenpeptid (Stötzler, et al., 1976), welches ebenfalls aus Vorläuferproteinen hergestellt wird. Diese Vorläuferpeptide (MFa1 und MFa2) bestehen aus 165 bzw. 120 Aminosäuren, welche tandemartig wiederholte Kopien des $\alpha$-Faktors enthalten (Singh, et al., 1983). Das fertig prozessierte Protein wird über den klassischen Hefe-Sekretionsweg sezerniert. Die Gene beider Pheromonvorläufer Peptide liegen dabei in einem Genom, wobei die Expression der Gene durch die Kreuzungstyp-Proteine reguliert werden.

Die Erkennung der Pheromone durch Zellen des entgegengesetzten Kreuzungstyps geschieht über spezifische Pheromon-Rezeptoren. Beide Rezeptoren (Ste2p, Ste3p) gehören zur Klasse der G-Protein-gekoppelten Siebentransmembran Domänen Proteine. Ste2p bindet dabei den $\alpha$-Faktor und wird von MATa Zellen hergestellt. Ste3p kommt in MATa Zellen vor und bindet spezifisch den a-Faktor. Die Rezeptoren aktivieren einen G-Protein Komplex, bestehend aus den drei Untereinheiten $\alpha, \beta$ und $\gamma$. Die beiden Untereinheiten $\beta$ und $\gamma$ bilden dabei ein Dimer (Dohlman und Thorner, 2001). Nach Aktivierung dissoziieren die $\alpha$ und $\beta \gamma$ Untereinheit und das Signal wird durch verschiedene Effektor-Moleküle übertragen und verstärkt. Ein Hauptziel des von der G $\beta \gamma$-Untereinheit übertragenen Signals ist dabei eine MAP (,,mitogen activated protein“) Kinase Kaskade. Dieser Signalweg ist schematisch in Abbildung 3 dargestellt. 


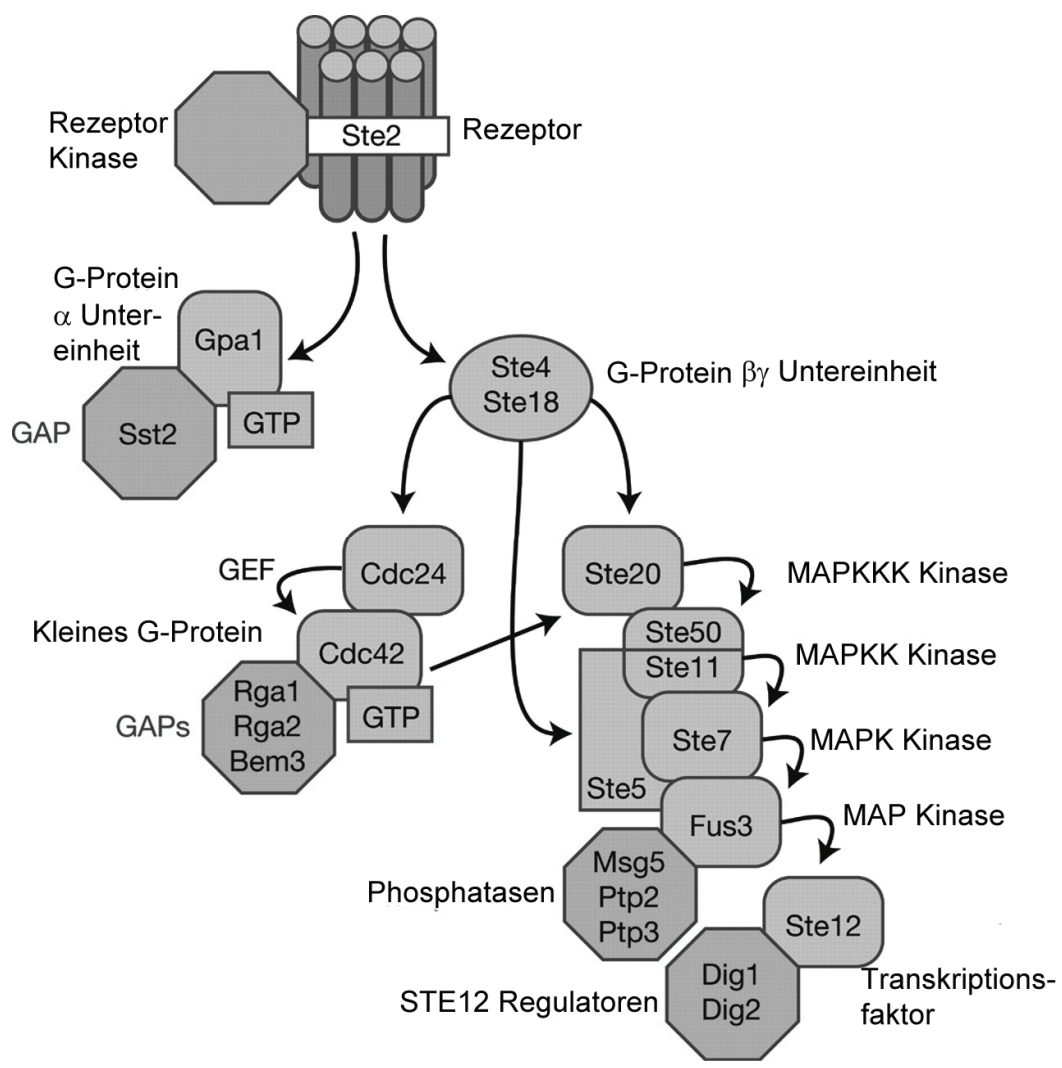

Abbildung 3: Schematische Darstellung des Pheromon-induzierten MAP Kinase Signalweges in S. cerevisiae. Nach der Induktion eines Siebentransmembran-Rezeptors durch das entsprechende Pheromon wird das Signal durch die $\beta \gamma$-Unterheit des G-Proteins weitergeleitet. Über die MAP Kinase Kaskade gelangt das Phosphorylierungssignal schließlich zum Transkriptionsfaktor STE12, welcher in der Lage ist, Zielgene zu aktivieren (verändert nach Wang und Dohlman, 2004). GAP: GTPaseaktivierendes Protein; GEF: GTP-Austauschfaktor („,GTP-exchange factor"); K: Kinase

Das Signal wird dabei durch die Phosphorylierung verschiedener MAP Kinasen weitergeleitet. Die letzte MAP Kinase dieses Signalweges (Fus3p) aktiviert dabei den Transkriptionsfaktor Ste12p, welcher wiederum an der Regulation Kreuzungs-spezifischer Gene beteiligt ist (Casselton L. A., 2002).

Dieses System kann als Modell für die Pheromon-Rezeptor-Systeme aller bisher untersuchten Ascomyceten dienen.

\subsubsection{Filamentöse heterothallische Ascomyceten: Neurospora crassa}

Neurospora crassa ist ein vielzelliger Ascomycet aus der Gruppe der Pyrenomyceten (Esser, 2000; Hawksworth, et al., 1995). Dieser Pilz ist haploid und in der Lage, sich sowohl über vegetative Mitosporen als auch über sexuelle Sporenbildung zu verbreiten. Männliche und weibliche Geschlechtsorgane werden an einem Myzel gebildet, wobei diese nicht in der Lage sind sich gegenseitig zu befruchten. $N$. crassa ist also heterothallisch (Esser, 2000). Der 
Einführung

sexuelle Zyklus beginnt unter Stickstoffmangel mit der Bildung eines Vorfruchtkörpers, dem Protoperithezium (Nelson und Metzenberg, 1992; Perkins und Barry, 1977). Die Befruchtung der Ascogonzelle mit einer männlichen Zelle innerhalb des Protoperitheziums erfolgt über eine spezialisierte Hyphe, die Trichogyne, welche aus dem Protoperithezium auswächst und mit der männlichen Zelle fusioniert. Als männliche Zellen (Gameten) können sowohl Mikrokonidien, Makrokonidien, als auch Hyphenfragmente zur Befruchtung dienen. Die Mikro- und Makrokonidien können als vegetative Sporen auch ein neues, haploides Myzel bilden (Esser, 2000).

Als Konidien werden mitotisch gebildete Aplanosporen bezeichnet. Diese unbeweglichen Sporen können ein- bis vielkernig sein und werden exogen an Konidienträgern gebildet (Esser, 2000).

Befruchtete Protoperithezien entwickeln sich zu reifen Perithezien, in denen aus den Ascogonzellen Asci mit je acht linear angeordneten, homokaryotischen Ascosporen entstehen. In Abbildung 4 ist der Lebenszyklus von N. crassa schematisch dargestellt.

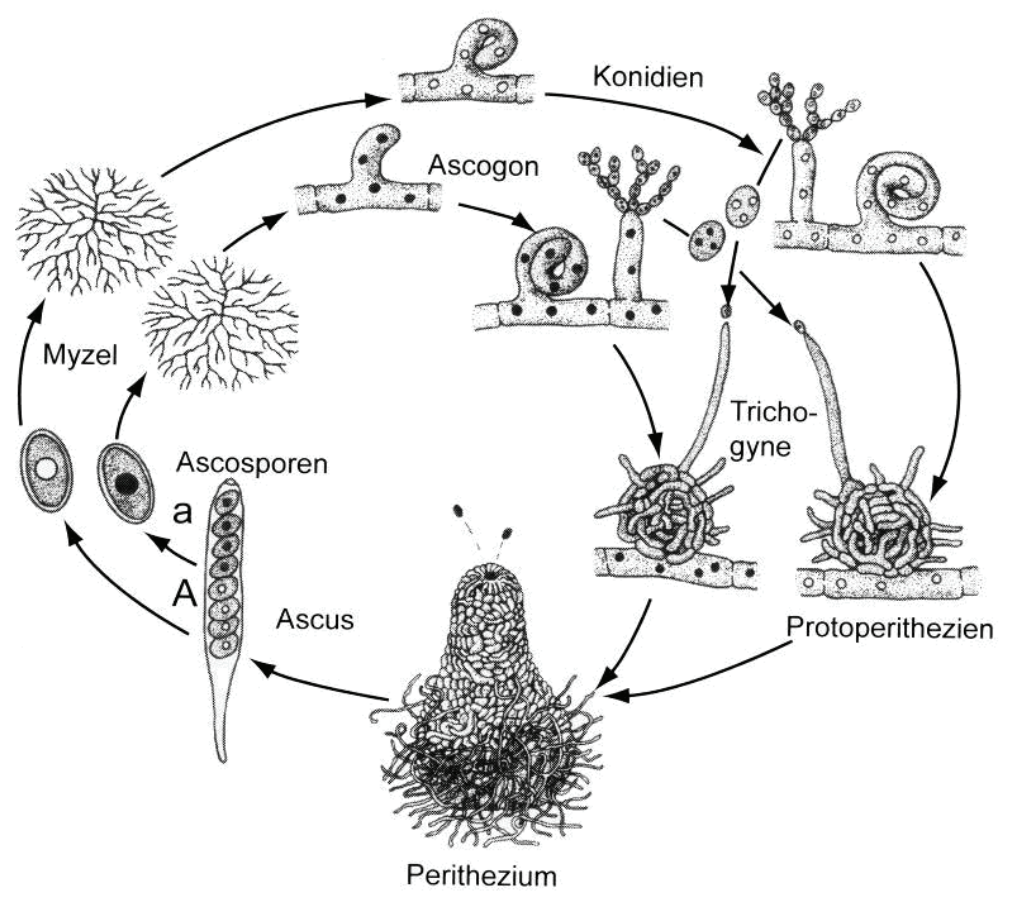

Abbildung 4: Schematische Darstellung des Lebenszyklus von Neurospora crassa. Bei $N$. crassa existieren zwei Kreuzungstypen, $A$ und $a$, und eine Kreuzung kann nur zwischen Stämmen unterschiedlichen Kreuzungstyps stattfinden. Aus der Ascospore entwickelt sich ein Myzel, an dem Ascogone (weibliche Gametangien) und Konidiosporen (männliche Gameten) entstehen. Aus dem Ascogon entwächst die Trichogyne. Sie kann mit einer Konidie des anderen Kreuzungstyps fusionieren. Die in den Asci enthaltenen Ascosporen entwickeln sich im Fruchtkörper (Perithezium). Nach Reifung werden die Ascosporen aus dem Fruchtkörper geschleudert. Weitere Details werden im Text erläutert (nach Esser 2000) 
$N$. crassa besitzt, ähnlich wie $S$. cerevisiae, ein bipolares Kreuzungstyp-System mit zwei verschiedenen Kreuzungstypen, MAT A und MAT $a$. Der MAT1-2 (MAT a) Locus besteht aus zwei Genen, MAT1-2-1 (mat a-1) und MAT1-2-2 (mat a-2) (Pöggeler und Kück, 2000; Staben und Yanofsky, 1990) (Abb. 1). Während die Funktion von MAT1-2-2 noch unbekannt ist, kodiert MAT1-2-1 für ein HMG-Domänen Protein, welches den Hauptregulator der sexuellen Entwicklung in MAT a Stämmen darstellt (Chang und Staben, 1994).

Der MAT1-1 Idiomorph besteht aus drei Genen, dem $\alpha$-Domänen Protein MAT1-1-1 (mat A-1), MAT1-1-2 (mat A-2) und dem HMG-Domänen Protein MAT1-1-3 (mat A-3) (Ferreira, et al., 1998; Glass N. L., et al., 1990a) (Abb. 1). In MAT A Stämmen stellt das Protein MAT1-1-1, ein Homolog des a1p Transkriptionsfaktors aus S. cerevisiae, den Hauptregulator der sexuellen Entwicklung dar (Bobrowicz, et al., 2002; Ferreira, et al., 1998; Glass N. L., et al., 1990a; Saupe, et al., 1996). Das Gen MAT1-1-2 kodiert für ein Protein mit einer PPF-Domäne, welche über keine bekannte DNA-Bindefunktion verfügt (Debuchy, et al., 2010; Debuchy und Turgeon, 2006). Das Protein MAT1-1-3 schließlich enthält eine HMG-Domäne (Ferreira, et al., 1996).

Einzeldeletionen der Gene MAT1-1-2 und MAT1-1-3 führen zu einer leicht verringerten Fertilität und keinem erkennbaren vegetativen Phänotyp in N. crassa. Die Deletion beider Gene führt dagegen zu einer drastisch verringerten Fertilität. Trotzdem sind die Mutanten immer noch fertil und in der Lage, wenn auch in geringer Zahl, Perithezien und Ascosporen zu bilden (Ferreira, et al., 1998).

Wie in S. cerevisiae kontrollieren die Kreuzungstyp-Gene in N. crassa die Expression von zwei spezifischen Pheromon-Genen ( $m f a-1$ and $c c g-4$ ) (Bobrowicz, et al., 2002). Das Protein MFa-1 kodiert für ein 24 Aminosäurepeptid, welches C-Terminal ein CAAX-Motiv beinhaltet. Damit zeigt es Homologien zu MFa-1 aus S. cerevisiae (Bobrowicz, et al., 2002). Das Gen $c c g-4$, welches in $M A T A$ Zellen exprimiert wird, kodiert für ein VorläuferPolypeptid, welches, wie MF $\alpha-1$ und MF $\alpha-2$ in $S$. cerevisiae, proteolytisch gespalten wird um fünf reife Pheromon-Polypeptide herzustellen. Die Sequenz dieser reifen Pheromone (QWCRIHGQSCW) ist homolog zu MFo-1 und MF $\alpha-2$ aus S. cerevisiae (Bobrowicz, et al., 2002). Es konnte ebenfalls gezeigt werden, dass beide Pheromone essentiell für die männliche Fertilität in N. crassa sind (Kim H. und Borkovich, 2006).

Die Expression der Pheromon-Rezeptor Gene ist dagegen Kreuzungstyp-unabhängig reguliert (Pöggeler und Kück, 2001). 
Einführung

\title{
1.3.3. Filamentöse Ascomyceten: Sordaria macrospora
}

Der filamentöse Ascomycet Sordaria macrospora, ein naher Verwandter von N. crassa, ist homothallisch und in der Lage den sexuellen Lebenszyklus ohne einen Kreuzungspartner zu vollenden. An einem vegetativen Myzel entwickeln sich, unter Laborbedingungen, nach 3 Tagen Ascogonien, welche sich im Laufe der Entwicklung zu Protoperithezien und schließlich reifen Perithezien differenzieren. Innerhalb der Perithezien kommt es in den ascogenen Hyphen zur Karyogamie und Meiose. Aus diesem Prozess entstehen dann reife Asci mit acht linear angeordneten Sporen (Esser, 2000; Pöggeler, et al., 2006a). Der Lebenszyklus von S. macrospora ist schematisch in Abbildung 5 dargestellt.

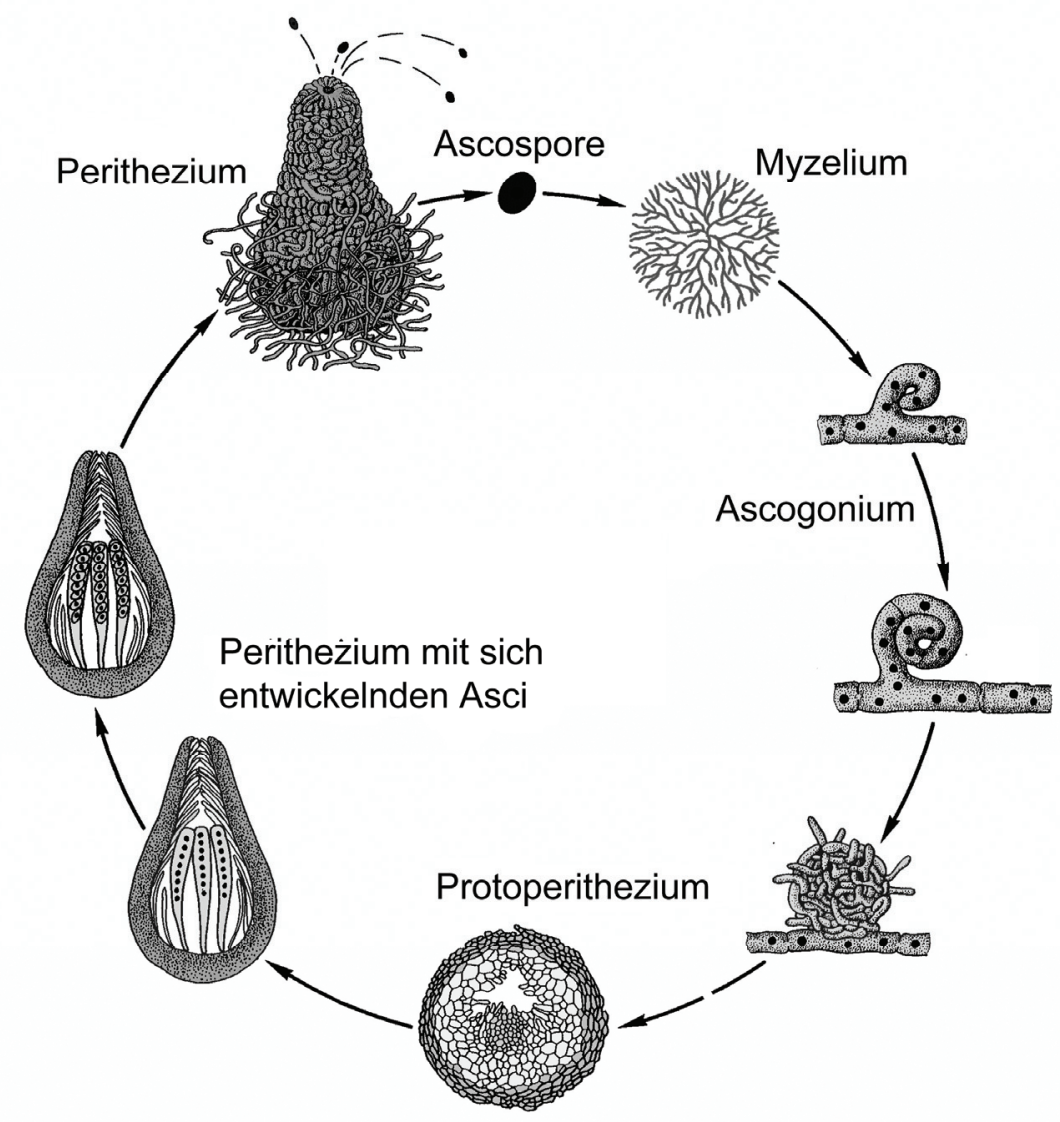

\begin{abstract}
Abbildung 5: Schematische Darstellung des Lebenszyklus von Sordaria macrospora. Aus einer Ascospore entwickelt sich zuerst ein Myzel. Während der Entwicklung des Peritheziums kommt es in den Ascogonzellen zur Bildung eines Dikaryons. Zwischen den beiden Kernen kommt es zur Karyogamie und nachfolgend zur meiotischen Teilung. Nach einer Reihe postmitotischer Teilungen sind acht Kerne vorhanden, welche im reifen Ascus in den Sporen vorliegen. Weitere Details werden im Text erläutert (verändert nach Esser, 2000).
\end{abstract}


Einführung

Obwohl S. macrospora homothallisch ist und keinen zweiten Kreuzungspartner benötigt, wurde im Genom ein Kreuzungstyp-Locus entdeckt (Pöggeler, et al., 1997). Dieser Locus zeigt Sequenzähnlichkeiten zu den MAT-Idiomorphen, sowohl MAT a als auch MAT A, aus $N$. crassa auf. Der Kreuzungstyp-Locus von S. macrospora besteht aus vier Genen (Abb. 1), dem HMG-Domänen Gen Smta-1 (MAT1-2-1), dem Gen SmtA-3 (MAT1-1-3), dem PPFDomänen Gen SmtA-2 (MAT1-1-2) und dem $\alpha$-Domänen Gen SmtA-1 (MAT1-1-1) und zeigt eine hohe Sequenzähnlichkeit zu den Kreuzungstyp-Genen aus N. crassa und anderen Sordariaceae (Pöggeler und Kück, 2000; Pöggeler, et al., 1997). Eine Besonderheit stellt dabei das Protein SMTA-3 dar, welches einen chimären Charakter zeigt und Ähnlichkeiten sowohl zu MAT1-2-2 als auch MAT1-1-3 aus N. crassa aufweist. Dabei fehlt SMTA-3 die für MAT1-1-3 Proteine typische HMG-Domäne und weist auch sonst keine bekannten funktionellen Domänen auf.

Wie in S. cerevisiae und N. crassa wurden in S. macrospora Pheromonvorläufer-Gene (ppg-1, ppg-2) und Rezeptor-Gene (pre-1, pre-2) gefunden (Pöggeler, 2000). Obwohl S. macrospora nicht darauf angewiesen ist einen kompatiblen Kreuzungspartner zu finden und mit diesem über Pheromonsignale einen Austausch von genetischem Material zu koordinieren, werden die Pheromon- und Rezeptor-Gene exprimiert und sind in die sexuelle Entwicklung involviert (Mayrhofer und Pöggeler, 2005; Mayrhofer, et al., 2006; Pöggeler, 2000). Mindestens ein funktionelles Pheromon-Rezeptor-Paar (PPG-1 / PRE-2 oder PPG-2 / PRE-1) muss für die normale sexuelle Entwicklung vorhanden sein. Stämme, welche ausschließlich funktionelle Rezeptoren tragen, sind ebenfalls in der Lage sich sexuell fortzupflanzen, im Vergleich zum Wildtyp (Wt) ist die Fertilität aber deutlich reduziert (Mayrhofer, et al., 2006).

\subsubsection{Filamentöse Ascomyceten: Penicillium chrysogenum}

Der Hyphenpilz Penicillium chrysogenum gehört zur Ordnung der Eurotiales innerhalb der Klasse der Ascomyceten (Esser, 2000). P. chrysogenum ist haploid und vermehrt sich ausschließlich über mitotisch gebildete Konidiosporen. Für die gesamte Gattung Penicillium ist die Form der Konidienträger namensgebend („Pinselschimmel“). Ein sexueller Zyklus ist für $P$. chrysogenum nicht bekannt.

Interessant, sowohl für Forschung als auch Industrie und Medizin, ist P. chrysogenum dagegen durch die Produktion von Inhibitoren bakteriellen Wachstums. Dieses Antibiotikum 
Einführung

wurde 1928 von Alexander Fleming entdeckt und, abgeleitet vom Gattungsnamen des Pilzes, als „Penicillin“ bezeichnet (Fleming, 1929).

Von Fleming selbst wurde der Stamm als Penicillium notatum beschrieben (Fleming, 1929). Spätere

Untersuchungen führten dazu, mehrere, bis dahin als einzelne Arten beschriebene Penicillium spp., als eine Art Penicillium chrysogenum (Thom) zusammenzufassen (Samson, et al., 1977).

Im Jahre 1944 wurde in Illinois, USA, ein neuer Stamm von P. chrysogenum (NRRL1951) von einer Melone isoliert (Raper, et al., 1944). Dieser Stamm war in der Lage, bedeutend größere Mengen an Penicillin zu produzieren als das ursprüngliche Isolat von Fleming (NRRL1249B21). Derivate dieses Stammes werden noch heute in der biotechnologischen Industrie als Produzenten von Penicillin in großem Maßstab genutzt (Demain und Elander, 1999; Keller, et al., 2005).

Durch das Fehlen eines bekannten sexuellen Zyklus in P. chrysogenum sind der genetischen Analyse und der Optimierung der produzierten Antibiotika-Mengen in den Stämmen Grenzen gesetzt. In anderen Pilzen, mit bekanntem sexuellen Zyklus, ist die sexuelle Fortpflanzung ein bekanntes Mittel zur konventionellen genetischen Analyse (Pöggeler, 2001), welches in P. chrysogenum nicht angewendet werden kann.

Nichtsdestoweniger wurde vor kurzer Zeit in einer Studie die Existenz von exprimierten Kreuzungstyp-Genen in P. chrysogenum nachgewiesen (Hoff, et al., 2008) (Abb. 1). Zusätzlich konnte gezeigt werden, dass Homologe zu Pheromon- und Rezeptor-Genen vorhanden sind, welche in anderen Spezies in die sexuelle Fortpflanzung involviert sind.

Damit erinnert P. chrysogenum an den nahe verwandten Pilz Aspergillus fumigatus. Dieser humanpathogene Ascomycet wurde lange ebenfalls als asexuell angesehen. Nach der Sequenzierung des Gesamtgenoms von A. fumigatus konnten allerdings ebenfalls Gene gefunden werden, welche in anderen Pilzen in den sexuellen Zyklus involviert sind (Galagan, et al., 2005) (Abb. 1). Darunter wurden auch Gene gefunden, welche für HMG-Domänen bzw. $\alpha$-Domänen Proteine kodieren (Paoletti, et al., 2005). Diese Gene wurden niemals zugleich in einem Genom gefunden, sondern waren in einem 1:1 Verhältnis innerhalb der verschiedenen Isolate verteilt, welches typisch für Kreuzungstyp-Gene ist und auf eine latente Sexualität innerhalb von A. fumigatus hindeutete. Mittlerweile konnte gezeigt werden, dass zwei A. fumigatus (MAT1-1 und MAT1-2) unter den richtigen Wachstumsumständen in der Lage ist, sich sexuell fortzupflanzen (O'Gorman, et al., 2009). 
Einführung

Ein sexueller Zyklus konnte für $P$. chrysogenum bisher nicht beschrieben werden, das Vorhandensein von Kreuzungstyp-Gene, Pheromonen und Rezeptoren lassen jedoch auf das Vorhandensein eines Solchen, wie im Fall A. fumigatus, schließen.

\subsection{Zusammenfassung}

Die Gruppe der Pilze lässt sich nach der Art der sexuellen Fortpflanzung grob in zwei Klassen unterteilen: die heterothallischen, selbst-sterilen, und die homothallischen, selbst-fertilen, Pilze (Lin und Heitman, 2007). Heterothallische Pilze benötigen zur sexuellen Vermehrung einen kompatiblen Kreuzungspartner unterschiedlichen Kreuzungstyps. Die Gene, welche für die Kreuzungstyp-Identität verantwortlich sind, liegen in speziellen Loci, den sogenannten $M A T$-Loci. In Ascomyceten wird für die unterschiedlichen Versionen der MAT-Loci der Begriff Idiomorph anstatt Allel verwendet, da die Loci an der gleichen Stelle in homologen Chromosomen liegen, die Nukleinsäuresequenzen jedoch hoch polymorph sind und für unterschiedliche Proteine kodieren (Metzenberg und Glass, 1990).

Homothallische Arten besitzen häufig ebenfalls Kreuzungstyp-Gene. Hier besitzt jedoch jedes Individuum die gleiche Art MAT-Locus, weswegen der Begriff Idiomorph hier nicht verwendet wird. Die Gene im Kreuzungstyp-Locus homothallischer Arten zeigen häufig Homologien zu Genen beiden Kreuzungstyps aus nahe verwandten, heterothallischen Arten (Pöggeler, 2001).

Die Proteine, welche im Kreuzungstyp-Locus kodiert werden, stellen putative Transkriptionsfaktoren dar und es wird angenommen, dass sie Gene der sexuellen Entwicklung direkt oder indirekt kontrollieren. Auch eine Beteiligung an vegetativen Vorgängen konnte bereits nachgewiesen werden (Ferreira, et al., 1998; Ferreira, et al., 1996; Glass N. L., et al., 1990a; Glass N. L. und Lee, 1992; Glass N. L. und Smith, 1994).

Bekannte Gene, deren Expression durch die MAT-Proteine reguliert wird, sind Pheromon- und Rezeptor-Gene (Herskowitz, 1989). Gene für zwei Pheromonvorläufer und entsprechende G-Protein gekoppelte Rezeptoren sind weit verbreitet in der Klasse der Ascomyceten und konnten bisher in vielen heterothallischen, homothallischen und sogar asexuellen Spezies nachgewiesen werden (Bistis, 1981; Bölker und Kahmann, 1993; Dohlman und Thorner, 2001; Lee J., et al., 2008; Pöggeler, 2000). Die Struktur und Sequenz dieser Pheromone und Rezeptoren ist hoch konserviert zwischen verschiedenen heterothallischen Ascomyceten wie S. cerevisiae (Kurjan, 1993), N. crassa (Bobrowicz, et al., 2002; Kim H., et al., 2002), 
Einführung

P. anserina (Coppin, et al., 2005) oder Magnaporthe grisea (Shen W. C., et al., 1999) und sind essentiell für die sexuelle Entwicklung (Coppin, et al., 2005; Kim H. und Borkovich, 2004).

In homothallischen Spezies konnten Pheromone und G-Protein gekoppelte Rezeptoren nachgewiesen werden. Die Funktion dieser Proteine ist hier aber unterschiedlich. Während S. macrospora und Aspergillus nidulans mindestens einen funktionellen Rezeptor und zur vollen Fertilität ein Pheromon-Rezeptor-Paar benötigen (Mayrhofer, et al., 2006; Seo, et al., 2004), ist der Ascomycet Gibberella zeae in der Lage den sexuellen Zyklus ohne funktionelle Pheromone oder Rezeptoren zu vollenden (Lee J., et al., 2008). 


\section{Problemstellung}

\subsection{Sordaria macrospora}

Die sexuelle Fortpflanzung ist ein komplexer zellulärer Prozess, der durch viele verschiedene Gene kontrolliert wird. Als Modellorganismus zur Untersuchung entwicklungsbiologischer Prozesse bietet $S$. macrospora mehrere Vorteile. Der Pilz ist nicht infektiös und lässt sich als koprophiler Organismus einfach kultivieren. Ein zusätzlicher Vorteil ist der einfache Lebenszyklus, der unter Laborbedingungen in sieben Tagen durchlaufen wird. Zudem besitzt S. macrospora keinen vegetativ-mitotischen Vermehrungszyklus über Konidiosporen, was eine Untersuchung der spezifischen Regelkreisläufe der sexuellen Entwicklung erleichtert (Kück, et al., 2009).

So konnten in S. macrospora durch Mutationsexperimente bereits Gene identifiziert werden, die an diesem Prozess beteiligt sind. So sind Mutanten der Gene inf 25 und inf40 nicht in der Lage, Asci und Ascosporen zu entwickeln (Nowrousian, et al., 1999). Die Gene pro1, prol1 und pro40 sind dagegen für eine Weiterentwicklung früher Protoperithezien zu reifen Perithezien essentiell. Mutanten dieser Gene sind daher steril (Masloff, et al., 2002; Masloff, et al., 1999; Pöggeler und Kück, 2004).

Wie in S. cerevisiae sind die Kreuzungstyp-Gene heterothallischer, filamentöser Ascomyceten in die direkte oder indirekte Regulation Kreuzungstyp-spezifischer Gene, wie von Pheromonen und Rezeptoren, involviert (Bardwell, 2005; Debuchy, et al., 2010; Debuchy und Turgeon, 2006; Kothe, 2008). In dem homothallischen Ascomyceten S. macrospora wurde ebenfalls ein Kreuzungstyp-Locus und Gene eines Pheromon-Rezeptor-Systems identifiziert (s. 1.3.3). Der Kreuzungstyp-Locus von S. macrospora enthält vier Gene, Smta-1 (MAT1-2-1), SmtA-1 (MAT-1-1-1), SmtA-2 (MAT1-2-1) und SmtA-3 (MAT1-1-3). Die Kreuzungstyp-Gene SmtA-1 und Smta-1 kodieren für Proteine mit konservierten DNABindedomänen und in einem Hefereportersystem konnte für SMTA-1 und SMTa-1 die Fähigkeit zur Transkriptionsaktivierung bereits nachgewiesen werden (Jacobsen, et al., 2002; Pöggeler, 2001). In einer Hefe-Zwei-Hybrid Analyse wurde für das Protein SMTa-1 eine Interaktion mit dem Kreuzungstyp-Protein SMTA-1 nachgewiesen (Jacobsen, et al., 2002). SMTA-1 wiederum interagiert mit den Transkriptionsfaktoren STE12 und MCM1 (Nolting und Pöggeler, 2006a; b). Homologe dieser Gene in S. cerevisiae sind unter anderem an der Regulation der Expression des $\alpha$-Faktor Pheromons und des $\alpha$-Faktor Rezeptors beteiligt 
(Johnson, 1995) und in einer $\Delta$ Smta-1 Deletionsmutante konnte gezeigt werden, dass dieses Protein direkt oder indirekt an der positiven Regulation der Expression des Pheromonvorläufer-Gens ppg-2 aus S. macrospora beteiligt ist (Pöggeler, et al., 2006b).

Die Funktion der anderen drei Gene (MAT1-1-1, MAT1-1-2, MAT1-1-3) ist bisher unbekannt. In dieser Studie sollten die MAT1-1 Gene von S. macrospora molekulargenetisch untersucht werden. Dazu wurden Gendeletionen der einzelnen Gene und eine Doppeldeletion von SmtA-2 und SmtA-3 erstellt. Die für die Einzeldeletionen verwendeten Deletionskonstrukte wurden in vorhergegangene Studien bereits hergestellt (Brzonkalik, 2006; Klix, 2007). Die entstandenen Mutanten wurden hinsichtlich ihres Phänotyps in der sexuellen und vegetativen Entwicklung untersucht.

Zusätzlich wurde die Genexpression in den Mutanten im Vergleich zum Wildtyp mittels einer Microarray-Analyse gegen N. crassa Oligo-Chips getestet. Die Expression der Pheromonund Rezeptor-Gene in den Mutanten wurde durch real-Time-PCR mit dem Wildtyp verglichen. Gene, welche in den Microarray Experimenten als unterschiedlich reguliert gefunden wurden, wurden außerdem mittels real-Time-PCR bestätigt. Da für SMTA-1 in einem Hefereportersystem bereits Interaktionspartner gefunden werden konnten, wurde ein solcher Test mit SMTA-2 gegen eine S. macrospora cDNA-Bank durchgeführt.

Zum besseren Verständnis der Vorgänge um die Kreuzungstyp-Proteine in vivo wurden die Proteine MAT1-1-2 und MAT1-1-3 mit verschiedenen fluoreszierenden Proteinen fusioniert und ihre Lokalisation in der Zelle mittels Fluoreszenzmikroskopie untersucht.

\subsection{Penicillium chrysogenum}

Der asexuelle Ascomycet Penicillium chrysogenum besitzt in der industriellen Biotechnologie einen hohen Stellenwert als Produzent des Antibiotikums Penicillin mit einem weltweiten Marktwert von etwa 8 Milliarden US\$ (Barber, et al., 2004).

Die Möglichkeit Pilze sexuell unter Laborbedingungen zu kreuzen stellt eine wichtige Methode der genetischen Analyse dar (Pöggeler, 2001). Gerade für die industrielle Nutzung ist es hierbei interessant Stämme zu entwickeln, welche benötigte Metabolite schneller und in größerer Menge herstellen.

Die Gattung Penicillium besteht aus vielen, scheinbar asexuellen Spezies. Durch das Fehlen eines sexuellen Zyklus sind die Spezies der Gattung Penicillium häufig schwierig durch konventionelle genetische Methoden zu verändern. In den asexuellen, humanpathogenen 
Problemstellung

Pilzen Aspergillus fumigatus und Penicillium marneffei, nahe Verwandte von P. chrysogenum, wurden durch Sequenzanalysen des Gesamtgenoms Gene gefunden, welche in Zusammenhang mit sexueller Entwicklung bekannt sind, darunter Kreuzungstyp-Gene und Gene der Pheromonproduktion (Galagan, et al., 2005; Paoletti, et al., 2005; Pöggeler, 2002; Woo, et al., 2006). In A. fumigatus konnte kürzlich sogar die Fähigkeit zur sexuellen Fortpflanzung bewiesen werden (O'Gorman, et al., 2009).

In $P$. chrysogenum wurde mittlerweile ebenfalls die Existenz von Kreuzungstyp-Genen und Genen der Pheromon Produktion und Erkennung nachgewiesen (Hoff, et al., 2008). In einer Kooperation mit dem Lehrstuhl für Allgemeine und Molekulare Botanik in Bochum, sollte in dieser Arbeit zusätzlich die Funktionalität der Pheromone und Pheromon-Rezeptoren aus P. chrysogenum untersucht werden. Dies sollte in einem heterologen System innerhalb von S. cerevisiae mittels eines Hemmhof-Tests („Halo-Test“) durchgeführt werden. Dieser Test wurde bereits für die Pheromone und Rezeptoren aus S. macrospora durchgeführt und etabliert (Mayrhofer und Pöggeler, 2005). 


\section{Material und Methoden}

\subsection{Material}

\subsubsection{Verwendete Organismen}

\section{Escherichia coli K12}

\section{SURE}

e14-(McrA $\left.{ }^{-}\right) \Delta$ (mcrCB-hsdSMR-mrr)171, endA1 supE44 thi-1 gyrA96 relA1 lac recB recJ sbcC umuC::Tn5 $\left(\operatorname{Kan}^{\mathrm{r}}\right)$ uvrC [F', proAB, $\operatorname{lacI}^{\mathrm{q}} \mathrm{Z} \Delta \mathrm{M} 15$ Tn10 $\left.\left(\mathrm{Tet}^{\mathrm{r}}\right)\right]^{\mathrm{c}}$; Rezipientenstamm für die Vermehrung von Plasmidvektoren und deren Derivaten.

\section{Saccharomyces cerevisiae}

\section{PJ69-4A}

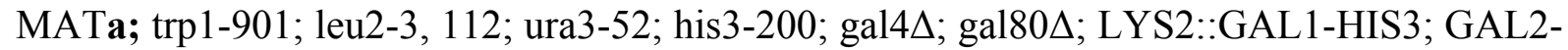
ADE2; met2::GAL7-lacZ; Stamm für die Herstellung von Deletionskonstrukten nach Colot, et al. (2006) durch homologe Rekombination (James, et al., 1996).

\section{BY4741}

MATa; his $3 \Delta 1$; leu2 $\Delta 0$; lys $2 \Delta 0$; ura3 $\Delta 0 ; \Delta$ sst2::KanMX4; Stamm für die Durchführung von Pheromon-Hemmhof-Tests als Wildtyp-Kontrolle; Stammsammlung „EuroScarf“ (Frankfurt).

\section{YDB103}

MATa; -leu2; -ura3; -trp1; $\Delta$ sst2::KanMX4; ste2 $\Delta$; Stamm für die Durchführung von Pheromon-Hemmhof-Tests mit heterolog exprimierten Pheromon-Rezeptoren (Ballon, et al., 2006).

\section{YLR452c}

MATa; his3 $\Delta 1$; leu2 $\Delta 0$; lys2 $\Delta 0$; ura3 $\Delta 0 ; \Delta$ sst2::KanMX4; Stamm für die Durchführung von Pheromon-Hemmhof-Tests mit heterolog exprimierten Pheromonen; Stammsammlung „EuroScarf“ (Frankfurt).

\section{AH109}

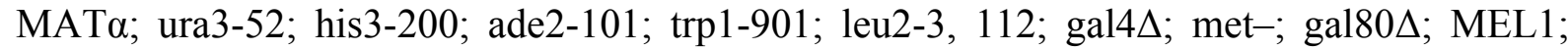
URA3::GAL1 $1_{\text {UAS }}-G A L 1_{\text {TATA }}$-lacZ; Stamm für die Nutzung in einem Hefereportersystem.

\section{Y187}

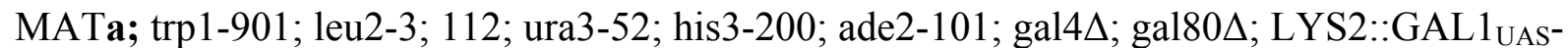

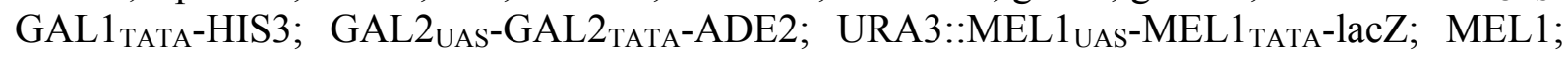
Stamm für die Nutzung in einem Hefereportersystem. 


\section{Sordaria macrospora}

Die verwendeten $S$. macrospora Stämme sind in Tabelle 1 aufgeführt.

Tabelle 1: Übersicht der in dieser Arbeit verwendeten S. macrospora Stämme.

\begin{tabular}{|c|c|c|}
\hline Stamm & Charakteristika & Referenz \\
\hline S48977 & Wildtyp & Stammsammlung RUB $^{1}$ \\
\hline S23442 (Fus1-1) & $\begin{array}{l}\text { fus1-1; Farbspormutante, } \\
\text { Wildtyp-Phänotyp }\end{array}$ & Stammsammlung RUB \\
\hline S67813 (R2) & $\begin{array}{l}\text { r2; Farbspormutante, Wildtyp- } \\
\text { Phänotyp }\end{array}$ & Stammsammlung RUB \\
\hline S66001 & $\begin{array}{l}\Delta \text { ku70::nat1; } \\
\text { Rezipientenstamm mit Defekt } \\
\text { im NHEJ-System }{ }^{2}\end{array}$ & (Pöggeler und Kück, 2006) \\
\hline WtRed & $\begin{array}{l}\text { dsRed; Fluoreszenzprotein } \\
\text { dsRED in Wildtyp-Hintergrund }\end{array}$ & diese Arbeit \\
\hline SmtA-3_Red & $\begin{array}{l}\text { SmtA-3_dsRed; Kreuzungstyp- } \\
\text { Gen gekoppelt mit dsRed }\end{array}$ & diese Arbeit \\
\hline$\Delta$ Smta-1 & $\Delta$ Smta-1::hph & (Pöggeler, et al., 2006b) \\
\hline$\Delta \mathrm{SmtA}-1$ & $\Delta$ SmtA-1::hph & (Klix, et al., 2010) \\
\hline$\Delta$ SmtA-1fus & $\Delta$ SmtA-1fus::hph & (Klix, et al., 2010) \\
\hline$\Delta$ SmtA-2 & $\Delta$ SmtA-2::hph & (Klix, et al., 2010) \\
\hline$\Delta$ SmtA-2fus & $\begin{array}{l}\Delta \text { SmtA-2::hph fus } 1-1 ; \\
\text { Farbspormutante in } \Delta \text { SmtA-2 } \\
\text { Hintergrund }\end{array}$ & (Klix, et al., 2010) \\
\hline$\Delta \mathrm{SmtA}-2 / 3$ & $\Delta$ SmtA-2/3::hph & (Klix, et al., 2010) \\
\hline$\Delta S m t A-2 / 3:: S m t A-2$ & $\Delta$ SmtA-2/3::hph SmtA-2 $2^{\text {ect }}$ & diese Arbeit \\
\hline$\Delta$ SmtA-2/3::SmtA-3 & $\Delta S m t A-2 / 3:: h p h S m t A-3^{e c t}$ & diese Arbeit \\
\hline$\Delta$ SmtA-2::SmtA-2 & $\Delta$ SmtA-2::hph SmtA-2 ${ }^{\text {ect }}$ & (Klix, et al., 2010) \\
\hline$\Delta$ SmtA-3 & $\Delta$ SmtA-3::hph & (Klix, et al., 2010) \\
\hline$\Delta$ SmtA-3fus & $\begin{array}{l}\Delta \text { SmtA-3::hph fus } 1-1 ; \\
\text { Farbspormutante in } \Delta \text { SmtA-2 } \\
\text { Hintergrund }\end{array}$ & (Klix, et al., 2010) \\
\hline$\Delta$ SmtA-2::A2-188 & $\Delta$ SmtA-2::hph pRSn-A2-188 & diese Arbeit \\
\hline$\Delta$ SmtA-2::A2-199 & $\Delta$ SmtA-2::hph pRSn-A2-199 & diese Arbeit \\
\hline$\Delta$ SmtA-2::A2-205 & $\Delta$ SmtA-2::hph pRSn-A2-205 & diese Arbeit \\
\hline$\Delta$ SmtA-2::A2-S-N & $\Delta$ SmtA-2::hph pRSn-A2-S-N & diese Arbeit \\
\hline$\Delta$ SmtA-2::SmtA-2_dsRed & $\Delta$ SmtA-2::hph pRHN-A2 & diese Arbeit \\
\hline$\Delta$ SmtA-2::SmtA-2_GFP & $\Delta$ SmtA-2::hph pRSnG-A2 & diese Arbeit \\
\hline$\Delta \mathrm{SmtA}-2::$ mat $A 2$ & $\begin{array}{l}\triangle \text { SmtA-2::hph N. crassa } \\
\text { mat A2 }\end{array}$ & diese Arbeit \\
\hline$\Delta S m t A-2:: S M R 1$ & $\begin{array}{l}\triangle \text { SmtA-2::hph P. anserina } \\
\text { SMR1 }\end{array}$ & diese Arbeit \\
\hline$\Delta$ SmtA-2::GFP & $\Delta$ SmtA-2::hph pRSnGFP & diese Arbeit \\
\hline
\end{tabular}




\subsubsection{Plasmide}

In Tabelle 2 sind alle in dieser Arbeit verwendeten Plasmide aufgeführt.

Tabelle 2: Liste der in dieser Arbeit verwendeten Plasmide. Ausgangsplasmide, besondere Charateristika und Referenzen sind aufgeführt.

\begin{tabular}{|c|c|c|c|}
\hline Plasmid & Ausgangsplasmid & Charakteristika & Referenz \\
\hline pRS426 & --- & $\begin{array}{c}\text { S. cerevisiae / E. coli } \\
\text { Schaukelvektor; URA3; } A m p^{r}\end{array}$ & $\begin{array}{c}\text { (Christianson, et al., } \\
\text { 1992) }\end{array}$ \\
\hline p1783 & --- & $g p d(p):: g f p:: \operatorname{trpC}(t) ; h p h$ & $\begin{array}{c}\text { (Pöggeler, et al., } \\
\text { 2003) }\end{array}$ \\
\hline pGADT7 & --- & $\begin{array}{l}\text { GAL4 Aktivierungsdomäne; } \\
\text { Leu2; } A m p^{r}\end{array}$ & $\begin{array}{c}\text { Clontech } \\
\text { laboratories Inc. }\end{array}$ \\
\hline pGBKT7 & --- & $\begin{array}{c}\text { GAL4 DNA Bindedomäne; } \\
\text { TRP1; Kan }{ }^{r}\end{array}$ & $\begin{array}{c}\text { Clontech } \\
\text { laboratories Inc. }\end{array}$ \\
\hline pPGK & --- & $\begin{array}{l}\text { PGK Promotor und } \\
\text { Terminator; URA3 }\end{array}$ & (Kang, et al., 1990) \\
\hline pRHN1 & --- & $\operatorname{gpd}(p):: D s R e d:: \operatorname{trp} C(t) ;$ nat1 & (Janus, et al., 2007) \\
\hline pRSnat & pRS426 & nat1 & (Klix, et al., 2010) \\
\hline pGAD-ranBPM & pGADT7 & $\begin{array}{l}\text { ranBPM fusioniert an GAL4- } \\
\text { AD }\end{array}$ & $\begin{array}{l}\text { (Tucker, et al., } \\
\text { 2009) }\end{array}$ \\
\hline pGB-A2 & pGBKT7 & $\begin{array}{c}\text { SmtA-2 fusioniert an GAL4- } \\
\text { BD }\end{array}$ & diese Arbeit \\
\hline $\begin{array}{l}\text { pPGK- } \\
\text { SmPPG1 }\end{array}$ & pPGK & S. macrospora ppg-1 ORF & $\begin{array}{l}\text { (Mayrhofer und } \\
\text { Pöggeler, 2005) }\end{array}$ \\
\hline $\begin{array}{c}\text { pPGK- } \\
\text { SmPRE2 }\end{array}$ & pPGK & S. macrospora pre-2 ORF & $\begin{array}{l}\text { (Mayrhofer und } \\
\text { Pöggeler, 2005) }\end{array}$ \\
\hline pPGK-PcPPG1 & pPGK & P. chrysogenum ppg-1 ORF & diese Arbeit \\
\hline pPGK-PcPRE2 & pPGK & P. chrysogenum pre-2 ORF & diese Arbeit \\
\hline pRHN-A3 & pRHN1 & $\begin{array}{c}\text { gpd }(p):: S m t A-3- \\
\text { DsRed::trpC }(t) ; \text { nat1 }\end{array}$ & diese Arbeit \\
\hline pRHN-A2 & pRHN1 & $\begin{array}{c}g p d(p):: S m t A-2- \\
D s R e d:: \operatorname{trp} C(t) ; \text { nat1 }\end{array}$ & diese Arbeit \\
\hline pRS-Ba1 & pRS426 & S. macrospora SmtA-1 ORF & diese Arbeit \\
\hline pRS-Ba2 & pRS426 & S. macrospora SmtA-2 ORF & (Klix, et al., 2010) \\
\hline pRS-Ba3 & pRS426 & S. macrospora SmtA-3 ORF & diese Arbeit \\
\hline pRSn-A2-188 & pRSnat & $\begin{array}{l}\text { S. macrospora SmtA-2 } \\
\text { ORF(Protein AS 1-188) }\end{array}$ & diese Arbeit \\
\hline pRSn-A2-199 & pRSnat & $\begin{array}{l}\text { S. macrospora SmtA-2 ORF } \\
\text { (Protein AS 1-199) }\end{array}$ & diese Arbeit \\
\hline pRSn-A2-205 & pRSnat & $\begin{array}{l}\text { S. macrospora SmtA-2 ORF } \\
\text { (Protein AS 1-205) }\end{array}$ & diese Arbeit \\
\hline pRSn-A2-S-N & pRSnat & $\begin{array}{l}\text { S. macrospora SmtA-2 ORF } \\
\text { (Protein AS 199-359) }\end{array}$ & diese Arbeit \\
\hline pRS- $\triangle \mathrm{A} 1$ & pRS426 & SmtA-1(p)::hph::SmtA-1(t) & (Brzonkalik, 2006) \\
\hline $\mathrm{pRS}-\triangle \mathrm{A} 2$ & pRS426 & SmtA-2(p)::hph::SmtA-2(t) & (Klix, 2007) \\
\hline $\mathrm{pRS}-\triangle \mathrm{A} 3$ & pRS426 & SmtA-3(p)::hph::SmtA-3(t) & (Klix, 2007) \\
\hline$p R S-\triangle A 2 / 3$ & pRS426 & SmtA-3(p)::hph::SmtA-2(t) & (Klix, et al., 2010) \\
\hline
\end{tabular}




\begin{tabular}{|c|c|c|c|}
\hline pRS-Ba2-S-N & pRS-Ba2 & $\begin{array}{c}\text { SmtA-2 ORF verkürzt mit } \\
\text { Sacl+Ncol (AS 199-359) }\end{array}$ & diese Arbeit \\
\hline pRSnGFP & pRSnat & $g p d(p):: g f p:: t r p C(t) ;$ nat1 & $\begin{array}{c}\text { Gehsing und } \\
\text { Nowrousian, pers. } \\
\text { Mitteilung }\end{array}$ \\
\hline pRS-NcA2 & pRSnat & N. crassa mat A-2; nat1 & diese Arbeit \\
\hline pRS-PaSMR1 & pRSnat & P. anserina SMR1; nat1 & diese Arbeit \\
\hline pRSnG-A2 & pRSnGFP & $\begin{array}{c}g p d(p):: S m t A-2-g f p:: \operatorname{trpC}(t) ; \\
n a t 1\end{array}$ & diese Arbeit \\
\hline
\end{tabular}

AD: Aktivierungsdomäne; Amp ${ }^{r}$ : Ampicillinresistenzkassette; AS: Aminosäure; BD: Bindedomäne; $h p h$ : Hygromycin B-Resistenzkassette; nat1: Nourseothricinresistenzkassette; (p): Promotor; (t):Terminator; URA3, LEU2, TRP1: Gene der Uracil (Ura), Leucin (Leu) oder Trypthophan (Trp) Biosynthese.

\subsubsection{Oligonukleotide}

In Tabelle 3 sind alle Oligonukleotide aufgeführt, die als PCR-Startermoleküle eingesetzt worden sind.

Tabelle 3: Liste der in dieser Arbeit verwendeten Oligostarternukleotide. Sequenzen, welche homolog zu Hefe-Vektoren zwecks homologer Rekombination sind, sind hervorgehoben. Spezifische Sequenzen für Restriktionsendonukleasen sind kursiv gehalten, durch die Oilgonukleotide eingeführte Punktmutationen sind unterstrichen.

\begin{tabular}{|c|l|}
\hline Name & \multicolumn{1}{|c|}{ Sequenz (5' --> 3') } \\
\hline $1783-f$ & GCTACATCCATACTCCATCC \\
\hline 1783-r & GTCTCAACTCCGGAGCTGAC \\
\hline A1-Ncol-f & CCATGG CCAGCGTCGATCAAA \\
\hline A1-Ncol-r & CCATGG CTGCTCCTCCATTGATCC \\
\hline A2-188-r & $\begin{array}{l}\text { GCGGATAACAATTTCACACAGGAAACAGC } \\
\text { TCATGTATGGTCAACATGCC }\end{array}$ \\
\hline A2-199-r & $\begin{array}{l}\text { GCGGATAACAATTTCACACAGGAAACAGC } \\
\text { TCATGGAGTGCCTGGAACGC }\end{array}$ \\
\hline A2-205-r & $\begin{array}{l}\text { GCGGATAACAATTTCACACAGGAAACAGC } \\
\text { TCAGCCAAAGAACTTGTGCC }\end{array}$ \\
\hline A2-GFP-f & $\begin{array}{l}\text { GCTTGACTAACAGCTACAGATCTAAGCTT } \\
\text { ATGGAGCTCATCAACACGCA }\end{array}$ \\
\hline A2-GFP-r & $\begin{array}{l}\text { CCGGTGAACAGCTCCTCGCCCTTGCTCAC } \\
\text { AATGTGATAAACGTGCTCCT }\end{array}$ \\
\hline A2-Ncol-f & CCATGG AGCTCATCAACACGC \\
\hline A2-Ncol-r & CCATGG CAATGTGATAAACGTGCTC \\
\hline A2-Ncol-RIPf & AGGCACTCCGTGGCACAAGTTCTTTGGCAATGTGGAAGTT \\
\hline A2-Ncol-RIPr & AACTTCCACATTGCCAAAGAACTTGTGCCACGGAGTGCCT \\
\hline A3-Ncol-f & CCATGG CTGCCCCAGACGTTG \\
\hline A3-Ncol-r & CCATGG CGGCGAGAATGTCTGGGT \\
\hline Ba1-5f & $\begin{array}{l}\text { GTAACGCCAGGGTTTCCCAGTCACGACG } \\
\text { GAGGAGCACGTTTATCACATT }\end{array}$ \\
\hline
\end{tabular}




\begin{tabular}{|c|c|}
\hline $\mathrm{Ba} 1-5 \mathrm{r}$ & $\begin{array}{l}\text { CСAAAAATGCTCCTTCAATATCAGTTAAC } \\
\text { AGAGGATGGTCATGAAGGGCG }\end{array}$ \\
\hline Ba1-3f & $\begin{array}{l}\text { GAGTAGATGCCGACCGGGAACCAGTTAAC } \\
\text { CAGAGGCAGATGACGTCGCCA }\end{array}$ \\
\hline Ba1-3r & $\begin{array}{l}\text { GCGGATAACAATTTCACACAGGAAACAGCT } \\
\text { GAGGGGTACGTCTTGTACAC }\end{array}$ \\
\hline Ba1Ko-f & GGTCTTGCGGATCACTTTGAC \\
\hline Ba1Ko-r & CGAGGCAACTTTTGGACACGG \\
\hline Ba1-Wt & GTAATCTTCTTCTCCCGCTGCGCG \\
\hline $\mathrm{Ba} 2-5 \mathrm{f}$ & $\begin{array}{l}\text { GTAACGCCAGGGTTTTCCCAGTCACGACG } \\
\text { AACGTCTGGGGCAGACATGC }\end{array}$ \\
\hline $\mathrm{Ba} 2-5 \mathrm{r}$ & $\begin{array}{l}\text { CAAAAAATGCTCCTTCAATATCAGTTAAC } \\
\text { TGCGTGTTGATGAGCTCCAT }\end{array}$ \\
\hline $\mathrm{Ba} 2-3 \mathrm{f}$ & $\begin{array}{l}\text { GAGTAGATGCCGACCGGGAACCAGTTAAC } \\
\text { GTGATCATCCCTGAAACTGC }\end{array}$ \\
\hline $\mathrm{Ba} 2-3 \mathrm{r}$ & $\begin{array}{l}\text { GCGGATAACAATTTCACACAGGAAACAGCT } \\
\text { TGATCGACGCTGGACATCG }\end{array}$ \\
\hline Ba2Ko-f & CATCACCTGAACCCTGCCAAAG \\
\hline Ba2Ko-r & GAGGATGGTCATGAAGGGCGA \\
\hline Ba2-Wt & TGACTGCTGCGTTGCGCTCGCC \\
\hline Ba3-5f & $\begin{array}{l}\text { GTAACGCCAGGGTTTTCCCAGTCACGACG } \\
\text { GTGCATCAAGTTGTCTTCCA }\end{array}$ \\
\hline Ba3-5r & $\begin{array}{l}\text { CAAAAAATGCTCCTTCAATATCAGTTAAC } \\
\text { AАTTGAACСTTCAGCGCTAC }\end{array}$ \\
\hline Ba3-3f & $\begin{array}{l}\text { GAGTAGATGCCGACCGGGAACCAGTTAAC } \\
\text { AACGTCTGGGGCAGACATGC }\end{array}$ \\
\hline Ba3-3r & $\begin{array}{l}\text { GCGGATAACAATTTCACACAGGAAACAGCT } \\
\text { GCGTGTTGATGAGCTCCAT }\end{array}$ \\
\hline Ba3Ko-f & GCCATGGTGGCCCTGAGTTCCG \\
\hline Ba3Ko-r & TCGTTGCTAGACCCAAACCAGC \\
\hline Ba3-Wt & TTATGCTTCAAACCCACGTTTG \\
\hline ctr3-f & CGTCGTTTGCGTCAGCAACAAC \\
\hline ctr3-r & AGAAACTTGCCAATCAGCGCCC \\
\hline GFP-A2-f & $\begin{array}{l}\text { TCACTCTCGGCATGGACGAGCTGTACAAG } \\
\text { GAGCTCATCAACACGCAACG }\end{array}$ \\
\hline GFP-A2-r & $\begin{array}{l}\text { TTGATGATTTCAGTAACGTTAAGTGGATC } \\
\text { TCAAATGTGATAAACGTGCT }\end{array}$ \\
\hline hph-3 & ACTCGTCCGAGGGCAAAGGAATAG \\
\hline hph-f & GTTAACTGATATTGAAGGAGCATTTTTGG \\
\hline hph-r & GTTAACTGGTTCCCGGTCGGCATCTACTC \\
\hline Nat-lig-f & CAATTGCTGCAG CAGCTATGACCATGATTACG \\
\hline Nat-lig-r & CAATTGCTGCAG CTTTGGTTTAGGGTTAGGGC \\
\hline NcA2-f & $\begin{array}{l}\text { GTAACGCCAGGGTTTTCCCAGTCACGACG } \\
\text { TTGTGATAGAGGGGTGCAGA }\end{array}$ \\
\hline NcA2-r & $\begin{array}{l}\text { GCGGATAACAATTTCACACAGGAAACAGC } \\
\text { ATCTGAAACCCATGAAGCCG }\end{array}$ \\
\hline orc-f & ACGCTTGACTCGTTCAAGGCAC \\
\hline
\end{tabular}




\begin{tabular}{|c|l|}
\hline orc-r & AGTCCTGCTTTTTCTGCCGCTG \\
\hline PaSMR1-f & $\begin{array}{l}\text { GTAACGCCAGGGTTTCCCAGTCACGACG } \\
\text { TGAGAAGAGGTGAACAGAAG }\end{array}$ \\
\hline PaSMR1-r & $\begin{array}{l}\text { GCGGATAACAATTTCACACAGGAAACAGC } \\
\text { CTGTTCATTTCTGTCCCAGT }\end{array}$ \\
\hline pGAD-AD3 & AGATGGTGCACGATGCACAG \\
\hline pks-f & GGTCATGGGCCACAGTCTCG \\
\hline pks-r & CGTGGCTGTTCATCGTGCAC \\
\hline ppg1-f & AAGCGCCAGGTTGACGAGC \\
\hline Ppg1-hom-f & $\begin{array}{l}\text { GTAATTATCTACTTTTACAACAAATAT } \\
\text { ATGAAGTTCACCTCCGTCGTC }\end{array}$ \\
\hline Ppg1-hom-r & $\begin{array}{l}\text { ATTGATCTATCGATTTCAATTCAATTCA } \\
\text { TTACTCGTCATCCTCTTCCTC }\end{array}$ \\
\hline ppg1-r & CGTCCTTCTTCTCCTCCTCGGT \\
\hline ppg2-f & CGGTATCTCGCCTCTCAACGT \\
\hline ppg2-r & GTTGTGCTCCCATTGTGCAGA \\
\hline pre1-f & GCATTCACGCCCACATCAAC \\
\hline pre1-r & GTTGTGCCGAAGGTGATGCA \\
\hline pre2-f & TCCACCCGTTCCATACCCTG \\
\hline Pre2-hom-f & $\begin{array}{l}\text { TAATTATCTACTTTTACAACAAATAT } \\
\text { ATGGCGACATCATCTCCAATTC }\end{array}$ \\
\hline Pre2-hom-r & ATTGATCTATCGATTCAATTCAATC \\
TCACACGATTGAATTGTCCTT
\end{tabular}

\subsubsection{Chemikalien}

aad UTP (Sigma-Aldrich, München), Adenin (Fluka Chemie GmbH, Buchs), Agar-Agar (Carl Roth GmbH und Co, Karlsruhe; Serva Electrophoresis GmbH, Heidelberg), Agarose (Biozym Scientific GmbH, Oldenburg), $\alpha$ mating factor (Sigma-Aldrich, München), Ameisensäure (Merck, Darmstadt), Ammoniumsulfat (Carl Roth GmbH und Co, Karlsruhe), Ampicillin (AppliChem, Darmstadt), artifizielles Pheromon (SmPPG1 / PcPPG1) (GenScript 
Corporation, Piscataway, USA), Bacto-Pepton/Trypton (Carl Roth GmbH und Co, Karlsruhe), Bacto-Yeast-Extract (Oxoid LTD., Hampshire, UK), Biotin (Sigma-Aldrich, München), Bromphenolblau (Merck, Darmstadt), Borsäure (Carl Roth $\mathrm{GmbH}$ und Co, Karlsruhe), Calciumchlorid (Carl Roth GmbH und Co, Karlsruhe), Chloroform (Merck, Darmstadt), CSM-Ade-His-Leu-Trp und CSM-Ade-His-Leu-Ura (MP Biomedicals, Illkirch, F), Desoxynukleosidtriphosphate (dNTPs) (Fermentas, St.-Leon-Rot, St.-Leon-Rot), DMSO = Dimethylsulfoxid (Merck, Darmstadt), EDTA = Ethylendiamin-N,N,N',N'-tetraessigsäureDinatriumsalz (Carl Roth GmbH und Co, Karlsruhe), Ethanol (VWR International, Haasrode, B), Ethidiumbromid (Boehringer, Mannheim), Formamid (Carl Roth GmbH und Co, Karlsruhe), Formaldehyd (Carl Roth GmbH und Co, Karlsruhe), Gene Ruler ${ }^{\mathrm{TM}}$ DNA Ladder Mix (Fermentas, St.-Leon-Rot), GeneScreen Hybridization Transfer Membran (PerkinElmer Lifesciences, Wellesley, USA), Glucose (AppliChem, Darmstadt), Glycerin (VWR International, Haasrode, B), Hefeextrakt (Oxoid, Cambridge, UK), Histidin (Merck, Darmstadt), Hygromycin B (Calbiochem Merck-Gruppe, Darmstadt), Isopropanol (AppliChem, Darmstadt), Kaliumacetat (Merck, Darmstadt), Kanamycin (Fluka Chemie GmbH, Buchs), Leucin (MP Biomedicals, Illkirch, F), Lithiumacetat (Carl Roth GmbH und Co, Karlsruhe), Maismehl (Mühle Levers, Bochum), Malzextrakt (Brau-Partner Kling, Heilbronn), Natriumacetat (Carl Roth GmbH und Co, Karlsruhe), Natriumchlorid (AppliChem GmbH, Darmstadt), Natriumhydroxid (Carl Roth GmbH und Co, Karlsruhe), Nourseothricin (Werner BioAgents, Jena), Phenol (AppliChem, Darmstadt), Saccharose (VWR International, Haasrode, B), Salzsäure (Carl Roth GmbH und Co, Karlsruhe), SDS = Natriumdodecylsulfat (Carl Roth GmbH und Co, Karlsruhe), Sorbit (Carl Roth GmbH und Co, Karlsruhe), Tetrazyklin (Serva Electrophoresis GmbH, Heidelberg), Tris = Tris-Hydroxymethyl-Aminomethan (Carl Roth GmbH und Co, Karlsruhe), Triton X-100 (Carl Roth GmbH und Co, Karlsruhe), Xylene Cyanol (Merck, Darmstadt), Yeast Nitrogen Base w/o Amino Acids and Ammonium Sulfate (Becton, Dickinson and Company, Sparks, USA), Zitronensäure-Monohydrat (Carl Roth GmbH und Co., Karlsruhe)

Bei Firmensitzen außerhalb Deutschlands ist das Land abgekürzt zusätzlich angegeben.

\subsubsection{Kits}

CloneJet $^{\text {TM }}$ PCR Cloning Kit (Fermentas, St.-Leon-Rot), DIG High Prime Labeling and Detection starter $\mathrm{Kit}^{\circledR}$ (Roche, Mannheim), Hexamer Primer (Fermentas, St.-Leon-Rot) HiSpeed ${ }^{\circledR}$ Plasmid Midi Kit (Qiagen, Hilden), HotStarTaq ${ }^{\circledR}$ Master Mix Kit (Qiagen, Hilden), polyATtract mRNA isolation system ${ }^{\circledR}$ (Promega, Mannheim), Qiaquick Gel Extraction Kit ${ }^{\circledR}$ (Qiagen, Hilden), Qiaprep Spin Miniprep Kit ${ }^{\circledR}$ (Qiagen, Hilden), qPCR MasterMix for SYBR Green $^{\circledR}$ (Eurogentec), SuperScript II Reverse Transcriptase ${ }^{\circledR}$ (Invitrogen, Darmstadt), Transcription High Fidelity cDNA Synthesis Kit ${ }^{\circledR}$ (Roche, Mannheim).

\subsubsection{Enzyme}

Calf-intestine Alkaline Phosphatase (Fermentas, St.-Leon-Rot), Blunting Enzyme Mix (CloneJet PCR Cloning Kit, Fermentas, St.-Leon-Rot), Glucanex (Schliessman, Schwäbisch Hall), Lysozym (Serva Electrophoresis GmbH, Heidelberg), Ribonuklease A (Roche, Mannheim), Restriktionsendonukleasen (Fermentas, St.-Leon-Rot), T4 DNA Ligase (Fermentas, St.-Leon-Rot). 


\subsubsection{Nährmedien}

\section{Escherichia coli}

LB: $1 \%(\mathrm{w} / \mathrm{v})$ Bacto-Trypton, 0,5\% (w/v) Hefeextrakt, 0,5\% (w/v) NaCl, $\mathrm{pH} 7,2 ;$ Festmedium mit 1,5\% (w/v) Agar; Zusatz von Ampicillin $(120 \mu \mathrm{g} / \mathrm{ml})$ zur Selektion von Transformanten.

SOC: $2 \%$ (w/v) Bacto-Trypton, 0,5\% (w/v) Hefeextrakt, $10 \mathrm{mM} \mathrm{NaCl}, 2,5 \mathrm{mM} \mathrm{KCl}, 10 \mathrm{mM}$ $\mathrm{MgCl}_{2}, 10 \mathrm{mM} \mathrm{MgSO} 4,20 \mathrm{mM}$ Glucose, $\mathrm{pH}$ 7,5.

\section{Saccharomyces cerevisiae}

YEPD: 2\% (w/v) Bacto-Pepton, 1\% (w/v) Bacto-Hefeextrakt, 2\% (w/v) Glucose, $\mathrm{pH} 5,8$; Festmedium mit 2\% (w/v) Agar, pH 5,8.

YPDA: 1\% (w/o) Bacto Yeast Extract, 2\% (w/o) Bacto Pepton, 2\% (w/o) Glucose, 0,003\% (w/o) Adenin-Hemisulfat, $\mathrm{pH}$ 5,8.

SD: $0,17 \%(\mathrm{w} / \mathrm{v})$ Hefe-Stickstoffbasis ohne Aminosäuren, $2 \%(\mathrm{w} / \mathrm{v})$ Glucose, $0,5 \%(\mathrm{w} / \mathrm{v})$ Ammoniumsulfat, 0,064\% CSM (-Ade-His-Leu-Ura) oder (-Ade-His-Leu-Trp) (MP Biochemicals, Illkirch, Frankreich), $\mathrm{pH}$ 5,8, für Festmedium 2\% (w/v) Agar (Serva Electrophoresis).

\section{Sordaria macrospora}

BMM: 0,8\% (w/v) Biomalz in Maismehlextrakt (25g/l), $\mathrm{pH}$ 6,5; Festmedium mit 0,8\% (w/v) Agar; zur Selektion von Transformanten Zugabe von $110 \mathrm{U} / \mu \mathrm{l}$ Hygromycin B; zur Herstellung von Einzelsporisolaten Zugabe von 5\% (w/v) Natriumacetat.

CM: $1 \%(\mathrm{w} / \mathrm{v})$ Glucose, 0,2\% (w/v) Trypton, 0,2\% (w/v) Hefeextrakt, 0,15\% (w/v) $\mathrm{KH}_{2} \mathrm{PO}_{4}$, $0,05 \%(\mathrm{w} / \mathrm{v}) \mathrm{KCl}, 0,05 \%(\mathrm{w} / \mathrm{v}) \mathrm{MgSO}_{4}, 0,37 \%$ (w/v) $\mathrm{NH}_{4} \mathrm{Cl}$, Spurenelemente $(10 \mathrm{mg} / \mathrm{l}$ $\left.\mathrm{ZnSO}_{4}, 10 \mathrm{mg} / 1 \mathrm{Fe}(\mathrm{II}) \mathrm{Cl}_{2}, 10 \mathrm{mg} / 1 \mathrm{MnCl}_{2}\right)$, pH 6,5.

CMS: CM mit 10,8\% (w/v) Saccharose; Festmedium mit 2\% (w/v) Agar.

SWG: 1x Westergaard's, 2\% (w/v) Glucose, 1\% (w/v) Arginin, 0,1\% (v/v) Biotin, pH 6,5; Festmedium mit 1,5\% (w/v) Agar. 


\subsubsection{Häufig verwendete Puffer und Lösungen}

Birnboim \& Doly-Lsg. 1: $50 \mathrm{mM}$ Glucose, $10 \mathrm{mM}$ EDTA, $25 \mathrm{mM}$ Tris/HCl, pH 8,0; vor Gebrauch $2 \mathrm{mg} / 1$ Lysozym frisch hinzugeben

Birnboim \& Doly-Lsg. 2: 0,2 M NaOH, 1\% SDS

Birnboim \& Doly-Lsg. 3: 3 M Kaliumacetat, 1,8 M Ameisensäure

Biotin-Stammlösung: 0,01\% (w/v) Biotin, 50\% (v/v) Ethanol

dNTP-Mix (10 mM): jeweils 10 mM dATP, dCTP, dGTP, dTTP, in $\mathrm{H}_{2} \mathrm{O}$

Denaturierungspuffer: $0,5 \mathrm{M} \mathrm{NaOH}, 1,5 \mathrm{M} \mathrm{NaCl}$, pH 12-13

DNA-Ladepuffer: $20 \mathrm{mM}$ EDTA, 0,25\% (w/v) Bromphenolblau, 60\% (w/v) Saccharose

Ethidiumbromid-Stammlösung: $10 \mathrm{mg} / \mathrm{ml} \mathrm{EtBr}$ in $\mathrm{H}_{2} \mathrm{O}$

MOPS-Puffer (10x): $200 \mathrm{mM}$ MOPS, $50 \mathrm{mM}$ NaAc, $10 \mathrm{mM}$ EDTA, pH 7,0

Neutralisierungspuffer: $2 \mathrm{M} \mathrm{NaCl}, 1 \mathrm{M}$ Tris/HCl, $\mathrm{pH}$ 5,5

Protoplastenpuffer (PPP): $13 \mathrm{mM} \mathrm{Na}_{2} \mathrm{HPO}_{4}, 45 \mathrm{mM} \mathrm{KH}_{2} \mathrm{PO}_{4}, 600 \mathrm{mM} \mathrm{KCl}, \mathrm{pH} \mathrm{6,0}$

Sc-Lysepuffer: 2\% Triton X-100, 1\% SDS, $100 \mathrm{mM} \mathrm{NaCl}, 10 \mathrm{mM}$ Tris, $1 \mathrm{mM}$ EDTA

Sm-Lysepuffer: $10 \mathrm{mM}$ Tris/HCl pH 8,0, $1 \mathrm{mM}$ EDTA, $100 \mathrm{mM} \mathrm{NaCl}, 2 \%$ SDS

SSPE (20x): 3,6 M NaCl, $200 \mathrm{mM}$ Natriumphosphat, $20 \mathrm{mM}$ EDTA, pH 7,4

TBE (10x): 1 M Tris, 1 M Borsäure, 20 mM EDTA, pH 8,3

TE(D)(10x): $100 \mathrm{mM}$ Tris, $10 \mathrm{mM}$ EDTA

TE(H): 50 mM Tris, 20 mM EDTA, pH 8,0

Transformationspuffer (TPS): $1 \mathrm{M}$ Sorbit, $80 \mathrm{mM} \mathrm{CaCl}_{2}, \mathrm{pH} \mathrm{7,4}$

Westergaardt's (5x): $0,5 \%(\mathrm{w} / \mathrm{v}) \quad \mathrm{KNO}_{3}, 0,5 \%$ (w/v) $\mathrm{KH}_{2} \mathrm{PO}_{4}, 0,25 \% \mathrm{MgSO}_{4} * 7 \mathrm{H}_{2} \mathrm{O}$, 0,05\% (w/v) $\mathrm{NaCl}, 0,05 \%$ (w/v) $\mathrm{CaCl}_{2}, 0,5 \mathrm{ml}$ Spurenelemente, 0,1\% (w/v) Chloroform

\subsection{Methoden}

Nicht näher ausgeführte, grundlegende molekularbiologische Methoden wurden nach Sambrook, et al. (2001) durchgeführt.

\subsubsection{Kulturbedingungen}

\section{Escherichia coli}

Die Anzucht von E. coli-Kulturen erfolgte bei $37^{\circ} \mathrm{C}$ auf LB-Festmedium oder in LBSchüttelkulturen bei $200 \mathrm{rpm}$.

\section{Saccharomyces cerevisiae}

Die Anzucht von S. cerevisiae-Kulturen erfolgte bei $30^{\circ} \mathrm{C}$ auf SD- und YEPD-Festmedium oder in SD- und YEPD-Schüttelkulturen bei $100 \mathrm{rpm}$.

\section{Sordaria macrospora}

Die Anzucht von S. macrospora-Kulturen erfolgte bei $24^{\circ} \mathrm{C}$ auf CMS- und BMMFestmedium oder in CM-, BMM- und SWG-Flüssigmedium.

\section{$\underline{\text { Kreuzungsexperimente }}$}

S. macrospora Stämme die entweder eine Kreuzungstyp-Gen Deletion oder eine Mutation in der Melanin-Biosynthese (Fus1-1 oder R2) aufwiesen wurden auf entgegengesetzten Seiten einer Petrischale mit BMM-Medium angeimpft. Nach sieben Tagen Inkubation bei $27^{\circ} \mathrm{C}$ 
wurden reife Perithezien aus der Kontaktzone beider Myzelien isoliert. Aus den Perithezien, welche Ascosporen beider Sporenfarbe enthielten (Wt + fus/r2), wurden je 100 Ascosporen isoliert und, nach dem Auskeimen, auf Selektionsmedium mit Hygromycin B überführt. Die so erhaltenen Nachkommen wurden bezüglich ihrer phänotypischen Charakteristika (Sporenfarbe, Resistenz) untersucht und nach dem Protokoll von Lee, et al. (2008) analysiert. Kreuzungen zwischen zwei verschiedenen Kreuzungstyp-Mutanten wurden entsprechend durchgeführt, wobei eine Mutante zusätzlich zur Gendeletion eine Farbspormutation (fus/r2) trug.

\subsubsection{Herstellung kompetenter Zellen und Transformation}

\section{Escherichia coli}

Zur Herstellung elektrokompetenter Zellen wurde eine E. coli-Kultur in LB-Flüssigmedium unter Zugabe von Tetrazyklin $(12,5 \mu \mathrm{g} / \mathrm{ml})$ bis zu einer $\mathrm{OD}_{600}$ von $0,5-0,6$ angezogen und dann mehrfach mit A. dest und 10\%igem Glycerin gewaschen. Aliquots von jeweils $40 \mu 1$ wurden bei $-80^{\circ} \mathrm{C}$ gelagert.

Die Transformation der elektrokompetenten E. coli-Zellen mit Plasmid-DNA erfolgte mittels Elektroporation nach Vorschrift von Dower, et al. (1988) mit dem „Electroporator 2510“ (Eppendorf) bei einer Spannung von 2,5 V. Die transformierten Zellen wurden in $1 \mathrm{ml} \mathrm{SOC-}$ Medium aufgenommen und auf LB-Festmedium ausplattiert, welches zur Selektion Ampicillin enthielt.

\section{Saccharomyces cerevisiae}

Für die Herstellung von elektrokompetenten Zellen wurde eine S. cerevisiae-Kultur in YEPDFlüssigmedium bis zu einer $\mathrm{OD}_{600}$ von 1,5 angezogen. Die Zellen wurden dann bei $5000 \mathrm{rpm}$ pelletiert und in Lithiumacetat und TE(D) aufgenommen. Nach Inkubation mit DTT bei $100 \mathrm{rpm}$ über eine Stunde wurden die Zellen mehrfach mit A. dest und Sorbitol gewaschen und zu $40 \mu \mathrm{l}$ aliquotiert. Die S. cerevisiae-Zellen wurden mit $100 \mathrm{ng}$ Plasmid-DNA nach Vorschrift von Becker und Lundblad (2001) mit dem „Electroporator 2510“ (Eppendorf) bei einer Spannung von 1,5 V transformiert. Nach der Elektroporation wurden die Zellen in $1 \mathrm{M}$ Sorbitol aufgenommen und auf SD-Selektionsmedium ausplattiert.

\section{Sordaria macrospora}

Zur Vorbereitung der Transformation wurde eine $S$. macrospora-Kultur nach der Vorschrift von Skatrud, et al. (1987) protoplastiert. Dazu wurde die Kultur über drei Tage in CMFlüssigmedium angezogen, dass Myzel geerntet und mit PPP gewaschen. Die Protoplastierung erfolgte bei $90-120$ minütiger Inkubation des Myzels bei $27^{\circ} \mathrm{C}$ und $100 \mathrm{rpm}$ in Glucanex-Lösung $(0,02 \mathrm{~g} / \mathrm{ml}$ in PPP). Die erhaltenen Protoplasten wurden mehrfach mit PPP gewaschen und ein Titer von $2 \times 10^{8}$ Zellen $/ \mathrm{ml}$ in TPS eingestellt. Die Transformation erfolgte verändert nach Skatrud, et al. (1987). Dazu wurden $120 \mu 1$ Protoplasten-Suspension mit $20 \mu \mathrm{g}$ der zu transformierenden DNA in PEG 6000-Lösung (25\% in TPS) für 20 min bei Raumtemperatur inkubiert und zur Regeneration auf CMS-Festmedium ausplattiert. Zur Selektion der Transformanten wurde das CMS-Festmedium nach ca. acht Stunden mit Hygromycin-Topagar $(0,8 \mathrm{M} \mathrm{NaCl}, 0,8 \%$ (w/v) Agar und $500 \mu \mathrm{g} / \mathrm{ml}$ Hygromycin B) überschichtet. Nach mehrtägiger Inkubation wurden die Transformanten auf BMMFestmedium mit Hygromycin $\mathrm{B}$ bei $27^{\circ} \mathrm{C}$ überführt. 


\subsubsection{Präparation von Nukleinsäuren}

Isolierung von Plasmid-DNA aus E. coli

Plasmid-DNA wurde mittels Mini- oder Midi-Präparation aus E. coli-Zellen isoliert. MiniPräparationen erfolgten nach modifizierter Vorschrift von Birnboim und Doly (1979) oder mit dem Qiaprep Spin Miniprep Kit ${ }^{\circledR}$ (Qiagen, Hilden) nach Vorschrift des Herstellers. MidiPräparationen wurden mittels QIAGEN HiSpeed MidiPrep $\mathrm{Kit}^{\circledR}$ nach Vorschrift des Herstellers durchgeführt.

\section{$\underline{\text { Isolierung von Plasmid-DNA aus } S \text {. cerevisiae }}$}

Für die Isolierung von Plasmid-DNA aus $S$. cerevisiae wurde eine einzelne Kolonie über Nacht in $10 \mathrm{ml} \mathrm{SD-Kultur}$ angezogen. Die Aufarbeitung erfolgte mit dem Qiaprep Spin Miniprep $\mathrm{Kit}^{\circledR}$ (Qiagen, Hilden). Aus der angezogenen Kultur wurden $2 \mathrm{ml}$ geerntet. Das Pellet wurde in $250 \mu \mathrm{l}$ Puffer A1 aufgenommen und mit $250 \mu$ l Glasperlen (Durchmesser 0,5 $\mathrm{mm}$, säurebehandelt) $5 \mathrm{~min}$ unter ständigem Schütteln resuspendiert. Danach wurde nach Angaben des Herstellers verfahren.

Alternativ wurde die Plasmid-DNA mittels Phenol-Chloroform Fällung aufgearbeitet (Hoffman, 2001). Die $10 \mathrm{ml}$ Kultur wurde für fünf Minuten bei $13000 \mathrm{rpm}$ zentrifugiert und das Pellet anschließend mit $1 \mathrm{ml} \mathrm{A.} \mathrm{dest} \mathrm{gewaschen.} \mathrm{Nach} \mathrm{erneuter} \mathrm{Zentrifugation} \mathrm{wurden}$ $200 \mu \mathrm{l}$ Sc-Lysepuffer, $200 \mu \mathrm{l}$ Phenol/Chloroform und 0,3 g Glasperlen $(0,25-0,5 \mathrm{~mm})$ hinzugegeben und der Ansatz für $8 \mathrm{~min}$ bei $8^{\circ} \mathrm{C}$ und $1400 \mathrm{rpm}$ geschüttelt. Nach erneuter Zentrifugation für 15 min wurde die obere Phase in ein neues Eppendorf-Gefäß überführt und getrocknet. Das entstandene Pellet wurde in $30 \mu \mathrm{l}$ A. dest aufgenommen.

$\underline{\text { Isolierung von Gesamt-Nukleinsäuren aus S. macrospora }}$

Die Isolierung von Gesamt-DNA aus $S$. macrospora Myzel erfolgte verändert nach Lecellier und Silar (1994). Nach Anzucht in CM- oder BMM-Medium in Petrischalen wurde das Myzel geerntet und mit Sm-Lysepuffer versetzt. Nach Zugabe einer Metallkugel (ca. $1 \mathrm{~mm}$ ) wurden die Zellen im TissueLyser (Qiagen, Hilden) aufgebrochen. Die Extraktion erfolgte mittels Phenol und Chloroform und anschließender Fällung mit Isopropanol. Das erhaltene DNAPellet wurde getrocknet und in A. dest aufgenommen.

\section{$\underline{\text { Isolierung von DNA aus Agarose-Gelen }}$}

Die Isolierung von DNA aus Agarose-Gelen erfolgte mit Hilfe des Qiaquick Gel Extraction Kits (Qiagen, Hilden).

\section{Fällung von Nukleinsäuren}

Zur Fällung von DNA aus wässrigen Lösungen wurde dem entsprechenden Probenvolumen 1/10 Teil Natriumacetat (3M, pH 7) zugegeben. Nach Zugabe des dreifachen Volumens Ethanol absolut wurde die Probe bei $-80^{\circ} \mathrm{C}$ für 10 min oder bei $-20^{\circ} \mathrm{C}$ ü.N. inkubiert. Nach Zentrifugation für $10 \mathrm{~min}$ bei $13000 \mathrm{rpm}$ wurde das entstandene Pellet mit 0,5 ml Ethanol (70\%) gewaschen. Nach erneuter Zentrifugation (10 min, $13000 \mathrm{rpm})$ wurde das Pellet getrocknet und in A. dest aufgenommen. 


\section{Mikrodialyse wässriger DNA-Lösungen}

Die Entfernung von Salzen aus wässrigen DNA-Lösungen erfolgte über Mikrodialyse. Dazu wurden Mikrodialysefilter (0,02 $\mu \mathrm{m}$ Porengröße, Millipore) auf die Wasseroberfläche einer mit A. dest gefüllten Petrischale gelegt und die Probe für 15 bis 30 min auf den Filter gegeben.

\section{$\underline{\text { Isolierung von Gesamt-RNA aus } S \text {. macrospora }}$}

Gesamt-RNA aus S. macrospora wurde nach einem veränderten Protokoll von Yarden, et al. (1992) durchgeführt (Nowrousian, et al., 2005). Das Myzel von S. macrospora-Stämmen wurde in flüssigem Stickstoff gemörsert bis es eine pulverförmige Konsistenz aufwies. Anschließend wurde der Extrakt mit RNA-Lysepuffer versetzt und von den Proteinen und übrigen Zellbestandteilen mittels Phenol-Chloroform-Extraktion getrennt. Die Fällung erfolgte mit Hilfe von Natriumacetat (analog zu 3.2.3) bei $-20^{\circ} \mathrm{C}$. Die erhaltenen GesamtNukleinsäuren wurden dann mit Desoxyribonuklease I (Fermentas, St.-Leon-Rot) nach Herstellerangaben behandelt um Gesamt-RNA zu erhalten.

Die poly(A)RNA wurde mittels des polyATtract mRNA Isolation System (Promega) nach Herstellerangaben isoliert.

\subsubsection{Modifizierung von Nukleinsäuren}

$\underline{\text { Polymerasekettenreaktion }}$

Die Polymerasekettenreaktion (Mullis und Faloona, 1987) ermöglicht es ausgehend von einer Matrizen-DNA eine Vielzahl identischer Kopien anzufertigen. Der verwendete StandardPCR-Ansatz mit dem HotStarTaq ${ }^{\circledR}$ MasterMix Kit wurde gemäß den Angaben des Herstellers (Qiagen, Hilden) zusammengestellt und enthielt Matrizen-DNA, Starteroligonukleotide und Polymerase Mastermix. Das Standard-PCR-Programm bestand aus einer Denaturierungsphase $\left(10 \mathrm{~min} ; 98^{\circ} \mathrm{C}\right)$, welche die Reaktion einleitete, der ein sich $40 \mathrm{x}$ wiederholender Zyklus aus Denaturierungsphase $\left(1,5 \mathrm{~min} ; 98^{\circ} \mathrm{C}\right)$, Hybridisierungsphase $(1,5 \mathrm{~min}$; spezifische Hybridisierungstemperatur) und Elongationsphase $\left(1,5-3 \mathrm{~min} ; 72^{\circ} \mathrm{C}\right)$ folgte. Amplifizierungen mittels MolTaq (Molzym, Bremen) wurden ebenfalls gemäß den Empfehlungen des Herstellers durchgeführt. Alle Amplifikationen erfolgten im ,i-Cycler“ der Firma Biorad (München).

\section{$\underline{\text { Reverse Transkription }}$}

Die Reverse Transkriptase (RT) ist eine DNA-abhängige RNA-Polymerase, welche einen komplementären DNA-Strang zu einer RNA-Matrize synthetisiert (,complementary DNA, cDNA"). Die cDNA wurde mittels des Transcription High Fidelity cDNA Synthesis Kit ${ }^{\circledR}$ (Roche, Mannheim) aus $2 \mu \mathrm{g}$ Gesamt-RNA oder mittels SuperScript II (Invitrogen, Darmstadt) aus poly(A)-RNA nach Herstellerangaben hergestellt.

\section{$\underline{\text { real-Time-PCR }}$}

Die quantitative Echtzeit-PCR (,quantitative real-Time-PCR, qRT-PCR“) ist eine Vervielfältigungsmethode von Nukleinsäuren, welche auf dem Prinzip der Polymerasekettenreaktion beruht (s. „Polymerasekettenreaktion“). Durch die Messung von 
Signalen fluoreszierender, DNA-interkalierender Substanzen (z.B. SYBRGreen) kann die Menge entstandener DNA nach jedem Vervielfältigungszyklus gemessen werden. Wird cDNA (s. „Reverse Transkription“) als Matrize eingesetzt kann durch den Vergleich mit einem Standard die Menge an mRNA in verschiedenen Proben im Vergleich zueinander ermittelt werden.

Für die quantitative real-Time-PCR wurde das qPCR Master Mix for SYBRGreen Kit (Eurogentec, Köln) nach Angaben des Herstellers im MasterCycler realplex ${ }^{2}$ (Eppendorf, Hamburg) benutzt.

\section{$\underline{\text { Hydrolyse von Nukleinsäuren }}$}

DNA wurde gezielt mit sequenzspezifischen Restriktionsendonukleasen des Typs II hydrolysiert. Dazu wurden Ansätze mit einem Volumen von 10-30 $\mu$ l hergestellt, wobei jeweils etwa $1 \mathrm{U}$ Enzym pro $\mu \mathrm{g}$ der zu hydrolysierenden DNA eingesetzt wurde. Die Reaktion erfolgte in einer Inkubationszeit von ca. $90 \mathrm{~min}$ bei $37^{\circ} \mathrm{C}$ im vom Hersteller (Fermentas, St.Leon-Rot) angegebenen Puffersystem.

\section{Dephosphorylierung}

Bei ungerichteten Ligationen zwischen einem Vektor und einem DNA-Fragment, welche mit einer einzelnen Restriktionsendonuklease hydrolysiert wurden, wurde die Vektor-DNA zuvor dephosphoryliert um eine Selbstligation (Ringschluss ohne Insert) zu verhindern. Die CalfIntestine Alkaline Phosphatase wurde dabei nach Angaben des Herstellers (Fermentas, St.Leon-Rot) genutzt.

\section{$\underline{\text { Ligation }}$}

Mit Hilfe der T4-Ligase aus phageninfizierten E. coli-Zellen können Phosphodiesterbindungen zwischen der 5'-Phosphatgruppe eines DNA-Fragmentes und der 3'Hydroxylgruppe eines anderen Fragmentes ausgebildet werden. Als Co-Faktor benötigt diese Ligase ATP, was unter Zugabe von T4-Ligase-Puffer dargereicht wurde. Das molare Verhältnis zwischen Plasmid-DNA und einzuklonierendem Fragment betrug in der Regel 1:7. Die Ligation erfolgte bei $14^{\circ} \mathrm{C}$ ü. N. oder für mindestens $3 \mathrm{Std}$. bei RT. Ligationen, die mit Hilfe des Qiagen PCR Cloning Kit (Qiagen, Hilden) durchgeführt wurden, erfolgten gemäß den Empfehlungen des Herstellers.

\section{$\underline{\text { Starteroligonukleotidsynthese }}$}

Die Neusynthese von Starteroligonukleotiden erfolgte als Auftragsarbeit der Firma Eurofins MWG Operon (Ebersberg).

\section{Sequenzierung}

DNA-Sequenzierungen wurden vom Göttinger-Genomics-Laboratory, Georg-August-Universität Göttingen, durchgeführt. 


\subsubsection{Erstellung rekombinanter Plasmide mittels homologer Rekombination}

Neben konventionellen Ligations-Strategien wurde zur Herstellung rekombinanter Plasmide auch die homologe Rekombination in S. cerevisiae genutzt wie von Colot, et al. (2006) beschrieben. Dabei können auch mehrere Fragmente gerichtet in einen Vektor eingebracht werden. In einer PCR werden an die Fragmente 29 bp lange Sequenzen fusioniert, welche homolog zum Vektor oder $\mathrm{zu}$ den anderen Fragmenten sind. Die Fragmente und der linearisierte Vektor pRS426 (EcoRI + XhoI) oder pRSnat (XhoI) (Tab. 2) wurden in den Hefestamm PJ69-4a transformiert, wo es zur homologen Rekombination kam. Die entstandenen rekombinanten Plasmide wurden dann aus der Hefe aufgearbeitet und verwendet.

\subsubsection{Gelelektrophorese}

\section{$\underline{\text { DNA }}$}

DNA-Fragmente wurden in 1\%igen 1x-TBE-Agarosegelen in horizontalen ElektrophoreseApparaturen (Mupid) bei einer elektrischen Spannung von 5-15 V/cm aufgetrennt (Sambrook, et al. 2001). Als Elektrophoresepuffer diente 0,5X TBE-Puffer. Als Größenstandard wurde Gene Ruler ${ }^{\mathrm{TM}}$ DNA Ladder Mix (Fermentas, St.-Leon-Rot) verwendet. Die DNA wurde nach 10 bis 20 minütiger Inkubation in Ethidiumbromid unter UV-Licht sichtbar gemacht.

\section{$\underline{\text { RNA }}$}

Für die Auftrennung von RNA wurden 1,2\%ige 1x MOPS-Agarosegele mit 5\% (v/v) Formaldehyd verwendet. RNA-Proben wurden mit RNA-Ladepuffer versetzt, bei $65^{\circ} \mathrm{C}$ für 15 min inkubiert und dann auf Eis abgekühlt. Die Elektrophorese erfolgte bei einer konstanten Stromspannung von $100 \mathrm{~V}$. RNA-Gele wurden vor der Inkubation in Ethidiumbromid $20 \mathrm{~min}$ in RNase-freiem A. dest inkubiert.

\subsubsection{Blotverfahren und nicht-radioaktiver Nachweis von Nukleinsäuren}

Herstellung nicht-radioaktiv markierter Nukleinsäuren

Zur Herstellung nicht-radioaktiv markierter DNA-Sonden wurde das DIG High Prime DNA Labeling and Detection Starter Kit von Roche (Mannheim) gemäß den Angaben des Herstellers benutzt. Die DNA-Sonden wurden dabei mittels „random-primed oligo-labeling“ mit DIG-11-dUTP markiert.

\section{$\underline{\text { Southern Hybridisierung }}$}

Durch das Blotverfahren können mittels Agarose-Gel aufgetrennte DNA-Fragmente durch Kapillarkraft auf eine GeneScreen Hybridization Transfer Membrane (PerkinElmer Lifesciences, Jügesheim) übertragen werden (Sambrook, et al., 2001; Southern, 1975). Der Transfer wurde bei RT ü.N. durchgeführt. Die Nukleinsäuren wurden danach auf der Membran mittels UV-Licht im „BioLink BLX ${ }^{\mathbb{B} \text { ، }}$ (Biometra, Göttingen) quervernetzt. Stringente Waschungen und Hybridisierung mit nicht-radioaktiv markierten Sonden erfolgte mittels DIG High Prime DNA Labeling and Detection Starter Kit (Roche, Mannheim) nach Angaben des Herstellers. Die Exposition erfolgte abschließend auf Röntgenfilme (Fuji X-RayMedical RX) für 1-2 Stunden. 


\subsubsection{Microarray Hybridisierung}

In dieser Studie wurden $N$. crassa Microarrays mit 10.910 70-mer Oligonukleotiden verwendet (Tian, et al., 2007). Microarray Proben von S. macrospora cDNA wurde durch Reverse Transkription von poly(A)-RNA (s. 3.2.4) in der Anwesenheit von Aminoallyl dUTPs (Sigma-Aldrich, München) durch SuperScript II (Invitrogen, Darmstadt) hergestellt.

Die cDNA wurde mit den Fluoreszenzfarbstoffen Alexa555 und Alexa 647 (beide Invitrogen, Darmstadt) markiert und anschließend mit dem Illustra Cyscribe GFX Purification Kit (Amersham/GE Healthcare, München) gereinigt. Die Hybridisierung wurde durchgeführt wie in Klix, et al. (2010) beschrieben.

Die erhaltenen Daten wurden mit MS Excel (Microsoft, Unterschleißheim), Bioconductor (Gentleman, et al., 2004) und dem MultiExperimentViewer (MeV) (Saeed, et al., 2003) analysiert. Die statistischen Analysen wurden innerhalb der Software-Umgebung „ $\mathrm{R}^{\text {“ }}$ (Version 2.7.2) unter Verwendung des „Linear Model for Microarray“ (Smyth, 2004) durchgeführt. Die Daten wurden normalisiert und skaliert wie in Klix, et al. (2010) beschrieben. Gene wurden als unterschiedlich reguliert angesehen wenn sie eine $\log _{2}$ Verhältnis $>1$ oder $<1$ aufwiesen und einen $P$-Wert (Wahrscheinlichkeitswert) von $<0,05$.

Details zur experimentellen Durchführung, Rohdaten und Ergebnisse der statistischen Untersuchung wurden in der öffentlichen Datenbank „ArrayExpress“ (http://www.ebi.ac.uk/arrayexpress) unter der Accession-Nummer E-MEXP-2600 hinterlegt.

\subsubsection{Hefe-Zwei-Hybrid Analyse}

Das Hefe-Zwei-Hybrid System („,Yeast-Two-Hybrid“, Y2H) dient dazu Protein-ProteinInteraktionen in einem heterologen System zu untersuchen. Die zu untersuchenden Proteine werden dafür mit der DNA-Bindedomäne (BD) bzw. der Aktivierungsdomäne (AD) des Transkriptionsfaktors GAL4 aus Hefe fusioniert. Bei einer Interaktion der beiden Proteine kommen GAL4-AD und GAL4-BD in räumliche Nähe. Gene, welche unter der Kontrolle eines GAL4-induzierbaren Promotors stehen können dadurch exprimiert werden. Es können hierbei verschiedene Reportergene genutzt werden um eine Protein-Protein-Interaktion indirekt phänotypisch sichtbar zu machen.

Für die Y2H Analyse wurde das MatchMaker ${ }^{\text {TM }}$ Gold (ClonTech, Saint-Germain-en-Laye, F) benutzt. Der Stamm Y187 (s. 3.1.1) trug dabei das Plasmid pGB-A2 (Tab. 1, „bait"), der Stamm AH109 eine $S$. macrospora cDNA-Bank kloniert in pGAD17 (Lehrstuhl für Allgemeine und Molekulare Botanik, Bochum, pers. Mitteilung, ,prey“). Die beiden Stämme wurden in $2 \mathrm{x}$ YPDA-Medium bei $30^{\circ} \mathrm{C}$ für $24 \mathrm{Std}$. gekreuzt. Diploide Stämme welche beide Plasmide beinhalten wurden auf SD-Medium ohne Leucin und Tryptophan selektioniert. Selektion auf eine Protein-Protein-Interaktion erfolgte auf SD-Medium ohne Histidin, Adenin, Leucin und Tryptophan. Die Plasmid-DNA wurde danach aus der Hefe aufgearbeitet und in E. coli transformiert (s. 3.2.2 und 3.2.3). Durch die unterschiedlichen Resistenzmarken der Plasmide pGBKT7 und pGADT7 (Tab. 2) konnte in E. coli gezielt auf „prey“-Plasmide selektioniert werden. Diese wurden dann weiter aufgearbeitet und sequenziert.

\subsubsection{Mikroskopie}

Für alle mikroskopischen Untersuchungen wurde das AxioImager M1 Mikroskop (Zeiss, Jena) verwendet. Für fluoreszenzmikroskopische Aufnahmen wurde als Lichtquelle das XCite $^{\circledR}$ 120PC (EXFO UK, Chandlers Ford, GB) benutzt. Proben von S. macrospora wurden 
auf Objektträgern mit einer dünnen Schicht BMM- oder SWG-Medium bei $24^{\circ} \mathrm{C}$ inkubiert. $S$. cerevisiae wurde in YEPD oder SD-Selektionsmedium angezogen und $5 \mu 1$ dieser Lösung auf Objektträger aufgebracht. Die Bilder wurden aufgenommen mit einer Photometrics CoolSNAP $H Q^{2}$ Kamera (Roper Scientific, Photometrics, Tucson, USA) und bearbeitet mit MetaMorph (Visitron System GmbH, Puchheim) und Adobe Photoshop CS2.

\subsubsection{Bilder}

Makroskopische Aufnahmen wurden mit der Powershot (Canon, Krefeld) aufgenommen. Bilder wurden mit dem Programm Adobe Photoshop CS2 bearbeitet.

\subsubsection{Analyse von Pheromon-Rezeptor-Interaktionen}

Hemmhof-Tests in $S$. cerevisiae mit heterolog exprimierten Pheromon-Rezeptoren aus S. macrospora und P. chrysogenum wurden wie von Mayrhofer und Pöggeler (2005) beschrieben durchgeführt. Dabei wurde der Stamm YDB103 mit den Plasmiden pPGK, pPGK-PcPRE2 und pPGK-SmPRE2 (Tab. 2) und BY4741 als Kontrolle verwendet. Künstliche Pheromone PcPPG1 (P. chrysogenum) und SmPPG1 (S. macrospora) wurden in einer Konzentration von $3 \mathrm{nmol}$ auf Cellulose-Filterplättchen von $6 \mathrm{~mm}$ Durchmesser (Sartorius Stedim GmbH, Göttingen; \#1291) aufgetragen. Als Kontrolle wurde künstlicher $\alpha$-Faktor (S. cerevisiae) in einer Konzentration von $3 \mathrm{nmol}$ verwendet.

Shmoo-Bildung wurde untersucht wie von Sprague (1991) beschrieben. Die Hefe-Stämme YDB103-pPGK-PcPRE2, YDB103-pPGK-SmPRE2 und BY4741 wurden bis zu einer Dichte von $5 \times 10^{6}$ bis $10^{7}$ Zellen/ml in YEPD-Medium inkubiert und mit künstlichem Pheromon in einer Konzentration von $5 \mu \mathrm{M}$ behandelt. Proben wurden nach $0 \mathrm{~h}, 2 \mathrm{~h}$ und $4 \mathrm{~h}$ mikroskopisch untersucht.

\subsubsection{Sicherheitsmaßnahmen}

Gentechnische Experimente der Sicherheitsstufe 1 wurden gemäß den Richtlinien des Gentechnikgesetztes (GenTG) vom 16.12.1993 (zuletzt geändert durch das Zweite Gesetz zur Änderung des GenTG vom 16.08.2002) durchgeführt. 


\section{Ergebnisse}

\subsection{Untersuchung der MAT1-1-Kreuzungstyp-Gene in S. macrospora}

\subsubsection{Herstellung der $M A T 1-1$ Deletionsmutanten}

Zur Untersuchung der Rolle der MAT1-1-spezifischen Kreuzungstyp-Gene in S. macrospora wurden Deletionsmutanten der drei Kreuzungstyp-Gene ( $\Delta$ SmtA-1, $\Delta$ SmtA-2 und $\Delta$ SmtA-3) erstellt. Da in dem nahe verwandten $N$. crassa eine Doppeldeletion der Gene MAT1-1-2/MAT1-1-3 reduzierte Fertilität verglichen mit den Einzelmutanten zeigt (Ferreira, et al., 1998), wurde außerdem die Doppelmutante $\Delta \mathrm{SmtA}-2 / 3$ in $S$. macrospora hergestellt. Die Deletionsplasmide pRS- $\Delta \mathrm{A} 1$, pRS- $\Delta \mathrm{A} 2$, pRS- $\Delta \mathrm{A} 3$ und pRS- $\Delta \mathrm{A} 2 / 3$ (Tab. 2) wurden wie unter Material und Methoden 3.2.5 beschrieben erstellt. Die 5' und 3' Region der zu deletierenden Gene wurden mit den entsprechenden Primern 5f/5r und 3f/3r amplifiziert. Die entstandenen Fragmente wiesen nun homologe Überhänge zu dem Vektor pRS426 (Tab. 2) und der ebenfalls amplifizierten $h p h$-Kassette auf. Nach der homologen Rekombination in Hefe wurden die Plasmide aufgearbeitet und das Deletionskonstrukt mittels den Primern 5f/3r amplifiziert und in den S. macrospora Stamm $\Delta$ ku70 (Tab. 1) transformiert, welcher einen Defekt im DNA-Reparaturmechanismus aufweist und besonders geeignet für gezielte DNA Modifikationen über homologe Rekombination ist (Pöggeler und Kück, 2006). Für die $\Delta$ SmtA-2/3 Doppeldeletion wurden dabei die 5'-Region des SmtA-3 Gens und die 3'-Region des SmtA-2 Gens verwendet, so dass beide Gene durch eine $h p h$-Kassette ersetzt wurden.

Die entstandenen Transformanten wurden auf Hygromycin B (Hyg) oder Nourseothricin (Nat) selektioniert und mit den Farbspormutanten Fus1-1 oder R2 (Tab. 1) gekreuzt, da Transformanten in Pilzen häufig heterokaryotisch sind und transformierte sowie nichttransformierte Kerne tragen. Einzelsporisolate dieser Kreuzungen wurden angefertigt und erneut auf Hyg und Nat selektioniert. Durch konventionelle genetische Verfahren war es außerdem möglich, Hygromycin-resistente Sporen ohne $\Delta$ ku70-Hintergrund (Nat-Resistenz) $\mathrm{zu}$ isolieren. Damit konnte gleichzeitig gezeigt werden, dass der MAT-Locus genetisch nicht mit ku70 gekoppelt ist und keines der MAT1-1 Gene essentiell ist. Die erhaltenen Einzelsporisolate der Deletionsmutanten wurden dann mittels PCR-Analyse und Southern Hybridisierung verifiziert (Abb. 6). 

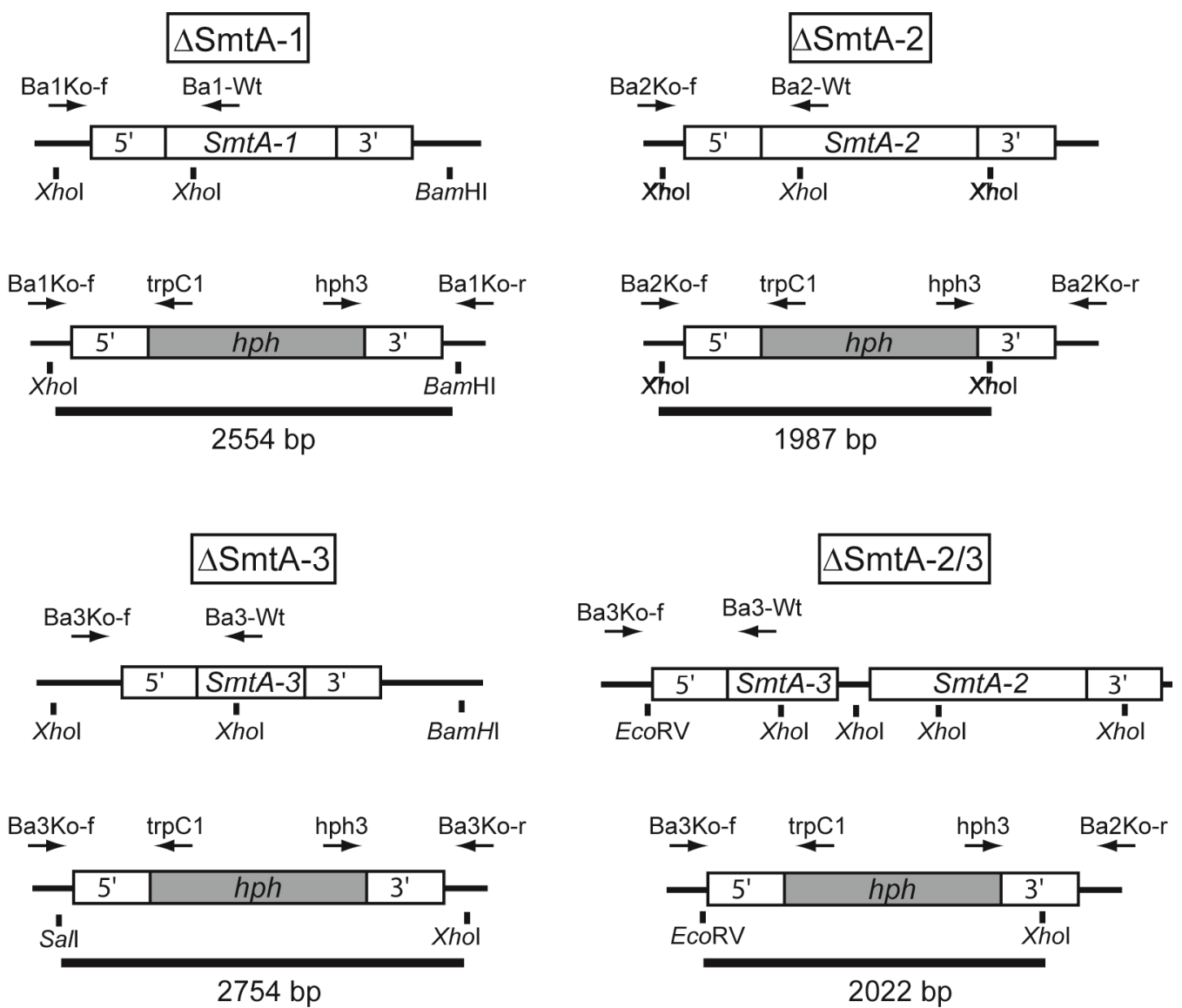

Abbildung 6: Schematische Übersicht über die Verhältnisse am entsprechenden Genort in Wt und den Deletionsstämmen $\Delta$ SmtA-1, $\Delta$ SmtA-2, $\Delta$ SmtA-3 und der Doppeldeletion $\Delta$ SmtA-2/3. Primer zur Verifizierung der homologen Rekombination und verbliebener Wt-Genkopien sind angegeben. Erkennungsstellen der Restriktionsendonukleasen und Größen der Fragmente, welche für die Southern Hybridisierung benutzt wurden sind eingezeichnet.

PCR Amplifikation mit spezifischen Oligostarternukleotiden („Primern“) für externe, flankierende Sequenzen in Kombination mit Primern spezifisch für die integrierte $h p h$-Kassette zeigte, dass die Hygromycinresistenzkassette in die zu deletierenden MAT-Gene integriert hatte und in den Einzelsporisolaten (ESIs) keine Wildtyp-Genkopien mehr vorhanden waren. Eine Southern Hybridisierung mit einer spezifischen immuno-markierten hph Sonde zeigte ebenfalls die homologe Integration der Deletionskassetten ohne heterolog integrierte Kopien aufzuzeigen (Abb. 7). 
A
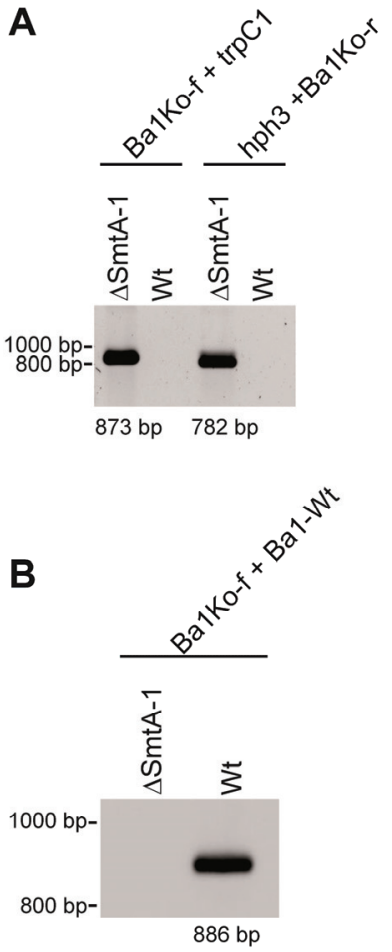

C

Abbildung 7: (A) PCR Analyse der homologen Rekombination in den Deletionsstämmen $\Delta$ SmtA-1, $\Delta$ SmtA-2, $\Delta$ SmtA-3 und der Doppeldeletion $\Delta$ SmtA-2/3. Oligostarternukleotide wie in Tab. 3 aufgeführt wurden zur Verifizierung der homologen Rekombination am Ziel-Locus benutzt. (B) Zusätzlich wurde eine PCR Analyse durchgeführt um ein Vorhandensein von Wildtyp-Kopien des Gens auszuschließen. (C) Southern Hybridisierung der verschiedenen Deletionsstämme und Wt mit einer $h p h$ Sonde.

Die untersuchten und verifizierten Deletionsmutanten wurden in den weiteren Studien als $\Delta$ SmtA-1, $\Delta$ SmtA-2, $\Delta$ SmtA-3 und $\Delta$ SmtA-2/3 (Tab. 1) zur Analyse genutzt. 


\subsubsection{Phänotypische Untersuchung der Deletionsmutanten}

Die verifizierten Deletionsmutanten wurden bezüglich ihrer sexuellen und vegetativen Entwicklung im Vergleich zum Wildtyp untersucht. Weder die Einzeldeletionsstämme noch der Doppeldeletionsstamm zeigten eine Veränderung in der vegetativen Morphologie des Myzels, der Wachstumsrate (durchschn. 1,5 cm/Tag auf BMM bei $27^{\circ} \mathrm{C}$ ) oder Trockengewicht (durchschn. 3,5 g nach 5 Tagen Wachstum auf BMM, 27 ${ }^{\circ} \mathrm{C}$ ).

Die Entwicklung sexueller Strukturen in den verschiedenen Deletionsmutanten im Vergleich zum Wildtyp wurde auf SWG-Medium analysiert. Alle Stämme zeigten nach drei Tagen die Bildung von Ascogonien, welche sich nach fünf Tagen $\mathrm{zu}$ jungen Protoperithezien weiterentwickelt hatten (Abb. 8).

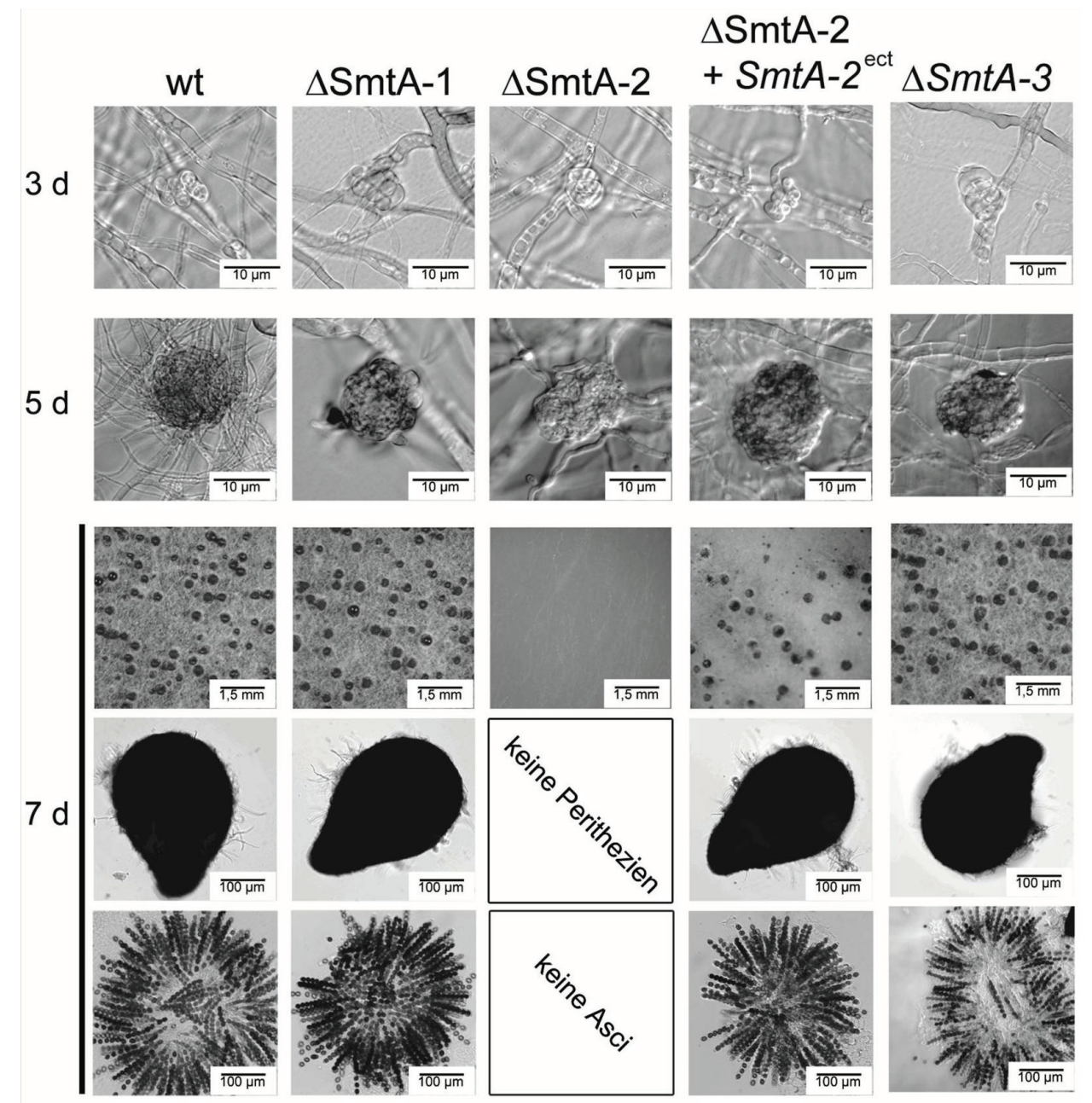

Abbildung 8: Mikroskopische Untersuchung der sexuellen Entwicklungsstadien von Wt und den Deletionsmutanten $\Delta$ SmtA-1, $\Delta$ SmtA-2 und $\Delta$ SmtA-3. Zu beachten ist, dass keinerlei reife Perithezien oder Asci in $\Delta$ SmtA-2 gefunden werden konnten. Die Mutante $\Delta$ SmtA-2 mit einer ektopisch integrierten Kopie von $S m t A-2$ zeigt dagegen Wildtyp-Phänotyp.

Alle Stämme wurden bei $27^{\circ} \mathrm{C}$ auf SWG angezogen und Bilder der Ascogonien, Protoperithezien und Perithezien und Asci (außer $\Delta$ SmtA-2) wurden nach 3, 5 und 7 Tagen Wachstum aufgenommen. 
Die Mutanten $\Delta$ SmtA-1 und $\Delta$ SmtA-3, ebenso wie der Wildtyp, produzierten reife Perithezien mit 100-150 Asci mit reifen, keimfähigen Ascosporen nach 7 Tagen Entwicklung. In der Deletionsmutante $\Delta$ SmtA-2 dagegen konnten selbst nach verlängerter Wachstumszeit weder reife Perithezien noch Ascosporen beobachtet werden.

Die $\Delta$ SmtA-2/3 Doppelmutante zeigte den gleichen Phänotyp wie $\Delta$ SmtA-2 (Abb. 9). Die Mutante ist steril und nicht in der Lage, reife Perithezien oder Ascosporen zu bilden.

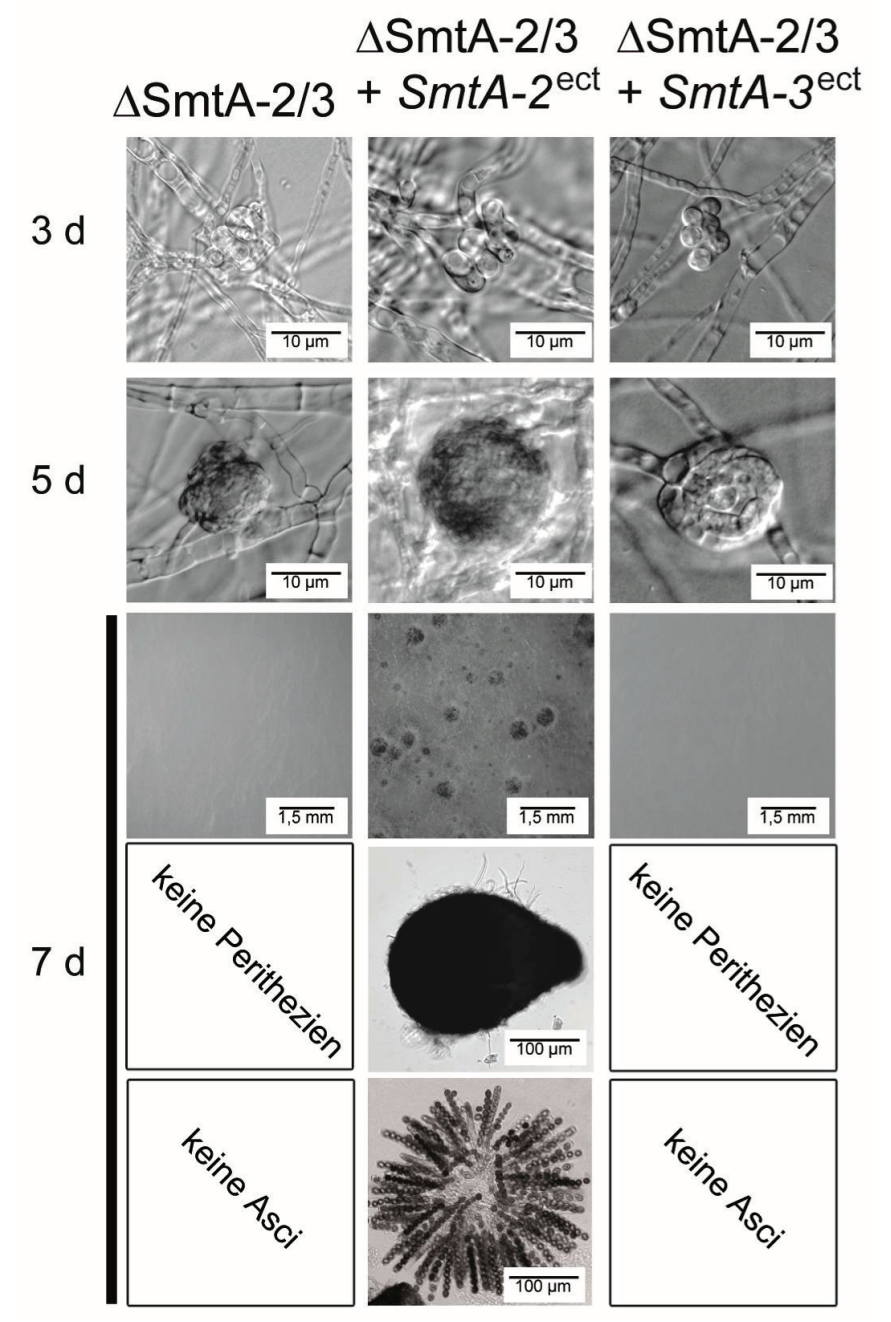

Abbildung 9: Mikroskopische Untersuchung der sexuellen Entwicklungsstadien von $\mathrm{Wt}$ und der Doppeldeletionsmutante $\Delta$ SmtA-2/3. $\mathrm{Zu}$ beachten ist, dass keinerlei reife Perithezien oder Asci in $\Delta$ SmtA-2/3 gefunden werden konnten. Die Mutante $\Delta \mathrm{SmtA}-2 / 3$ mit einer ektopisch integrierten Kopie von $S m t A-2$ zeigt fertilen Wildtyp-Phänotyp, während $\Delta$ SmtA-2/3::SmtA-3 ${ }^{\text {ect }}$ steril ist.

Alle Stämme wurden bei $27^{\circ} \mathrm{C}$ auf SWG angezogen und Bilder der Ascogonien, Protoperithezien und Perithezien und Asci (außer $\Delta$ SmtA-2/3) wurden nach 3, 5 und 7 Tagen Wachstum aufgenommen.

Komplementationsanalysen mit $\Delta$ SmtA-2 und $\Delta$ SmtA-2/3 wurden mit den Plasmiden pRS-Ba2 und pRS-Ba3 durchgeführt, welche die Gene SmtA-2 bzw. SmtA-3 unter der Kontrolle ihrer jeweiligen 5' und 3' regulierenden Elemente tragen. Da beide Plasmide keine eigene Resistenzmarke für $S$. macrospora tragen, wurde eine Kotransformation mit dem Plasmid pRSnat (Nat-Resistenz) durchgeführt. Für die Einzeldeletion $\Delta$ SmtA-2 konnte 
gezeigt werden, dass der Phänotyp durch eine ektopisch integrierte Kopie von SmtA-2 komplementiert werden konnte. $\triangle \operatorname{SmtA}-2:: \operatorname{Smt} A-2^{\text {ect }}$ ist fertil und besitzt einen Wildtypähnlichen Phänotyp (Abb. 8). Das Gleiche gilt für die Doppeldeletion $\Delta$ SmtA-2/3. Durch die ektopische Integration von SmtA-2 ist die Mutante wieder vollständig fertil, während sich bei Integration von $S m t A-3$ keine Änderung ergibt (Abb. 9). $\Delta$ SmtA-2/3::Smt $A-3^{\text {ect }}$ ist weiterhin steril und nicht in der Lage reife Ascosporen auszubilden.

Kreuzungen zwischen den verschiedenen Deletionsmutanten und einer selbst-fertilen Farbspormutante (Fus 1-1) wurden durchgeführt um zu testen ob die fertilen Deletionsstämme $(\Delta$ SmtA-1 und $\Delta$ SmtA-3) und die sterilen Deletionsstämme ( $\Delta$ SmtA-2 und $\Delta$ Smta-1) fähig sind mit dem Teststamm zu kreuzen. Alle Kreuzungen zeigten reife Kreuzungs-Perithezien in der Kontaktzone beider Myzelien. Die Anzahl der fertilen Asci pro Perithezium (120-150) war ähnlich zum Wildtyp. Die Perithezien enthielten Asci mit kompletten Tetraden von acht Ascosporen welche in einem 1:1 Muster für die Resistenz gegen Hygromycin B und braune Sporenfarbe segregierten (Tab. 4).

Tabelle 4: Segregation der Selektionsmarken in den Nachkommen aus Kreuzungen zwischen verschiedenen Kreuzungstyp-Gendeletionen und einem selbst-fertilen Teststamm Fus1-1, welcher braune Ascosporen produziert.

\begin{tabular}{|c|c|c|c|c|c|}
\hline \multicolumn{6}{|c|}{ Anzahl an Nachkommen jedes Phänotyps ${ }^{1}$} \\
\hline \multirow{2}{*}{ Stamm } & \multicolumn{2}{|c|}{ Parental } & \multicolumn{2}{|c|}{ Rekombinant } & \multirow{2}{*}{ Gesamt } \\
\hline & $\mathrm{HygR}_{\text {fus }}^{+}$ & $\mathrm{HygS}_{\text {fus }}^{-}$ & ${\mathrm{HygS} / \text { fus }^{+}}^{+}$ & HygR/fus & \\
\hline$\Delta$ Smta-1 & 24 & 31 & 28 & 22 & 105 \\
\hline$\Delta \mathrm{SmtA}-1$ & 29 & 17 & 32 & 21 & 99 \\
\hline$\Delta \mathrm{SmtA}-2$ & 16 & 21 & 23 & 15 & 75 \\
\hline$\Delta \mathrm{SmtA}-3$ & 31 & 25 & 23 & 24 & 115 \\
\hline
\end{tabular}

${ }^{1}$ Getestet wurde auf die Selektionsmarkern Hygromycin B Resistenz (HygR/HygS für Resistenz/Sensitivität) und Sporenfarbe (fus ${ }^{+} /$fus ${ }^{-}$für schwarze/braune Sporen). Das Segregationsmuster der Marken zeigte ein 1:1:1:1 Verhältnis; $P$-Wert $<0,015$.

In S. macrospora wurden bereits verschiedene sterile Mutanten untersucht, welche in der Lage waren miteinander $\mathrm{zu}$ kreuzen. Nach Hyphenanastomose enthalten die heterokaryotischen Hyphen jeweils eine funktionelle Kopie des mutierten Gens, was meist ausreichend ist für die Fruchtkörperbildung und -entwicklung. Wie zu erwarten waren die sterilen Kreuzungstyp-Mutanten $\Delta$ SmtA-2 und $\Delta$ Smta-1 in der Lage mit den fertilen Mutanten $\Delta$ SmtA-1 und $\Delta$ SmtA-3 zu kreuzen und keimfähige Ascosporen zu entwickeln. Kreuzungen zwischen beiden sterilen Mutanten $\Delta$ SmtA-2 und $\Delta$ Smta-1 bildeten dagegen 
weder Perithezien noch Ascosporen aus (Daten nicht gezeigt). Beide Mutanten sind also nicht in der Lage die jeweiligen Defekte zu komplementieren. Es ist dabei unklar ob dies auf einen Defekt in der Hyphenanastomose zurückzuführen ist und sich kein Heterokaryon ausbilden kann, was für eine Komplementation notwendig wäre.

\subsubsection{Untersuchung der funktionellen Domäne des $M A T 1-1-2$ Gens mittels}

\section{Komplementationsanalyse}

Zur Untersuchung putativer funktioneller Domänen in dem MAT1-1-2 Protein aus S. macrospora wurde eine Komplementationsanalyse mit den homologen Genen aus $N$. crassa und P.anserina in $\Delta$ SmtA-2 durchgeführt. Zusätzlich wurden Verkürzungskonstrukte des $S m t A-2$ Gens erstellt und in $\Delta$ SmtA-2 transformiert (Abb. 10). Die Verkürzungskonstrukte enthielten dabei unterschiedlich viele Aminosäuren der putativen funktionellen PPF-Domäne (Prolin, Prolin, Phenylalanin) (Debuchy, et al., 2010) und unterschiedlich lange Teile der C- oder N-Terminalen Sequenz von der PPF-Domäne aus. Die Plasmide pRS_NcA2 (N. crassa MAT1-1-2), pRS_SMR1 (P. anserina MAT1-1-2), pRS_A2-188 (SMTA-2 verkürzt bis Aminosäure 188), pRS_A2-199 und pRS_A2-205 und wurden dabei über homologe Rekombination in Hefe erstellt. Das Verkürzungskonstrukt A2-S-N wurde aus dem Vektor pRS-Ba2 durch Hydrolyse mit den Restriktionsendonukleasen SalI und NcoI erstellt. Nach der Hydrolyse wurden die entstandenen Überhänge des Plasmids mit „Blunting Mix“ aus dem CloneJet ${ }^{\mathrm{TM}}$ Kit von Fermentas (St.-Leon-Rot) behandelt und entfernt. Das so entstandene, lineare Fragment mit stumpfen DNA-Enden wurde zu einem zirkulären Plasmid re-ligiert. Der so entstandene Vektor enthält das MAT1-1-2 Gen aus S. macrospora mit einer Deletion der 5'-Region.

Die Integration der Komplementationskontrukte wurde mittels PCR überprüft (Anhang A1). 
Ergebnisse

A

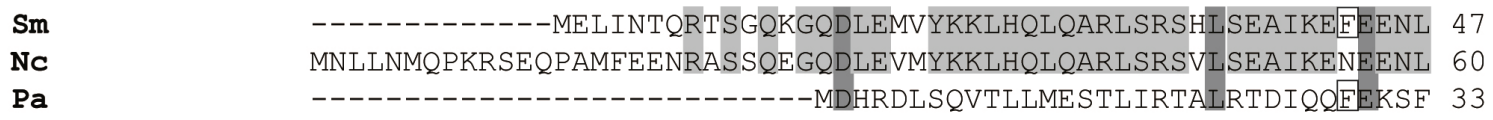

QCLFHEAKILICTKRTKYRQSWFGSSNEFGPNNEEKI IKAACCVIESTNMILNFLSFLEK 107 RCLFHEAKLLICSTRTKYRQSWFGSSNEFGSSDERRIIKTSCCIIESTNTILNFLSFLEK 120 EQI IEQAGVFIATITEEHFIS------LSLVVMDEDVLIRHLCGELASKLA_IEGELSEHQQ 87

KRGLPSGGDQRLQQAAYKGQQFATRLLRSLTIHKDAQEI PGKEFGLVCGKEVHVLGGHVV 167 NRGLPFGGDRLQQAAYKGQQEAFRLLRSLTLHKAAQEVPGKDEGLVYGKDVYVLNGHIL 180 TIQRTSSGGDASLAKQVKAATVEVLELIQTLIYHKEAADYPGKHLGMMYDRDVKYFGGTLF 147

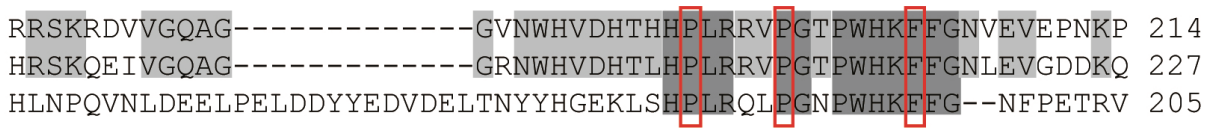

LEULFDFTSPKSDRNGHRKFPVI IPETAMFIQD国ISSEEQEQVATIHTENEHAQPPALTPI 274 LRLFDDDAAVDSYRVGPQKFFVVIPETAEFYFGRSQQQHQRVATIHTENGHVQPPAPTSI 287 EHAADTALFRENPRPG--DLTUSIPGIILELIP国FREHEKFRQLMLEHSQLPLPILLEE 263

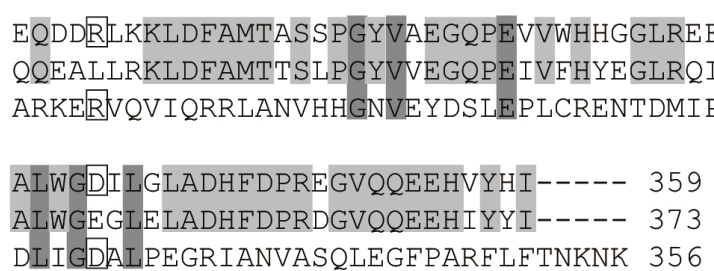

B

P P F

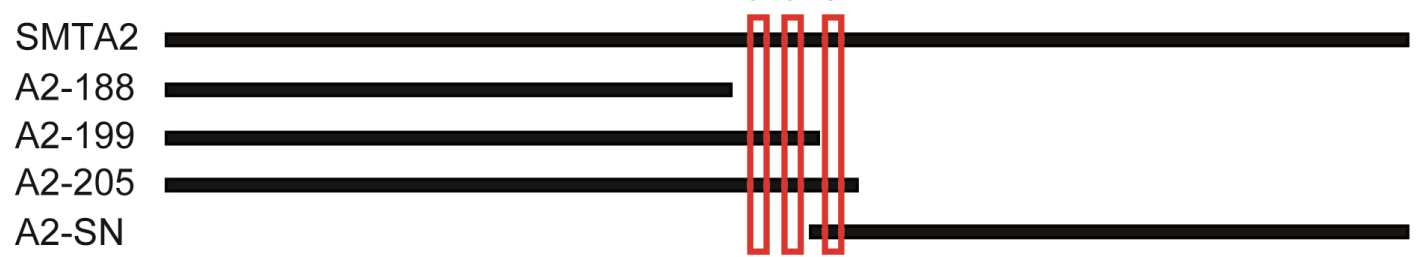

Abbildung 10: Schematische Darstellung der zur Komplementationsanalyse verwendeten Konstrukte. (A) Gegenüberstellung der Sequenzen des MAT1-1-2 Proteins aus $S$. macrospora (Sm), N. crassa (Nc) und $P$. anserina (Pa). Gleiche Sequenzabschnitte zwischen $\mathrm{Sm}$ und Nc sind hellgrau, die zwischen allen dreien dunkelgrau hinterlegt. Gleiche Sequenzabschnitte zwischen Sm und Pa sind in schwarzen Kästchen angezeigt. (B) Schematische Darstellung der verschiedenen Verkürzungskonstrukte von SMTA-2. Die Zahlen geben an, bis zu welcher Aminosäure die native Sequenz des SMTA-2 Proteins intakt ist. Bei S-N handelt es sich um eine Deletion im 5' Bereich des Gens. Die drei konservierten Aminosäuren der putativen PPF-Domäne sind jeweils rot hervorgehoben.

Nach Transformation der Deletionsmutante $\Delta$ SmtA-2 mit den Plasmiden pRS_NcA2 (N. crassa MAT1-1-2) und pRS_SMR1 (P. anserina MAT1-1-2) zeigte sich auch nach verlängerter Wachstumszeit von 14 Tagen keine Veränderung des sterilen Phänotyps. Als Kontrolle diente das Plasmid pRS_Ba2 mit dem S. macrospora Wildtyp-Gen SmtA-2. Alle Gene stehen unter der Kontrolle ihrer nativen Promotoren und Terminatoren (Abb. 11). 
A
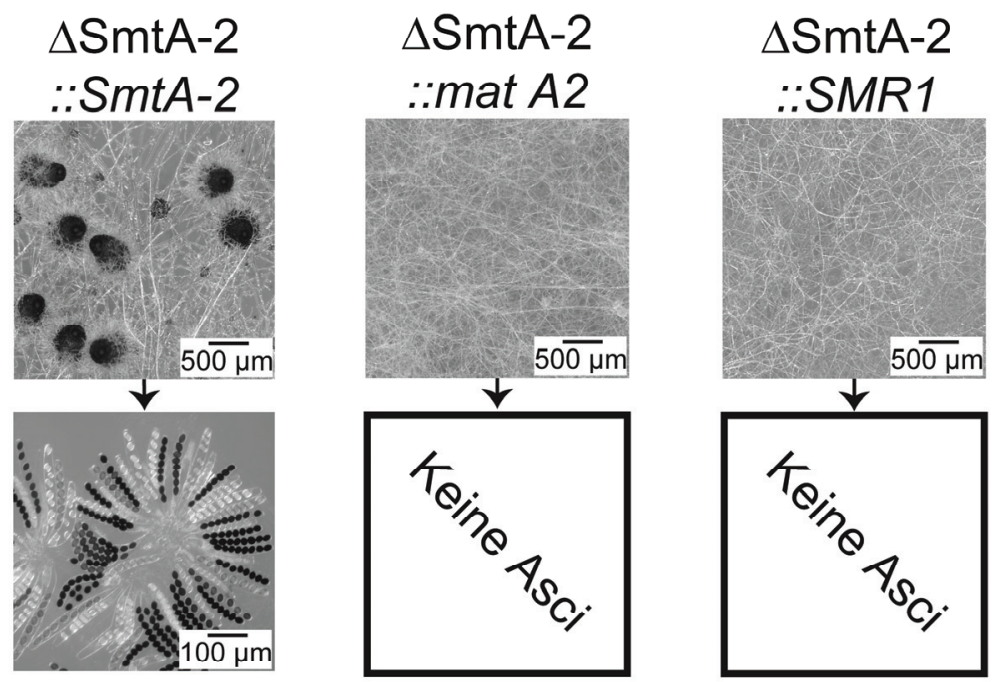

B
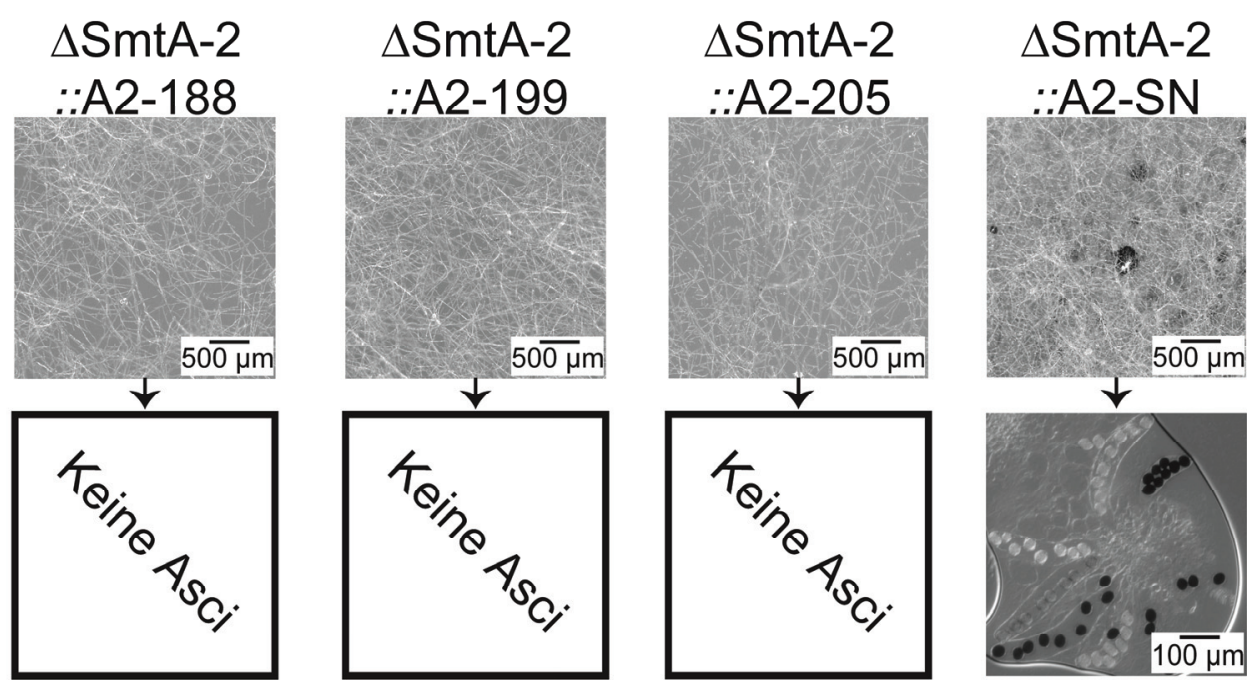

Abbildung 11: Komplementationsstudie der Deletionsmutante $\Delta$ SmtA-2 mit verschiedenen $M A T 1-1-2$ Konstrukten. (A) Komplementation mit den MAT1-1-2 Genen aus S. macrospora (SmtA-2), N. crassa (mat A2) und P. anserina (SMR1). (B) Komplementation mit verschiedenen Abschnitten des SMTA-2 Proteins. 188: AS 1-188; 199: AS 1-199; 205: AS 1-205; SN: AS 199-359

Alle Untersuchungen wurden nach einer verlängerten Wachstumszeit von 21 Tagen auf Vollmedium durchgeführt. AS: Aminosäure.

Die homologen MAT1-1-2 Proteine aus $N$. crassa und P. anserina sind also nicht in der Lage, die Funktion von SMTA-2 im heterologen System in S. macrospora zu übernehmen.

Bei Transformation mit den Verkürzungskonstrukten von SmtA-2 zeigten die Konstrukte A2-188, A2-199 und A2-205 keine Veränderung des sterilen Phänotyps (Abb. 11). Diese Konstrukte kodieren für den N-Terminus des MAT1-1-2 Proteins aus S. macrospora bis zur Aminosäureposition 188 bzw. 199 und 205. Damit werden unterschiedlich viele konservierte Aminosäuren der putativen PPF-Domäne eingeschlossen (Debuchy, et al., 2010) (s. Abb. 10). 
Im Gegensatz dazu besitzt das Konstrukt A2-S-N den C-Terminalen Teil des MAT1-1-2 Proteins, angefangen vom konservierten Phenylalanin der PPF-Domäne. Hier zeigte sich eine partielle Komplementation des Defekts der $\Delta$ SmtA-2 Deletion. Die Protoperithezien entwickelten sich nach einer verlängerten Inkubationszeit von bis $\mathrm{zu} 21$ Tagen zu pigmentierten Perithezien, die allerdings maximal 50\% der Größe von Wildtyp Perithezien erreichen (Abb. 11). Diese Perithezien enthalten teilweise keinerlei Ascosporen, bilden mit einer Frequenz von etwa 10\% jedoch 3 bis 15 Asci mit 8 Ascosporen aus. Die Ascosporen erreichen eine normale Pigmentierung, liegen jedoch nicht als geordnete Tetrade innerhalb des Ascus vor, sondern scheinen in der Ebene verschoben.

Für die Funktionalität des MAT1-1-2 Proteins aus S. macrospora scheint der C-Terminus essentiell, aber nicht ausreichend zu sein. Der N-Terminus alleine ist nicht in der Lage den sexuellen Defekt der $\Delta$ SmtA-2 Mutante zu komplementieren.

\subsubsection{Transkriptionelle Expression der Pheromon- und Rezeptor-Gene}

Es wurde bereits gezeigt, dass Pheromonvorläufer-Gene und die entsprechenden Rezeptoren in die sexuelle Entwicklung von S. macrospora involviert sind (Mayrhofer, et al., 2006). In dem nahe verwandten Ascomyceten N. crassa werden die Pheromonvorläufer-Gene in einer Kreuzungstyp-spezifischen Weise exprimiert. Das Gen $m f a-1$, homolog zu dem a-Faktorähnlichen ppg-2 aus S. macrospora, ist in MAT1-2 (mat a) Stämmen exprimiert, während ccg-4, homolog zu dem $\alpha$-Faktor-ähnlichen ppg-1 aus S. macrospora, in MAT1-1 (mat A) Stämmen exprimiert wird (Bobrowicz, et al., 2002).

Da eine $\triangle$ SmtA-2 Mutante steril ist und Homologe des Proteins SMTA-1 in vielen Ascomyceten in die sexuelle Entwicklung involviert sind (Debuchy, et al., 2010), wurden das $\alpha$-Domänen Protein SMTA-1 und das PPF-Domänen Protein SMTA-2 hinsichtlich ihres Effekts auf die Transkription der Pheromon- und Rezeptor-Gene untersucht. Mittels quantitativer real-Time-PCR (s 3.2.4) wurden die mRNA Mengen der vier transkribierten Gene ppg-1, ppg-2, pre-1 und pre-2 in den Mutanten $\Delta$ SmtA-1 und $\Delta$ SmtA-2 mit dem Wildtyp-Stamm verglichen. Alle real-Time-PCR Experimente wurden dreifach durchgeführt mit isolierter RNA aus fünf Tage altem Myzel, da bereits gezeigt werden konnte, dass die entsprechenden Gene zu diesem Zeitpunkt gut exprimiert sind (Mayrhofer, et al., 2006). Als Starteroligonukleotide wurden die Paare ppg1-f / ppg1-r (ppg-1), ppg2-f / ppg-2r (ppg-2), pre1-f / pre1-r (pre-1), pre2-f/ pre2-r (pre-2) und als Standard Starteroligonukleotide für die 
kleine rRNA Untereinheit („small subunit ribosomal RNA“, SSU rRNA) SSU-f / SSU-r (Tab. 3) verwendet (Abb. 12).

A

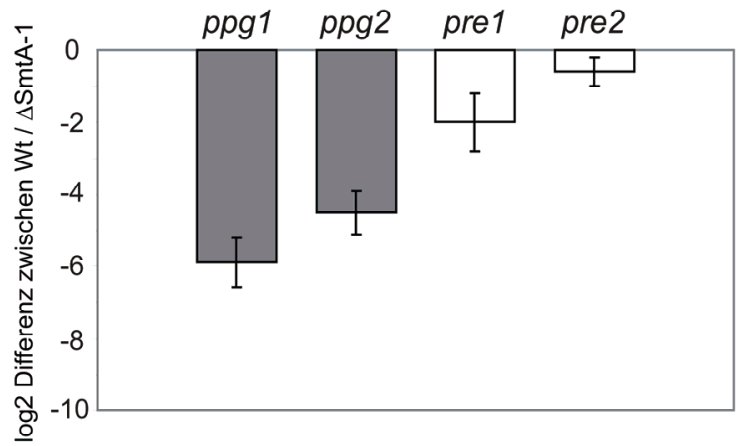

B

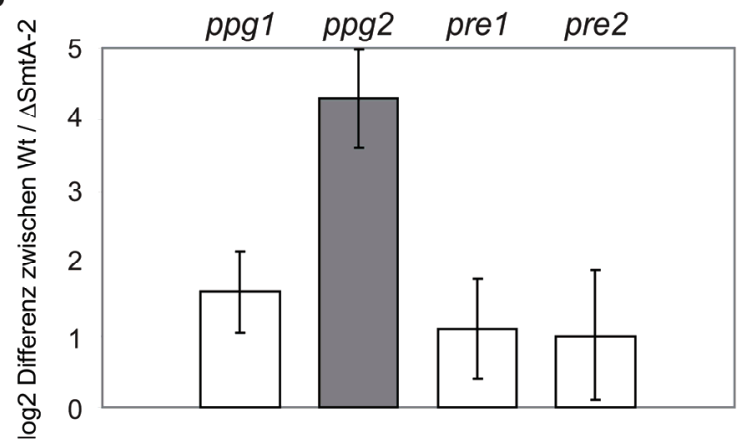

Abbildung 12: Quantitative real-Time-PCR Analyse der Pheromone ppg-1 und ppg-2 und ihrer entsprechenden Rezeptoren pre-1 und pre-2 in den Mutanten $\triangle$ SmtA-1 (A), $\Delta$ SmtA-2 (B) und $\Delta$ Smta-1 (C) im Vergleich zum Wildtyp. Das Verhältnis ist angegeben als Logarithmus (Basis 2) aus dem Mittelwert von drei unabhängigen Experimenten. Mittelwerte wurden berechnet mit dem Programm REST (Pfaffl, et al., 2002). Die Pheromon-Gene ppg1 und ppg-2 in $\Delta$ SmtA-1 und ppg-2 in $\Delta$ SmtA-2 (graue Balken) sind signifikant reguliert $(P$-Wert jeweils 0,$001 ; 0,008$ und 0,001 berechnet mit REST (Pfaffl, et al., 2002)) Gezeigt sind die Mittelwerte dreier Experimente \pm der Standardabweichung.

C

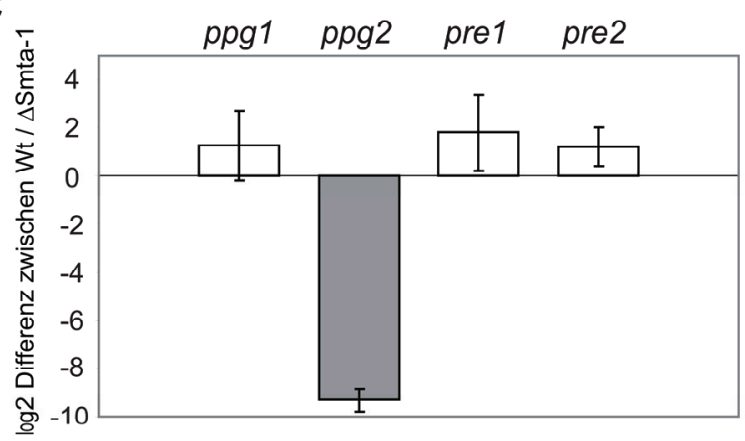

Die Transkriptmenge der Pheromonvorläufer-Gene ppg-1 und ppg-2 ist in der Deletionsmutante $\triangle$ SmtA-1 im Vergleich zum Wildtyp signifikant herunterreguliert. Im Durchschnitt ist die Menge der ppg-1 mRNA um das 60fache, die der ppg-2 mRNA um das 16fache reduziert. Im Gegensatz dazu ist die Transkriptmenge von ppg-2 in der Mutante $\Delta$ SmtA-2 signifikant um das 20fache erhöht, während ppg-1 im Vergleich zum Wildtyp nicht unterschiedlich reguliert ist (Abb. 12). 
Dies zeigt, dass das Kreuzungstyp-Protein SMTA-1 als positiver Regulator der Expression beider Pheromonvorläufer-Gene dient, während SMTA-2 einen negativen Regulator für die Expression von ppg-2 darstellt. Während in SMTa-1 Pheromonvorläufer-Gen ppg-2 signifikant herunterreguliert ist (siehe auch Pöggeler, et al., 2006b), zeigte sich in keiner der Kreuzungstyp-Mutanten ein Einfluss auf die Expression der Rezeptor-Gene (Abb. 12).

\subsubsection{Microarray Analyse von $\Delta$ SmtA-1 und $\Delta$ SmtA-2}

Durch die enge Verwandtschaft zwischen den beiden Spezies S. macrospora und N. crassa ist es möglich, Microarrays von N. crassa mit Proben von S. macrospora zu verwenden. Die Sequenzidentität in den Exonsequenzen beider Spezies liegt bei 89,5\% und es konnte bereits gezeigt werden, dass Microarray Analysen zwischen beiden Spezies möglich sind (Nowrousian, et al., 2005; Nowrousian, et al., 2004; Pöggeler, et al., 2006b).

Um differentiell regulierte Gene in den Kreuzungstyp-Mutanten zu identifizieren, wurden Microarray Hybridisierungen mit Proben aus S. macrospora Wt, $\Delta$ SmtA-1 und $\Delta$ SmtA-2 auf $N$. crassa 70mer Oligonukleotid-Arrays mit 10.910 Oligonukleotiden, welche den 10.526 putativen ORFs und intergenischen oder telomerischen Regionen entsprechen (Tian, et al., 2007), getestet. Die Proben wurden von vier bis fünf Tage altem S. macrospora Myzel gewonnen. $\mathrm{Zu}$ diesem Zeitpunkt beginnen die Protoperithezien im Wildtyp sich zu reifen Perithezien weiterzuentwickeln, während die Entwicklung an dieser Stelle in $\Delta$ SmtA-2 anhält. $\mathrm{Zu}$ diesem Zeitpunkt der Entwicklung wurden auch schon andere sterile Mutanten erfolgreich mit dem Wildtyp in Microarray Analysen verglichen (Nowrousian, et al., 2005; Pöggeler, et al., 2006b).

Gene wurden als differentiell exprimiert angesehen, wenn sie, im Vergleich zum Wildtyp, 2 fach hoch- oder herunterreguliert waren bei einem $P$-Wert von $<0,05$ (Nowrousian, et al., 2007a). Verglichen mit dem Wildtyp wurden so 73 Gene gefunden, welche in der Deletionsmutante $\Delta$ SmtA-1 herauf- und 905 welche herunterreguliert waren (Abb. 11). In der Mutante $\Delta$ SmtA-2 waren dagegen 111 Gene herauf- und 743 herunterreguliert. Dabei waren 23 Gene sowohl in der fertilen Mutante $\Delta$ SmtA-1 als auch in der sterilen $\Delta$ SmtA-2 Mutante herauf- und 497 Gene in beiden herunterreguliert (Abb. 13).

Experimentelle Details und die Daten sämtlicher untersuchter Gene sind in der öffentlichen Datenbank „ArrayExpress“ (http://www.ebi.ac.uk/arrayexpress) unter der Accession-Nummer E-MEXP-2600 zugänglich. 

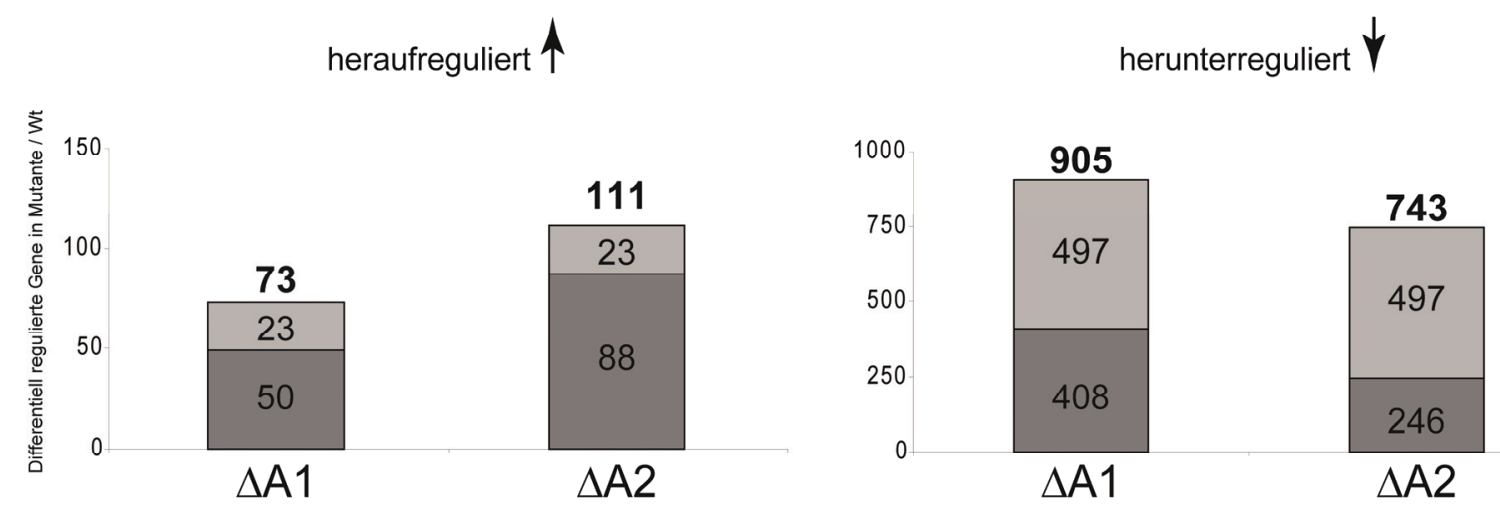

Abbildung 13: Anzahl der Gene welche in den Microarray Analysen als differentiell reguliert gefunden wurden. Die Gesamtzahl der in den beiden Mutanten $\Delta$ SmtA-1 und $\Delta$ SmtA-2 im Vergleich zum Wildtyp differentiell regulierten Gene ist angegeben. Gene, welche in beiden Mutanten gleich reguliert im Vergleich zum Wildtyp sind, sind in hellgrau markiert. Gene welche ausschließlich in einer der Mutanten reguliert sind, sind in dunkelgrau dargestellt.

Die in $\Delta$ SmtA-1 und $\Delta$ SmtA-2 differentiell regulierten Gene wurden weiterhin untersucht mit der FunCat Datenbank (Ruepp, et al., 2004). Dabei wurden Gene mit bekannter oder putativer Funktion in 17 funktionelle Gruppen unterteilt (Abb. 14).

In beiden Deletionsstämmen zeigen die regulierten Gene eine große Bandbreite möglicher Funktionen innerhalb des Organismus, die sich dabei nicht auf eine bestimmte physiologische oder metabolische Funktion beschränken lässt. Um die Microarray Ergebnisse zu bestätigen und mögliche Kandidaten-Gene für weitere Untersuchungen $\mathrm{zu}$ identifizieren, wurden zusätzliche real-Time-PCR Analysen durchgeführt um das Expressionsniveau spezifischer Gene in den Mutanten im Vergleich zum Wildtyp genau zu bestimmen. 
$\Delta \mathrm{SmtA}-1$

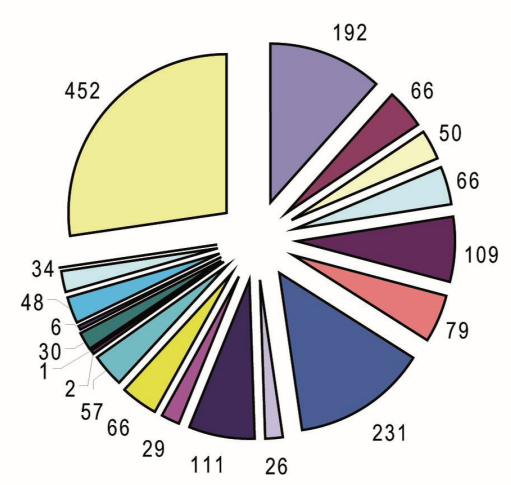

$\Delta \mathrm{SmtA}-2$

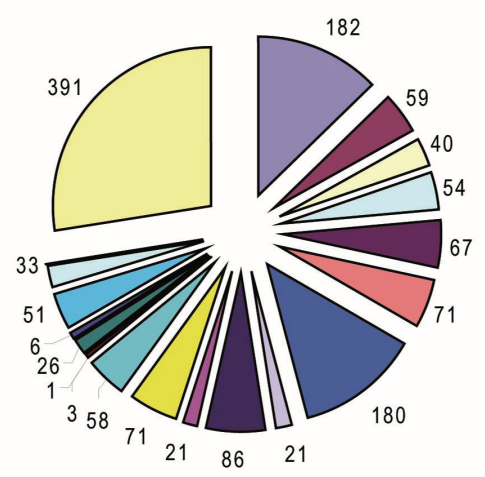

\begin{tabular}{|lll|}
\hline$\square$ Metabolis mus & $\square$ Regulation des Metabolis m us und Protein Funktion & $\square$ Zellschicksal \\
$\square$ Energie & $\square$ Zellulärer Transport & $\square$ Entwicklung \\
$\square$ Zellzyklus \&DNA Prozessierung & $\square$ Zelluläre Kom munikation /Signal Transduktion & $\square$ Biogenese zellulärer Komponenten \\
$\square$ Transkription & $\square$ Zell Abwehr & $\square$ Zelltyp Differenzierung \\
$\square$ Protein Synthese & $\square$ Interaktion mit der Umwelt & $\square$ Unklassifiziert \\
$\square$ Protein Prozessierung & $\square$ System ische Interaktion mit der Umwelt & \\
$\square$ Proteine mit Bindefunktion & $\square$ Transposon Elemente & \\
\hline
\end{tabular}

Abbildung 14: Funktionelle Klassifikation verschiedener differentiell regulierter Gene in $\Delta$ SmtA-1 und $\Delta$ SmtA-2 verglichen mit Wt. Herauf- und herunterregulierte Gene sind zusammen aufgelistet, die Analyse wurde mithilfe der FunCat Datenbank durchgeführt (Ruepp, et al., 2004).

Zunächst wurden dabei vier Gene der Melanin-Biosynthese untersucht: eine Polyketidsynthase $(p k s)$, eine Scytalondehydratase $(s d h)$, eine Tetrahydroxynaphtalenredukatse (teh) und eine Trihydroxynapthalenredukatse (tih) (Engh, et al., 2007a). Das Gen teh konnte dabei in früheren Microarray Analysen als differentiell reguliert in verschiedenen anderen, sterilen S. macrospora Mutanten, darunter die Kreuzungstyp-Mutante $\Delta$ Smta-1, gefunden werden (Pöggeler, et al., 2006b). Für die real-Time Analyse wurden die Starteroligonukleotidpaare pks-f / pks-r, sdh-f / sdh-r, teh-f / teh-r und tih-r / tih-r (Tab. 3) verwendet (Abb. 15). 


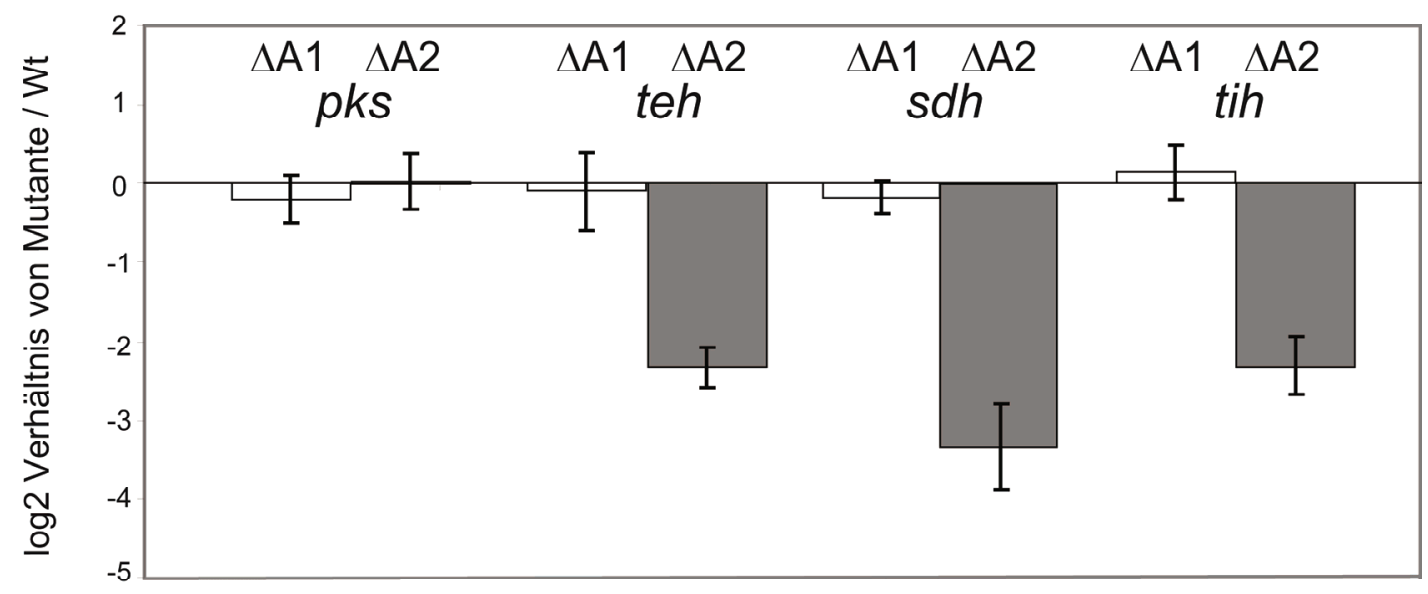

Abbildung 15: Quantitative real-Time-PCR Analyse von Melanin-Biosynthese Genen in $\Delta$ SmtA-1 und $\Delta$ SmtA-2 im Vergleich zum Wildtyp. Die Expression der Gene $t e h, s d h$ und tih ist in $\Delta$ SmtA-2 signifikant herunterreguliert ( $P$-Werte 0,001; 0,003 und 0,002; berechnet mit REST (Pfaffl, et al., 2002)) während keines der Gene in $\Delta$ SmtA-1 signifikant reguliert ist. Gezeigt sind die Mittelwerte dreier Experimente \pm der Standardabweichung.

Im Vergleich zum Wildtyp war keines der untersuchten Gene in der Mutante $\Delta$ SmtA-1 differentiell reguliert, während die Gene teh, sdh und tih in $\Delta$ SmtA-2 signifikant herunterreguliert waren. Die Expression der Polyketidsynthase (pks) war in keiner der Mutanten verändert.

Des Weiteren wurden zwei Kupferhomeostase Gene (sod-2 und ctr-3) untersucht (Borghouts, et al., 2002b). Dazu wurden die Primerpaare sod-f / sod-r und ctr-f / ctr-r (Tab. 3) verwendet (Abb. 16).

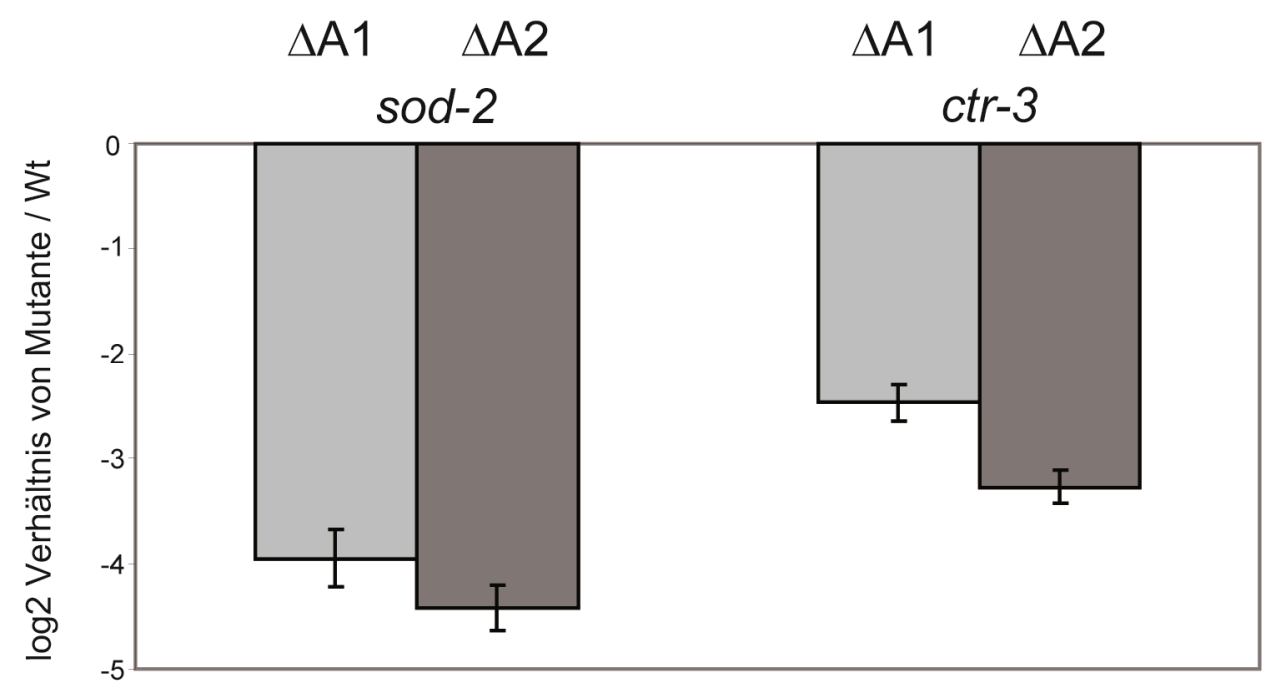

Abbildung 16: Quantitative real-Time-PCR Analyse der Gene der Kupferhomeostase Gene sod-2 und ctr-3 in $\Delta$ SmtA-1 und $\Delta$ SmtA-2 verglichen zum Wt. Die Gene sind in beiden Mutanten signifikant herunterreguliert $(P$-Wert $\Delta$ SmtA-1 0,009 und 0,$011 ; P$-Wert $\Delta$ SmtA-2 0,005 und 0,007 berechnet mit REST (Pfaffl, et al., 2002)). 
Die Expression der Gene sod-2 und ctr-3 war dabei sowohl in der fertilen Mutante $\Delta$ SmtA-1 als auch in der sterilen Mutante $\Delta$ SmtA-2 erniedrigt. Das Expressionsniveau lag dabei in beiden Fällen in $\triangle$ SmtA-2 deutlich niedriger als in $\triangle$ SmtA-1.

Zusätzlich wurde eine Untereinheit des „origin recognition complex“ (ORC) getestet. Der ORC ist für die Erkennung des Replikationsursprungs von DNA verantwortlich und Erkennungssequenzen des ORC finden sich hundert- bis tausendfach auf eukaryotischen Chromosomen (Bell und Dutta, 2002). Die Expression des Gens der Untereinheit 3 des ORC (orc-3) war dabei in der Kreuzungstyp-Deletion $\Delta \mathrm{SmtA}-2$ herunterreguliert, während in $\triangle$ SmtA-1 kein Unterschied zum Wildtyp gefunden wurde (Abb. 17). Das Expressionslevel war dabei in $\triangle$ SmtA-2 etwa 5 fach niedriger als im Wildtyp.

orc-3

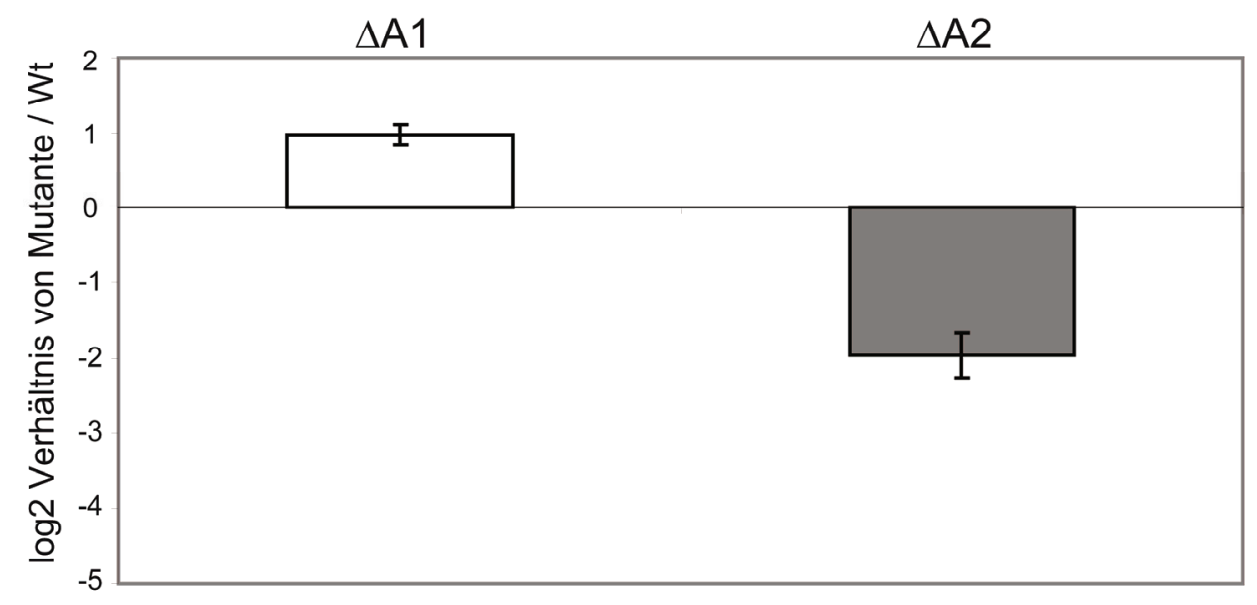

Abbildung 17: Quantitative real-Time-PCR Analyse der Untereinheit 3 des ,origin recognition complex“ (orc-3) in den Mutanten $\Delta$ SmtA-1 und $\Delta$ SmtA-2 im Vergleich zum Wildtyp. Die Expression ist signifikant herunterreguliert in $\Delta$ SmtA-2 (dunkelgrau), jedoch nicht in $\Delta$ SmtA-1 (weiß) (P-Wert 0,006 berechnet mit REST (Pfaffl, et al., 2002)).

Die Ergebnisse der real-Time-PCR Analyse der drei Gene sod-2, ctr-3 und orc-3 stimmten dabei mit den Ergebnissen der Microarray Analyse überein. 


\subsubsection{Lokalisation der Keuzungstyp-Proteine mittels Fluoreszenzmikroskopie}

Zur Untersuchung der Lokalisation der verschiedenen Kreuzungstyp-Proteine wurden die Plasmide pRHN-A2, pRHN-A3 und pRSnG-A2 erstellt (Tab. 2). Die darauf kodierten Kreuzungstyp-Proteine sind entweder mit dem Fluoreszenzprotein dsRED (Janus, et al., 2007) (SMTA-2, SMTA-3) oder GFP (Pöggeler, et al., 2003) fusioniert (SMTA-2). Für die Herstellung des Plasmids pRHN-A2 wurde zuvor eine SmtA-2 Version mit einer Punktmutation mittels der Primer A2-NcoI-RIPf / A2-NcoI-RIPr (s. Tab. 3) erstellt. Durch diese Mutation enthält diese Version keine NcoI Restriktionsstelle mehr, die Aminosäurezusammensetzung des kodierten Proteins wird jedoch nicht verändert. Das Gen ist in vivo voll funktionell (Daten nicht gezeigt).

Da Deletionsmutanten des Kreuzungstyp-Gens SMTA-3 keinen unterscheidbaren Phänotyp zeigen, konnte in diesem Fall keine Komplementationsanalyse durchgeführt werden. Das Plasmid pRHN-A3 wurde in S. macrospora Wt transformiert. Die Plasmide pRHN-A2 und pRSnG-A2 dagegen wurden in den Deletionsstamm $\triangle$ SmtA-2 transformiert, um das kodierte Fusionsprotein auf Funktionalität zu überprüfen. Bei voller Funktionalität des SMTA-2_GFP oder SMTA2_dsRed Proteins in vivo sollte der sterile Phänotyp der $\Delta$ SmtA-2 Mutante komplementiert werden. Als Negativkontrolle dienten die Leerplasmide pRHN1nat und pRSnGFP, welche ausschließlich für dsRed bzw. GFP kodieren. Die Integration aller Fluoreszenzkonstrukte wurde mittels PCR nachgewiesen (s. Anhang A2).

Die Ergebnisse der fluoreszenz-mikroskopischen Analyse von SMTA-3_dsRED, SMTA-2_dsRed und SMTA-2_GFP sind in Abb. 18 abgebildet.

Mit dem Leerplasmid pRHN1, welches dsRED unter dem konstitutiven gpd-Promotor enthält, ist deutlich eine Fluoreszenz im Cytoplasma zu erkennen. Die Fluoreszenz der SMTA-3_dsRED und SMTA-2_dsRed Proteine lokalisiert ähnlich zu dsRED. Das Gleiche gilt für die Fluoreszenz des GFP-Leerplasmids pRSnGFP und SMTA-2_GFP. Alle drei Fusionsproteine verteilen sich gleichmäßig über die Zelle im Cytoplasma. Es konnte keine konzentrierte Fluoreszenz in Organellen oder der Vakuole nachgewiesen werden. Vielmehr sind die Vakuolen frei von Fluoreszenz. 
Ergebnisse

WtRed
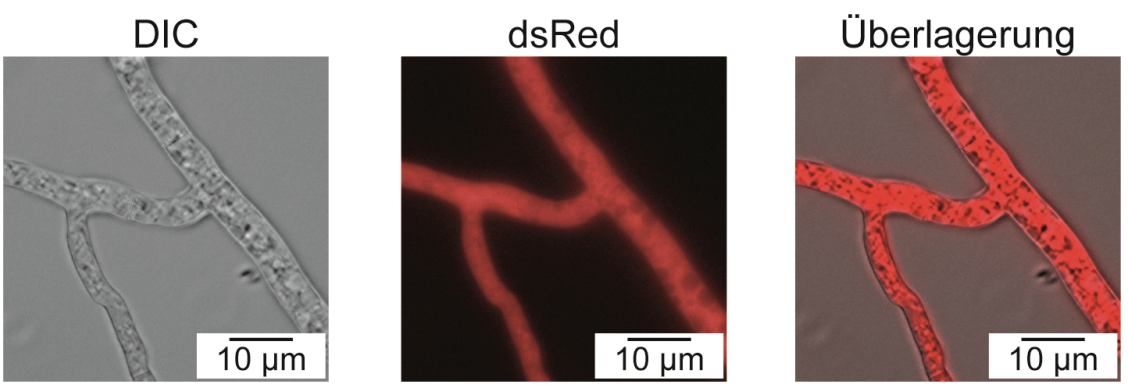

$\Delta$ SmtA-2::SmtA-2_dsRed
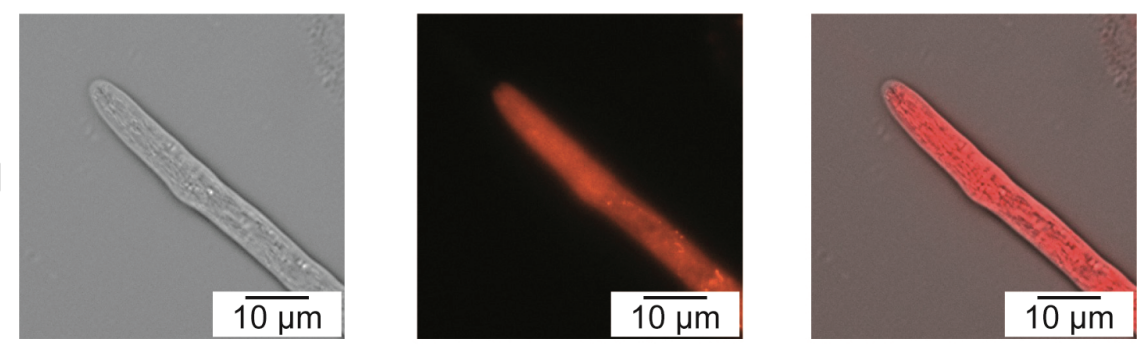

SmtA-3_Red
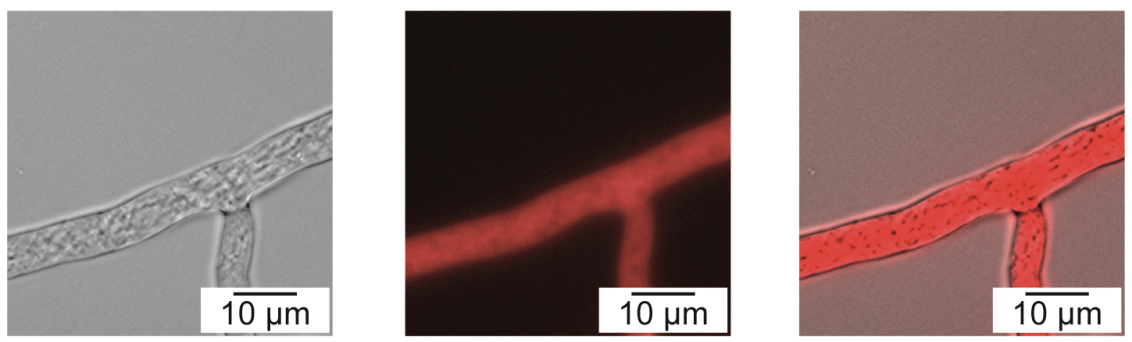

DIC

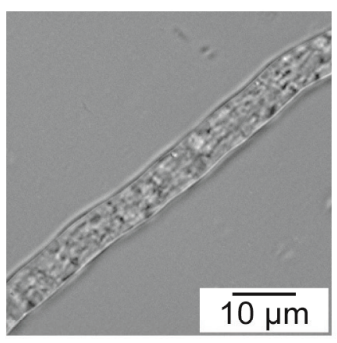

GFP
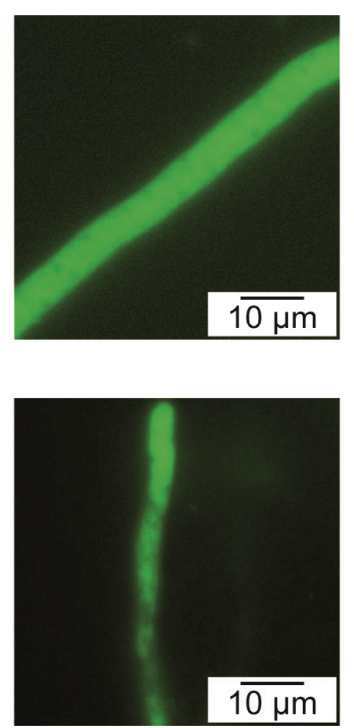

Überlagerung
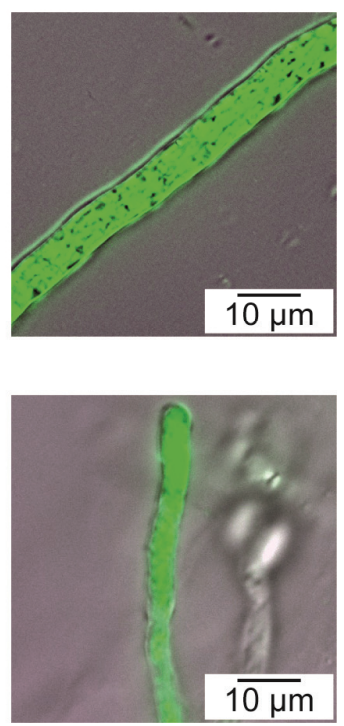

Abbildung 18: Fluoreszenzmikroskopische Untersuchung von $S$. macrospora Wildtyp transformiert mit dsRED (WtRed) oder SMTA-3_dsRED. $\triangle$ SmtA-2 wurde entweder mit GFP-Leerplasmid pRSnGFP ( $\triangle$ SmtA-2::GFP) oder dem Gen SmtA-2 fusioniert mit dsRed (ASmtA-2::SmtA-2_dsRed) oder GFP (ASmtA-2::SmtA-2_GFP) transformiert.

Alle Aufnahmen wurden nach 3 Tagen Wachstum auf SWG Medium durchgeführt. 
Im Hintergrund des $\Delta$ SmtA-2 Stammes mit den Plasmiden pRSnG-A2 und pRHN-A2 ist eine leichte Veränderung des sterilen Phänotyps von $\Delta \mathrm{SmtA}-2 \mathrm{zu}$ beobachten. Es bilden sich pigmentierte Perithezien, welche, im Gegensatz zum Wildtyp, jedoch klein bleiben und keine Ascosporen enthalten (s. Anhang A2)

Die Fusionsproteine SMTA-2_dsRed und SMTA-2_GFP sind also nur partiell funktionell.

\subsubsection{Interaktionspartner des Kreuzungstyp-Proteins SMTA-2}

Um mögliche Interaktionspartner des Kreuzungstyp-Proteins SMTA-2 zu identifizieren, wurde eine Hefe-Zwei-Hybrid Analyse gegen eine S. macrospora cDNA-Bank durchgeführt. Dazu wurde das Plasmid pGB-A2 (Tab. 2) verwendet, welches für das Protein SMTA-2 fusioniert an die GAL4-Bindedomäne kodiert. Die Funktionalität des Konstrukts in S. cerevisiae wurde mittels der Kreuzung mit dem Stamm AH109+pGAD-ranBPM (Tab. 2) verifiziert. Dieser trägt das Protein RanBPM fusioniert an die GAL4-Aktivierungsdomäne. Dieses System wurde etabliert, da bekannt ist, dass RanBPM mit der GAL4-Bindedomäne interagieren kann. Eine Interaktion ist also unabhängig vom Fusionsprotein möglich, solange das Konstrukt korrekt translatiert und in den Zellkern transportiert wird (Tucker, et al., 2009). Bei Interaktion beider Fusionsproteine wird die Expression von Histidin- und Adeninbiosynthesegenen (H, A) aktiviert, welche unter der Kontrolle GAL-inudzierbarer Promotoren stehen. Auf den Plasmiden sind dagegen Leucin- und Trypthophanbiosynthesegene (L, T) kodiert. Ein Wachstum auf SD-Medium ohne Histidin, Adenin, Leucin und Trypthophan (SD-HALT) ist dementsprechend nur möglich, wenn beide Plasmide in einem Organismus vorliegen und die kodierten Proteine interagieren. Eine Transaktivierungsaktivität von SMTA-2 wurde mit dem Leervektor pGADT7 (Tab. 2) ausgeschlossen (Abb. 19).

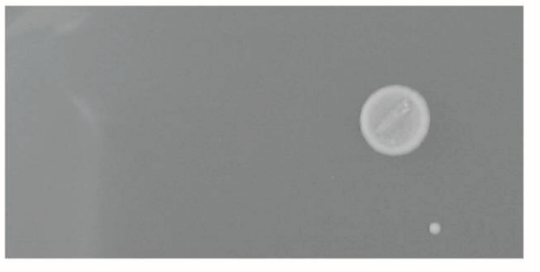

Abbildung 19: Darstellung der Hefestämme mit den Plasmiden pGB-A2 + pGADT7 (Transaktivierungskontrolle) und pGB-A2 + pGAD-ranBPM (Expressionskontrolle). Die Stämme wurden auf SD-HALT für $48 \mathrm{~h}$ angezogen.

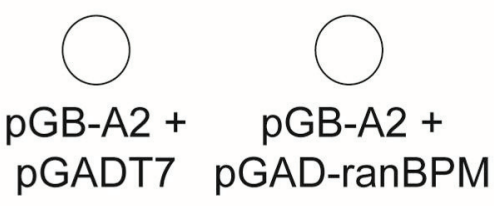


Ergebnisse

Die Plasmide mit putativen Interaktionspartnern wurden aufgearbeitet und sequenziert. Die erhaltenen Sequenzen wurden mittels BlastX Suchalgorithmus (Altschul, et al., 1990) mit den öffentlichen Datenbanken „Neurospora crassa Database“ $(\mathrm{NcD})$, „Aspergillus Database“ (AD) (http://www.broadinstitute.org/science/data) und „Saccharomyces Genome Database“ (SGD) (http://www.yeastgenome.org) verglichen. In der NcD sind dabei Informationen zu Proteinen aus N. crassa, in der AD zu verschiedenen Aspergillus Spezies und in der SGD zu S. cerevisiae gespeichert. Die Ergebnisse der Datenbankvergleiche sind in Tabelle 5 aufgeführt. Es wurden nur solche Proteine aufgeführt, welche bei den Vergleichen einen Erwartungswert (e-Wert) von unter 0,05 aufwiesen. Dadurch konnten 49 Proteine als potentielle Interaktionspartner von SMTA-2 identifiziert werden. 


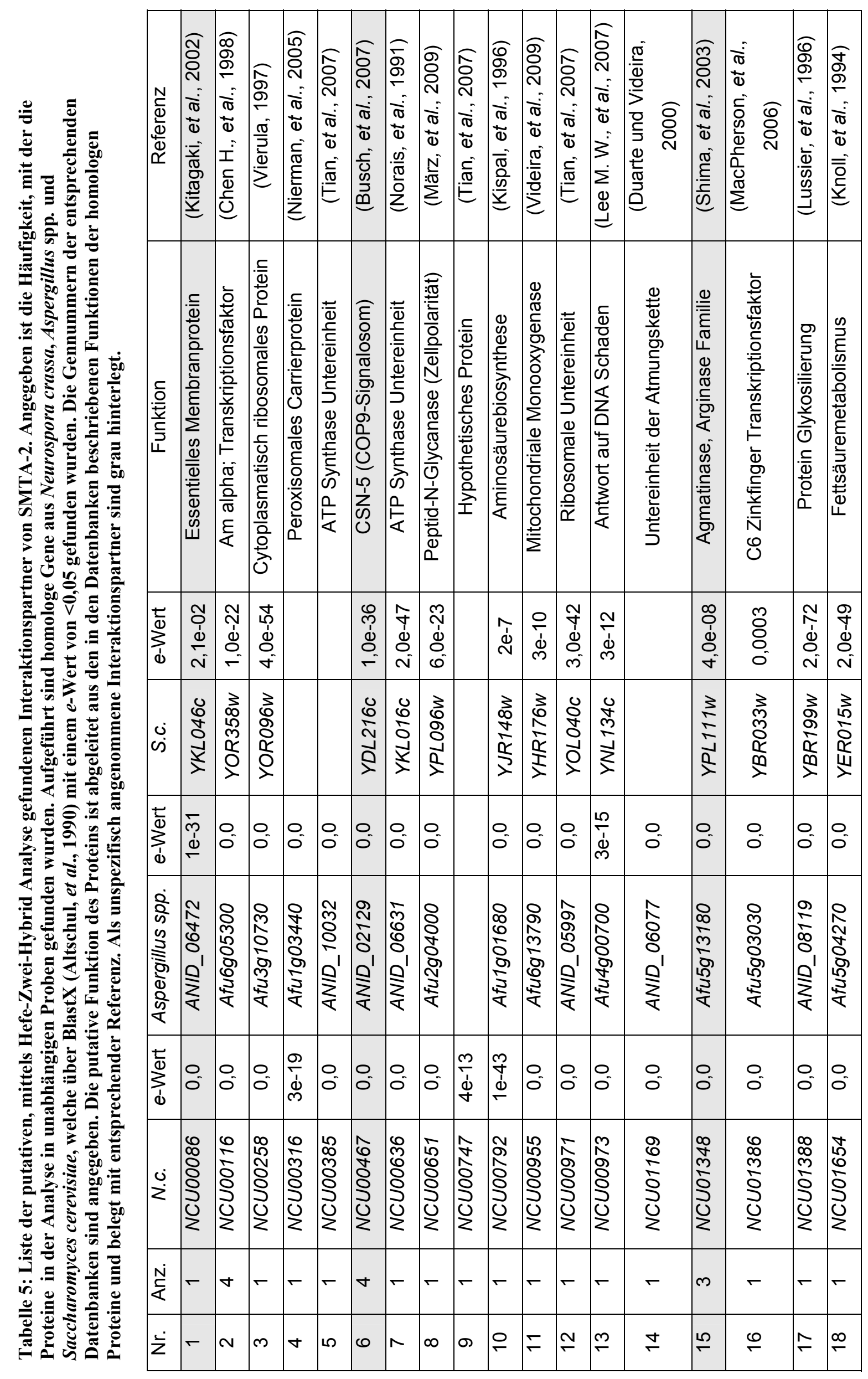

$\sigma$
0
$\stackrel{0}{0}$
$\omega$ 


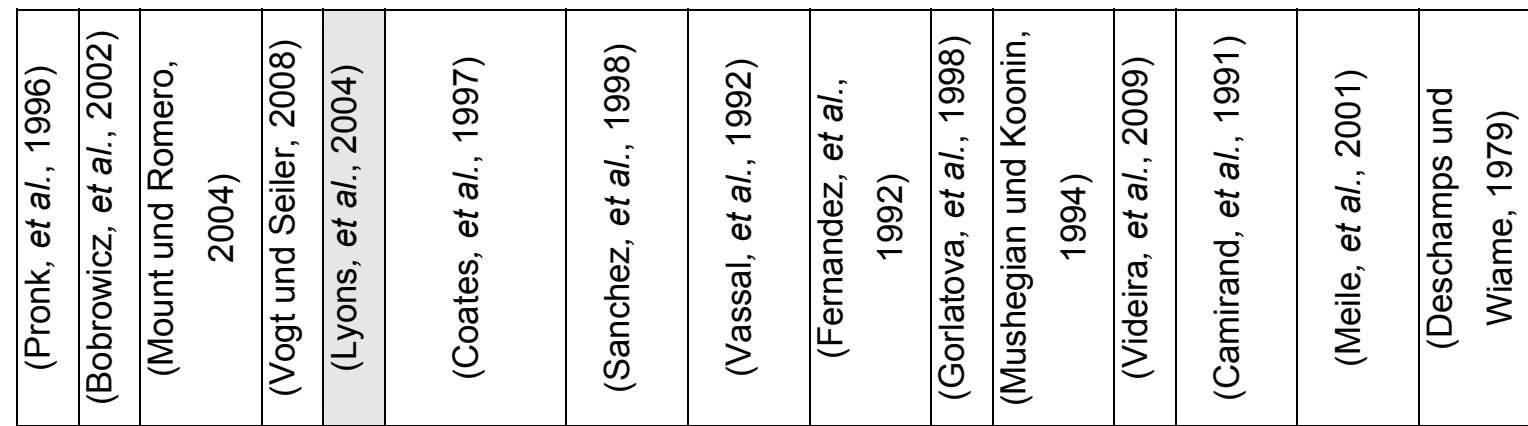

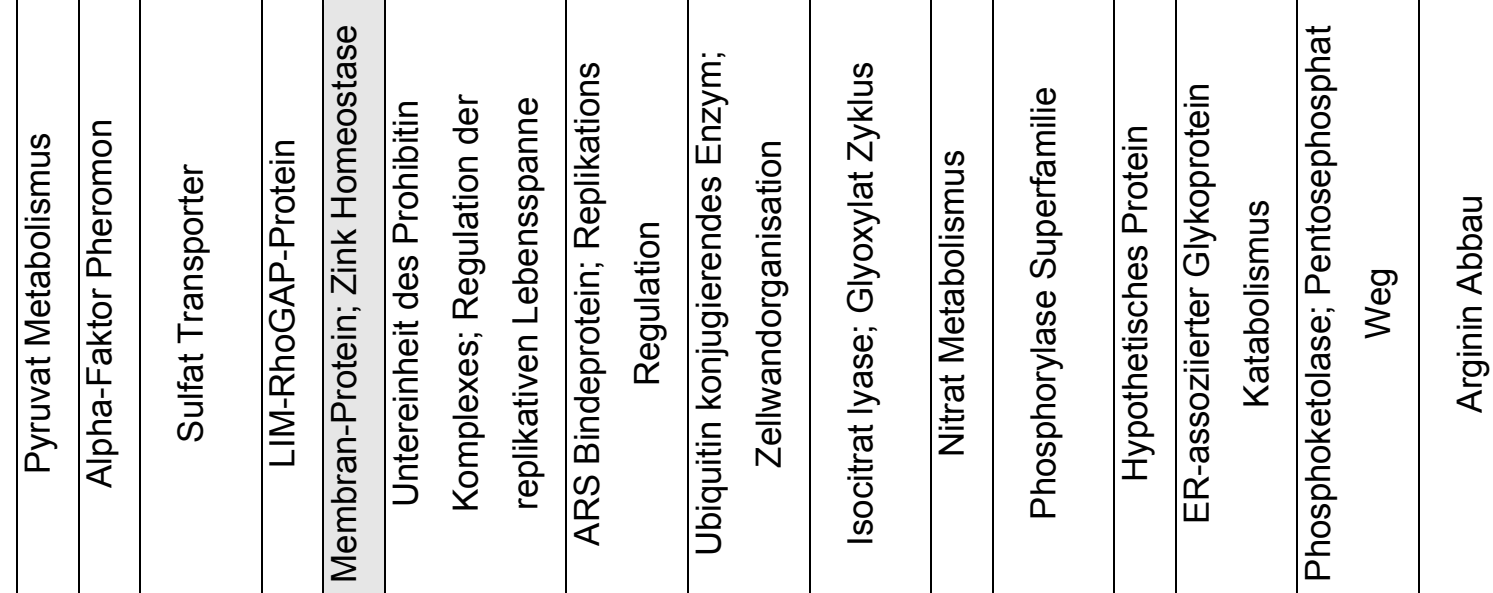

\begin{tabular}{|c|c|c|c|c|c|c|c|c|c|}
\hline $\begin{array}{l}\widehat{o} \\
0 \\
1 \\
0 \\
\tilde{m}\end{array}$ & $\frac{1}{0}$ & $\begin{array}{l}\hat{\sigma} \\
\dot{\delta} \\
0 \\
0\end{array}$ & $\frac{\stackrel{\infty}{\circ}}{\stackrel{\phi}{\grave{d}}}$ & $\begin{array}{l}0 \\
0 \\
\dot{d} \\
0 \\
\text { in }\end{array}$ & $\begin{array}{l}0 \\
\varnothing \\
\varnothing \\
0\end{array}$ & $\begin{array}{l}0 \\
\text { o } \\
0 \\
\text { d } \\
N\end{array}$ & $\begin{array}{l}\text { ô } \\
\text { d. } \\
\text { o. } \\
\text { o. }\end{array}$ & $\begin{array}{l}\stackrel{N}{d} \\
\dot{\Phi} \\
\infty \\
\infty\end{array}$ & $\begin{array}{l}\stackrel{\sim}{N} \\
\dot{\delta} \\
\stackrel{N}{N}\end{array}$ \\
\hline $\begin{array}{l}0 \\
\infty \\
0 \\
\frac{1}{\nu}\end{array}$ & 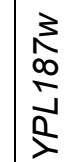 & $\underset{\frac{N}{\sqrt{n}}}{\frac{1}{0}}$ & 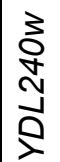 & 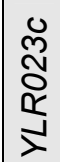 & $\frac{\stackrel{\sim}{N}}{\stackrel{N}{\frac{N}{0}}}$ & $\begin{array}{l}\underset{N}{N} \\
\underset{\mathbf{X}}{\alpha} \\
\underset{\Sigma}{\Sigma}\end{array}$ & $\begin{array}{l}0 \\
0 \\
0 \\
\frac{R}{4} \\
\frac{1}{\lambda}\end{array}$ & $\frac{3}{\frac{3}{2}}$ & 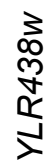 \\
\hline
\end{tabular}
\begin{tabular}{|l|l|l|l|l|l|l|l|l|l|l|l|l|l}
0 & 0 & 0 & 0 & 0 & 0 & 0 & 0 & 0 & 0 & 0 & 0 & 0 & 0 \\
0 & 0 & 0 & 0 & 0 & 0 & 0 & 0 & 0 & 0 & 0 & 0 & 0 & 0
\end{tabular}

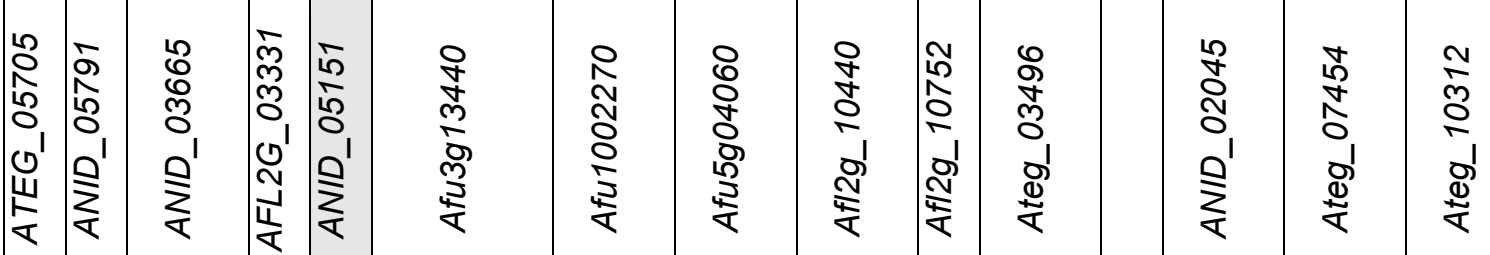

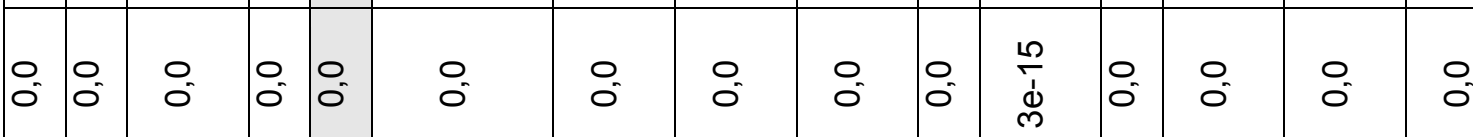

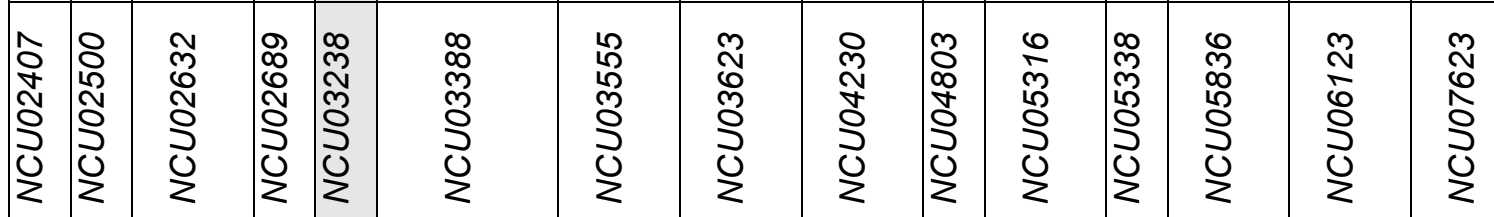

\begin{tabular}{|c|c|c|c|c|c|c|c|c|c|c|c|c|c|c|}
\hline$\checkmark$ & - & $r$ & - & $N$ & $N$ & $r$ & $r$ & - & $r$ & $r$ & $\nabla$ & $r$ & $\infty$ & $\sim$ \\
\hline 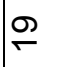 & & $\bar{\sim}$ & N & $\stackrel{\sim}{N}$ & $\stackrel{\Xi}{\sim}$ & $\stackrel{\circ}{\sim}$ & $\stackrel{\bullet}{\sim}$ & $\hat{N}$ & $\stackrel{\infty}{\sim}$ & $\stackrel{\text { D }}{ }$ & ஜ্ & $\bar{m}$ & లె & $\stackrel{m}{m}$ \\
\hline
\end{tabular}




\begin{tabular}{|c|c|c|c|c|c|c|c|c|c|c|c|c|}
\hline 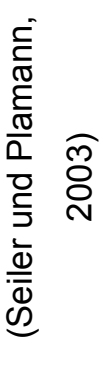 & 1 & $\mid$ & 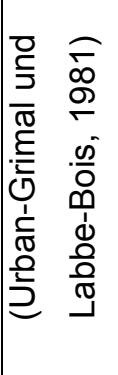 & 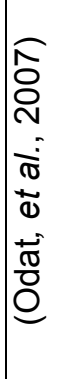 & 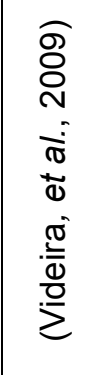 & 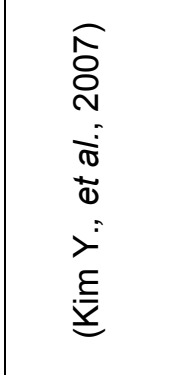 & 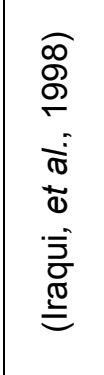 & 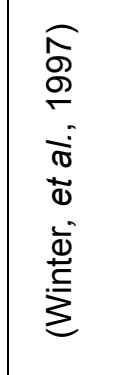 & 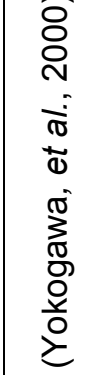 & 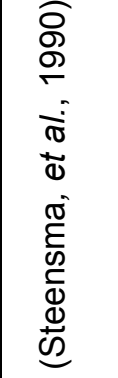 & 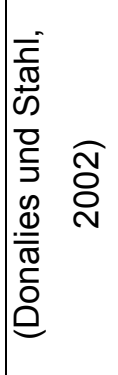 & 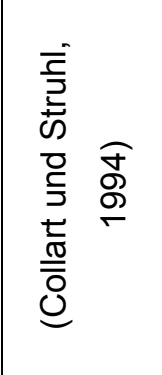 \\
\hline 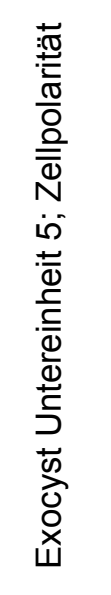 & 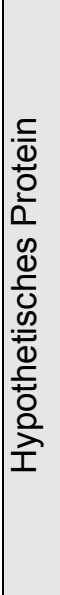 & 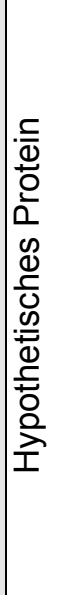 & 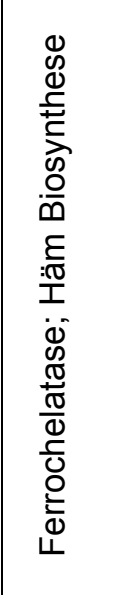 & 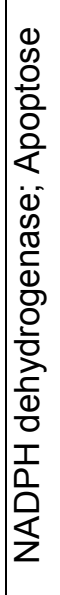 & 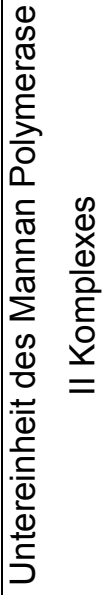 & 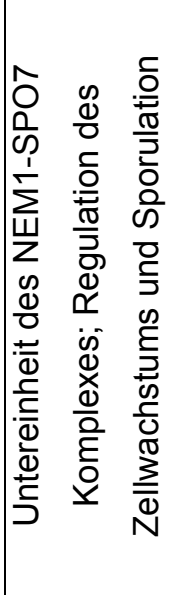 & 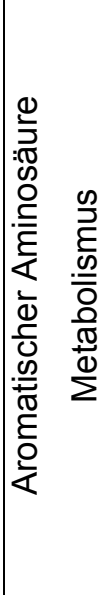 & 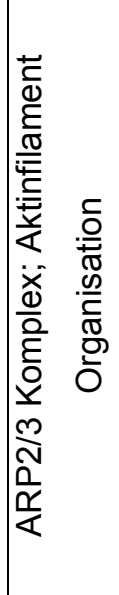 & 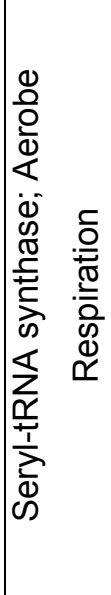 & 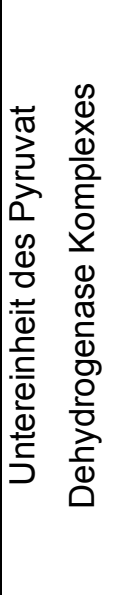 & 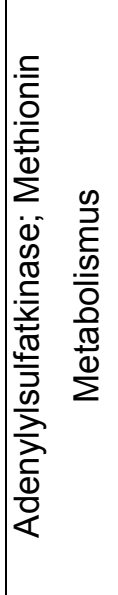 & 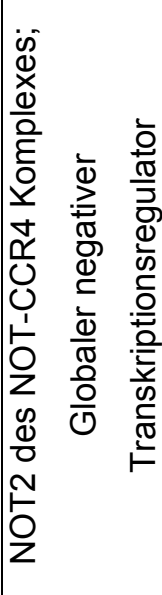 \\
\hline 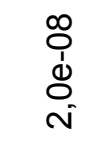 & & & $\begin{array}{l}8 \\
0 \\
\dot{d} \\
\text { i } \\
\text { ind }\end{array}$ & $\stackrel{\nabla}{\frac{\nabla}{d}}$ & $\begin{array}{l}\hat{m} \\
\dot{d} \\
0 \\
\text { r }\end{array}$ & $\begin{array}{l}\stackrel{0}{N} \\
\dot{d} \\
0 \\
N\end{array}$ & $\begin{array}{l}\text { mे } \\
\dot{\phi} \\
\text { D. }\end{array}$ & $\begin{array}{l}\text { o } \\
\text { ه } \\
\text { ه }\end{array}$ & $\begin{array}{l}\infty \\
\dddot{L} \\
\dot{\phi} \\
0 \\
0\end{array}$ & $\begin{array}{l}\frac{0}{d} \\
\dot{\phi} \\
\omega^{\circ}\end{array}$ & $\begin{array}{l}\text { \丶 } \\
\text { d } \\
\text { m) }\end{array}$ & $\begin{array}{l}0 \\
\bar{d} \\
\dot{d} \\
i\end{array}$ \\
\hline $\begin{array}{l}8 \\
8 \\
\frac{8}{8} \\
\frac{x}{2}\end{array}$ & & & $\begin{array}{l}\frac{3}{0} \\
\frac{1}{2} \\
\frac{0}{2}\end{array}$ & $\begin{array}{l}\frac{3}{2} \\
\frac{1}{2} \\
\frac{2}{1} \\
\frac{2}{2}\end{array}$ & $\begin{array}{l}\mathscr{0} \\
\stackrel{2}{0} \\
\stackrel{1}{\lambda}\end{array}$ & $\begin{array}{l}0 \\
\dot{y} \\
\delta \\
\frac{\alpha}{1} \\
\frac{\alpha}{1}\end{array}$ & 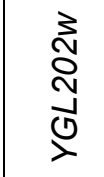 & $\begin{array}{l}0 \\
2 \\
0 \\
0 \frac{1}{1} \\
\vdots\end{array}$ & $\begin{array}{l}\frac{3}{2} \\
\frac{1}{0} \\
\frac{k}{1} \\
\frac{0}{1}\end{array}$ & 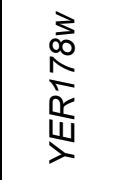 & $\begin{array}{l}\frac{1}{8} \\
\frac{1}{8} \\
0\end{array}$ & 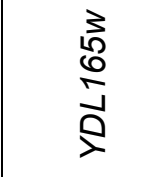 \\
\hline & $0_{0}^{\circ}$ & & $\begin{array}{l}0 \\
0\end{array}$ & $0^{0}$ & OO & $\begin{array}{l}0 \\
0\end{array}$ & $\begin{array}{l}0 \\
0\end{array}$ & OO & OO & $\begin{array}{l}0 \\
0\end{array}$ & O্. & $\begin{array}{l}0 \\
0\end{array}$ \\
\hline 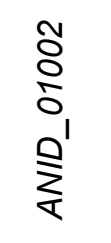 & 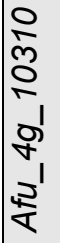 & & 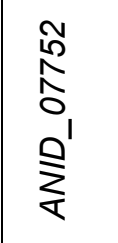 & 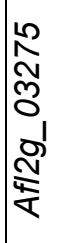 & 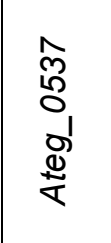 & 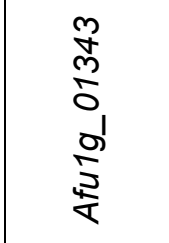 & 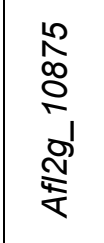 & 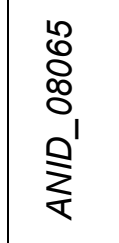 & 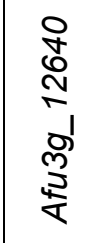 & 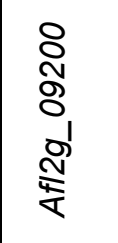 & $\begin{array}{l}\frac{\pi}{2} \\
\frac{5}{\delta} \\
\overbrace{1} \\
\sum_{4}\end{array}$ & 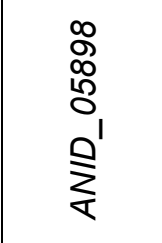 \\
\hline$O_{0}^{\circ}$ & $\begin{array}{l}\stackrel{p}{0} \\
\stackrel{d}{N}\end{array}$ & & $0_{0}^{\circ}$ & $0_{0}^{\circ}$ & $\stackrel{0}{\circ}$ & O. & $\stackrel{0}{\circ}$ & $\begin{array}{l}\text { ָ̦ } \\
\stackrel{d}{\infty}\end{array}$ & $O_{0}^{\circ}$ & $\stackrel{0}{0}$ & $\overbrace{0}^{\circ}$ & $O_{0}^{\circ}$ \\
\hline 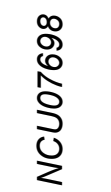 & $\begin{array}{l}8 \\
0 \\
0 \\
\infty \\
0 \\
0 \\
0 \\
z\end{array}$ & 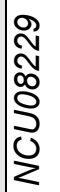 & 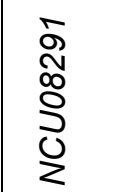 & \begin{tabular}{l}
8 \\
8 \\
$\infty$ \\
$\infty$ \\
\hdashline \\
\hdashline \\
\hdashline \\
$z$
\end{tabular} & 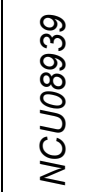 & 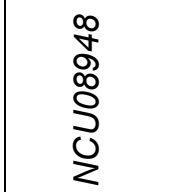 & $\begin{array}{l}0 \\
\frac{1}{2} \\
\stackrel{2}{2} \\
\stackrel{0}{2}\end{array}$ & 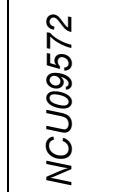 & 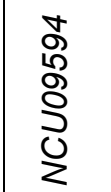 & 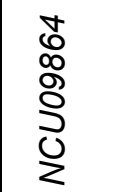 & 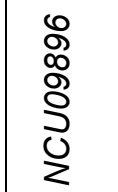 & 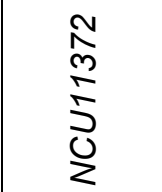 \\
\hline$r$ & - & N & $\sim$ & $r$ & - & $m$ & $\sim$ & - & - & $r$ & - & $r$ \\
\hline ঙे & 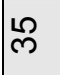 & ফ্লি & $\hat{m}$ & 价 & శ్లి & 우 & $\bar{\tau}$ & $\stackrel{\sim}{\sim}$ & $\stackrel{\mathscr{q}}{+}$ & ষ & $\stackrel{0}{+}$ & $\stackrel{\mathscr{Q}}{+}$ \\
\hline
\end{tabular}




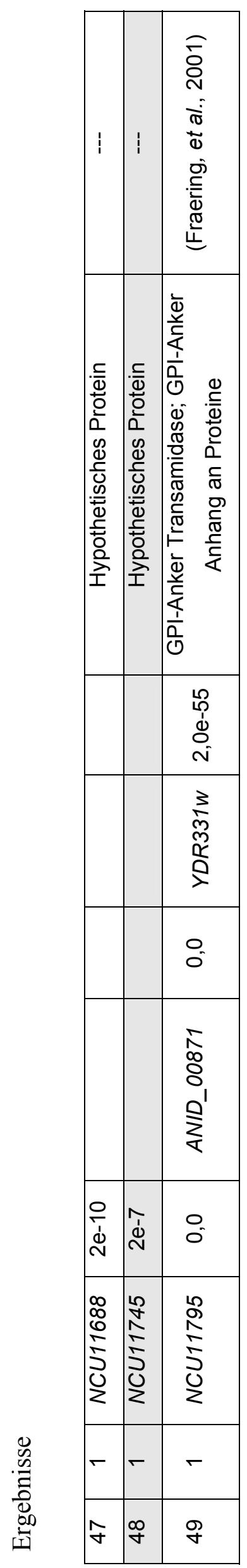


In den Interaktionsanalysen wurde unter anderem Untereinheit 5 des COP9-Signalosoms (CSN 5; Protein 6) gefunden. Für dieses ist, ähnlich zu RanBPM, eine Interaktion mit der GAL4-Bindedomäne beschrieben (Nordgard, et al., 2001; Tucker, et al., 2009), was zu einem falsch-positiven Ergebnis führen kann.

Alle erhaltenen Proteine wurden zusätzlich mit dem Leervektor pGBKT7 auf Interaktion mit der GAL4-Bindedomäne allein getestet. In Abbildung 20 sind beispielhaft Interaktionstests der Proteine 1, 6, 15, 23, 35 und 48 (s. Tab. 5) mit pGBKT7 dargestellt.
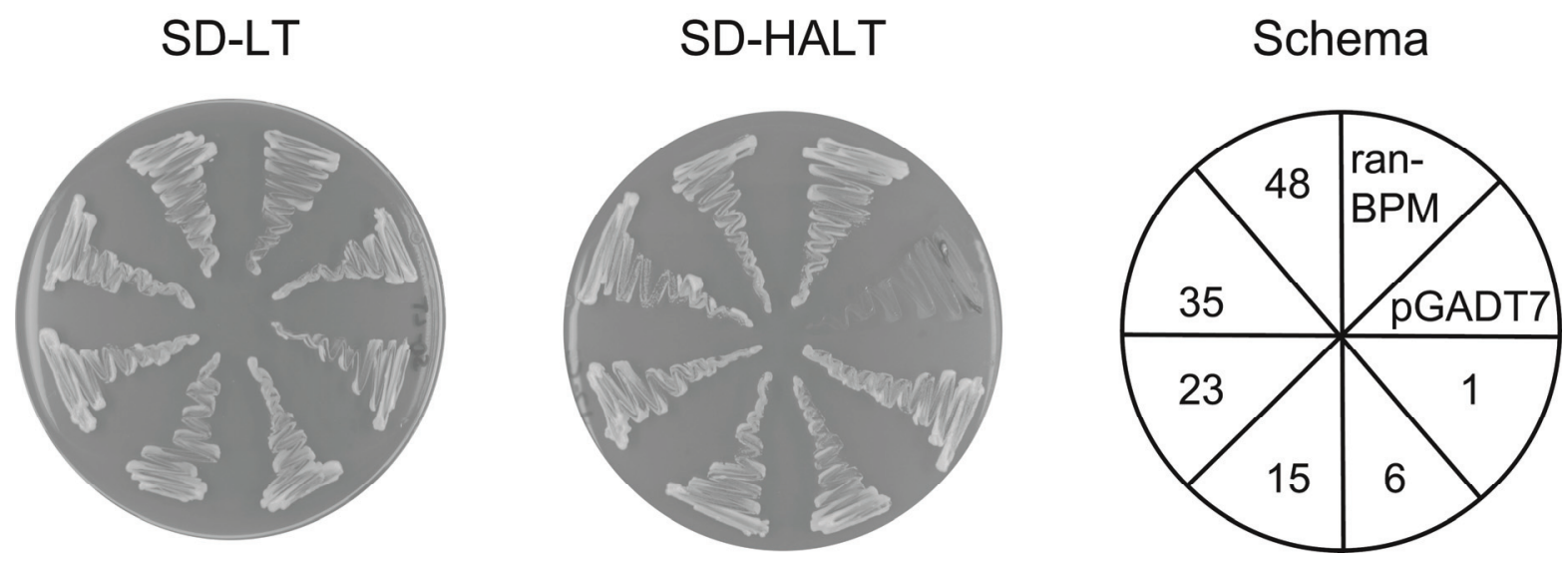

Abbildung 20: Darstellung der Interaktionskontrolle verschiedener Proteine mit pGBKT7. Die Proteine 1, 6, 15, 23, 35 und 48 zeigen deutliches Wachstum auf Selektionsmedium in Gegenwart des Leerplasmids. Als Positivkontrolle wurde das Protein RanBPM verwendet, als Negativkontrolle diente das Leerplasmid pGADT7. Inkubation erfolgte auf SD-LT bzw. SD-HALT Medium für 48 h.

Auf SD-HALT Medium ist nach $48 \mathrm{~h}$ ein deutliches Wachstum zu erkennen, was auf eine Interaktion dieser Proteine mit der GAL4-Bindedomäne hinweist. Das Protein RanBPM interagiert nachweislich mit der Bindedomäne und wird hier als Positivkontrolle verwendet (Tucker, et al., 2009). Das Leerplasmid pGADT7 dient als Negativkontrolle.

Die Interaktionspartner 1, 6, 15, 23, 35 und 48 (Tab. 5) konnten so als spezifische Interaktionspartner ausgeschlossen werden.

Bei den Proteinen 32 und 42 zeigte sich bei der Interaktion mit SMTA-2 dagegen ein teilweise eingeschränktes Wachstum (Daten nicht gezeigt). Da dies nur bei einem Teil der Proben und nicht reproduzierbar auftrat, wurden diese beiden Proben weiterhin als putative Interaktionspartner von SMTA-2 behandelt. 


\subsection{Analyse der Pheromone und Rezeptoren aus P. chrysogenum}

Um die Funktionalität der Pheromon- und Rezeptor-Proteine aus dem asexuellen Ascomyceten P. chrysogenum zu untersuchen, wurde als heterologes System die Bäckerhefe S. cerevisiae verwendet. Die Gene für das Pheromonvorläuferpeptid ppg-1 und den entsprechenden Rezeptor pre-2 wurden dazu in das Plasmid pPGK eingebracht (Tab. 2). In diesem Vektorsystem stehen die Gene unter der transkriptionellen Kontrolle des konstitutiven $p g k$-Promotors aus S. cerevisiae (Kang, et al., 1990). Als Kontrolle wurden die S. macrospora Gene pre-2 und ppg- 1 verwendet, für die eine Funktionalität in diesem System bereits gezeigt werden konnte (Mayrhofer und Pöggeler, 2005). Die Plasmide pPGK-PcPRE2 und pPGK-SmPRE2 wurden dabei in den Stamm YDB103, die Plasmide pPGK-PcPPG1 und pPGK-SmPPG1 in den Stamm YLR452c eingebracht (3.1.1). Beide Stämme weisen dabei eine Deletion des Gens sst-2 auf. Der Stamm YDB103 weist dabei zusätzlich eine Deletion des Hefe-Pheromon-Rezeptors STE2 auf.

Nach Pheromon-Induktion kommt es in haploiden Zellen von Saccharomyces cerevisiae zu verschiedenen Antwortmechanismen. Einer davon ist ein Zellzyklusarrest in der $\mathrm{G}_{1}$-Phase des Zellzyklus. Falls nach einer solchen Induktion jedoch keine Paarung mit einer haploiden Zelle unterschiedlichen Kreuzungstyps stattfindet, wird dieser Zyklus-Arrest aufgehoben und es kommt zu einer Desensibilisierung gegenüber dem Pheromon-Signal. Ein entscheidender Faktor dieser Desensibilisierung ist das Protein SST-2 aus der „Regulator for G-Protein Signaling“ (RGS) Familie (Dohlman, et al., 1996; Dohlman und Thorner, 2001; Wang und Dohlman, 2004)

Als Positivkontrolle diente der Stamm BY4741. Die Stämme YDB103+pPGK-PcPRE2 und YDB103+pPGK-SmPRE2 wurden dann mit künstlichem Pheromon oder Überstand von YLR452c+PcPPG1 (P. chrysogenum PPG-1) und YLR452c+SmPPG1 (S. macrospora PPG-1), wie unter 3.2.9 beschrieben, behandelt (Abb. 21). 
A

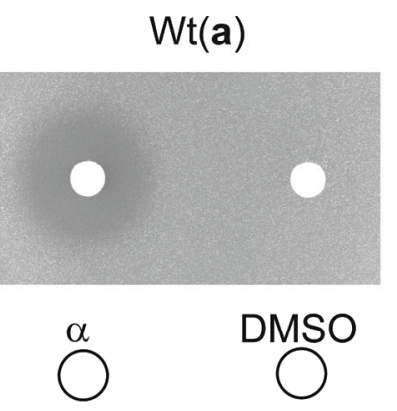

PCPRE2

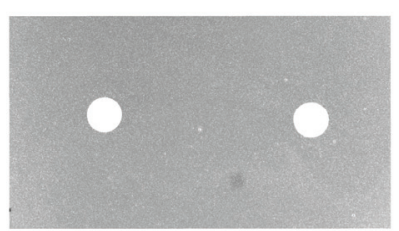

$\bigodot^{\alpha} \bigcirc^{\text {DMSO }}$
SmPRE2

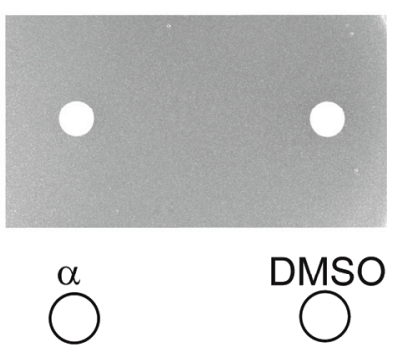

B

PcPRE2

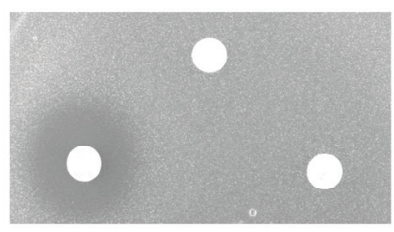

$\overbrace{}^{\text {DMSO }}$

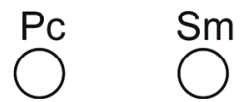

SmPRE2
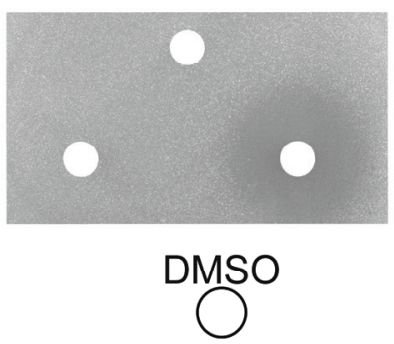

$\bigcirc^{\mathrm{Pc}} \bigodot^{\mathrm{Sm}}$

Abbildung 21: Pheromon induzierter Wachstumsarrest in S. cerevisiae Stämmen, welche heterolog die Pheromon-Rezeptoren aus $P$. chrysogenum oder $S$. macrospora exprimierten. (A) Kontrolle der Stämme YDB103+pPGK-PcPRE2 (PcPRE2) und YDB103+pPGK-SmPRE2 (SmPRE2) mittels künstlichem $\alpha$-Faktor Pheromon ( $\alpha$ ) verglichen mit dem Stamm BY4741 (Wt a). (B) Zellzyklusarrest der S. cerevisiae Stämme behandelt entweder mit künstlichem $S$. macrospora $(\mathrm{Sm})$ oder $P$. chrysogenum (Pc) Pheromon.

Alle Pheromone wurden in einer Konzentration von 3 nmol, gelöst in DMSO, eingesetzt. Als Kontrolle diente DMSO ohne Pheromonzusatz.

Nach Behandlung mit dem artifiziellen $P$. chrysogenum Pheromon zeigte sich deutlich die Entwicklung eines Hemmhofes bei dem Hefe-Stamm mit dem heterolog exprimierten P. chrysogenum Pheromon-Rezeptor. Auch bei den Stämmen mit dem S. macrospora Rezeptor zeigte sich nach Behandlung mit künstlichem S. macrospora Pheromon ein deutlicher Hemmhof.

Neben den künstlichen Pheromonen wurden außerdem die beiden Hefestämme YLR452c+pPGK-PcPPG1 und YLR452c+pPGK-SmPPG1 verwendet. Diese exprimieren heterolog die entsprechenden Pheromone unter Kontrolle des pgk-Promotors. Die Zellen wurden ü.N. in Selektionsmedium angezogen und der zellfreie Überstand wie zuvor beschrieben auf die Zellen mit den heterolog exprimierten Rezeptoren gegeben. Dabei konnte 
Ergebnisse

in keinem Fall, weder für P. chrysogenum noch für S. macrospora ein Wachstumsarrest beobachtet werden (Daten nicht gezeigt).

Nach Pheromon-Induktion zeigt $S$. cerevisiae nicht nur einen Zellzyklusarrest, sondern auch morphologische Änderungen der Zellform. Induzierte Zellen zeigen polarisiertes Wachstum in Richtung des potentiellen Paarungspartners, was zu einer speziellen, birnenförmigen Zellform führt, die auch als „Shmoo“ bezeichnet wird. Zur Verifikation der Ergebnisse der Hemmhof-Tests wurden die Hefe-Stämme mit den heterolog exprimierten Rezeptoren wie in 3.2.12 beschrieben angezogen und mit artifiziellem Pheromon behandelt (Abb. 22).

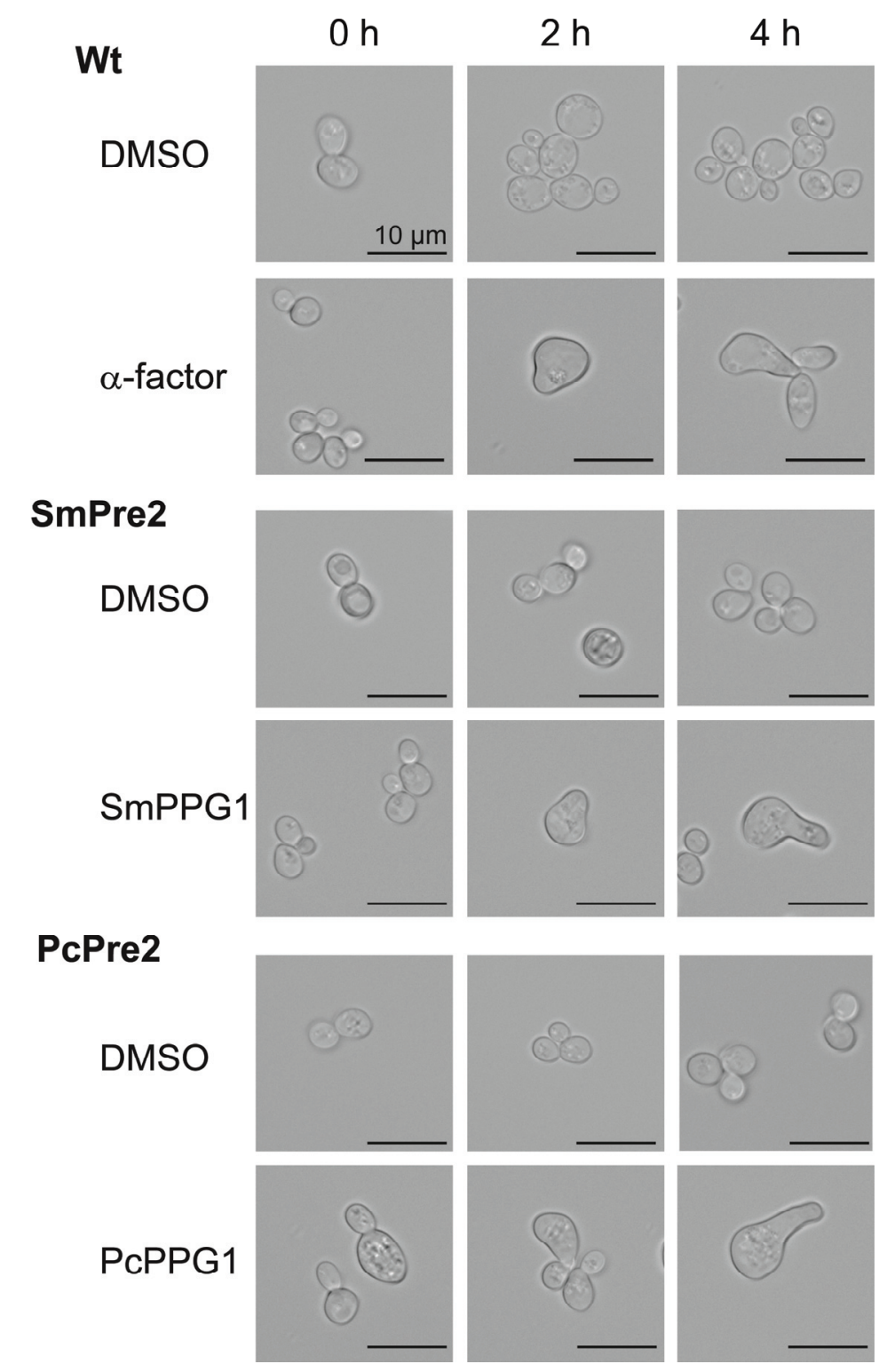

Abbildung 22: „Shmoo“-Bildung von $S$. cerevisiae als Antwort auf die artifiziellen Pheromone $\alpha$-Faktor, PcPPG1 und SmPPG1. Die künstlichen Pheromone wurden in einer Konzentration von $5 \mu M$ eingesetzt und die Reaktion der Zellen nach 0,2 und 4 Stunden (h) gezeigt. Als Kontrolle wurde DMSO eingesetzt und ein MATa Wildtyp-Stamm mit artifiziellem $\alpha$-Faktor behandelt. 
Ergebnisse

Bei Behandlung der Stämme mit den heterolog exprimierten Pheromon-Rezeptoren war nach Behandlung mit dem entsprechenden Pheromon deutlich eine Änderung der Zellmorphologie zu einem „Shmoo“ zu beobachten. Diese Änderung zeigte sich nicht in den Kontrollen, welche mit DMSO behandelt waren. Als Positivkontrolle diente ein MATa Wildtyp-Stamm, welcher mit künstlichem $\alpha$-Faktor behandelt wurde. 


\section{Diskussion}

\subsection{Ein HMG-Domänen Protein und ein PPF-Domänen Protein sind die Hauptregulatoren der sexuellen Entwicklung in S. macrospora}

Die sexuelle Entwicklung in $S$. macrospora und die damit verbundene Ausbildung dreidimensionaler Fruchtkörper ist ein apandrischer Prozess und benötigt nicht die Paarung zweier kompatibler Kreuzungspartner. Ähnlich zu anderen homothallischen Ascomyceten besitzt auch $S$. macrospora einen Kreuzungstyp-Locus mit Homologen zu den Sordariomyceten MAT Genen MAT1-1-1, MAT1-1-2, MAT1-1-3 und MAT1-2-1 (Kück, et al., 2009; Pöggeler, 2007) (Abb. 1). Andere homothallische Ascomyceten, darunter Neurospora africana, $N$. dodgei, N. galapagosensis und N. lineolata besitzen ausschließlich Homologe zu MAT1-1 Genen, aber keinerlei Homologe zu MAT1-2 (Glass N. L., et al., 1990a; Glass N. L., et al., 1988). Aufgrund dieser Erkenntnisse wurde von Debuchy und Turgeon (2006) postuliert, dass die minimale Kreuzungstyp-Struktur in homothallischen Sordariomyceten aus den Genen MAT1-1-1, MAT1-1-2 und einem HMG-Domänen kodierenden Gen, entweder MAT1-1-3 oder MAT1-2-1, besteht. Diese Struktur kann dabei für andere Klassen der Ascomyceten nicht angenommen werden. So trägt der homothallische Eurotiomycet Aspergillus nidulans zwei ungekoppelte Homologe zu MAT1-1-1 und MAT1-2-1, welche beide in die sexuelle Entwicklung involviert und für diese ausreichend sind (Paoletti, et al., 2005; Pyrzak, et al., 2008).

In S. macrospora konnte bereits gezeigt werden, dass das Gen Smta-1 (MAT1-2-1) in die sexuelle Entwicklung involviert ist. SMTa-1 ist an der direkten oder indirekten Regulation verschiedenster Gene beteiligt und Deletionsmutanten des Gens sind steril (Pöggeler, et al., 2006b). Dies zeigt Ähnlichkeiten mit anderen, hetero- wie auch homothallischen Ascomyceten, bei welchen das Gen MAT1-2-1 für die sexuelle Entwicklung essentiell ist (Chang und Staben, 1994; Lee J., et al., 2003; Paoletti, et al., 2007; Pyrzak, et al., 2008).

In Interaktionsstudien konnte nachgewiesen werden, dass das Protein SMTa-1 (MAT1-2-1) mit SMTA-1 (MAT1-1-1) in S. macrospora interagiert (Jacobsen, et al., 2002). Trotzdem zeigt eine $\Delta$ SmtA-1 Deletionsmutante keinerlei sichtbaren Phänotyp (Abb. 8). Damit steht S. macrospora im Gegensatz $\mathrm{zu}$ allen anderen, bisher untersuchten Ascomyceten wo MAT1-1-1 den Hauptregulator der sexuellen Entwicklung in MAT1-1 Stämmen darstellt (Bobrowicz, et al., 2002; Debuchy, et al., 1993; Ferreira, et al., 1996; Glass N. L., et al., 
1990a; Lee J., et al., 2003; Saupe, et al., 1996). Bisher stellt S. macrospora damit den einzigen untersuchten Ascomyceten dar, welcher kein funktionelles MAT1-1-1 Gen für die sexuelle Reproduktion benötigt. Stattdessen benötigt $S$. macrospora ein funktionelles HMGDomänen Protein für die sexuelle Entwicklung (MAT1-2-1). Damit zeigen sich Ähnlichkeiten zu der evolutionär älteren Gruppe der Zygomyceten. Diese besitzen Kreuzungstyp-Loci, welche ausschließlich HMG-Domänen Proteine enthalten (Idnurm, et al., 2008) (Abb. 1). Es wird daher angenommen, dass der ursprüngliche Zustand des Kreuzungstyp-Locus in einem putativen gemeinsamen Vorfahren dem der heterothallischen Zygomyceten mit einem HMGDomänen kodierenden Gen entspricht. Die höher entwickelten Ascomyceten und Basidiomyceten erlangten dagegen im Laufe ihrer Entwicklung weitere KreuzungstypProteine, wie $\alpha$-Domänen und Homeodomänen Proteine (Casselton L.A., 2008; Dyer, 2008; Idnurm, et al., 2008).

Ein Gen, welches ausschließlich in der Gruppe der Sordariomyceten innerhalb der Ascomyceten gefunden wurde, ist das Gen MAT1-1-2. Während Deletionen des Gens MAT1-1-2 in N. crassa lediglich einen leichten Phänotyp zeigen und fast als redundant bezeichnet werden können (Ferreira, et al., 1998), zeigen Deletionsmutanten in P. anserina einen Arrest in der Fruchtkörperentwicklung und Sterilität (Debuchy, et al., 2010; Turgeon und Debuchy, 2007).

In S. macrospora ist SmtA-2 (MAT1-1-2) essentiell für die sexuelle Entwicklung (Abb. 8). Deletionsmutanten zeigen einen Arrest in der Fruchtkörperentwicklung, ähnlich zu P. anserina. Außerdem zeigen sich Ähnlichkeiten zu $\Delta$ MAT1 Mutanten aus Gibberella zeae. Deletionen der drei MAT1-1 spezifischen Gene führte zur Selbststerilität des homothallischen G. zeae (Lee J., et al., 2003). Da aber alle MAT1-1 Gene, inklusive MAT1-1-2, deletiert wurden, kann nicht genau bestimmt werden, welches oder welche deletierten Gene zur Selbststerilität führen. Die G. zeae Mutanten $\triangle$ MAT1-1 (Deletion aller MAT1-1 spezifischer Kreuzungstyp-Gene) und $\triangle$ MAT1-2 (Deletion von MAT1-2-1) waren in der Lage mit einem selbst-fertilen Wt-Stamm zu kreuzen und beide Deletionsstämme kreuzten miteinander wie heterothallische Stämme (Lee J., et al., 2003).

Die $S$. macrospora Deletionsmutanten $\Delta$ Smta-1, $\Delta$-SmtA-1, $\Delta$ SmtA-2 oder $\Delta$ SmtA-3 mit einem selbst-fertilen Wt-Stamm gekreuzt wurden, entwickelten sich reife Perithezien an der Berührungsfläche beider Myzelien. In jeder dieser Kreuzungen segregierten die verschiedenen Marker (Sporenfarbe in Wt, Hygromycin-Resistenz in Mutante) in einem 1:1 
Verhältnis (Tab. 4). Kreuzungen der sterilen $\Delta$ Smta-1 oder $\Delta$ SmtA-2 Stämme mit der fertilen Mutanten $\triangle$ SmtA-1 führte ebenfalls zu reifen Perithezien und keimfähigen Ascosporen. Kreuzungen von $\Delta$ Smta-1 und $\Delta$ SmtA-2 dagegen zeigten weder reife Ascosporen noch Perithezien, die Stämme blieben steril. Es ist daher möglich, dass beide Proteine SMTa-1 und SMTA-2 eine einzelne Funktion oder einen einzelnen Regulationsweg beeinflussen (Hartman, et al., 2001). Dabei ist sowohl denkbar, dass beide Proteine in Hyphenanastomose involviert sind und die Deletion beider Gene die Ausformung eines Heterokaryons verhindert, als auch, dass beide Gene in einem Zellkern vorliegen und exprimiert sein müssen um funktionell $\mathrm{zu}$ sein. Für das HMG-Domänen Gen SMR2 (MAT1-1-3) aus P. anserina konnte eine solche Zellkern-spezifische Expression bereits nachgewiesen werden (Turgeon und Debuchy, 2007). Ebenfalls für $P$. anserina wurde die Theorie aufgestellt, dass es in den Zellen, welche an der Ausbildung der sexuellen Strukturen beteiligt sind, während der sexuellen Entwicklung und Migration der Zellkerne zu einem Wachstumsarrest kommt (Turgeon und Debuchy, 2007).

Ähnlich zu dieser Theorie kann davon ausgegangen werden, dass das S. macrospora Kreuzungstyp-Protein SMTa-1, ähnlich wie FPR1 aus P. anserina, den Hauptregulator der internukleären Erkennung und Migration darstellt. Und ähnlich wie FPR1 könnte auch SMTa-1 einen Wachstumsarrest an dieser Stelle es Entwicklungszyklus vermitteln. Dieser Arrest wiederum könnte von SMTA-2 aufgehoben werden, welches allerdings im selben Nukleus wie SMTa-1 vorliegen müsste (Abb. 23).

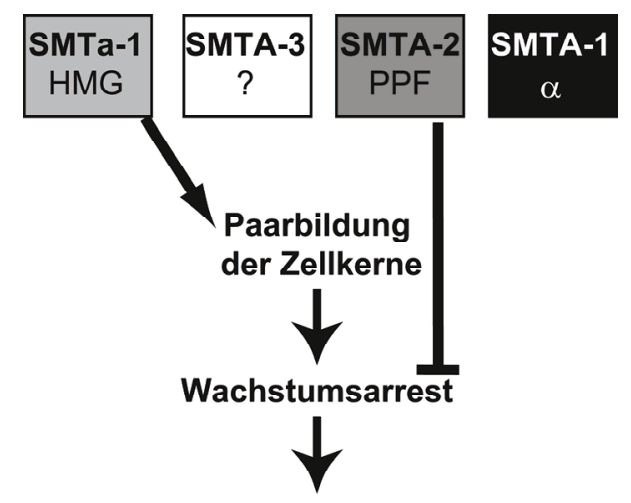

Abbildung 23: Mögliches Modell der sexuellen Regulation in $S$. macrospora durch die Proteine SMTa-1 und SMTA-2. Das HMG-Domänen Protein SMTa-1 ist essentiell für die Paarung der Zellkerne vor der Bildung der ascogenen Hyphe. Der dadurch ausgelöste Wachstumsarrest wird durch das Protein SMTA-2 im Zuge der sexuellen Entwicklung wieder aufgelöst.

Ausbildung der ascogenen Hyphe

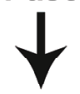

Karyogamie und Meiose

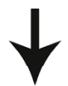

Reifes Perithezium mit Ascosporen 
In der $\Delta$ SmtA-3 Deletionsmutante konnte kein Phänotyp festgestellt werden (Abb. 8). Auch in der $\Delta$ SmtA-2/3 Doppelmutante konnte, durch die Komplementation durch SmtA-2, nachgewiesen werden, dass alle Unterschiede im Vergleich zum Wildtyp durch die Deletion von SmtA-2 herbeigeführt wurden (Abb. 9). Das Gen SmtA-3 scheint daher für ein nicht-funktionales Protein zu kodieren, welches für die sexuelle Entwicklung nicht essentiell ist. Eine regulatorische Funktion, möglicherweise als ein Art von cis-Element, bei der Koexpression mit Smta-1 (Pöggeler und Kück, 2000), kann nicht ausgeschlossen werden.

\subsection{SMTA-2 besitzt mindestens eine funktionelle Domäne im C-Terminus, unabhängig von der PPF-Domäne}

Das Gen MAT1-1-2 ist konserviert in den Kreuzungstyp-Loci aller bisher untersuchten Sordariomyceten, konnte außerhalb dieses Taxons jedoch nicht identifiziert werden. In allen bisher untersuchten Sordariomyceten konnte innerhalb des MAT1-1-2 Proteins eine konservierte Sequenz von drei Aminosäuren, Prolin, Prolin und Phenylalanin, gefunden werden, welche als PPF-Domäne bezeichnet wird (Debuchy, et al., 2010). Ob es sich bei diesem Sequenzmotiv jedoch um eine funktionelle Domäne handelt, ist nicht bekannt.

Um mögliche funktionelle Domänen innerhalb des MAT1-1-2 Proteins aus S. macrospora zu identifizieren, wurde eine Komplementationsanalyse durchgeführt. Bei dieser wurden verschiedene Konstrukte des MAT1-1-2 Gens in die sterile Deletionsmutante $\triangle$ SmtA-2 eingebracht um zu testen inwieweit diese Konstrukte in der Lage, sind den sterilen Phänotyp zu komplementieren.

Dabei wurden zum einen die MAT1-1-2 Gene aus den nahe verwandten N. crassa (mat A-2) und $P$. anserina $(S M R l)$ verwendet. Diese besitzen, außerhalb der konservierten PPF-Domäne, eine Aminosäureähnlichkeit von 72,1\% (N. crassa) und 22,9\% (P. anserina). In keiner der gefundenen Transformanten $\triangle$ SmtA-2::mat A-2 oder $\triangle$ SmtA-2::SMR1 konnte eine Komplementation des sterilen Phänotyps beobachtet werden (Abb. 11). Da die entsprechenden Gene unter der Kontrolle ihrer nativen Promotoren und Terminatoren aus $N$. crassa bzw. P. anserina standen, lässt sich an dieser Stelle nicht mit Sicherheit sagen, ob die Proteine in S. macrospora nicht funktionell oder lediglich nicht exprimiert sind.

Neben dem kompletten SmtA-2 Gen ist lediglich das Konstrukt A2-S-N in der Lage, den sterilen Phänotyp zu komplemementieren (Abb. 11). Dieses Konstrukt kodiert für den 
C-Terminus des SMTA-2 Proteins ausgehend vom Phenylalanin der PPF-Domäne. Bei allen anderen Konstrukte, welche den N-Terminus bis zur Aminosäure (AS) 188, 199, 205 und 307 enthielten, konnte keine Komplementation beobachtet werden. Die Konstrukte 188 und 199 enthalten dabei Teile der PPF-Domäne, die Konstrukte 205 und 307 enthalten diese komplett. Aus diesen Daten lässt sich schließen, dass die konservierte PPF-Domäne entweder keine oder zumindest keine essentielle Rolle bei der Funktionalität von SMTA-2 spielt. Vielmehr scheint eine bisher nicht identifizierte Sequenz im C-Terminus die essentielle Domäne des Proteins darzustellen. Dies steht im Einklang mit den Ergebnissen der heterologen Komplementation mit mat $A-2$ und SMR1. Die kodierten Proteine zeigen zu SMTA-2 im C-Terminus eine Sequenzübereinstimmung von 63\% (N. crassa) bzw. 18\% (P. anserina). Gerade dieser Teil der Proteine weist also eine geringere Ähnlichkeit auf als der N-Terminale Teil und die PPF-Domäne.

Weitere Studien werden nötig sein, um die exakte Lage der funktionellen Aminosäuren in SMTA-2 zu identifizieren. Insgesamt lässt sich jedoch sagen, dass, trotz der funktionellen Ähnlichkeiten, die MAT1-1-2 Kreuzungstyp-Proteine zwischen verschiedenen Vertretern der Sordariomyceten wenig konserviert scheinen.

\subsection{Die Proteine MAT1-1-2 und MAT1-1-3 lokalisieren im Cytosol}

Mittels der Fusion der Kreuzungstyp-Proteine MAT1-1-2 und MAT1-1-3 mit den Fluoreszenzproteinen dsRED und GFP sollte die Lokalisation der Kreuzungstyp-Proteine innerhalb der Zelle untersucht werden. Die Fluoreszenzplasmide pRHN-A2, pRSnG-A2 (MAT1-1-2) und pRHN-A3 (MAT1-1-3) konnten erfolgreich erstellt und transformiert werden (Abb. 18).

SMTA-3 lokalisiert cytosolisch. Eine Fluoreszenz in Organellen oder der Vakuole ist nicht nachweisbar, auch nicht während der sexuellen Entwicklung in den Zellen der sich entwickelten Perithezien. Da in dieser Studie keine biologische Funktion von SMTA-3 nachgewiesen werden konnte, kann an dieser Stelle aus der Lokalisation des MAT1-1-3 Proteins aus $S$. macrospora keine weiteren Schlüsse gezogen werden. SMTA-3 verfügt weder über bekannte funktionelle Domänen, noch ein bekanntes Lokalisierungssignal. Ob die hier gefundene Lokalisation für homologe Proteine aus anderen Pilzen anwendbar ist, ist aufgrund dieser fehlenden Domänen fraglich. 
Für das Kreuzungstyp-Protein MAT1-1-2 (SMTA-2) konnten ebenfalls Fluoreszenzplasmide hergestellt und in S. macrospora transformiert werden. Beide Fusionsproteine, A2_dsRed und A2_GFP, lokalisieren im Cytosol (Abb. 18). Diese Ergebnisse stehen im Einklang mit der vorausgesagten Lokalisation des homologen Proteins SMR1 aus P. anserina, welches laut Debuchy und Turgeon (2006) ebenfalls im Cytosol lokalisiert sein soll. Eine in silico Voraussage mittels des Programms WolfPSORT (Horton, et al., 2007) (http://wolfpsort.org) erbrachte ebenfalls das Cytoplasma als wahrscheinlichste Lokalisation des SMTA-2 Proteins in S. macrospora. Eine zusätzliche Lokalisation im Zellkern wird vorausgesagt, lässt sich mit den hier vorgestellten Daten jedoch nicht bestätigen. Dabei ist jedoch zu beachten, dass weder SMTA-2_GFP noch SMTA-2_dsRed in vivo voll funktionell sind. Die Funktionalität der Fusionsproteine wurde dabei im Hintergrund der $\Delta$ SmtA-2 Mutante untersucht. Bei voller Funktionalität hätten die Fusionsproteine in der Lage sein müssen, den sterilen Phänotyp der Deletionsmutante zu komplementieren, was für beide Proteine nicht der Fall war (s. Anhang A2). Im Gegensatz zu $\Delta$ SmtA-2 allein, sind die Fluoreszenzstämme in der Lage, größere, pigmentierte Perithezien zu bilden, was in der Deletionsmutante niemals beobachtet wird. Diese Perithezien erreichen jedoch nicht die Größe im Wt und es konnten weder Asci noch Ascosporen gefunden werden. Die Komplementation ist also partiell, aber nicht vollständig.

Beide Fluoreszenzproteine, dsRed und GFP, sind C-Terminal an das SMTA-2 Protein fusioniert. Wie in den Komplementationsanalysen gezeigt (s. 5.2), scheint dieser Bereich des Proteins für die Funktionalität essentiell zu sein. Die Fusion eines Fluoreszenzproteins an diesen essentiellen Teil des MAT1-1-2 Proteins scheint die Funktionalität weitestgehend einzuschränken. Die hier gezeigten Daten über die intrazelluläre Lokalisation des MAT1-1-2 Proteins in S. macrospora müssen also als vorläufig betrachtet werden. Solange kein voll funktionales SMTA-2 innerhalb der Zelle lokalisiert werden kann, eventuell über eine NTerminale Fusion mit einem Fluoreszenzprotein, kann über die Lokalisation keine allgemein gültige Aussage getroffen werden.

\subsection{Die Proteine SMTA-1 und SMTA-2 sind an der Regulation der}

\section{Expression von Pheromon-Genen beteiligt}

In der Gruppe der Ascomyceten liegen zwei Pheromon- und entsprechende Rezeptor-Gene in einem Genom vor. In $S$. cerevisiae und $P$. anserina konnte gezeigt werden, dass diese Gene 
direkt durch die Kreuzungstyp-Proteine reguliert werden (Coppin, et al., 2005; Herskowitz, 1989). In anderen heterothallischen Arten wie $N$. crassa oder $P$. anserina werden die Pheromon-Gene in einem Kreuzungstyp-spezifischen Muster exprimiert und sind essentiell für männliche Fertilität der Stämme (Bobrowicz, et al., 2002; Coppin, et al., 2005; Kim H. und Borkovich, 2006).

In S. macrospora und anderen homothallischen Ascomyceten werden sowohl die Pheromonvorläufer-Gene als auch die Rezeptor-Gene konstitutiv exprimiert (Kim H. K., et al., 2008; Paoletti, et al., 2007; Pöggeler, 2000; Pöggeler und Kück, 2001) und in S. macrospora sind sie an der sexuellen Entwicklung beteiligt (Mayrhofer, et al., 2006).

In einer früheren Studie konnte bereits gezeigt werden, dass das Kreuzungstyp-Protein SMTa-1 an der Regulation der Expression des Pheromonvorläufer-Gens ppg-2 beteiligt ist (Pöggeler, et al., 2006b). Die Ergebnisse dieser Studie konnten hier noch einmal bestätigt werden (Abb. 12). Die mRNA Menge des Pheromon-Gens ppg-2 ist in der $\Delta$ Smta-1 Deletionsmutante um das bis zu 500 fache erniedrigt verglichen zum Wildtyp.

In der Deletionsmutante $\Delta$ SmtA-1 ist die Expression beider Pheromon-Gene ppg-1 und ppg-2 um das 60- bzw. 16fache herunterreguliert (Abb. 12, 24). Während also SMTa-1 ausschließlich die Expression eines Pheromon-Gens (ppg-2) reguliert, ist das KreuzungstypProtein SMTA-1 direkt oder indirekt an der Regulation beider Gene (ppg-1 und ppg-2) beteiligt. In früheren Hefe-Zwei-Hybrid Analysen wurde gezeigt, dass SMTa-1 und SMTA-1 in der Lage sind miteinander zu interagieren (Jacobsen, et al., 2002). Die hier vorgestellten Daten lassen den Schluss zu, dass das Lipopeptid-Gen ppg-2 direkt oder indirekt von dem Kreuzungstyp-Protein SMTa-1 reguliert wird, während in die Regulation der Genexpression des Peptidpheromons ppg-1 ein Heterodimer aus SMTA-1 und SMTA-1 involviert ist.

Außerdem konnte in früheren Studien gezeigt werden, dass Einzelmutanten der Pheromonoder Rezeptor-Gene keinen Phänotyp bezüglich der vegetativen oder sexuellen Entwicklung zeigten (Mayrhofer, et al., 2006). Doppeldeletionen der Pheromon-Rezeptor-Paare

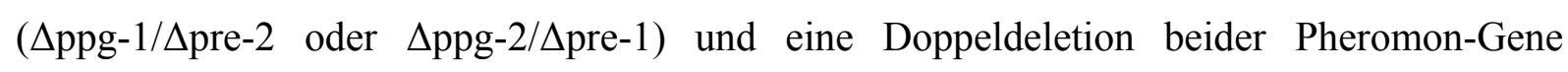
( $\Delta$ ppg-1/Appg-2) zeigten dagegen eine drastisch reduzierte Anzahl an Perithezien und Ascosporen verglichen zum Wildtyp, alle Deletionen waren jedoch grundsätzlich fertil. Die einzige sterile Deletionsmutante stellt die Doppeldeletion beider Pheromon-Rezeptoren

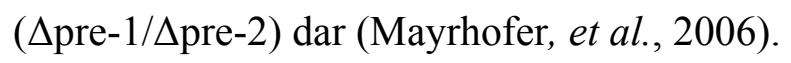


Bei der Herunterregulierung beider Pheromon-Gene in der Kreuzungstyp-Mutante $\Delta$ SmtA-1 zeigte sich dagegen kein Unterschied zum Wildtyp in der Anzahl der Perithezien und Ascosporen (Abb. 8). Eine mögliche Erklärung hierfür wäre, dass die Expressionsstärke eines oder beider Pheromon-Gene immer noch hoch genug ist, um eine Wildtyp-ähnliche sexuelle Entwicklung zu ermöglichen. Dies ist sehr wahrscheinlich, da gerade das Pheromon-Gen ppg-2 in $\Delta$ SmtA-1 nur um das 16 fache herunterreguliert ist, im Gegensatz zu ppg-1 (60fach) oder ppg-2 in $\Delta$ Smta-1 (500fach). Außerdem sind, wie bereits ausgeführt, die Pheromone für die sexuelle Entwicklung in S. macrospora wichtig, aber nicht essentiell (Mayrhofer, et al., 2006). Essentiell dagegen sind die Pheromon-Rezeptoren, welche in der Mutante $\Delta$ SmtA-1 jedoch nicht differentiell reguliert sind im Vergleich zum Wildtyp (Abb. 12).

In der sterilen Mutante $\Delta$ SmtA-2 ist die Expression des Lipopeptid-Pheromon ppg-2 um das 20 fache heraufreguliert (Abb. 12, 24). Ein ähnlicher Phänotyp konnte in einer Reihe sogenannter pro-Mutanten gefunden werden (Nowrousian, et al., 2005). Diese Mutanten wurden nach ihrem gemeinsamen Phänotyp benannt. Sie sind, ähnlich wie $\Delta$ SmtA-2, steril und die sexuelle Entwicklung blockiert im Stadium junger Protoperithezien. Dabei stellen die verschiedenen pro-Gene sehr unterschiedliche Klassen von Genen dar. So kodiert prol für einen Zinkfinger Transkriptionsfaktor (Masloff, et al., 2002; Masloff, et al., 1999), während das Protein PRO11 cytosolisch und membranständig lokalisiert ist und Ähnlichkeiten mit Striatin aus Säugetieren aufweist (Pöggeler und Kück, 2004). PRO40 schließlich ist assoziiert mit Woronin-Bodies in S. macrospora (Engh, et al., 2007b).

All diesen Mutanten, einschließlich $\triangle$ SmtA-2, ist gemein, dass sie steril sind und nicht in der Lage, reife Perithezien oder Ascosporen zu bilden. Die gesteigerte Expression des Pheromon-Gens ppg-2 scheint dabei allerdings keine Rolle zu spielen, da eine Überexpression des Gens in Wildtyp keinen Phänotyp zeigte (Daten nicht gezeigt). In dem homothallischen G. zeae konnte das Transkript des Pheromon-Gens GzPPG1 weder in $\triangle$ MAT1-1 noch in $\triangle$ MAT1-2 Stämmen nachgewiesen werden. Die Transkriptmenge des Gens GzPPG2 dagegen war in einer $\triangle$ MAT1-1 Mutante deutlich erhöht (Kim H. K., et al., 2008). Da hier jedoch alle MAT1-1 spezifischen Gene, MAT1-1-1, MAT1-1-2 und MAT1-1-3 deletiert waren, lässt sich nicht sagen, welche Gendeletion die Heraufregulierung von GzPPG2 verursachte (Lee J., et al., 2003). In dem homothallischen Ascomyceten A. nidulans zeigte eine Deletion des 
MAT1-1-1 Gens keinerlei Einfluss auf die Expression des Peptidpheromon-Gens ppgA oder der Pheromon-Rezeptoren (Paoletti, et al., 2007).

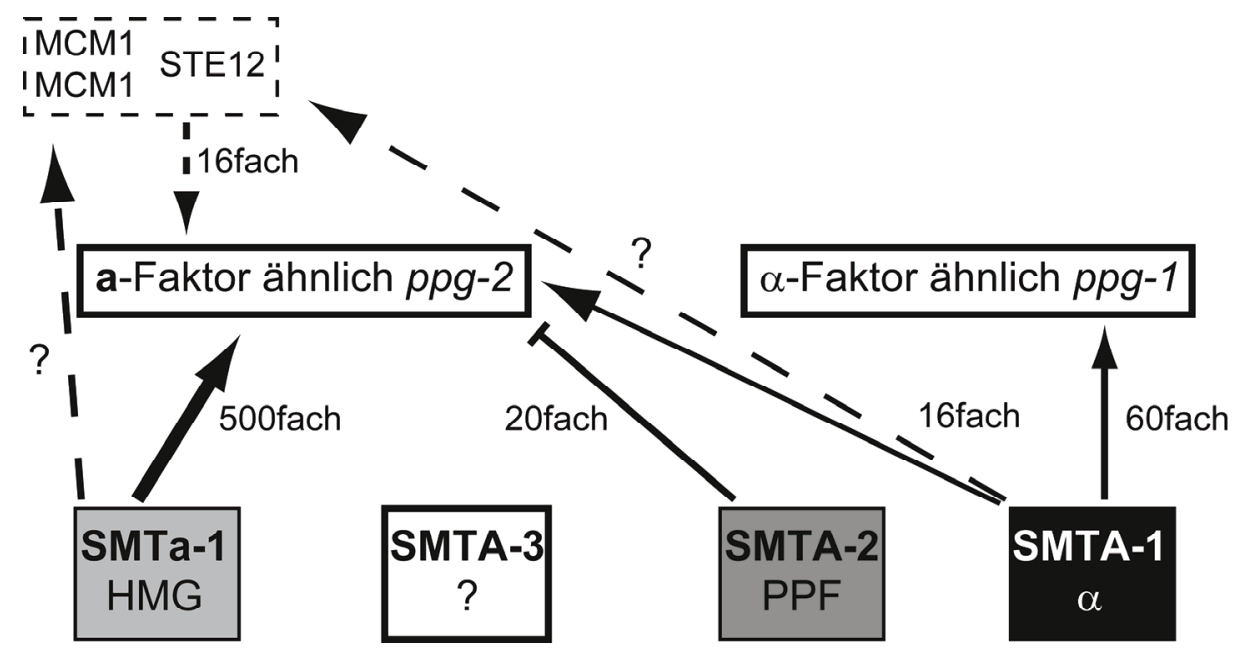

Abbildung 24: Modell der Regulation der Pheromon-Gene durch die Kreuzungstyp-Proteine in S. macrospora. Während SMTa-1 und SMTA-1 die Expression der Pheromon-Gene positiv regulieren, hemmt SMTA-2 die Expression von ppg-2. Bekannte Interaktionspartner, welche bei den Regulationen eine Rolle spielen könnten, sind mit gestrichelten Linien gekennzeichnet (nach Jacobsen, et al., 2002; Nolting und Pöggeler, 2006a; Nolting und Pöggeler, 2006b).

Die Expression der Pheromon-Rezeptor Gene pre-1 und pre-2 war dagegen weder in $\triangle$ SmtA-1 noch in $\triangle$ SmtA-2 im Vergleich zum Wildtyp verändert (Abb. 12). Dies ist ähnlich zu N. crassa wo die Kreuzungstyp-Proteine ebenfalls keinen Einfluss auf die Expression der Rezeptoren zeigen (Pöggeler und Kück, 2001).

Grundsätzlich lässt sich nach diesen Ergebnissen sagen, dass die Expression der PheromonGene in homothallischen Pilzen deutlich weniger stark reguliert $\mathrm{zu}$ sein scheint als die stringente Kreuzungstyp-spezifische Regulation in heterothallischen Pilzen.

\subsection{Die Kreuzungstyp-Proteine SMTA-1 und SMTA-2 regulieren die}

\section{Expression verschiedener Gene}

In dieser Studie wurde eine Microarray Analyse mit N. crassa Chips durchgeführt um die Rolle der MAT1-1 spezifischen Kreuzungstyp-Proteine SMTA-1 und SMTA-2 bei der Regulation anderer Gene als die der Pheromone und Rezeptoren zu untersuchen. In der Mutante $\Delta$ SmtA-1 waren 978 Gene und in der Mutante $\Delta$ SmtA-2 853 Gene im Vergleich zum Wildtyp um das wenigstens 2 fache herauf- oder herunterreguliert $(P<0,05)$ (Abb. 13). Ein 
Großteil dieser Gene war in beiden Mutanten auf die gleiche Weise reguliert. Nur 7,5\% $(\Delta \mathrm{SmtA}-1)$ bzw. $13 \%(\Delta \mathrm{SmtA}-2)$ der als differentiell reguliert gefundenen Gene waren heraufreguliert. In $S$. cerevisiae aktiviert das SMTA-1 Ortholog $\alpha 1 \mathrm{p}$ zusammen mit den Transkriptionsfaktoren STE12 und MCM1 (Bruhn und Sprague, 1994; Yuan, et al., 1993) die Expression fünf MATa spezifischer Gene (Galgoczy, et al., 2004). Das Kreuzungstyp-Protein SMTA-1 interagiert in S. macrospora ebenfalls mit den Transkriptionsfaktoren STE12 und MCM1 (Nolting und Pöggeler, 2006a; b), jedoch scheint eine weit größere Anzahl an Genen von SMTA-1 reguliert zu sein als von $\alpha 1 \mathrm{p}$ in $S$. cerevisiae. In dieser Studie wurden allerdings, im Gegensatz zu der in Hefe, direkte wie auch indirekte Regulationen nachgewiesen. Es ist daher wahrscheinlich, dass zumindest ein Teil der hier gefundenen Regulationen indirekt erfolgt.

Das Kreuzungstyp-Protein SMTA-2 erhält keine bekannten Domänen welche spezifisch für eine DNA-Bindung oder einen Transkriptionsfaktor sind. Es interagiert nachweislich nicht mit den Transkriptionsfaktoren SMTa-1 oder SMTA-1 oder den assoziierten Transkriptionsfaktoren STE12 oder MCM1 (Jacobsen, et al., 2002; Nolting und Pöggeler, 2006a; b). Trotzdem wurden in der Microarray Analyse eine große Anzahl von Genen als differentiell reguliert identifiziert. Bei einem Vergleich beider Mutanten konnten 519 Gene gefunden werden, welche in beiden Mutanten dereguliert sind. Dies lässt, trotz der sehr unterschiedlichen Phänotypen beider Mutanten vermuten, dass beide Proteine an den gleichen metabolischen oder regulatorischen Prozessen beteiligt sind, obwohl sie nicht direkt interagieren.

Zusätzlich durchgeführte real-Time-PCR Analysen waren in Übereinstimmung mit den Microarray Ergebnissen. Die Regulation der Gene sod-2 und ctr-3 durch die beiden Kreuzungstyp-Proteine SMTA-1 und SMTA-2 (Abb. 16) macht eine Beteiligung beider Proteine an der Kupferhomeostase wahrscheinlich. In P. anserina konnte in früheren Studien gezeigt werden, dass der Transkriptionsfaktor GRISEA, welcher vom Kupferspiegel innerhalb der Zelle abhängig ist, einen wichtigen Einfluss auf den Phänotyp und die Lebensspanne von P. anserina hat (Borghouts, et al., 1997). Eine Mutation des grisea Gens führt zu einer veränderten Morphologie, Defekten in der Perithezienbildung und einer verlängerten Lebensspanne (Borghouts und Osiewacz, 1998). Die Gene PaSod2 (NCU01213 in N. crassa), welches für eine mitochondriale Superoxiddismutase kodiert, und PaCtr3 (NCU00830 in N. crassa), eine hochaffine Kupferpermease, wurden als Zielgene der Regulation durch 
GRISEA identifiziert (Borghouts, et al., 2002a; Borghouts, et al., 2001). In S. macrospora sind die beiden homologen Gene sod-2 und ctr-3 in den Mutanten $\Delta$ SmtA-1 und $\Delta$ SmtA-2 signifikant herunterreguliert, obwohl das Homolog zu grisea (NCU04773 in N. crassa) selbst nicht beeinflusst wird. Außerdem konnten Homologe zu einer gering-affinen Kupferpermease (NCU03281), einem Metalothionein Gen (NCU05561) und einem Gen (NCU00829), welches ähnlich einem Kupfer-Transporter (,cupric reductase FRE2 facilitating copper uptake”) in S. cerevisiae ist (Georgatsou, et al., 1997), als herunterreguliert in beiden Mutanten identifiziert werden. Einen Einfluss auf die sexuelle Entwicklung scheint die Regulation der Kupferhomeostase jedoch nicht zu haben, da in beiden Mutanten, der fertilen $\Delta$ SmtA-1 und der sterilen $\triangle \mathrm{SmtA}-2$, die fraglichen Gene gleich reguliert sind. Außerdem konnte der sterile Phänotyp von $\Delta$ SmtA-2, im Gegensatz zu der P. anserina GRISEA Mutante (Marbach, et al., 1994), durch eine Zugabe von Kupfer zum Medium nicht komplementiert werden (Daten nicht gezeigt).

Da $\Delta$ SmtA-1 in der Lage ist, Perithezien und keimfähige Ascosporen zu bilden, kann die Sterilität von $\Delta$ SmtA-2 nicht durch die Deregulation der in beiden Mutanten gefundenen Gene verursacht werden. Von den 854 in $\Delta$ SmtA-2 deregulierten Genen, waren 225 Gene heraufund 86 Gene herunterreguliert, die in $\Delta$ SmtA-1 nicht als differentiell reguliert identifiziert werden konnten. Diese Gene scheinen also spezifisch für $S m t A-2$ zu sein und damit wahrscheinlich involviert in die Fruchtkörperentwicklung und damit die Fertilität in S. macrospora. Zwei dieser Gene sind dabei in die Kontrolle des Zellzyklus involviert. Das Gen, welches homolog zu NCU02683 aus N. crassa ist, kodiert für die Untereinheit 3 des „origin recognition complex“ (ORC). ORC3 ist hochkonserviert und essentiell in allen Eukaryoten (Duncker, et al., 2009). Der ORC bindet an die Startpunkte der DNA-Replikation und rekrutiert Präreplikative Komplex Proteine in der $\mathrm{G}_{1}$-Phase des Zellzyklus, welcher dann in der S-Phase die Replikation durchführt. Zusätzlich ist der ORC an der Heterochromatinbildung beteiligt (Bell und Dutta, 2002). In Drosophila melanogaster und verschiedenen Säugetieren konnte außerdem gezeigt werden, dass eine Deletion oder Deregulation des homologen Gens zu schweren Störungen der Zellproliferation führt (Huang, et al., 2005; Pinto, et al., 1999).

Ähnlich dazu wurde die mRNA Menge des Orthologs des S. cerevisiae Proteins CDC23 als signifikant reduziert in $\triangle \mathrm{SmtA}-2$ gefunden. $\mathrm{CDC} 23$ ist eine essentielle Untereinheit des „Anaphase Promoting Complex/Cyclosome“ (APC/C), einer Ubiquitin-Protein Ligase, 
welche für die Degradation von Anaphase-Inhibitoren während der mitotischen Metaphase/Anaphase benötigt wird (Pesin und Orr-Weaver, 2008). Beide Gene sind in der Mutante $\triangle$ SmtA-2 signifikant herunterreguliert (Abb. 17), was auf einen Einfluss von SMTA-2 auf den Zellzyklus hinweist. SMTA-2 könnte dabei als ein Aktivator der DNA Replikation und der Zellproliferation dienen, durch die Regulation der Genexpression von orc-3 und $c d c-23$. Andere Untereinheiten des ORC oder APC/C konnten allerdings in $\Delta$ SmtA-2 nicht als differentiell reguliert identifiziert werden.

Bei einem Vergleich mit früheren Microarray Analysen anderer, steriler S. macrospora Mutanten, konnten vier Gene identifiziert werden, welche in allen herunterreguliert waren (Tab. 6).

Tabelle 6: Gene, welche bei Microarray Analysen in verschiedenen sterilen Mutanten als differentiell reguliert gefunden wurden. Zwei Gene waren außerdem in der fertilen Mutante $\Delta$ SmtA-1 als dereguliert gefunden. Angegeben sind die log2 Verhältnisse der Genexpression zwischen Mutante und Wildtyp.

\begin{tabular}{|c|c|c|c|c|c|c|c|}
\hline Nummer & Beschreibung & pro1 & pro11 & pro22 & $\Delta$ Smta-1 & $\Delta$ SmtA-2 & $\Delta \mathrm{SmtA-1}$ \\
\hline NCU04533 & $\begin{array}{c}\text { abundant perithecial } \\
\text { protein (APP), Sordaria } \\
\text { macrospora }\end{array}$ & $-3,64$ & $-4,27$ & $-3,12$ & $-2,99$ & $-2,43$ & 0,6 \\
\hline NCU04928 & $\begin{array}{l}\text { mold-specific MS8 } \\
\text { protein, Ajellomyces } \\
\text { capsulatus }\end{array}$ & $-3,31$ & $-2,22$ & $-3,07$ & $-3,11$ & $-1,07$ & $-0,65$ \\
\hline NCU09111 & $\begin{array}{c}\text { glucose-6-phosphate 1- } \\
\text { dehydrogenase, } \\
\text { Neurospora crassa }\end{array}$ & $-1,85$ & $-1,02$ & $-1,77$ & $-1,33$ & $-1,06$ & $-0,48$ \\
\hline NCU09390 & $\begin{array}{c}\text { tetrahydroxynaphthalene } \\
\text { reductase, Sordaria } \\
\text { macrospora }\end{array}$ & $-2,32$ & $-1,68$ & $-2,00$ & $-2,19$ & $-1,79$ & $-0,39$ \\
\hline NCU04931 & $\begin{array}{l}\text { putative G protein- } \\
\text { coupled receptor alpha } \\
\text { (Botryotinia fuckeliana) }\end{array}$ & $-2,89$ & $-3,52$ & $-3,28$ & $-3,24$ & $-1,48$ & $-1,21$ \\
\hline NCU08055 & $\begin{array}{c}\text { bZip transcription factor } \\
\text { (Neurospora crassa); } \\
\text { IDI-4 (Podospora } \\
\text { anserina) }\end{array}$ & $-1,09$ & $-1,54$ & $-1,59$ & $-2,18$ & $-1,63$ & $-1,15$ \\
\hline
\end{tabular}

Zusätzlich wurden zwei Gene gefunden, welche in allen sterilen Mutanten und der fertilen $\Delta$ SmtA-1 Mutante herunterreguliert waren. 
$\mathrm{Zu}$ den Genen, welche in den sterilen Mutanten herunterreguliert waren, zählen die Gene appl und tih. Das Protein APP (abundant perithecial protein) wird dabei in reifen Perithezien gefunden und kommt niemals in sterilen Mutanten vor (Nowrousian, et al., 2007b). Das Gen tih kodiert für eine Trihydroxynaphtalenreduktase, einen Bestandteil des Melanin Bioysntheseweges (Engh, et al., 2007a). Die Gene der Melanin Biosynthese sind in $\Delta$ SmtA-2 signifikant herunterreguliert, in $\triangle \mathrm{SmtA}-1$ dagegen nicht (Abb. 15). Melanin wird in S. macrospora hauptsächlich in reifen Perithezien und Ascosporen gefunden. Es ist sehr wahrscheinlich, dass die Expression dieser vier Gene Fruchtkörper-spezifisch und nicht Kreuzungstyp-spezifisch ist.

\subsection{SMTA-2 interagiert mit verschiedenen regulatorischen Proteinen}

Um mögliche Interaktionspartner des Kreuzungstyp-Proteins SMTA-2 zu identifizieren, wurde eine Hefe-Zwei-Hybrid Analyse gegen eine S. macrospora cDNA-Bank durchgeführt. Das Plasmid pGB-A2 wurde zuvor in einem pGAD-ranBPM und pGADT7 Hintergrund auf Funktionalität bzw. Transaktivierung getestet (Abb. 19).

In dieser Analyse konnten 48 putative Interaktionspartner identifiziert werden (Tab. 5). Diese wurden erneut mit den Plasmiden pGB-A2 und pGBKT7 als Negativkontrolle auf spezifische Interaktion mit SMTA-2 untersucht (Abb. 20). Dabei wurde für die Proteine 1, 6, 15, 23, 35 und 48 eine Interaktion auch mit der GAL4-Bindedomäne allein (pGBKT7) nachgewiesen. Diese Proteine wurden daraufhin als nicht-spezifische Interaktionen verworfen.

Die anderen Proteine, welche als putative Interaktionspartner von SMTA-2 festgestellt wurden, decken eine breite Varianz möglicher Funktionen ab. So wurden fünf putative Transkriptionsfaktoren $(2,16,25,46)$ gefunden, drei Proteine, welche in die Vermittlung der Zellpolarität und Hyphenseptierung involviert sind $(8,22,42)$ und drei Proteine $(14,20,34)$, welche generell an der sexuellen Entwicklung beteiligt sind (Abb. 25). 


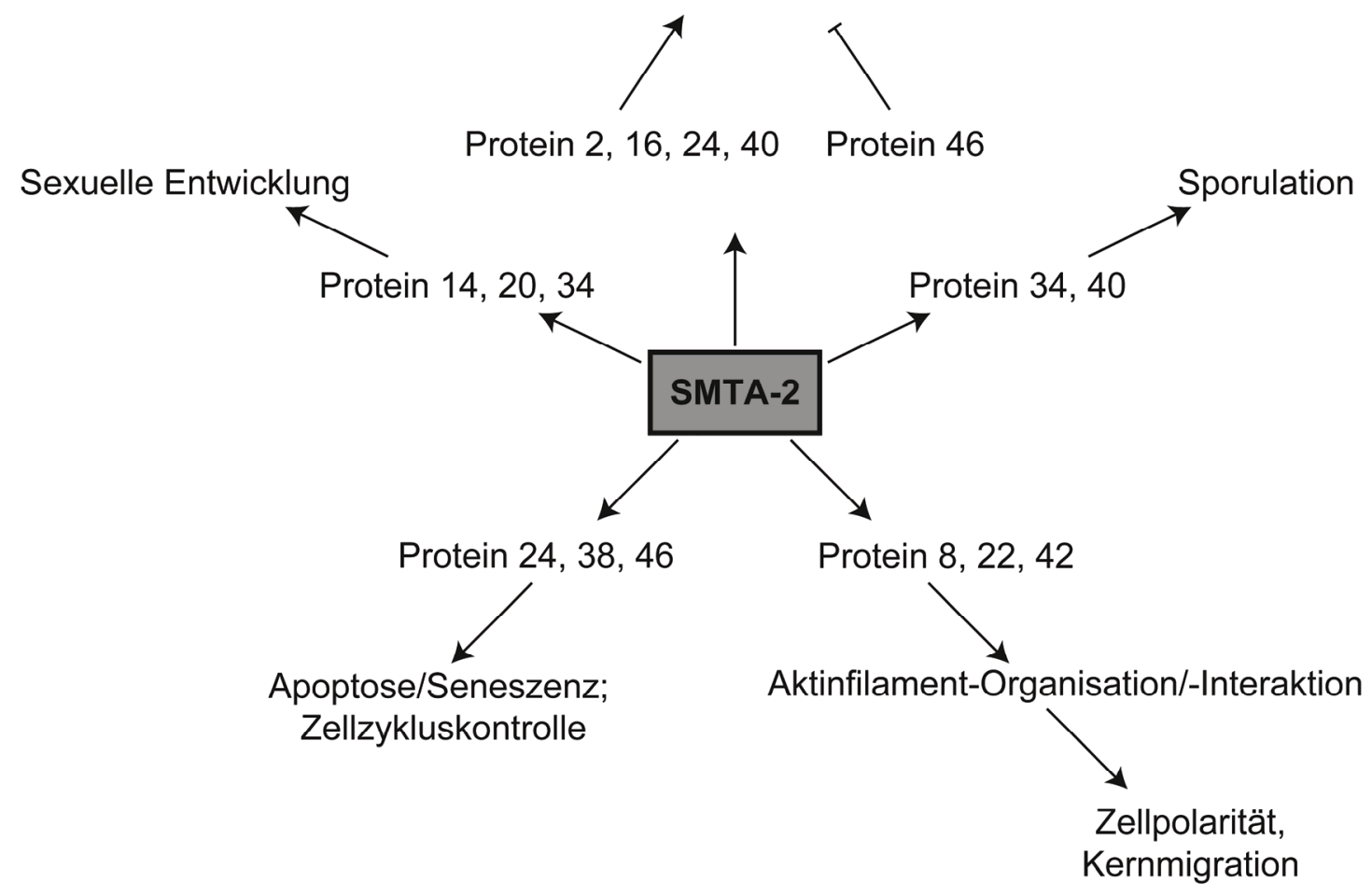

Abbildung 25: Schematische Darstellung der Prozesse in welche putative Interaktionspartner von SMTA-2 involviert sind. Die angegebenen Nummern entsprechen den Proteinen in Tab. 5. Bekannte Funktionen der Interaktionspartner wurden den Datenbanken NcD, AD und SGD entnommen und sich in Tab. 5 als Referenzen angegeben.

Die Homologe zu den vier Proteinen 2, 16, 25 und 46 stellen in anderen Organismen bekannte Regulatoren der Genexpression dar (Chen H., et al., 1998; Collart und Struhl, 1994; Masloff, et al., 1999; Sanchez, et al., 1998).

Das Protein 2 stellt dabei ein Homolog zu dem Protein AAB-1 aus N. crassa dar. Dieses Protein konnte als DNA-Bindefaktor identifiziert werden, welcher die gleiche Spezifität wie der HAP2/3/4/5 Heteromerkomplex aus S. cerevisiae besitzt (Chen H. und Kinsey, 1995). Mutationen im aab-1 Gen führen in $N$. crassa zu reduziertem vegetativem Wachstum und einer verringerten Anzahl an mitotisch gebildeten Konidiosporen. Außerdem zeigt eine solche Mutante weibliche Sterilität, ist aber weiterhin männlich fertil (Chen H., et al., 1998). Von den bekannten Genen aus N. crassa, welche durch AAB-1 reguliert werden, (NCU01808, NCU06189, NCU05689 und NCU09816) konnte lediglich das Gen NCU01808 in der $\Delta$ SmtA-2 Mutante als differentiell reguliert identifiziert werden (s 4.1.5). Für das homologe Hefeprotein HAP5 sind dabei in der SGD 132 verschiedene Interaktionspartner eingetragen (Costanzo, et al., 2010). Ein solcher Wert lässt auf einen eher unspezifischen 
Interaktionspartner schließen, dies lässt sich durch die hier durchgeführten Experimente jedoch nicht bestätigen.

Protein 16 zeigt Homologien zu einem putativen C6 Transkriptionsfaktor aus A. fumigatus (MacPherson, et al., 2006). In S. macrospora konnte für einen C6 Zinkfinger Transkriptionsfaktor (PRO1) bereits eine Beteiligung an der sexuellen Entwicklung gezeigt werden (Masloff, et al., 1999). Protein 16 zeigt außer dem C6 Konsensusmotiv allerdings keine Ähnlichkeit zu PRO1.

Das Protein 25 zeigt Homologien zu dem Protein ABP2 aus $S$. pombe. ABP2 ist beschrieben als Bindeprotein von Autonom-Replizierenden-Sequenz (ARS) Elementen (Sanchez, et al., 1998). ARS Elemente stellen den Startpunkt der Replikation auf chromosomalen Sequenzen dar, welche auch die autonome Replikation von Plasmiden unterstützen. Für ABP2 konnte gezeigt werden, dass dieses Protein an der Kontrolle des Eintritts in die Mitose beteiligt ist (Sanchez, et al., 1998). Obwohl in S. pombe ein Einfluss von ABP2 nur auf die Mitose beschrieben ist, kann ein ähnlicher Einfluss auf die Meiose und die damit verbundene sexuelle Entwicklung in S. macrospora nicht ausgeschlossen werden. In einer ABP2 Mutante in S. pombe konnte außerdem gezeigt werden, dass ABP2 eine Rolle im UV-induzierten Zellzyklusarrest spielen könnte (Sanchez, et al., 1998). Da ein Zellzyklusarrest während der sexuellen Entwicklung in P. anserina (Debuchy und Turgeon, 2006) und S. macrospora vorhergesagt ist, erscheint ein Zusammenhang mit dem homologen Protein ABP2 sinnvoll.

Das Protein 46 schließlich zeigt Homologien zu dem CCR4-NOT Komplex aus S. cerevisiae. Dieser Komplex stellt einen negativen Regulator verschiedener Gene dar, welche verschiedene zelluläre Funktionen übernehmen (Collart und Struhl, 1994). Eine Mutation des Proteins NOT2 führt dabei zu einem $\mathrm{G}_{1}$-Zellzyklusarrest und einem konstitutiv aktivierten Pheromon Signalweg (de Barros Lopes, et al., 1990; Reed, 1980; Shuster und Byers, 1989). Homologe der Gene, welche in S. cerevisiae durch den CCR4-Not Komplex negativ reguliert werden (HIS4, TBP, STE4, BIK1) (Collart und Struhl, 1993; 1994; de Barros Lopes, et al., 1990), wurden in den Microarray Analysen der $\Delta$ SmtA-2 Mutante erneut als nicht reguliert identifiziert. Für das Protein NOT2 sind in der SGD 80 Interaktionspartner unterschiedlicher Funktion eingetragen. Dies lässt, ähnlich wie bei Protein 2 auf einen unspezifischen Interaktionspartner schließen.

Ein Einfluss auf den Zellzyklus kann auch für die Proteine 24 und 38 angenommen werden. Protein 24 zeigt Homologien zu PHB2, einer Untereinheit des Prohibitin-Komplexes in Hefe. 
Dieser Komplex lokalisiert an den Mitochondrien und hat Einfluss sowohl auf die Funktionalität der Mitochondrien, als auch auf die Lebensspanne des gesamten Organismus (Coates, et al., 1997). Mutanten in S. cerevisiae zeigen dabei einen verlängerten Zellzyklus. Das Protein 38 dagegen zeigt Homologien zu OYE2 in S. cerevisiae. Dieses Protein spielt eine Rolle bei der Regulation radikaler Sauerstoffspezies (ROS) und damit der Regulation des Programmierten Zelltods (,,programmed cell death“, PCD) (Odat, et al., 2007). PCD in Hefe kann dabei, unter anderem, durch einen Überschuss an Pheromon während der sexuellen Phase ausgelöst werden (Severin und Hyman, 2002) als auch einen Effekt der natürlichen Seneszenz darstellen (Herker, et al., 2004). OYE2 kann dabei durch die Neutralisierung des von Mitochondrien gebildeten ROS und der Interaktion mit Aktin-Filamenten, den Zelltod sowohl verhindern, als, durch die Interaktion mit dem Protein OYE3, auch hervorrufen (Odat, et al., 2007).

Weitere gefundene Interaktionspartner (Proteine 8, 22, 42) stehen mit Zellpolarität und Septierung im Zusammenhang (März, et al., 2009; Seiler und Plamann, 2003; Winter, et al., 1997). Die Proteine 8 und 22 wurden in dem filamentösen Ascomyceten N. crassa bereits umfassend untersucht (März, et al., 2009; Vogt und Seiler, 2008). Ein direkter Zusammenhang mit der sexuellen Entwicklung in N. crassa wurde dabei nicht beschrieben. Sowohl das RHO1-spezifische GTPase-aktivierende Protein LRG1 (Protein 22) als auch die Peptid N-Glycanase 1 (Protein 8) sind an der Vermittlung der Zellpolarität in vegetativen Hyphen und dem Septierungsprozess beteiligt (März, et al., 2009; Seiler und Plamann, 2003; Vogt und Seiler, 2008). Für Homologe des Proteins 42, einer Untereinheit des Actinzugehörigen Protein (,actin-related protein“, ARP) Komplexes, ist bekannt, dass sie in S. cerevisiae ebenfalls an der Vermittlung der Zellpolarität beteiligt sind (Winter, et al., 1997) und dass LRG1 aus S. cerevisiae mit dem ARP2/3 Komplex interagiert (Costanzo, et al., 2010). Für N. crassa und S. macrospora konnte die Beteiligung von Actin-Filamenten und zugehöriger Komplexe auch an der Kernmigration und der Septierung ascogener Hyphen gezeigt werden (Roca, et al., 2010; Thompson-Coffe und Zickler, 1993).

Ein grundsätzlicher weiterer Aspekt ist die Regulation der Genexpression durch Aktin (Zheng, et al., 2009). Dabei wird die Transkription sowohl durch die von Aktin vermittelte Remodulierung der Chromatinstruktur (Shen X., et al., 2003) als auch durch den Transport von Transkriptionsfaktoren in den Zellkern oder aus ihm hinaus (Favot, et al., 2005; Haller, et al., 2004) reguliert. Bei all diesen unterschiedlichen Funktionen spielen Aktin-bindende 
Proteine (ABP) eine essentielle Rolle (dos Remedios, et al., 2003). Für den ARP2/3 Komplex konnte bisher keine Beteiligung an regulatorischen Prozessen gezeigt werden, kann aber auch nicht ausgeschlossen werden.

Der putative Interaktionspartner 34 ist homolog zu Sec5p aus $S$. cerevisiae, einer Untereinheit des Exocyst Komplexes (TerBush, et al., 1996). Der Exocyst Komplex ist in Hefe und anderen eukaryotischen Organismen an der Anbindung und räumlichen Kontrolle von postGolgi Vesikeln an der Plasmamembran vor der Vesikelfusion beteiligt (Guo, et al., 1999; Mehta, et al., 2005). In den unizellulären Hefen S. cerevisiae und S. pombe konnte eine Beteiligung des Exocyst Komplexes auch an der sexuellen Entwicklung nachgewiesen werden (Neiman, 1998; Sharifmoghadam, et al., 2010). Dabei spielt der Exocyst Komplex sowohl eine Rolle bei der Agglutination zweier kompatibler Kreuzungspartner, als auch in der post-meiotischen Sporulation. Zusätzlich dazu konnte in S. cerevisiae nachgewiesen werden, dass die Rho-GTPase CDC42 mit dem Exocyst Komplex interagiert (Yamashita, et al., 2010). Durch CDC42 kann damit eine indirekte Interaktion zwischen LRG1 (Interaktionspartner 22) und dem Exocyst Komplex (Interaktionspartner 34) und damit auch SMTA-2 hergestellt werden. Während in dem homothallischen Ascomyceten S. macrospora die Agglutination zweier Kreuzungspartner unwahrscheinlich ist, lässt die Beteiligung des Exocyst Komplexes an der Sporenbildung auf eine Regulation dieses Prozesses durch das Protein SMTA-2 schließen.

Eine Beteiligung an der Sporenbildung konnte auch für das homologe Hefe Protein zu dem Interaktionspartner 40 nachgewiesen werden (Siniossoglou, et al., 1998). Mutanten des sogenannten Nem1p Proteins zeigen dabei eine veränderte Zellkernmorphologie und Sporenbildung. Während die mitotische Vermehrung nicht beeinträchtigt ist, sind die Mutanten nicht in der Lage, Meiosporen zu bilden (Siniossoglou, et al., 1998). Es wurde dabei vorgeschlagen, dass ein Komplex aus Nem1p-Spo7p die Kernmembranproliferation negativ reguliert und somit ein Auswachsen der Kernmembran an bestimmten Stellen verhindert. Dies könnte wiederum auch durch eine Inhibition der Biosynthese besonders langkettiger Fettsäuren zu erklären sein (Schneiter, et al., 1996). Passend dazu wurde für SMTA-2 auch ein Gen der Fettsäuresynthese als putativer Interaktionspartner identifiziert (Protein 18).

In N. crassa konnte von Duarte und Videira (2000) gezeigt werden, dass die Funktionalität des Komplex I der mitochondrialen Atmungskette für die sexuelle Entwicklung essentiell ist. 
Eine Untereinheit dieser Atmungskette konnte auch als Interaktionspartner von SMTA-2 identifiziert werden (Protein 14). Die Regulation von Stoffwechselprozessen scheint dabei gerade während der sexuellen Entwicklung stark kontrolliert zu sein, da Defekte an Komplex I in N. crassa keine Auswirkungen auf das vegetative Wachstum zeigen (Duarte und Videira, 2000). Auch in S. macrospora konnte bereits gezeigt werden, dass Stoffwechselprozesse einen Einfluss auf die sexuelle Entwicklung haben. So führen Defekte in der ATP Citratlyase ACL1 zu Sterilität (Nowrousian, et al., 1999). Das Protein ACL1 spielt dabei eine wichtige Rolle bei der Acetyl-CoA Synthese, welches wiederum in Eukaryoten hauptsächlich für die Fettsäure- und Sterolbiosynthese benötigt wird. Dies verweist wiederum auf Interaktionspartner 18. Ein weiterer Interaktionspartner, welcher in die Acetyl-CoA Synthese involviert sein könnte, ist Interaktionspartner 19 (Schneiter, et al., 1996). Zusätzlich konnten verschiedene andere Proteine gefunden werden, welche an unterschiedlichen Stoffwechselprozessen beteiligt sind (bspw. Protein 7, 10, 32, 33, 39, 41, 45). So zeigt das Protein 33 Homologien zu einer Ornithintransamidase aus S. cerevisiae, welche am Arginin Metabolismus beteiligt ist (Middelhoven, 1964). Für das entsprechende S. cerevisiae Gen CAR2 konnte gezeigt werden, dass der Kreuzungstyp eine Rolle bei der Transkriptionsstärke spielt (Deschamps und Wiame, 1979) und der Transkriptionsfaktor MCM1 an der Regulation der Genexpression beteiligt ist (Messenguy und Dubois, 1993). MCM1 konnte dabei bereits als Interaktionspartner des Kreuzungstyp-Proteins SMTA-1 in S. macrospora nachgewiesen werden (Nolting und Pöggeler, 2006a).

Der putative Interaktionspartner Protein 26 stellt ein Ubiquitin-konjugierendes Enzym dar. Ubiquitin-konjugierende Enzyme dienen als Ubiquitin Träger, welche das Ubiquitin auf spezifische, andere Proteine übertragen können. Das Ubiquitin dient dabei als Signalpeptid für den Abbau durch das 26S Proteasom (Jentsch und Schlenker, 1995). Durch diesen gezielten Abbau von Proteinen, werden verschiedenste zelluläre Funktionen reguliert, wie DNA Reparatur, Zellzykluskontrolle oder Zellstressantwort (Vassal, et al., 1992). Dieser protealytische Signalweg ist außerdem in den Prozess der Degradation am Endoplasmatischen Retikulum (ER) involviert (Kopito, 1997). So konnte für den filamentösen Ascomyceten A. nidulans nachgewiesen werden, dass das COP9-Signalosom, ein Teil der Ubiquitinabhängigen Protein Degradation, auch eine Rolle bei der Fruchtkörperentwicklung in diesem Pilz spielt (Busch, et al., 2007). Ob die Interaktion von SMTA-2 mit Protein 26 dabei eine Rolle bei der Ubiquitinierung anderer Proteine spielt oder SMTA-2 selbst Ubiquitiniert wird, 
ist unklar. In einer bioinformatischen Analyse der SMTA-2 Sequenz mit zwei unabhängigen Programmen (http://bdmpub.biocuckoo.org (Xue, et al., 2006); http://www.ubpred.org) wurden zwei mögliche Ubiquitinierungssequenzen in SMTA-2 an den Aminosäurepositionen 13 und 225 gefunden. Besonders die Sequenz an Position 225, also im C-Terminus des Proteins, könnte im Zusammenhang mit der essentiellen Rolle des C-Terminus (s. 5.2) eine Rolle spielen.

Viele Glykoproteine niederer wie höherer Eukaryoten werden durch sogenannte Glykosylphosphatidylinositol (GPI) Anker in die Zellwand eingebracht (Englund, 1993; McConville und Ferguson, 1993). Das Anhängen eines GPI Ankers an spezifische Proteine ist ein essentieller Prozess, wie in S. cerevisiae (Leidich, et al., 1994; Leidich, et al., 1995; Vossen, et al., 1995), A. fumigatus (Li, et al., 2007) und N. crassa (Bowman, et al., 2006) beschrieben. Dabei spielen GPI Anker Proteine hauptsächlich eine Rolle bei der Zellwandintegrität und zusammenhängenden Prozessen. Mutanten der GPI Anker Synthese in $N$. crassa zeigen eine veränderte Morphologie vegetativer Zellen und sind nicht in der Lage, Protoperithezien zu entwickeln (Bowman, et al., 2006). Da eine GPI Anker Transamidase (Protein 49) als putativer Interaktionspartner von SMTA-2 gefunden wurde, ist ein Zusammenhang mit der sexuellen Entwicklung auch in S. macrospora recht wahrscheinlich.

Ein weiterer erwähnenswerter putativer Interaktionsparter ist das Protein 20. Dieses Protein stellt das $\alpha$-Faktor ähnliche Pheromon PPG-1 aus S. macrospora dar (Pöggeler, 2000). Eine Beteiligung dieses Pheromons an der sexuellen Entwicklung konnte, wie in 5.4 beschrieben, bereits nachgewiesen werden und wird durch das Kreuzungstyp-Protein SMTA-1 positiv reguliert. Eine Regulation des entsprechenden Pheromon-Vorläufergens konnte für SMTA-2 nicht nachgewiesen werden (Abb. 10). Soweit bekannt, ist diese Studie die Erste, welche eine mögliche direkte Interaktion zwischen einem Kreuzungstyp-Protein und einem Pheromon zeigt. $\mathrm{Ob}$ diese Interaktion eine Form der intrazellulären Signaltransduktion oder der Übertragung von Signalen unterschiedlicher Zellen oder sogar Zellkernen darstellt, ist nicht klar. Da das Gen ppg-1 von dem Kreuzungstyp-Protein SMTA-1 reguliert wird, muss ein Einfluss der Interaktion dieses Pheromons mit SMTA-2 auf den putativen, von SMTa-1 ausgelösten und von SMTA-2 aufgehobenen Zellzyklusarrest (Abb. 23) ausgeschlossen werden. 
Abschließend lässt sich sagen, dass putative Interaktionspartner von SMTA-2 gefunden werden konnten, die in Prozesse der Genexpressions-Regulation, der Regulation von Zellpolarität und Sporulation involviert sind als auch auf den Zellzyklus und Apoptose einen Einfluss haben. Diese putativen Interaktionen müssen allerdings noch auf ihre genaue Spezifität, gerade auch in vivo, getestet werden. Die Lokalisation von SMTA-2 im Cytoplasma (Abb. 18) lässt dabei vor allem ebenfalls cytoplasmatisch lokalisierte Interaktionspartner wie Protein 8, 22 und 42 möglich erscheinen, während Interaktionen mit nukleär lokalisierten Proteinen wie 2, 16, 25 und 46 möglich, aber nicht wahrscheinlich sind.

\subsection{Zusammenfassung der Untersuchung der MAT1-1 spezifischen Gene aus}

\section{$\underline{\text { S. macrospora }}$}

\subsubsection{Das $\alpha$-Domänen Protein SMTA-1 ist nicht essentiell für die sexuelle}

\section{Entwicklung in S. macrospora}

In dieser Studie konnte gezeigt werden, dass das MAT1-1-1 Gen aus S. macrospora für die sexuelle Entwicklung nicht essentiell ist (s. 5.1). Damit stellt S. macrospora den ersten untersuchten Ascomyceten dar, in dem ein $\alpha$-Domänen Protein nicht essentiell für den sexuellen Zyklus ist. Gleichzeitig konnte aber gezeigt werden, dass die Expression der Pheromon-Gene (s. 5.4) und anderer Gene (s. 5.5) von SMTA-1 reguliert wird. Außerdem konnte in früheren Studien eine Interaktion von SMTA-1 mit anderen Faktoren nachgewiesen werden, die in die Regulation der sexuellen Entwicklung involviert sind, hier vor allem STE12, MCM1 und das Kreuzungstyp-Protein SMTa-1 (Nolting und Pöggeler, 2006a; b). Durch die Interaktion mit SMTa-1 könnte dabei auch die Regulation des Pheromongens ppg-2 erklärt werden, welche durch das Kreuzungstyp-Protein SMTa-1 (500fach) (Pöggeler, et al., 2006b) deutlich stärker reguliert wird als SMTA-1 (16fach). Dies deutet darauf hin, dass sich MAT1-1-1 in S. macrospora im Laufe der evolutionären Entwicklung von einem Hauptregulator der sexuellen Entwicklung in einem heterothallischen Vorfahren zu einem nicht-essentiellen Faktor im jetzigen homothallischen Organismus entwickelt hat.

Das MAT1-2-1 Gen dagegen, welches auch in anderen Sordariomyceten den Hauptregulator MAT1-2-spezifischer Funktionen darstellt, ist in S. macrospora für die sexuelle Entwicklung essentiell (Pöggeler, et al., 2006b). Es ist denkbar, dass dieses Gen im Laufe der Evolution Punktmutationen akkumuliert hat, welche schließlich zur Fähigkeit der Selbstung führten. 
Während dieses Schrittes von einem heterothallischen zu einem homothallischen Organismus, wäre das MAT1-1-1 Gen als zweiter Regulator überflüssig. Die Regulation der Genexpression verschiedener Gene durch SMTA-1 (s. 5.4, 5.5) lassen den Schluss zu, dass die Funktion und Wichtigkeit des Kreuzungstyp-Proteins zwar eingeschränkt, jedoch in Teilen noch vorhanden ist (Abb. 26). Dies stützt außerdem die Theorie eines heterothallischen Vorfahren von S. macrospora.

\subsubsection{Das Protein SMTA-3 zeigt keine Funktion in S. macrospora}

Ähnlich zu SMTA-1 zeigt das Kreuzungstyp-Protein keine essentielle Funktion innerhalb des sexuellen Zyklus (s. 5.1) (Abb. 26). Im Gegensatz zu den MAT1-1-3 Proteinen anderer Sordariomyceten besitzt SMTA-3 keine funktionelle HMG-Domäne. Das Gen SmtA-3 ist kotranskribiert mit dem essentiellen Kreuzungstyp-Gen Smta-1 und eine regulatorische Funktion als cis-regulatorisches Element auf die Expression von Smta-1 kann nicht ausgeschlossen werden. Offensichtlich ist allerdings auch diese putative regulatorische Funktion für die sexuelle Entwicklung und die Funktionalität von SMTa-1 nicht essentiell.

\subsubsection{Das PPF-Domänen Protein SMTA-2 ist essentiell für die postmeiotische Entwicklung in $S$. macrospora}

Im Gegensatz zu den Kreuzungstyp-Proteinen SMTA-1 und SMTA-3, spielt SMTA-2 eine essentielle Rolle bei der sexuellen Reproduktion. Die molekulare Funktion der MAT1-1-2 Homologe anderer Sordariomyceten ist unbekannt, jedoch wurde die biologische Funktion in $P$. anserina bereits untersucht. Mutationen in SMR1 (MAT1-1-2) führen zu einem kompletten Arrest der sexuellen Entwicklung nach Fertilisation und vor der Ausbildung ascogener Hyphen. Es wurde daher postuliert, dass die internukleäre Erkennung, welche während der Ausbildung der ascogenen Hyphe stattfindet, zu einem Entwicklungsarrest führt, welcher nach erfolgreicher Kernerkennung und -migration von MAT1-1-2 aufgehoben wird (Debuchy, et al., 2010). In N. crassa zeigen Mutationen im MAT1-1-2 Gen einen weit weniger deutlichen Phänotyp (Ferreira, et al., 1998). Einzelmutanten des Gens zeigen keinen phänotypischen Unterschied zum Wildtyp und nur Doppelmutanten mit MAT1-1-3 zeigen eine reduzierte Fertilität. Es wurde daraus geschlossen, dass die Proteine MAT1-1-2 und MAT1-1-3 aus N. crassa an Postfertilisationsprozessen nach Kernmigration und Meiose beteiligt sein könnten (Ferreira, et al., 1998). 
Der sterile Phänotyp der $\Delta$ SmtA-2 Mutante in S. macrospora zeigt mehr Ähnlichkeiten zu P. anserina als zu N. crassa. In früheren Studien konnte gezeigt werden, dass das Kreuzungstyp-Gen Smta-1 (MAT1-2-1) für die sexuelle Entwicklung in S. macrospora essentiell ist (Pöggeler, et al., 2006b). In heterothallischen Vertretern der Sordariomyceten kontrolliert das HMG-Domänen Protein MAT1-2-1 die MAT1-2-spezifischen Funktionen der Zelle und ist an der Erkennung zweier Kerne vom MAT1-1 und MAT1-2 Kreuzungstyp vor der Kernmigration und der Ausbildung der ascogenen Hyphe beteiligt (Debuchy, et al., 2010; Turgeon und Debuchy, 2007). In S. macrospora konnten verschiedene putative Interaktiospartner von SMTA-2 identifiziert werden (s. 5.6), welche bei einem Zellzyklusarrest eine Rolle spielen könnten. Darunter sind sowohl regulatorische Komplexe, wie der Prohibitin-Komplex, als auch Gene, welche in metabolische Prozesse beteiligt sind. Da die Ausbildung und Reifung der sexuellen Strukturen ein für den Organismus energieaufwändiger Prozess ist, könnte die Regulation wichtiger metabolischer Komponenten an einem solchen Entwicklungsarrest durchaus beteiligt sein.

Zusätzlich wurden aber auch Proteine gefunden, welche an Prozessen der Sporenbildung und der Zellpolarität beteiligt sind. Bei den Komplementationsversuchen mit verkürzten SMTA-2 Konstrukten in $\Delta$ SmtA-2 (s. 5.2) zeigte sich, dass der C-Terminale Teil von SMTA-2 in der Lage ist, den sterilen Phänotyp der Mutante teilweise zu komplementieren. Die dabei entstehenden Asci und Ascosporen zeigen jedoch im Vergleich zum Wildtyp Defekte in der Verteilung der Ascosporen innerhalb der Asci. Putative Interaktionspartner von SMTA-2 könnten hierbei sowohl an der Ascosporenentwicklung, als auch, durch Interaktion mit Aktinfilamenten und Motorkomplexen, an der räumlichen Bewegung und Ausrichtung der geordneten Sporentetraden beteiligt sein.

Die Lokalisation von SMTA-2 im Cytoplasma (s. 5.3) ist ebenfalls ein Hinweis auf mögliche Interaktionspartner, welche ebenfalls cytoplasmatisch lokalisiert sind (LRG1, PGN1, ARP2/3). Ein direkter Einfluss auf die Genregulation wird durch diese Daten nicht unterstützt. Ein indirekter Einfluss durch die Steuerung der Lokalisation von Transkriptionsfaktoren und regulatorischen Komplexen lässt sich dabei nicht ausschließen (Abb. 26). Ein wichtiger Punkt hierbei ist ebenfalls, dass die verwendeten Fluoreszenzkonstrukte offenbar nicht die volle Funktionalität des Wildtyp SMTA-2 besitzen. Der C-Terminale Teil von SMTA-2 scheint dabei essentiell zu sein, während der N-Terminale Abschnitt für die Ascosporen- und Ascusentwicklung wichtig, jedoch nicht essentiell ist 
Diskussion

(s. 5.2). Die konservierten Aminosäuren Prolin, Prolin und Phenylalanin (PPF), welche als putative funktionelle Domäne in anderen Sordariomyceten beschrieben sind (Debuchy, et al., 2010), scheinen in S. macrospora keine essentielle Rolle zu spielen. Grundsätzlich kann eine funktionelle Rolle der PPF-Domäne nicht ausgeschlossen werden, da ein rein C-Terminales Konstrukt von SMTA-2 lediglich eine partielle Funktionalität aufweist.

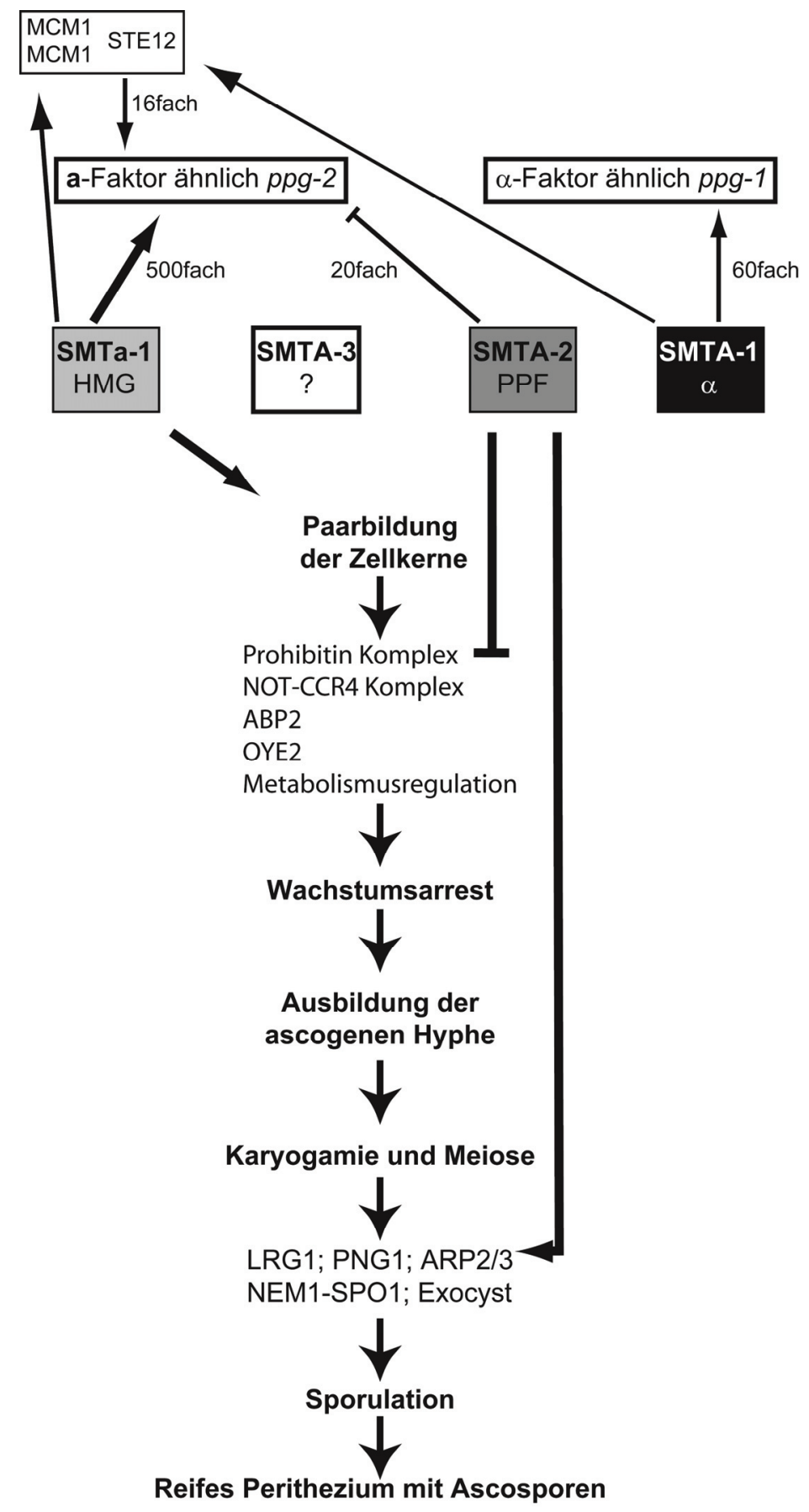

Abbildung 26: Modell der funktionellen Abläufe während der sexuellen Entwicklung in S. macrospora. 


\subsection{Der asexuelle Ascomycet $P$. chrysogenum besitzt funktionelle Pheromone und Rezeptoren}

Der filamentöse Ascomycet Penicillium chrysogenum besitzt große Bedeutung als Produzent des $\beta$-Lactam Antibiotikums Penicillin (Demain und Elander, 1999; Keller, et al., 2005). Obwohl P. chrysogenum in der Lage ist, sich vegetativ über Konidiosporen zu vermehren, ist ein sexueller Zyklus nicht bekannt.

Erst kürzlich wurde jedoch das Vorhandensein von Kreuzungstyp-Genen und Komponenten eines Pheromon-Rezeptor-Systems in P. chrysogenum nachgewiesen (Hoff, et al., 2008).

Die Gene der putativen Pheromone und Rezeptoren wurden in einem heterologen System in S. cerevisiae eingebracht und konstitutiv exprimiert. Bei Behandlung der Hefestämme, welche die Pheromon-Rezeptor Gene exprimieren, mit künstlichem Polypeptid auf Basis der abgeleiteten Proteinsequenz des Pheromon Gens ppg-1 konnte in Hemmhof-Tests die Induktion eines Wachstumsarrests durch das Pheromon nachgewiesen werden (Abb. 21). In mikroskopischen Studien zeigte sich, dass die so behandelten Zellen eine deutliche „Shmoo“Bildung zeigen, eine typische Veränderung der Zellmorphologie in S. cerevisiae nach Pheromon-Behandlung (Abb. 22). Als Standard wurde der Pheromon-Rezeptor PRE-2 aus S. macrospora mit dem entsprechenden künstlichen Pheromon verwendet, da die Funktionalität in diesem heterologen System bereits belegt ist (Mayrhofer und Pöggeler, 2005).

Vergleiche zwischen $S$. macrospora und $P$. chrysogenum zeigen deutlich, dass auch der Pheromon-Rezeptor von $P$. chrysogenum funktionell ist. In dem heterologen Hefesystem ist auch dieser in der Lage, einen Pheromon-induzierten Zellzyklusarrest herbeizuführen.

Auch die Pheromone aus P. chrysogenum und S. macrospora wurden in Hefe überexprimiert und als Überstand auf die Rezeptor-Stämme gegeben. In keinem Fall konnte hier ein Wachstumsarrest festgestellt werden (Daten nicht gezeigt). Dies könnte zum einen darauf hindeuten, dass das Pheromon, im Gegensatz $\mathrm{zu}$ dem korrespondieren Rezeptor in P. chrysogenum nicht funktionell ist. Da ein Wachstumsarrest allerdings auch bei der S. macrospora Positivkontrolle nicht beobachtet werden konnte und die künstlichen Pheromone auf der Sequenz des Pheromons beruhen, ist es wahrscheinlicher, dass die 
Diskussion

Pheromone in dem entsprechenden Hefe-Stamm nicht korrekt exprimiert oder sekretiert werden.

Grundsätzlich scheint $P$. chrysogenum über ein funktionierendes Pheromon-Rezeptor-Paar zu verfügen. Es ist nicht klar, ob die Komponenten dieses Systems auch in P. chrysogenum exprimiert werden und funktionell sind, jedoch lässt dieses Ergebnis den Schluss zu, dass ein sexueller Zyklus in $P$. chrysogenum nicht nur möglich sondern auch recht wahrscheinlich ist. Damit rückt $P$. chrysogenum in die Nähe anderer, medizinisch und industriell relevanter, ursprünglich asexueller Ascomyceten, für die mittlerweile ein sexueller Zyklus beschrieben werden konnte, so zum Beispiel der humanpathogene Aspergillus fumigatus (O'Gorman, et al., 2009). 


\section{Literaturverzeichnis}

Altschul S. F., Gish W., Miller W., Myers E. W., Lipman D. J. (1990). Basic local alignment search tool. J Mol Biol 215, 403-10.

Anderegg R. J., Betz R., Carr S. A., Crabb J. W., Duntze W. (1988). Structure of Saccharomyces cerevisiae mating hormone a-factor. Identification of S-farnesyl cysteine as a structural component. J Biol Chem 263, 18236-40.

Astell C. R., Ahlstrom-Jonasson L., Smith M., Tatchell K., Nasmyth K. A., Hall B. D. (1981). The sequence of the DNAs coding for the mating-type loci of Saccharomyces cerevisiae. Cell 27, 15-23.

Ballon D. R., Flanary P. L., Gladue D. P., Konopka J. B., Dohlman H. G., Thorner J. (2006). DEP-domain-mediated regulation of GPCR signaling responses. Cell 126, 1079-93.

Barber M. S., Giesecke U., Reichert A., Minas W. (2004). Industrial enzymatic production of cephalosporin-based $\beta$-lactams. Adv Biochem Eng Biotechnol 88, 179-215.

Bardwell L. (2005). A walk-through of the yeast mating pheromone response pathway. Peptides 26, 339-50.

Becker D. M., Lundblad V. (2001). Introduction of DNA into yeast cells. Curr Protoc Mol Biol Chapter 13, Unit13 7.

Bell S. P., Dutta A. (2002). DNA replication in eukaryotic cells. Annu. Rev. Biochem. 71, 333-374.

Birnboim H. C., Doly J. (1979). A rapid alkaline extraction procedure for screening recombinant plasmid DNA. Nucleic Acids Res 7, 1513-23.

Bistis G. N. (1981). Chemotropic interactions between trichogynes and conidia of opposite mating type Neurospora crassa. Mycologia 73, 959-975.

Blakeslee A. (1904). Sexual Reproduction in the Mucorinae. Proc. Am. Acad. Sci 40, 205319.

Bobrowicz P., Pawlak R., Correa A., Bell-Pedersen D., Ebbole D. J. (2002). The Neurospora crassa pheromone precursor genes are regulated by the mating type locus and the circadian clock. Mol Microbiol 45, 795-804.

Bölker M., Kahmann R. (1993). Sexual pheromones and mating responses in fungi. Plant Cell 5, 1461-1469.

Borghouts C., Kimpel E., Osiewacz H. D. (1997). Mitochondrial DNA rearrangements of Podospora anserina are under the control of the nuclear gene grisea. Proc Natl Acad Sci US $A$ 94, 10768-10773. 
Borghouts C., Osiewacz H. D. (1998). GRISEA, a copper-modulated transcription factor from Podospora anserina involved in senescence and morphogenesis, is an ortholog of MAC1 in Saccharomyces cerevisiae. Mol. Gen. Genet. 260, 492-502.

Borghouts C., Scheckhuber C. Q., Stephan O., Osiewacz H. D. (2002a). Copper homeostasis and aging in the fungal model system Podospora anserina: differential expression of $\mathrm{PaCtr} 3$ encoding a copper transporter. Int J Biochem Cell Biol. 34, 1355-1371.

Borghouts C., Scheckhuber C. Q., Werner A., Osiewacz H. D. (2002b). Respiration, copper availability and SOD activity in P. anserina strains with different lifespan. Biogerontology 3, 143-153.

Borghouts C., Werner A., Elthon T., Osiewacz H. D. (2001). Copper-modulated gene expression and senescence in the filamentous fungus Podospora anserina. Mol Cell Biol 21, 390-399.

Bowman S. M., Piwowar A., Al Dabbous M., Vierula J., Free S. J. (2006). Mutational analysis of the glycosylphosphatidylinositol (GPI) anchor pathway demonstrates that GPIanchored proteins are required for cell wall biogenesis and normal hyphal growth in Neurospora crassa. Eukaryot Cell 5, 587-600.

Bruhn L., Sprague G. F., Jr. (1994). MCM1 point mutants deficient in expression of $\alpha$ specific genes: residues important for interaction with $\alpha 1$. Mol Cell Biol 14, 2534-44.

Brzonkalik K. (2006). Molekulargenetische Analyse von Kreuzungstypproteinen des filamentösen Ascomyceten Sordaria macrospora, Ruhr-Universität.

Busch S., Schwier E. U., Nahlik K., Bayram Ö., Helmstaedt K., Draht O. W., Krappmann S., Valerius O., Lipscomb W. N., Braus G. H. (2007). An eight-subunit COP9 signalosome with an intact JAMM motif is required for fungal fruit body formation. Proc Natl Acad Sci US A 104, 8089-94.

Camirand A., Heysen A., Grondin B., Herscovics A. (1991). Glycoprotein biosynthesis in Saccharomyces cerevisiae. Isolation and characterization of the gene encoding a specific processing alpha-mannosidase. $J$ Biol Chem 266, 15120-7.

Casselton L. A. (2002). Mate recognition in fungi. Heredity 88, 142-7.

Casselton L. A. (2008). Fungal sex genes-searching for the ancestors. Bioessays 30, 711-714.

Chang S., Staben C. (1994). Directed replacement of $m t A$ by $m t a-1$ effects a mating type switch in Neurospora crassa. Genetics 138, 75-81.

Chen H., Crabb J. W., Kinsey J. A. (1998). The Neurospora aab-1 gene encodes a CCAAT binding protein homologous to yeast HAP5. Genetics 148, 123-30. 
Chen H., Kinsey J. A. (1995). Purification of a heteromeric CCAAT binding protein from Neurospora crassa. Mol Gen Genet 249, 301-8.

Chen P., Sapperstein S. K., Choi J. D., Michaelis S. (1997). Biogenesis of the Saccharomyces cerevisiae mating pheromone a-factor. J Cell Biol 136, 251-69.

Christianson T. W., Sikorski R. S., Dante M., Shero J. H., Hieter P. (1992). Multifunctional yeast high-copy-number shuttle vectors. Gene 110, 119-122.

Coates P. J., Jamieson D. J., Smart K., Prescott A. R., Hall P. A. (1997). The prohibitin family of mitochondrial proteins regulate replicative lifespan. Curr Biol 7, 607-10.

Collart M. A., Struhl K. (1993). CDC39, an essential nuclear protein that negatively regulates transcription and differentially affects the constitutive and inducible HIS3 promoters. Embo J 12, $177-86$.

Collart M. A., Struhl K. (1994). NOT1(CDC39), NOT2(CDC36), NOT3, and NOT4 encode a global-negative regulator of transcription that differentially affects TATA-element utilization. Genes Dev 8, 525-37.

Colot H. V., Park G., Turner G. E., Ringelberg C., Crew C. M., Litvinkova L., Weiss R. L., Borkovich K. A., Dunlap J. C. (2006). A high-throughput gene knockout procedure for Neurospora reveals functions for multiple transcription factors. Proc Natl Acad Sci US A 103, 10352-7.

Coppin E., de Renty C., Debuchy R. (2005). The function of the coding sequences for the putative pheromone precursors in Podospora anserina is restricted to fertilization. Eukaryot Cell 4, 407-20.

Costanzo M., Baryshnikova A., Bellay J., Kim Y., Spear E. D., Sevier C. S., Ding H., Koh J. L., Toufighi K., Mostafavi S., Prinz J., St Onge R. P., VanderSluis B., Makhnevych T., Vizeacoumar F. J., Alizadeh S., Bahr S., Brost R. L., Chen Y., Cokol M., Deshpande R., Li Z., Lin Z. Y., Liang W., Marback M., Paw J., San Luis B. J., Shuteriqi E., Tong A. H., van Dyk N., Wallace I. M., Whitney J. A., Weirauch M. T., Zhong G., Zhu H., Houry W. A., Brudno M., Ragibizadeh S., Papp B., Pal C., Roth F. P., Giaever G., Nislow C., Troyanskaya O. G., Bussey H., Bader G. D., Gingras A. C., Morris Q. D., Kim P. M., Kaiser C. A., Myers C. L., Andrews B. J., Boone C. (2010). The genetic landscape of a cell. Science 327, 425-31.

de Barros Lopes M., Ho J. Y., Reed S. I. (1990). Mutations in cell division cycle genes CDC36 and CDC39 activate the Saccharomyces cerevisiae mating pheromone response pathway. Mol Cell Biol 10, 2966-72.

Debuchy R., Arnaise S., Lecellier G. (1993). The mat- allele of Podospora anserina contains three regulatory genes required for the development of fertilized female organs. Mol Gen Genet 241, 667-73. 
Debuchy R., Berteaux-Lecelier V., Silar P. (2010). Mating systems and sexual morphogenesis in ascomycetes in K. A. Borkovich and D. J. Ebbole (Eds), Cellular and molecular biology of filamentous fungi, ASM Press, pp. 501-535.

Debuchy R., Turgeon B. G. (2006). Mating-type structure, evolution, and function in euascomycetes. in U. Kües and R. Fischer (Eds), Growth, differentiation and sexuality., Springer, pp. 293-323.

Demain A. L., Elander R. P. (1999). The $\beta$-lactam antibiotics: past, present, and future. Antonie Van Leeuwenhoek 75, 5-19.

Deschamps J., Wiame J. M. (1979). Mating-type effect on cis mutations leading to constitutivity of ornithine transaminase in diploid cells of Saccharomyces cerevisiae. Genetics 92, 749-58.

Dohlman H. G., Song J., Ma D., Courchesne W. E., Thorner J. (1996). Sst2, a negative regulator of pheromone signaling in the yeast Saccharomyces cerevisiae: expression, localization, and genetic interaction and physical association with Gpal (the G-protein alpha subunit). Mol Cell Biol 16, 5194-209.

Dohlman H. G., Thorner J. W. (2001). Regulation of G protein-initiated signal transduction in yeast: paradigms and principles. Annu Rev Biochem 70, 703-54.

Dolan J. W., Fields S. (1991). Cell-type-specific transcription in yeast. Biochim Biophys Acta 1088, 155-69.

Donalies U. E., Stahl U. (2002). Increasing sulphite formation in Saccharomyces cerevisiae by overexpression of MET14 and SSU1. Yeast 19, 475-84.

dos Remedios C. G., Chhabra D., Kekic M., Dedova I. V., Tsubakihara M., Berry D. A., Nosworthy N. J. (2003). Actin binding proteins: regulation of cytoskeletal microfilaments. Physiol Rev 83, 433-73.

Dower W. J., Miller J. F., Ragsdale C. W. (1988). High efficiency transformation of E. coli by high voltage electroporation. Nucleic Acids Res 16, 6127-45.

Duarte M., Videira A. (2000). Respiratory chain complex I is essential for sexual development in Neurospora and binding of iron sulfur clusters are required for enzyme assembly. Genetics 156, 607-15.

Duncker B. P., Chesnokov I. N., McConkey B. J. (2009). The origin recognition complex protein family. Genome Biol. 10, 214.

Dyer P. S. (2008). Evolutionary biology: genomic clues to original sex in fungi. Curr Biol 18, R207-9. 
Engh I., Nowrousian M., Kück U. (2007a). Regulation of melanin biosynthesis via the dihydroxynaphthalene pathway is dependent on sexual development in the ascomycete Sordaria macrospora. FEMS Microbiol Lett 275, 62-70.

Engh I., Würtz C., Witzel-Schlomp K., Zhang H. Y., Hoff B., Nowrousian M., Rottensteiner H., Kück U. (2007b). The WW domain protein PRO40 is required for fungal fertility and associates with Woronin bodies. Eukaryot Cell 6, 831-43.

Englund P. T. (1993). The structure and biosynthesis of glycosyl phosphatidylinositol protein anchors. Annu Rev Biochem 62, 121-38.

Esser K. (2000). Cryptogams-Cyanaobacteria, Fungi, Algae and Lichens. Cambridge University Press.

Favot L., Hall S. M., Haworth S. G., Kemp P. R. (2005). Cytoplasmic YY1 is associated with increased smooth muscle-specific gene expression: implications for neonatal pulmonary hypertension. Am J Pathol 167, 1497-509.

Fernandez E., Moreno F., Rodicio R. (1992). The ICL1 gene from Saccharomyces cerevisiae. Eur J Biochem 204, 983-90.

Ferreira A. V., An Z., Metzenberg R. L., Glass N. L. (1998). Characterization of mat A-2, mat A-3 and $\Delta$ matA mating-type mutants of Neurospora crassa. Genetics 148, 1069-79.

Ferreira A. V., Saupe S., Glass N. L. (1996). Transcriptional analysis of the $m t A$ idiomorph of Neurospora crassa identifies two genes in addition to $m t A-1$. Mol Gen Genet 250, 767-74.

Fleming A. (1929). On the antibacterial action of cultures of a penicillium, with special reference to their use in the isolation of B. influenzae. Br. J. Exp. Pathol. 10, 226-236.

Fraering P., Imhof I., Meyer U., Strub J. M., van Dorsselaer A., Vionnet C., Conzelmann A. (2001). The GPI transamidase complex of Saccharomyces cerevisiae contains Gaalp, Gpi8p, and Gpi16p. Mol Biol Cell 12, 3295-306.

Galagan J. E., Calvo S. E., Cuomo C., Ma L. J., Wortman J. R., Batzoglou S., Lee S. I., Basturkmen M., Spevak C. C., Clutterbuck J., Kapitonov V., Jurka J., Scazzocchio C., Farman M., Butler J., Purcell S., Harris S., Braus G. H., Draht O., Busch S., D'Enfert C., Bouchier C., Goldman G. H., Bell-Pedersen D., Griffiths-Jones S., Doonan J. H., Yu J., Vienken K., Pain A., Freitag M., Selker E. U., Archer D. B., Penalva M. A., Oakley B. R., Momany M., Tanaka T., Kumagai T., Asai K., Machida M., Nierman W. C., Denning D. W., Caddick M., Hynes M., Paoletti M., Fischer R., Miller B., Dyer P., Sachs M. S., Osmani S. A., Birren B. W. (2005). Sequencing of Aspergillus nidulans and comparative analysis with $A$. fumigatus and A. oryzae. Nature 438, 1105-15.

Galgoczy D. J., Cassidy-Stone A., Llinas M., O'Rourke S. M., Herskowitz I., DeRisi J. L., Johnson A. D. (2004). Genomic dissection of the cell-type-specification circuit in Saccharomyces cerevisiae. Proc Natl Acad Sci U S A 101, 18069-74. 
Gentleman R. C., Carey V. J., Bates D. M., Bolstad B., Dettling M., Dudoit S., Ellis B., Gautier L., Ge Y., Gentry J., Hornik K., Hothorn T., Huber W., Iacus S., Irizarry R., Leisch F., Li C., Maechler M., Rossini A. J., Sawitzki G., Smith C., Smyth G., Tierney L., Yang J. Y., Zhang J. (2004). Bioconductor: open software development for computational biology and bioinformatics. Genome Biol. 5, R80.

Georgatsou E., Mavrogiannis L. A., Fragiadakis G. S., Alexandraki D. (1997). The yeast Fre1p/Fre2p cupric reductases facilitate copper uptake and are regulated by the coppermodulated Mac1p activator. J. Biol. Chem. 272, 13786-13792.

Glass N. L., Grotelueschen J., Metzenberg R. L. (1990a). Neurospora crassa A mating-type region. Proc Natl Acad Sci US A 87, 4912-6.

Glass N. L., Lee L. (1992). Isolation of Neurospora crassa A mating type mutants by repeat induced point (RIP) mutation. Genetics 132, 125-33.

Glass N. L., Metzenberg R. L., Raju N. B. (1990b). Homothallic Sordariaceae from nature: The absence of strains containing only the a mating type sequence. Experimental Mycology 14, 274-289.

Glass N. L., Smith M. L. (1994). Structure and function of a mating-type gene from the homothallic species Neurospora africana. Mol Gen Genet 244, 401-9.

Glass N. L., Vollmer S. J., Staben C., Grotelueschen J., Metzenberg R. L., Yanofsky C. (1988). DNAs of the two mating-type alleles of Neurospora crassa are highly dissimilar. Science 241, 570-3.

Gorlatova N., Tchorzewski M., Kurihara T., Soda K., Esaki N. (1998). Purification, characterization, and mechanism of a flavin mononucleotide-dependent 2-nitropropane dioxygenase from Neurospora crassa. Appl Environ Microbiol 64, 1029-33.

Grosschedl R., Giese K., Pagel J. (1994). HMG domain proteins: architectural elements in the assembly of nucleoprotein structures. Trends Genet 10, 94-100.

Guo W., Roth D., Walch-Solimena C., Novick P. (1999). The exocyst is an effector for Sec4p, targeting secretory vesicles to sites of exocytosis. Embo J 18, 1071-80.

Haller K., Rambaldi I., Daniels E., Featherstone M. (2004). Subcellular localization of multiple PREP2 isoforms is regulated by actin, tubulin, and nuclear export. J Biol Chem 279, 49384-94.

Hartman J. L. t., Garvik B., Hartwell L. (2001). Principles for the buffering of genetic variation. Science 291, 1001-4.

Hawksworth D. L., Kirk P. M., Sutton B. C., Pegler D. N. (1995). Dictionary of the fungi, 8 edn. Univeristy press. 
Herker E., Jungwirt H., Lehmann K. A., Maldener C., Fröhlich K. U., Wissing S., Büttner S., Fehr M., Sigrist S., Madeo F. (2004). Chronological aging leads to apoptosis in yeast. J Cell Biol 164, 501-507.

Herskowitz I. (1988). Life cycle of the budding yeast Saccharomyces cerevisiae. Microbiol Rev 52, 536-53.

Herskowitz I. (1989). A regulatory hierarchy for cell specialization in yeast. Nature 342, 74957.

Hoff B., Pöggeler S., Kück U. (2008). Eighty years after its discovery, Fleming's Penicillium strain discloses the secret of its sex. Eukaryot Cell 7, 465-70.

Hoffman C. S. (2001). Preparation of yeast DNA. Curr Protoc Mol Biol Chapter 13, Unit13 11.

Horton P., Park K. J., Obayashi T., Fujita N., Harada H., Adams-Collier C. J., Nakai K. (2007). WoLF PSORT: protein localization predictor. Nucleic Acids Res 35, W585-7.

Hsueh Y. P., Heitman J. (2008). Orchestration of sexual reproduction and virulence by the fungal mating-type locus. Curr. Opin. Microbiol. 11, 517-524.

Huang Z., Zang K., Reichardt L. F. (2005). The origin recognition core complex regulates dendrite and spine development in postmitotic neurons. J. Cell Biol. 170, 527-535.

Hull C. M., Johnson A. D. (1999). Identification of a mating type-like locus in the asexual pathogenic yeast Candida albicans. Science 285, 1271-5.

Idnurm A., Walton F. J., Floyd A., Heitman J. (2008). Identification of the sex genes in an early diverged fungus. Nature 451, 193-6.

Iraqui I., Vissers S., Cartiaux M., Urrestarazu A. (1998). Characterisation of Saccharomyces cerevisiae ARO8 and ARO9 genes encoding aromatic aminotransferases I and II reveals a new aminotransferase subfamily. Mol Gen Genet 257, 238-48.

Jacobsen S., Wittig M., Pöggeler S. (2002). Interaction between mating-type proteins from the homothallic fungus Sordaria macrospora. Curr Genet 41, 150-8.

James P., Halladay J., Craig E. A. (1996). Genomic libraries and a host strain designed for highly efficient two-hybrid selection in yeast. Genetics 144, 1425-36.

Janus D., Hoff B., Hofmann E., Kuck U. (2007). An efficient fungal RNA-silencing system using the DsRed reporter gene. Appl Environ Microbiol 73, 962-70.

Jentsch S., Schlenker S. (1995). Selective protein degradation: a journey's end within the proteasome. Cell 82, 881-4. 
Johnson A. D. (1995). Molecular mechanisms of cell-type determination in budding yeast. Curr Opin Genet Dev 5, 552-8.

Kanematsu S., Adachi Y., Ito T. (2007). Mating-type loci of heterothallic Diaporthe spp.: homologous genes are present in opposite mating-types. Curr Genet 52, 11-22.

Kang Y. S., Kane J., Kurjan J., Stadel J. M., Tipper D. J. (1990). Effects of expression of mammalian $\mathrm{G} \alpha$ and hybrid mammalian-yeast $\mathrm{G} \alpha$ proteins on the yeast pheromone response signal transduction pathway. Mol Cell Biol 10, 2582-90.

Keller N. P., Turner G., Bennett J. W. (2005). Fungal secondary metabolism - from biochemistry to genomics. Nat Rev Microbiol 3, 937-47.

Kim H., Borkovich K. A. (2004). A pheromone receptor gene, pre-1, is essential for mating type-specific directional growth and fusion of trichogynes and female fertility in Neurospora crassa. Mol Microbiol 52, 1781-98.

Kim H., Borkovich K. A. (2006). Pheromones are essential for male fertility and sufficient to direct chemotropic polarized growth of trichogynes during mating in Neurospora crassa.

Eukaryot Cell 5, 544-54.

Kim H., Metzenberg R. L., Nelson M. A. (2002). Multiple functions of $m f a-1$, a putative pheromone precursor gene of Neurospora crassa. Eukaryot Cell 1, 987-99.

Kim H. K., Lee T., Yun S. H. (2008). A putative pheromone signaling pathway is dispensable for self-fertility in the homothallic ascomycete Gibberella zeae. Fungal Genet Biol 45, 118896.

Kim Y., Gentry M. S., Harris T. E., Wiley S. E., Lawrence J. C., Jr., Dixon J. E. (2007). A conserved phosphatase cascade that regulates nuclear membrane biogenesis. Proc Natl Acad Sci U S A 104, 6596-601.

Kispal G., Steiner H., Court D. A., Rolinski B., Lill R. (1996). Mitochondrial and cytosolic branched-chain amino acid transaminases from yeast, homologs of the myc oncogeneregulated Eca39 protein. J Biol Chem 271, 24458-64.

Kitagaki H., Wu H., Shimoi H., Ito K. (2002). Two homologous genes, DCW1 (YKL046c) and DFG5, are essential for cell growth and encode glycosylphosphatidylinositol (GPI)anchored membrane proteins required for cell wall biogenesis in Saccharomyces cerevisiae. Mol Microbiol 46, 1011-22.

Klix V. (2007). Molekulargenetische Analyse des Kreuzungstyp-Locus des filamentösen Ascomyceten Sordaria macrospora, Ruhr-Universität.

Klix V., Nowrousian M., Ringelberg C., Loros J. J., Dunlap J. C., Pöggeler S. (2010). Functional characterization of MAT1-1-specific mating-type genes in the homothallic 
ascomycete Sordaria macrospora provides new insights into essential and nonessential sexual regulators. Eukaryot Cell 9, 894-905.

Knoll L. J., Johnson D. R., Gordon J. I. (1994). Biochemical studies of three Saccharomyces cerevisiae acyl-CoA synthetases, Faa1p, Faa2p, and Faa3p. J Biol Chem 269, 16348-56.

Kopito R. R. (1997). ER quality control: the cytoplasmic connection. Cell 88, 427-30.

Kothe E. (2008). Sexual attraction: on the role of fungal pheromone/receptor systems (A review). Acta Microbiol Immunol Hung 55, 125-43.

Kuchler K., Sterne R. E., Thorner J. (1989). Saccharomyces cerevisiae STE6 gene product: a novel pathway for protein export in eukaryotic cells. Embo J 8, 3973-84.

Kück U., Pöggeler S., Nowrousian M., Nolting N., Engh I. (2009). Sordaria macrospora, a model system for fungal development in T. Anke and D. Weber (Eds), The Mycota.

Physiology and genetics: selected basic and applied aspects, Springer Verlag, pp. 17-39.

Kurjan J. (1993). The pheromone response pathway in Saccharomyces cerevisiae. Annu Rev Genet 27, 147-79.

Lecellier G., Silar P. (1994). Rapid methods for nucleic acids extraction from Petri dishgrown mycelia. Curr Genet 25, 122-3.

Lee J., Lee T., Lee Y. W., Yun S. H., Turgeon B. G. (2003). Shifting fungal reproductive mode by manipulation of mating type genes: obligatory heterothallism of Gibberella zeae. Mol Microbiol 50, 145-52.

Lee J., Leslie J. F., Bowden R. L. (2008). Expression and function of sex pheromones and receptors in the homothallic ascomycete Gibberella zeae. Eukaryot Cell 7, 1211-21.

Lee M. W., Kim B. J., Choi H. K., Ryu M. J., Kim S. B., Kang K. M., Cho E. J., Youn H. D., Huh W. K., Kim S. T. (2007). Global protein expression profiling of budding yeast in response to DNA damage. Yeast 24, 145-54.

Leidich S. D., Drapp D. A., Orlean P. (1994). A conditionally lethal yeast mutant blocked at the first step in glycosyl phosphatidylinositol anchor synthesis. J Biol Chem 269, 10193-6.

Leidich S. D., Kostova Z., Latek R. R., Costello L. C., Drapp D. A., Gray W., Fassler J. S., Orlean P. (1995). Temperature-sensitive yeast GPI anchoring mutants gpi2 and gpi3 are defective in the synthesis of $\mathrm{N}$-acetylglucosaminyl phosphatidylinositol. J Biol Chem 270, 13029-35.

Li H., Zhou H., Luo Y., Ouyang H., Hu H., Jin C. (2007). Glycosylphosphatidylinositol (GPI) anchor is required in Aspergillus fumigatus for morphogenesis and virulence. Mol Microbiol 64, 1014-27. 
Lin X., Heitman J. (2007). Mechanisms of homothallism in fungi and transitions between heterothallism and homothallism. in J. Heitman, J. W. Kronstad, J. W. Taylor and L. A. Casselton (Eds), Sex in fungi., ASM Press, pp. 35-57.

Lussier M., Sdicu A. M., Camirand A., Bussey H. (1996). Functional characterization of the $Y U R 1, K T R 1$, and KTR2 genes as members of the yeast KRE2/MNT1 mannosyltransferase gene family. J Biol Chem 271, 11001-8.

Lyons T. J., Villa N. Y., Regalla L. M., Kupchak B. R., Vagstad A., Eide D. J. (2004). Metalloregulation of yeast membrane steroid receptor homologs. Proc Natl Acad Sci US A 101, 5506-11.

MacPherson S., Larochelle M., Turcotte B. (2006). A fungal family of transcriptional regulators: the zinc cluster proteins. Microbiol Mol Biol Rev 70, 583-604.

Marbach K., Fernández-Larrea J., Stahl U. (1994). Reversion of a long-living, undifferentiated mutant of Podospora anserina by copper. Curr Genet 26, 184-186.

März S., Funakoshi Y., Negishi Y., Suzuki T., Seiler S. (2009). The Neurospora peptide- $N$ glycanase ortholog PNG1 is essential for cell polarity despite its lack of enzymatic activity. $J$ Biol Chem 285, 2326-32.

Masloff S., Jacobsen S., Pöggeler S., Kück U. (2002). Functional analysis of the C6 zinc finger gene prol involved in fungal sexual development. Fungal Genet Biol 36, 107-16.

Masloff S., Pöggeler S., Kück U. (1999). The prol(+) gene from Sordaria macrospora encodes a $\mathrm{C} 6$ zinc finger transcription factor required for fruiting body development. Genetics 152, 191-9.

Mayrhofer S., Pöggeler S. (2005). Functional characterization of an $\alpha$-factor-like Sordaria macrospora peptide pheromone and analysis of its interaction with its cognate receptor in Saccharomyces cerevisiae. Eukaryot Cell 4, 661-72.

Mayrhofer S., Weber J. M., Pöggeler S. (2006). Pheromones and pheromone receptors are required for proper sexual development in the homothallic ascomycete Sordaria macrospora. Genetics 172, 1521-33.

McConville M. J., Ferguson M. A. (1993). The structure, biosynthesis and function of glycosylated phosphatidylinositols in the parasitic protozoa and higher eukaryotes. Biochem $J$ 294 ( Pt 2), 305-24.

Mehta S. Q., Hiesinger P. R., Beronja S., Zhai R. G., Schulze K. L., Verstreken P., Cao Y., Zhou Y., Tepass U., Crair M. C., Bellen H. J. (2005). Mutations in Drosophila sec 15 reveal a function in neuronal targeting for a subset of exocyst components. Neuron 46, 219-32. 
Meile L., Rohr L. M., Geissmann T. A., Herensperger M., Teuber M. (2001). Characterization of the D-xylulose 5-phosphate/D-fructose 6-phosphate phosphoketolase gene (xfp) from Bifidobacterium lactis. J Bacteriol 183, 2929-36.

Messenguy F., Dubois E. (1993). Genetic evidence for a role for MCM1 in the regulation of arginine metabolism in Saccharomyces cerevisiae. Mol Cell Biol 13, 2586-92.

Metzenberg R. L., Glass N. L. (1990). Mating type and mating strategies in Neurospora. Bioessays 12, 53-59.

Middelhoven W. J. (1964). The Pathway of Arginine Breakdown in Saccharomyces cerevisiae. Biochim Biophys Acta 93, 650-2.

Mount D. B., Romero M. F. (2004). The SLC26 gene family of multifunctional anion exchangers. Pflugers Arch 447, 710-21.

Mullis K. B., Faloona F. A. (1987). Specific synthesis of DNA in vitro via a polymerasecatalyzed chain reaction. Methods Enzymol 155, 335-50.

Mushegian A. R., Koonin E. V. (1994). Unexpected sequence similarity between nucleosidases and phosphoribosyltransferases of different specificity. Protein Sci 3, 1081-8.

Nasmyth K. A. (1982). The regulation of yeast mating-type chromatin structure by SIR: an action at a distance affecting both transcription and transposition. Cell 30, 567-78.

Neiman A. M. (1998). Prospore membrane formation defines a developmentally regulated branch of the secretory pathway in yeast. J Cell Biol 140, 29-37.

Nelson M. A., Metzenberg R. L. (1992). Sexual development genes of Neurospora crassa. Genetics 132, 149-62.

Nierman W. C., Pain A., Anderson M. J., Wortman J. R., Kim H. S., Arroyo J., Berriman M., Abe K., Archer D. B., Bermejo C., Bennett J., Bowyer P., Chen D., Collins M., Coulsen R., Davies R., Dyer P. S., Farman M., Fedorova N., Feldblyum T. V., Fischer R., Fosker N., Fraser A., Garcia J. L., Garcia M. J., Goble A., Goldman G. H., Gomi K., Griffith-Jones S., Gwilliam R., Haas B., Haas H., Harris D., Horiuchi H., Huang J., Humphray S., Jimenez J., Keller N., Khouri H., Kitamoto K., Kobayashi T., Konzack S., Kulkarni R., Kumagai T., Lafon A., Latge J. P., Li W., Lord A., Lu C., Majoros W. H., May G. S., Miller B. L., Mohamoud Y., Molina M., Monod M., Mouyna I., Mulligan S., Murphy L., O'Neil S., Paulsen I., Penalva M. A., Pertea M., Price C., Pritchard B. L., Quail M. A., Rabbinowitsch E., Rawlins N., Rajandream M. A., Reichard U., Renauld H., Robson G. D., Rodriguez de Cordoba S., Rodriguez-Pena J. M., Ronning C. M., Rutter S., Salzberg S. L., Sanchez M., Sanchez-Ferrero J. C., Saunders D., Seeger K., Squares R., Squares S., Takeuchi M., Tekaia F., Turner G., Vazquez de Aldana C. R., Weidman J., White O., Woodward J., Yu J. H., Fraser C., Galagan J. E., Asai K., Machida M., Hall N., Barrell B., Denning D. W. (2005). Genomic sequence of the pathogenic and allergenic filamentous fungus Aspergillus fumigatus. Nature 438, 1151-6. 
Nolting N., Pöggeler S. (2006a). A MADS box protein interacts with a mating-type protein and is required for fruiting body development in the homothallic ascomycete Sordaria macrospora. Eukaryot Cell 5, 1043-56.

Nolting N., Pöggeler S. (2006b). A STE12 homologue of the homothallic ascomycete Sordaria macrospora interacts with the MADS box protein MCM1 and is required for ascosporogenesis. Mol Microbiol 62, 853-68.

Norais N., Prome D., Velours J. (1991). ATP synthase of yeast mitochondria.

Characterization of subunit $\mathrm{d}$ and sequence analysis of the structural gene ATP7. J Biol Chem 266, 16541-9.

Nordgard O., Dahle O., Andersen T. O., Gabrielsen O. S. (2001). JAB1/CSN5 interacts with the GAL4 DNA binding domain: a note of caution about two-hybrid interactions. Biochimie 83, 969-71.

Nowrousian M., Frank S., Koers S., Strauch P., Weitner T., Ringelberg C., Dunlap J. C., Loros J. J., Kück U. (2007a). The novel ER membrane protein PRO41 is essential for sexual development in the filamentous fungus Sordaria macrospora. Mol Microbiol 64, 923-37.

Nowrousian M., Masloff S., Pöggeler S., Kück U. (1999). Cell differentiation during sexual development of the fungus Sordaria macrospora requires ATP citrate lyase activity. Mol Cell Biol 19, 450-60.

Nowrousian M., Piotrowski M., Kück U. (2007b). Multiple layers of temporal and spatial control regulate accumulation of the fruiting body-specific protein APP in Sordaria macrospora and Neurospora crassa. Fungal Genet Biol 44, 602-14.

Nowrousian M., Ringelberg C., Dunlap J. C., Loros J. J., Kück U. (2005). Cross-species microarray hybridization to identify developmentally regulated genes in the filamentous fungus Sordaria macrospora. Mol Genet Genomics 273, 137-49.

Nowrousian M., Würtz C., Pöggeler S., Kück U. (2004). Comparative sequence analysis of Sordaria macrospora and Neurospora crassa as a means to improve genome annotation. Fungal Genet. Biol. 41, 285-292.

Odat O., Matta S., Khalil H., Kampranis S. C., Pfau R., Tsichlis P. N., Makris A. M. (2007). Old yellow enzymes, highly homologous FMN oxidoreductases with modulating roles in oxidative stress and programmed cell death in yeast. J Biol Chem 282, 36010-23.

O'Gorman C. M., Fuller H. T., Dyer P. S. (2009). Discovery of a sexual cycle in the opportunistic fungal pathogen Aspergillus fumigatus. Nature 457, 471-4.

Paoletti M., Rydholm C., Schwier E. U., Anderson M. J., Szakacs G., Lutzoni F., Debeaupuis J. P., Latge J. P., Denning D. W., Dyer P. S. (2005). Evidence for sexuality in the opportunistic fungal pathogen Aspergillus fumigatus. Curr Biol 15, 1242-8. 
Paoletti M., Seymour F. A., Alcocer M. J., Kaur N., Calvo A. M., Archer D. B., Dyer P. S. (2007). Mating type and the genetic basis of self-fertility in the model fungus Aspergillus nidulans. Curr Biol 17, 1384-9.

Perkins D. D., Barry E. G. (1977). The cytogenetics of Neurospora. Adv Genet 19, 133-285.

Pesin J. A., Orr-Weaver T. L. (2008). Regulation of APC/C activators in mitosis and meiosis. Annu. Rev. Cell. Dev. Biol. 24, 475-499.

Pfaffl M. W., Horgan G. W., Dempfle L. (2002). Relative expression software tool (REST) for group-wise comparison and statistical analysis of relative expression results in real-time PCR. Nucleic Acids Res 30, e36.

Pinto S., Quintana D. G., Smith P., Mihalek R. M., Hou Z. H., Boynton S., Jones C. J., Hendricks M., Velinzon K., Wohlschlegel J. A., Austin R. J., Lane W. S., Tully. T., Dutta A. (1999). latheo encodes a subunit of the origin recognition complex and disrupts neuronal proliferation and adult olfactory memory when mutant. Neuron 23, 45-54.

Pöggeler S. (2000). Two pheromone precursor genes are transcriptionally expressed in the homothallic ascomycete Sordaria macrospora. Curr Genet 37, 403-11.

Pöggeler S. (2001). Mating-type genes for classical strain improvements of ascomycetes. Appl Microbiol Biotechnol 56, 589-601.

Pöggeler S. (2002). Genomic evidence for mating abilities in the asexual pathogen Aspergillus fumigatus. Curr Genet 42, 153-60.

Pöggeler S. (2007). MAT and its role in the homothallic ascomycete Sordaria macrospora in J. Heitman, J. W. Kronstad, J. W. Taylor and L. Casselton (Eds), Sex in Fungi, ASM Press, pp. 171-188.

Pöggeler S., Kück U. (2000). Comparative analysis of the mating-type loci from Neurospora crassa and Sordaria macrospora: identification of novel transcribed ORFs. Mol Gen Genet 263, 292-301.

Pöggeler S., Kück U. (2001). Identification of transcriptionally expressed pheromone receptor genes in filamentous ascomycetes. Gene 280, 9-17.

Pöggeler S., Kück U. (2004). A WD40 repeat protein regulates fungal cell differentiation and can be replaced functionally by the mammalian homologue striatin. Eukaryot Cell 3, 232-40.

Pöggeler S., Kück U. (2006). Highly efficient generation of signal transduction knockout mutants using a fungal strain deficient in the mammalian ku70 ortholog. Gene 378, 1-10. 
Pöggeler S., Masloff S., Hoff B., Mayrhofer S., Kück U. (2003). Versatile EGFP reporter plasmids for cellular localization of recombinant gene products in filamentous fungi. Curr Genet 43, 54-61.

Pöggeler S., Nowrousian M., Kück U. (2006a). Fruiting body development in ascomycetes in U. Kües and R. Fischer (Eds), The Mycota I: Growth, Differentiation and Sexuality, Springer Verlag, pp. 325-355.

Pöggeler S., Nowrousian M., Ringelberg C., Loros J. J., Dunlap J. C., Kück U. (2006b). Microarray and real-time PCR analyses reveal mating type-dependent gene expression in a homothallic fungus. Mol Genet Genomics 275, 492-503.

Pöggeler S., Risch S., Kück U., Osiewacz H. D. (1997). Mating-type genes from the homothallic fungus Sordaria macrospora are functionally expressed in a heterothallic ascomycete. Genetics 147, 567-80.

Pronk J. T., Yde Steensma H., Van Dijken J. P. (1996). Pyruvate metabolism in Saccharomyces cerevisiae. Yeast 12, 1607-33.

Pyrzak W., Miller K. Y., Miller B. L. (2008). Mating type protein Mat1-2 from asexual Aspergillus fumigatus drives sexual reproduction in fertile Aspergillus nidulans. Eukaryot Cell 7, 1029-40.

Raper K. B., Alexander D. F., Coghill R. D. (1944). Penicillin: II. Natural Variation and Penicillin Production in Penicillium notatum and Allied Species. J Bacteriol 48, 639-59.

Raudaskoski M., Kothe E. (2010). Basidiomycete mating type genes and pheromone signaling. Eukaryot Cell 9, 847-59.

Reed S. I. (1980). The selection of $S$. cerevisiae mutants defective in the start event of cell division. Genetics 95, 561-77.

Roca M. G., Kuo H. C., Lichius A., Freitag M., Read N. D. (2010). Nuclear dynamics, mitosis and the cytoskeleton during the early stages of colony initiation in Neurospora crassa.

Eukaryot Cell.

Ruepp A., Zollner A., Maier D., Albermann K., Hani J., Mokrejs M., Tetko I., Guldener U., Mannhaupt G., Munsterkotter M., Mewes H. W. (2004). The FunCat, a functional annotation scheme for systematic classification of proteins from whole genomes. Nucleic Acids Res 32, $5539-45$.

Saeed A. I., Sharov V., White J., Li J., Liang W., Bhagabati N., Braisted J., Klapa M., Currier T., Thiagarajan M., Sturn A., Snuffin M., Rezantsev A., Popov D., Ryltsov A., Kostukovich E., Borisovsky I., Liu Z., Vinsavich A., Trush V., Quackenbush J. (2003). TM4: a free, opensource system for microarray data management and analysis. Biotechniques 34, 374-8. 
Sambrook J., Fritsch E., Maniatis T. (2001). Molecular cloning: a laboratory manual., 2nd Ed. edn. Cold Spring Harbor Laboratory, Cold Spring Habor.

Samson R. A., Hadlok R., Stolk A. C. (1977). A taxonomic study of the Penicillium chrysogenum series. Antonie Van Leeuwenhoek 43, 169-75.

Sanchez J. P., Murakami Y., Huberman J. A., Hurwitz J. (1998). Isolation, characterization, and molecular cloning of a protein (Abp2) that binds to a Schizosaccharomyces pombe origin of replication (ars3002). Mol Cell Biol 18, 1670-81.

Saupe S., Stenberg L., Shiu K. T., Griffiths A. J., Glass N. L. (1996). The molecular nature of mutations in the mt A-1 gene of the Neurospora crassa A idiomorph and their relation to mating-type function. Mol Gen Genet 250, 115-22.

Schimek C., Wostemeyer J. (2009). Carotene derivatives in sexual communication of zygomycete fungi. Phytochemistry 70, 1867-75.

Schneiter R., Hitomi M., Ivessa A. S., Fasch E. V., Kohlwein S. D., Tartakoff A. M. (1996). A yeast acetyl coenzyme A carboxylase mutant links very-long-chain fatty acid synthesis to the structure and function of the nuclear membrane-pore complex. Mol Cell Biol 16, 7161-72.

Seiler S., Plamann M. (2003). The genetic basis of cellular morphogenesis in the filamentous fungus Neurospora crassa. Mol Biol Cell 14, 4352-64.

Seo J. A., Han K. H., Yu J. H. (2004). The gprA and gprB genes encode putative G proteincoupled receptors required for self-fertilization in Aspergillus nidulans. Mol Microbiol 53, 1611-23.

Severin F. F., Hyman A. A. (2002). Pheromone induces cell death in S. cerevisiae. Curr Biol 12, R233-R445.

Sharifmoghadam M. R., de Leon N., Hoya M., Curto M. A., Valdivieso M. H. (2010). Different steps of sexual development are differentially regulated by the Sec8p and Exo70p exocyst subunits. FEMS Microbiol Lett 305, 71-80.

Shen W. C., Bobrowicz P., Ebbole D. J. (1999). Isolation of pheromone precursor genes of Magnaporthe grisea. Fungal Genet Biol 27, 253-63.

Shen X., Ranallo R., Choi E., Wu C. (2003). Involvement of actin-related proteins in ATPdependent chromatin remodeling. Mol Cell 12, 147-55.

Shima J., Sakata-Tsuda Y., Suzuki Y., Nakajima R., Watanabe H., Kawamoto S., Takano H. (2003). Disruption of the CAR1 gene encoding arginase enhances freeze tolerance of the commercial baker's yeast Saccharomyces cerevisiae. Appl Environ Microbiol 69, 715-8.

Shore P., Sharrocks A. D. (1995). The MADS-box family of transcription factors. Eur $J$ Biochem 229, 1-13. 
Shuster E. O., Byers B. (1989). Pachytene arrest and other meiotic effects of the start mutations in Saccharomyces cerevisiae. Genetics 123, 29-43.

Singh A., Chen E. Y., Lugovoy J. M., Chang C. N., Hitzeman R. A., Seeburg P. H. (1983). Saccharomyces cerevisiae contains two discrete genes coding for the $\alpha$-factor pheromone. Nucleic Acids Res 11, 4049-63.

Siniossoglou S., Santos-Rosa H., Rappsilber J., Mann M., Hurt E. (1998). A novel complex of membrane proteins required for formation of a spherical nucleus. Embo J 17, 6449-64.

Skatrud P. L., Queener S. W., Carr L. G., Fisher D. L. (1987). Efficient integrative transformation of Cephalosporium acremonium. Curr Genet 12, 337-48.

Smyth G. K. (2004). Linear models and empirical bayes methods for assessing differential expression in microarray experiments. Stat Appl Genet Mol Biol 3, Article3.

Southern E. M. (1975). Detection of specific sequences among DNA fragments separated by gel electrophoresis. J Mol Biol 98, 503-17.

Souza C. A., Silva C. C., Ferreira A. V. (2003). Sex in fungi: lessons of gene regulation. Genet Mol Res 2, 136-47.

Sprague G. F., Jr. (1991). Assay of yeast mating reaction. Methods Enzymol 194, 77-93.

Staben C., Yanofsky C. (1990). Neurospora crassa a mating-type region. Proc Natl Acad Sci $U S A$ 87, 4917-21.

Steensma H. Y., Holterman L., Dekker I., van Sluis C. A., Wenzel T. J. (1990). Molecular cloning of the gene for the E1 alpha subunit of the pyruvate dehydrogenase complex from Saccharomyces cerevisiae. Eur J Biochem 191, 769-74.

Stötzler D., Klitz H. H., Duntze W. (1976). Primary structure of the $\alpha$-factor peptides from Saccharomyces cerevisiae. Eur. J. Biochem. 69, 397-400.

Strathern J. N., Klar A. J., Hicks J. B., Abraham J. A., Ivy J. M., Nasmyth K. A., McGill C. (1982). Homothallic switching of yeast mating type cassettes is initiated by a double-stranded cut in the MAT locus. Cell 31, 183-92.

TerBush D. R., Maurice T., Roth D., Novick P. (1996). The Exocyst is a multiprotein complex required for exocytosis in Saccharomyces cerevisiae. Embo J 15, 6483-94.

Thompson-Coffe C., Zickler D. (1993). Cytoskeleton interactions in the ascus development and sporulation of Sordari macrospora. Journal of Cell Science, 883-898. 
Tian C., Kasuga T., Sachs M. S., Glass N. L. (2007). Transcriptional profiling of cross pathway control in Neurospora crassa and comparative analysis of the Gcn 4 and CPC1 regulons. Eukaryot Cell 6, 1018-1029.

Tucker C. L., Peteya L. A., Pittman A. M., Zhong J. (2009). A genetic test for yeast twohybrid bait competency using RanBPM. Genetics 182, 1377-9.

Turgeon B. G., Debuchy R. (2007). Cochliobolus and Podospora: Mechanisms of sex determination and the evolution of reproductive lifestyle. in J. Heitman, J. W. Kronstad, J. W. Taylor and L. Casselton (Eds), Sex in fungi., ASM Press, pp. 93-121.

Turgeon B. G., Yoder O. C. (2000). Proposed nomenclature for mating type genes of filamentous ascomycetes. Fungal Genet. Biol. 31, 1-5.

Urban-Grimal D., Labbe-Bois R. (1981). Genetic and biochemical characterization of mutants of Saccharomyces cerevisiae blocked in six different steps of heme biosynthesis. Mol Gen Genet 183, 85-92.

van den Ende H. (1967). Sexual factor of the Mucorales. Nature 215, 211-2.

Vassal A., Boulet A., Decoster E., Faye G. (1992). QRI8, a novel ubiquitin-conjugating enzyme in Saccharomyces cerevisiae. Biochim Biophys Acta 1132, 211-3.

Videira A., Kasuga T., Tian C., Lemos C., Castro A., Glass N. L. (2009). Transcriptional analysis of the response of Neurospora crassa to phytosphingosine reveals links to mitochondrial function. Microbiology 155, 3134-41.

Vierula P. J. (1997). Cloning and characterization of a Neurospora crassa ribosomal protein gene, crps-7. Curr Genet 31, 139-43.

Vogt N., Seiler S. (2008). The RHO1-specific GTPase-activating protein LRG1 regulates polar tip growth in parallel to Ndr kinase signaling in Neurospora. Mol Biol Cell 19, 4554-69.

Vossen J. H., Ram A. F., Klis F. M. (1995). Identification of SPT14/CWH6 as the yeast homologue of hPIG-A, a gene involved in the biosynthesis of GPI anchors. Biochim Biophys Acta 1243, 549-51.

Wang Y., Dohlman H. G. (2004). Pheromone signaling mechanisms in yeast: a prototypical sex machine. Science 306, 1508-9.

Winter D., Podtelejnikov A. V., Mann M., Li R. (1997). The complex containing actin-related proteins Arp2 and Arp3 is required for the motility and integrity of yeast actin patches. Curr Biol 7, 519-29.

Woo P. C., Chong K. T., Tse H., Cai J. J., Lau C. C., Zhou A. C., Lau S. K., Yuen K. Y. (2006). Genomic and experimental evidence for a potential sexual cycle in the pathogenic thermal dimorphic fungus Penicillium marneffei. FEBS Lett 580, 3409-16. 
Xue Y., Li A., Wang L., Feng H., Yao X. (2006). PPSP: prediction of PK-specific phosphorylation site with Bayesian decision theory. BMC Bioinformatics 7, 163.

Yamashita M., Kurokawa K., Sato Y., Yamagata A., Mimura H., Yoshikawa A., Sato K., Nakano A., Fukai S. (2010). Structural basis for the Rho- and phosphoinositide-dependent localization of the exocyst subunit Sec3. Nat Struct Mol Biol 17, 180-6.

Yarden O., Plamann M., Ebbole D. J., Yanofsky C. (1992). cot-1, a gene required for hyphal elongation in Neurospora crassa, encodes a protein kinase. Embo J 11, 2159-66.

Yokogawa T., Shimada N., Takeuchi N., Benkowski L., Suzuki T., Omori A., Ueda T., Nishikawa K., Spremulli L. L., Watanabe K. (2000). Characterization and tRNA recognition of mammalian mitochondrial seryl-tRNA synthetase. J Biol Chem 275, 19913-20.

Yuan Y. O., Stroke I. L., Fields S. (1993). Coupling of cell identity to signal response in yeast: interaction between the $\alpha 1$ and STE12 proteins. Genes Dev 7, 1584-97.

Zhang L., Baasiri R. A., Van Alfen N. K. (1998). Viral repression of fungal pheromone precursor gene expression. Mol Cell Biol 18, 953-9.

Zheng B., Han M., Bernier M., Wen J. K. (2009). Nuclear actin and actin-binding proteins in the regulation of transcription and gene expression. Febs $J$ 276, 2669-85. 


\section{Anhang}

7.1. Überprüfung der Integration der Komplementationskonstrukte

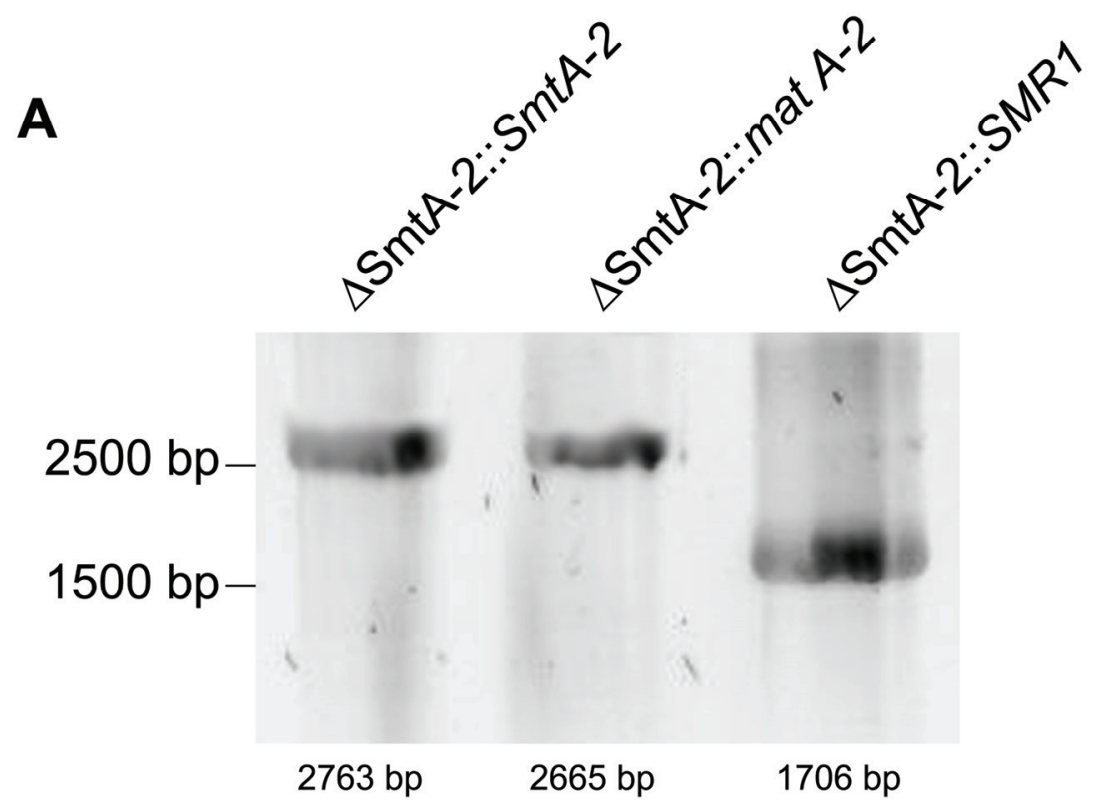

B
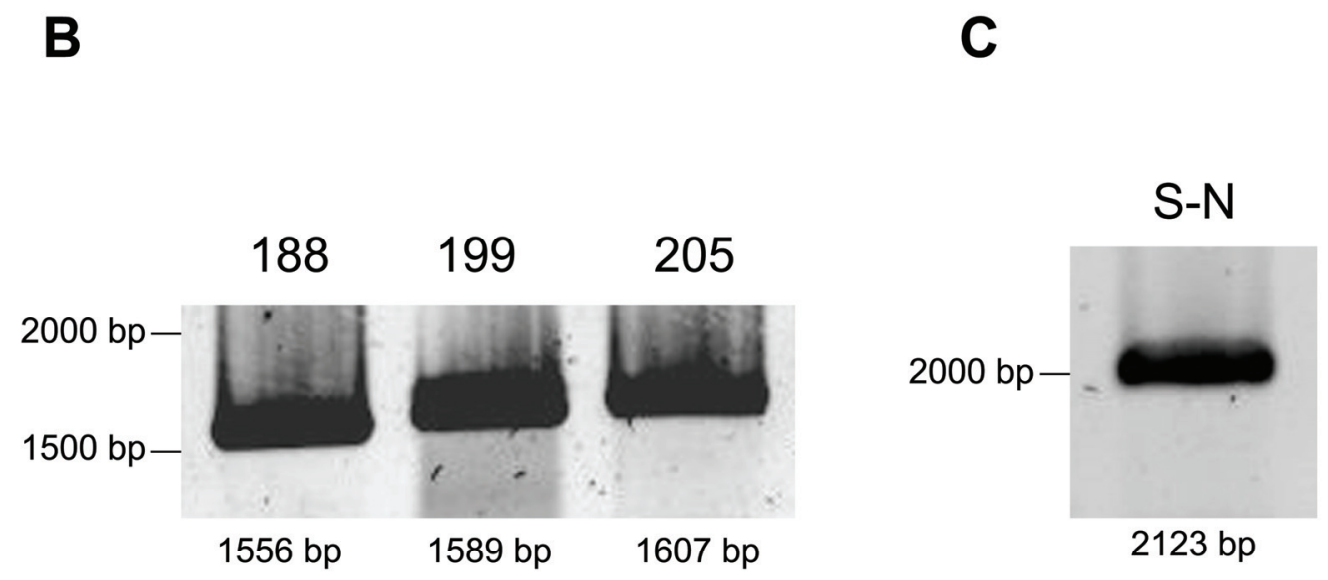

Anhang A1: Überprüfung der Integration der verschiedenen Komplementationskonstrukte in $\Delta$ SmtA-2. Die Analyse wurde mittels PCR mit den Starteroligonukleotiden pRS-Seq-F / pRS-Seq-r durchgeführt. Die erwarteten Bandengrößen für die Komplementation mit $S$. macrospora SmtA-2, $N$. crassa mat A-2 und $P$. anserina SMR1 (A) sind angegeben. Ebenfalls aufgeführt sind die Ergebnisse für die Komplementationskonstrukte A2-188, A2-199, A2-205 (B) und A2-SN (C). 


\section{2.Überprüfung der Integration der Fluoreszenzkonstrukte}
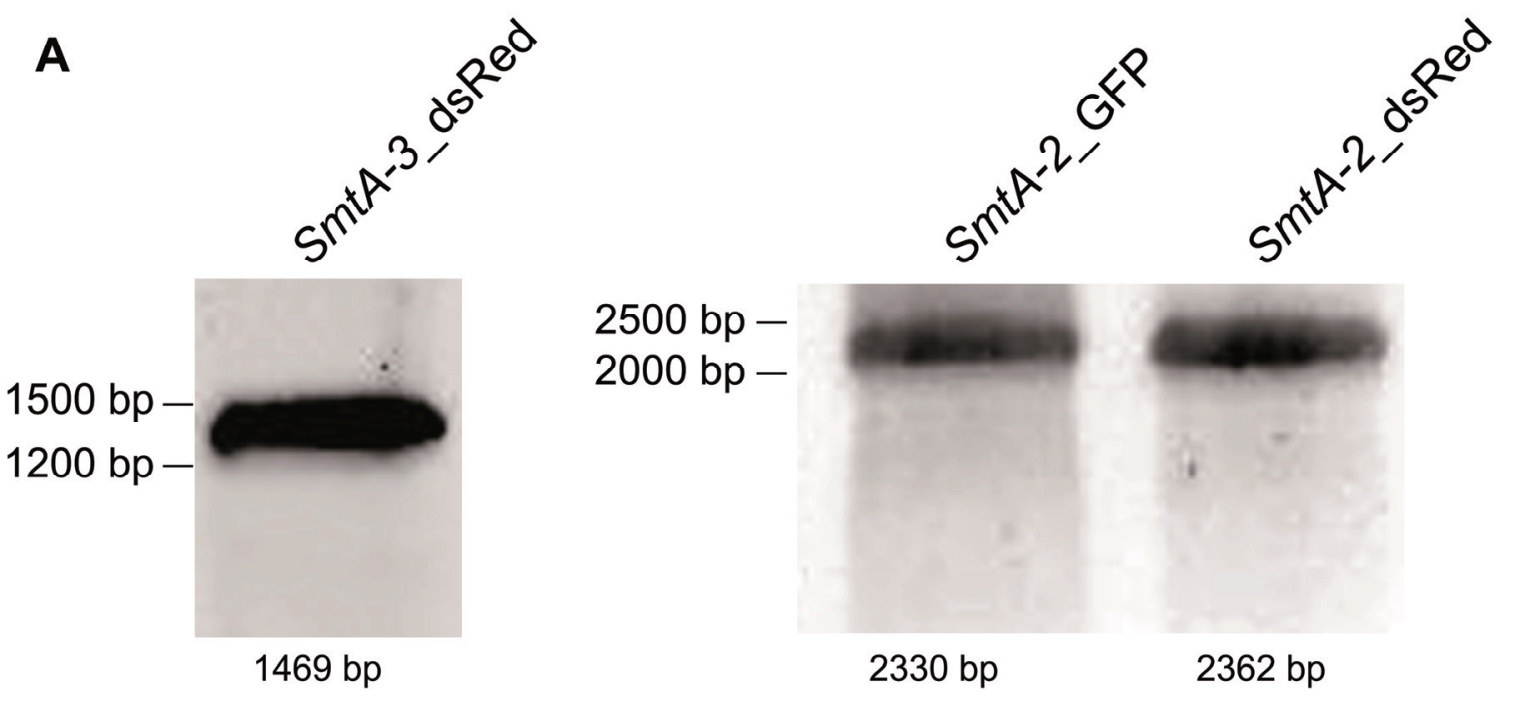

B
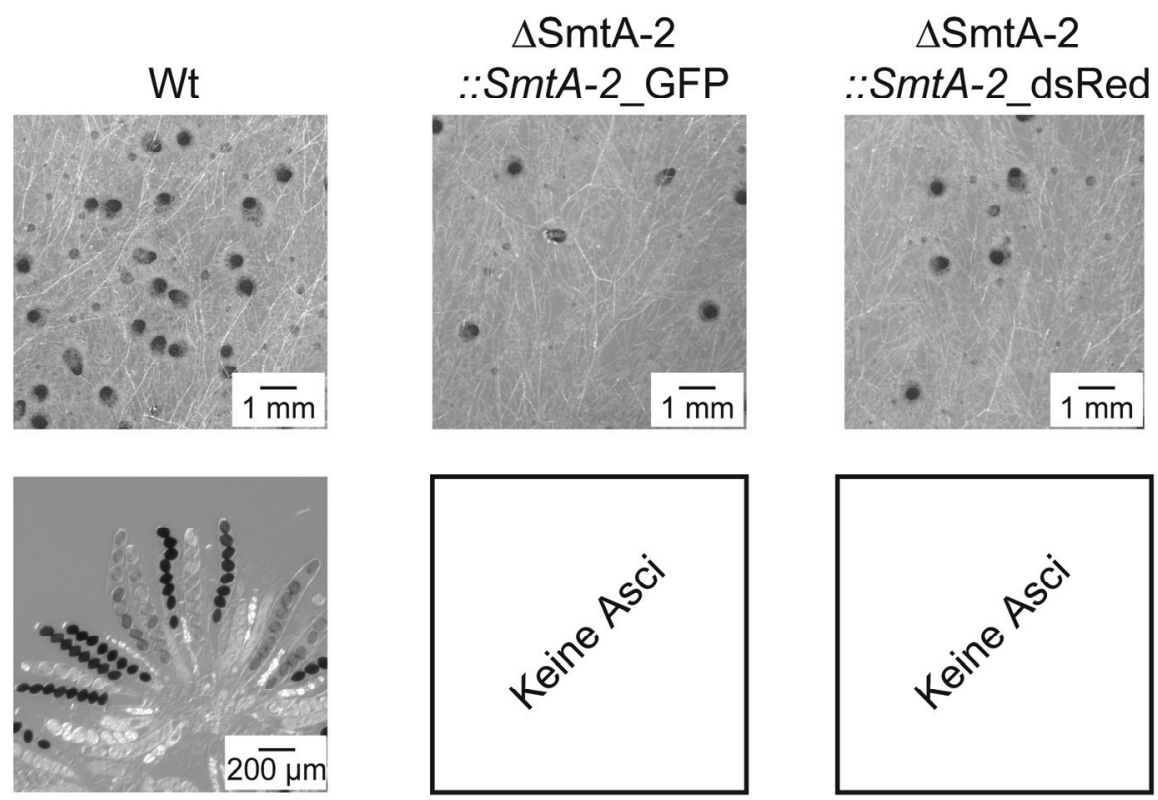

Anhang A2: (A) Überprüfung der Integration der verschiedenen Fluoreszenzkonstrukte in die S. macrospora Transformanten mit den Starteroligonukleotiden 1783-f / 1783-r. Die Nukleotide binden im Promotor bzw. Terminator der Konstrukte. Gesamt-DNA der Transformanten wurde nach 3 Tagen Wachstum auf BMM-Flüssigmedium isoliert. (B) Komplementation der Fluoreszenzkonstrukte Smt $A$-2_GFP und $S m t A-2$ dsRed in $\Delta$ SmtA-2. Es konnte in keiner der Transformanten eine vollständige Komplementation des sterilen Phänotyps der Mutante beobachtet werden. 


\subsection{Curriculum vitae V.Klix}

\section{Personal Data}

Name

Birth details
Volker Klix, Dipl-Biol.

29.04.1982 in Essen, Germany

\section{$\underline{\text { Education }}$}

Dr. rer.-nat. (PhD.) at the Georg-August University Göttingen, Germany (begin 04/2007)

- Topic of doctoral thesis: „Charakterisierung des Kreuzungstyp-Locus des filamentösen Ascomyceten Sordaria macrospora" (Functional characterization of the mating-type locus of the filamentous ascomycete Sordaria macrospora)

Diploma thesis at the Ruhr-University Bochum, Germany (10/2002 - 03/2007)

- Topic of diploma thesis: "Molekulargenetische Charakterisierung des Kreuzungstyp-Locus des filamentösen Ascomyceten Sordaria macrospora" (Molecular and genetic characterization of the mating-type locus of the filamentous ascomycete Sordaria macrospora)

- Grade "Sehr gut" equates Grade A

Abitur at the Gymnasium Borbeck, Essen, Germany (1992 - 2001)

- Grade "Gut” equates Grade B

\section{Practical Experience}

Doctoral research $(04 / 2007$ - 10/2010)

Georg-August University Göttingen, Germany, Dept. Genetics of Eukaryotic Microorganisms (advisor: Prof. Dr. Stefanie Pöggeler)

Characterization of the MAT1-1 mating-type genes of the homothallic ascomycete Sordaria macrospora

- Experience with nucleic acid isolation

- Experience with handling of E. coli and S. cerevisiae

- Performed transformation of $S$. macrospora

- Created mutant strains of different genes

- Experience with Southern blot-, real-Time PCR- and microarray analysis

- Experience with heterologous gene expression in S. cerevisiae

- Created fluorescence tagged versions of different proteins and performed fluorescence microscopy

- Experience with sequence analysis, use of Blast algorithms in public databases 


\section{Publications}

Klix V, Nowrousian M, Ringelberg C, Loros JJ, Dunlap JC, Pöggeler S. (2010) Functional characterization of MAT1-1-specific mating-type genes in the homothallic ascomycete Sordaria macrospora provides new insights into essential and nonessential sexual regulators. Eukaryot. Cell 9(6): 894-905

Klix V, Nowrousian M, Ringelberg C, Loros JJ, Dunlap JC, Pöggeler S. (2010) Characterization of mating-type mutants of the homothallic ascomycete Sordaria macrospora by realTime PCR, cross-species microarray and yeast-two-hybrid analysis. Biospektrum, Abstractband zur VAAM-Jahrestagung 2010 (Sonderband)

Klix V, Nowrousian M, Ringelberg C, Loros JJ, Dunlap JC, Pöggeler S. (2009) Cross-species microarray and real-Time PCR analysis of differentially regulated genes in mating-type mutants of the homothallic ascomycete Sordaria macrospora. Biospektrum, Abstractband zur VAAM-Jahrestagung 2009 (Sonderband)

\section{Teaching experience}

$2006-2007 \quad$ Instructor in practical courses at the Ruhr-University Bochum, GER

2007 - present $\quad$ Supervision of students in practical courses/lab courses

Supervision of Diploma- and Bachelor students at the Dept. Genetics of

Eukaryotic Microorganisms

\section{Conference Proceedings}

VAAM Symposium „Molecular Biology of Fungi“, Hamburg (GER) poster presentation 9th European Conference on Fungal Genetics, Edinburgh (UK)

2009 poster presentation

VAAM Symposium „Molecular Biology of Fungi“, Münster (GER)

Talk: "Cross-species microarray and real-Time PCR analysis for characterization of mating-type mutants of the homothallic ascomycete Sordaria macrospora"

VAAM annual meeting, 2009, Bochum (GER) poster presentation 